\title{
Room Temperature Chemoselective Reductive Alkylation of Amines Catalyzed by a Well-Defined Iron(II) Complex using Hydrogen.
}

Alexis Lator, ${ }^{\mathrm{a}}$ Quentin Gaignard Gaillard, ${ }^{\mathrm{a}}$ Delphine S. Mérel, ${ }^{\mathrm{a}}$ Jean-Francois Lohier, ${ }^{\mathrm{a}}$ Sylvain Gaillard, ${ }^{\mathrm{a}}$ Albert Poater, ${ }^{\mathrm{b} *}$ Jean-Luc Renaud ${ }^{\mathrm{a} *}$

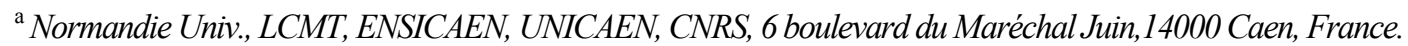

${ }^{b}$ Departament de Química, Institut de Química Computacional i Catàlisi (IQCC), University of Girona, Campus de Montilivi, 17071 Girona, Catalonia, Spain.

\section{Supporting Information}


NMR Spectra

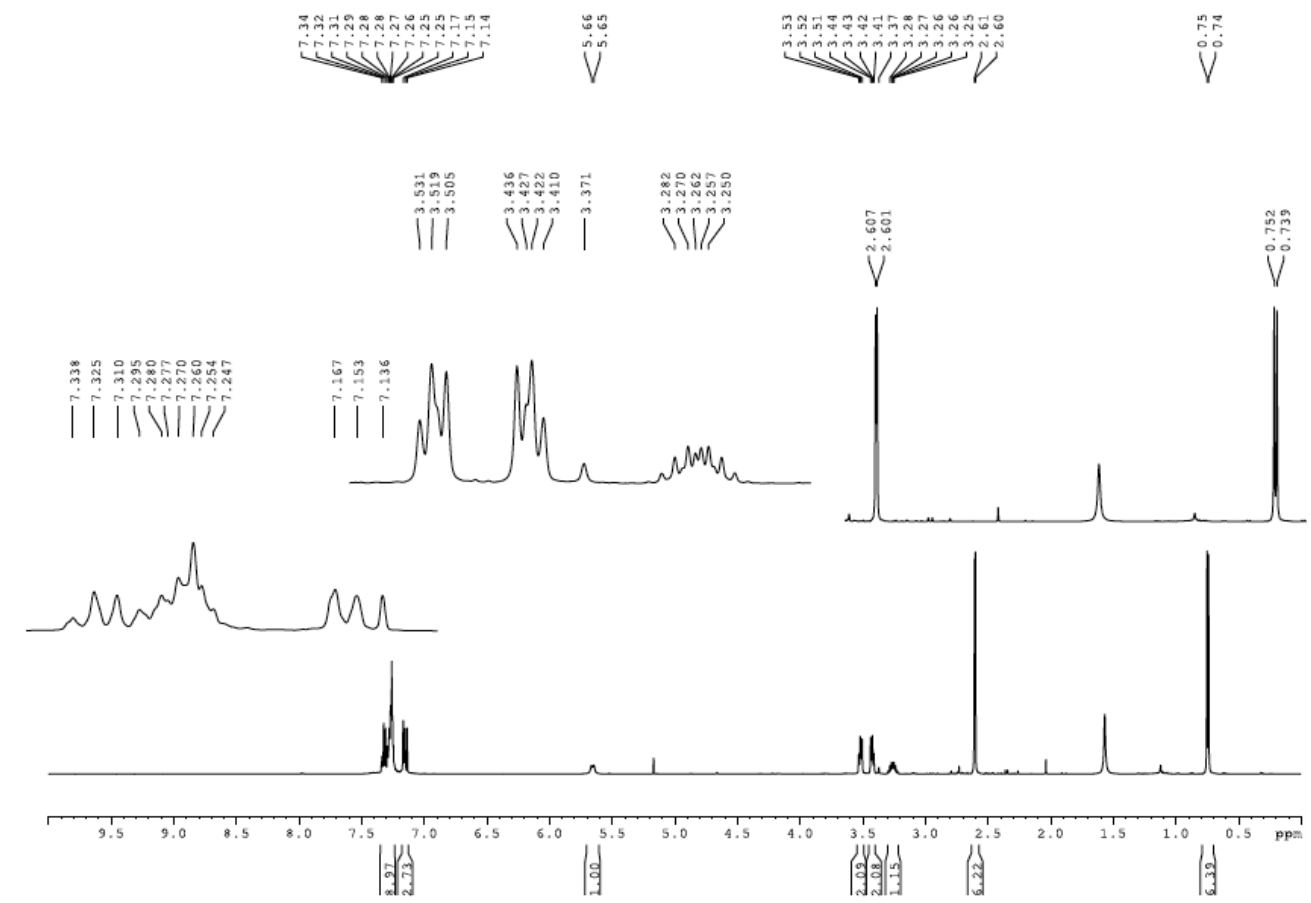

Figure S1. $\quad-{ }^{1}$ H-NMR Spectra of 2.

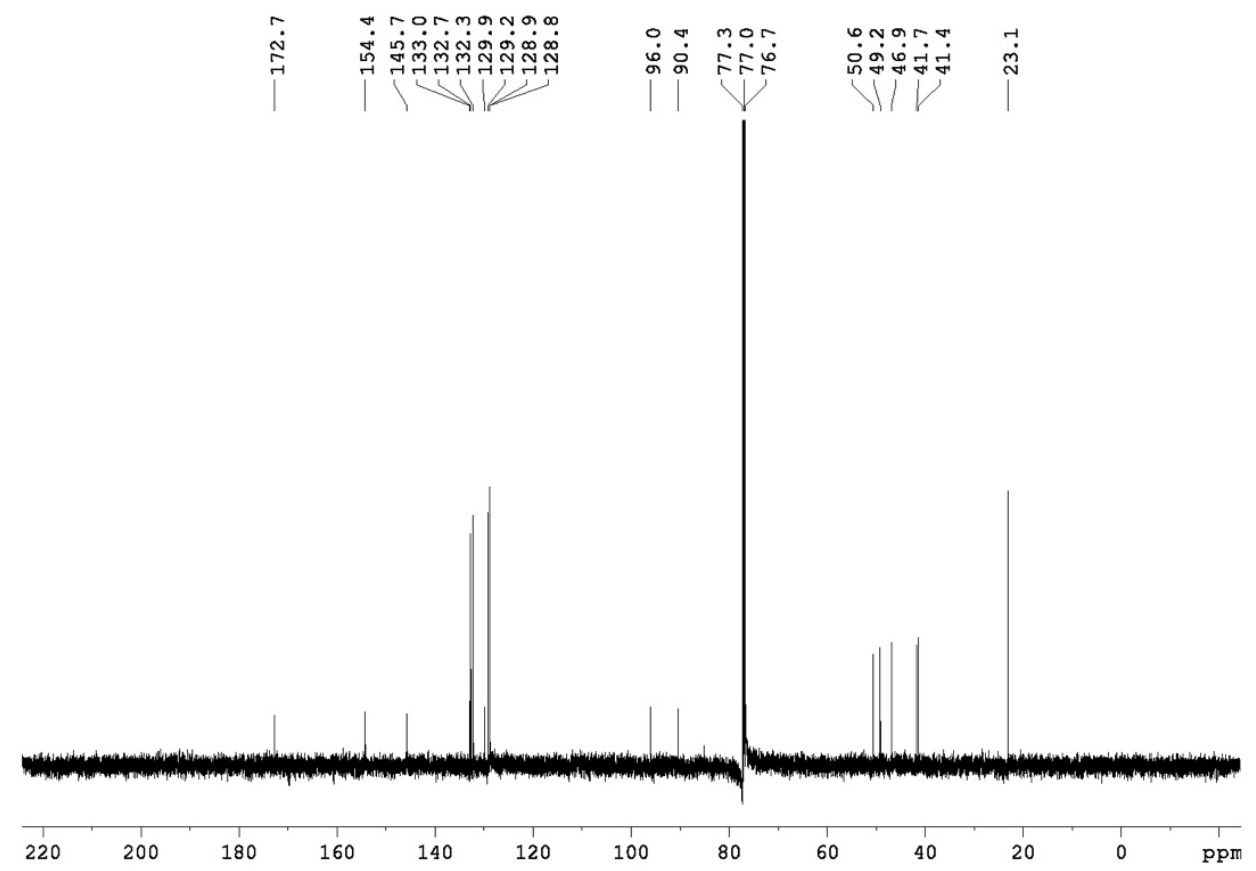

Figure S2. $\quad{ }^{13} \mathrm{C}-\mathrm{NMR}$ Spectra of 2. 


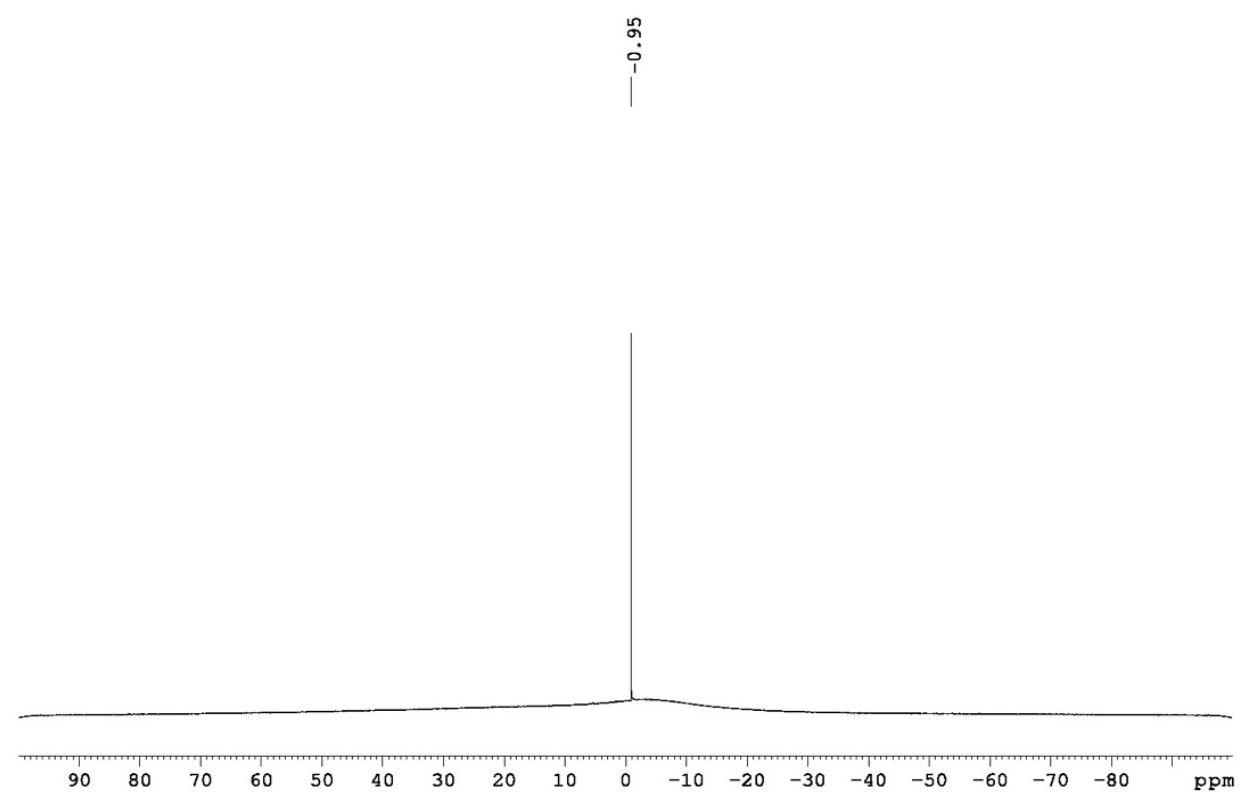

Figure S3. $\quad{ }^{19}$ F-NMR Spectra of 2.

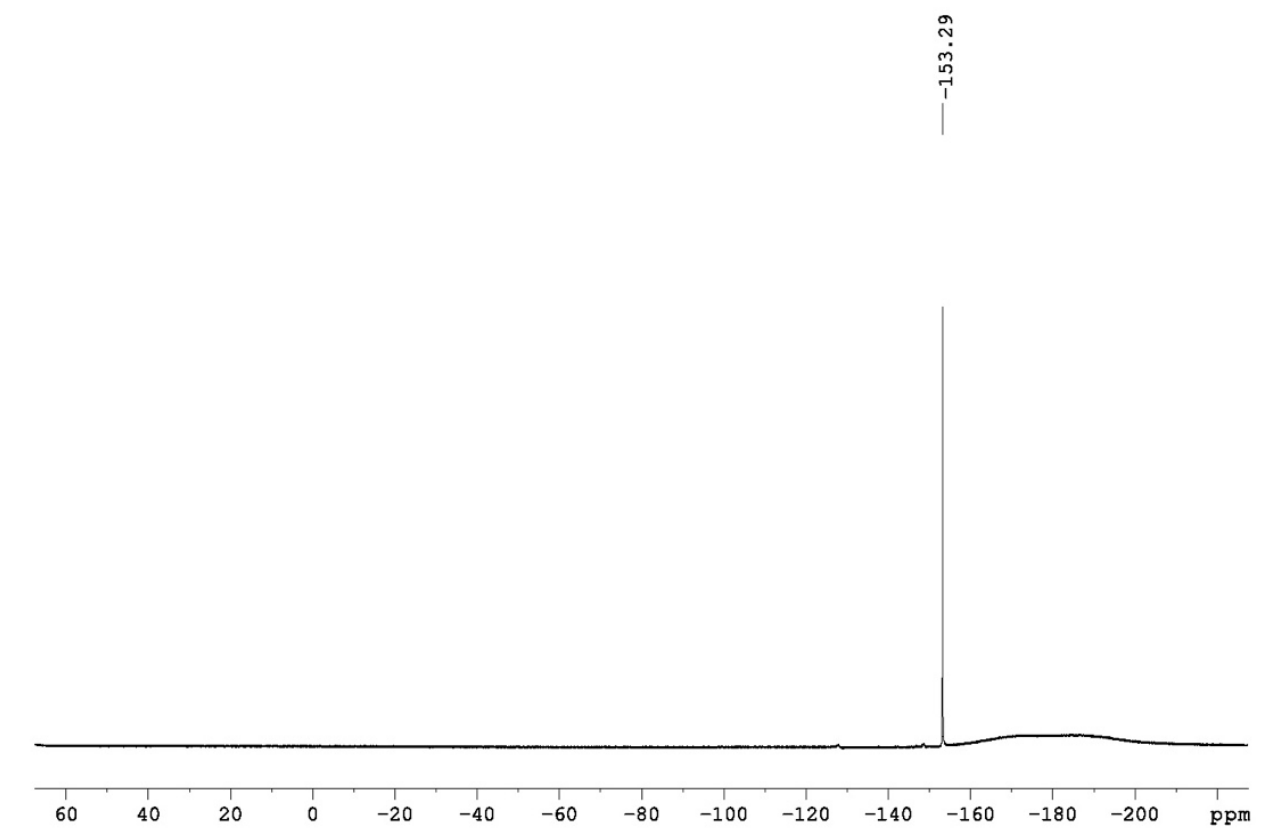

Figure S4. $\quad{ }^{11}$ B-NMR Spectra of 2. 


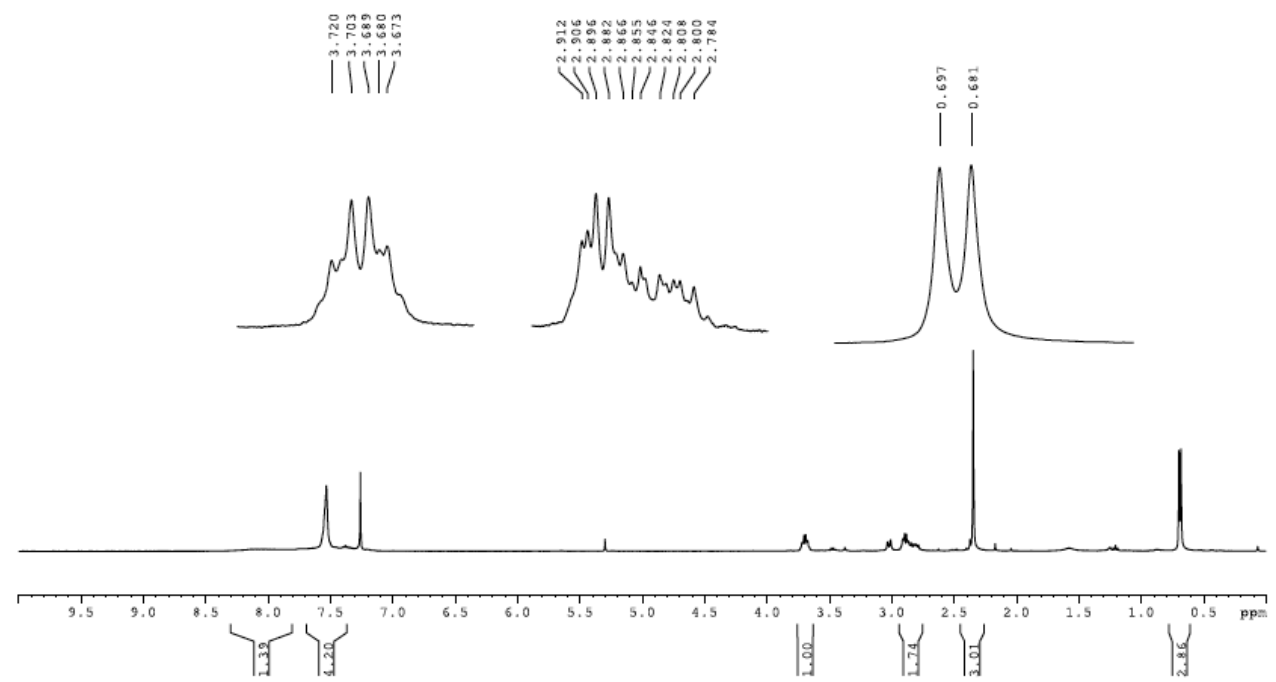

Figure S5. $\quad{ }^{1} \mathrm{H}-\mathrm{NMR}$ Spectra of Fe3.

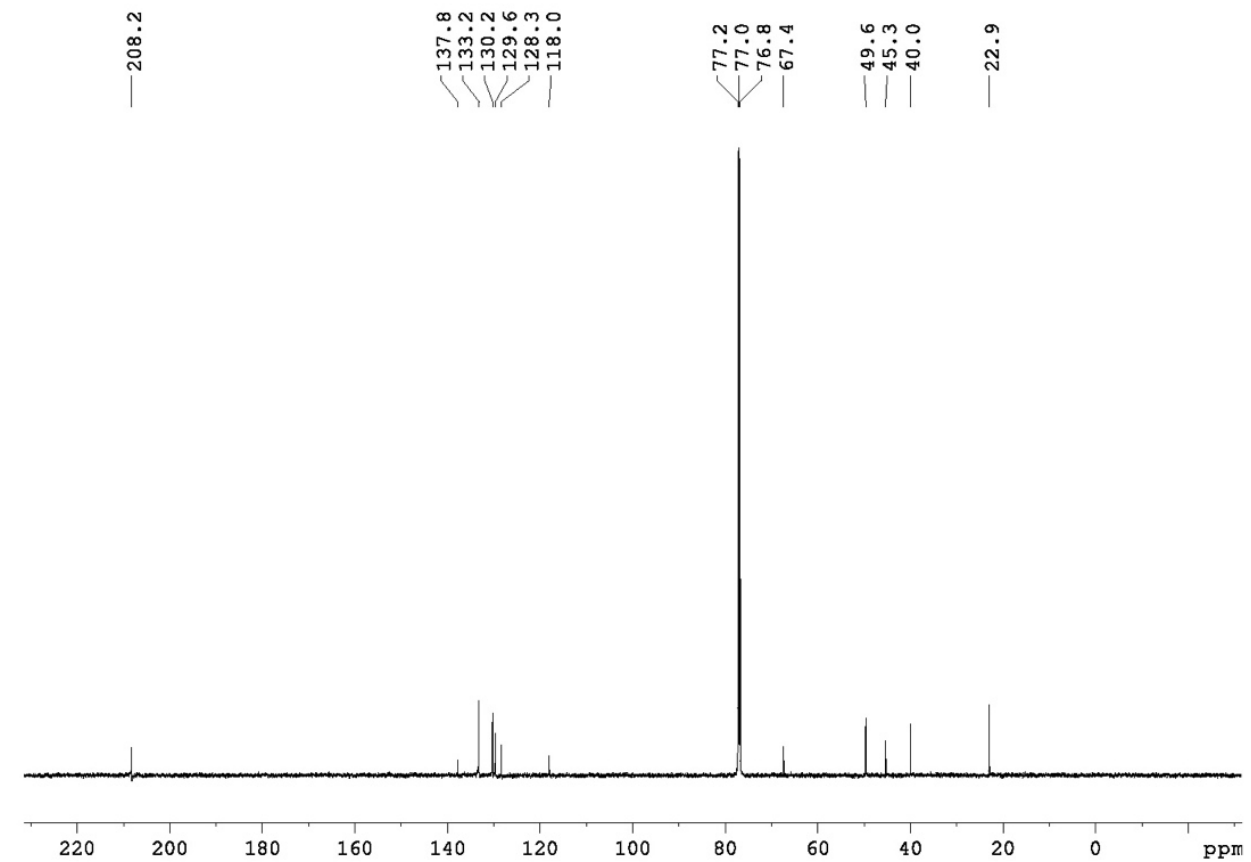

Figure S6. $\quad{ }^{13} \mathrm{C}-\mathrm{NMR}$ Spectra of Fe3. 


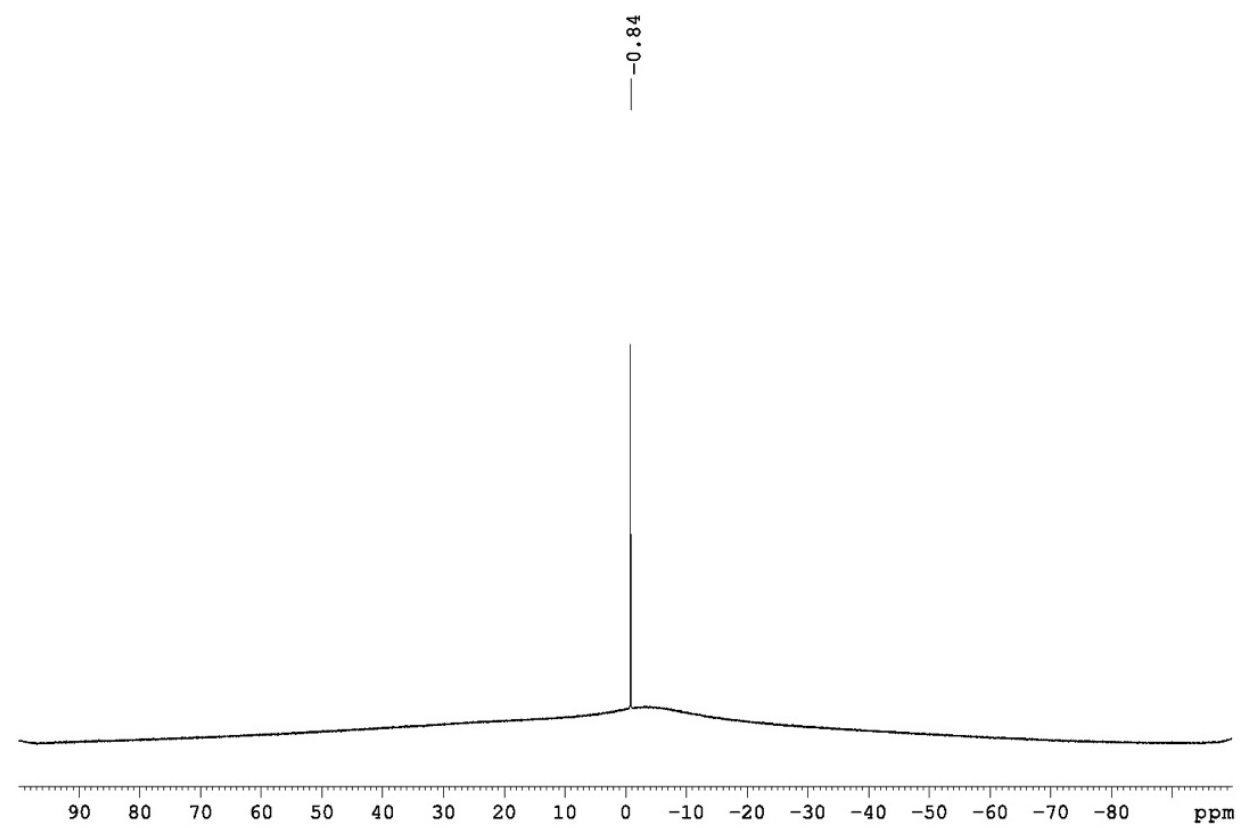

Figure S7. $\quad{ }^{11}$ B-NMR Spectra of Fe3.

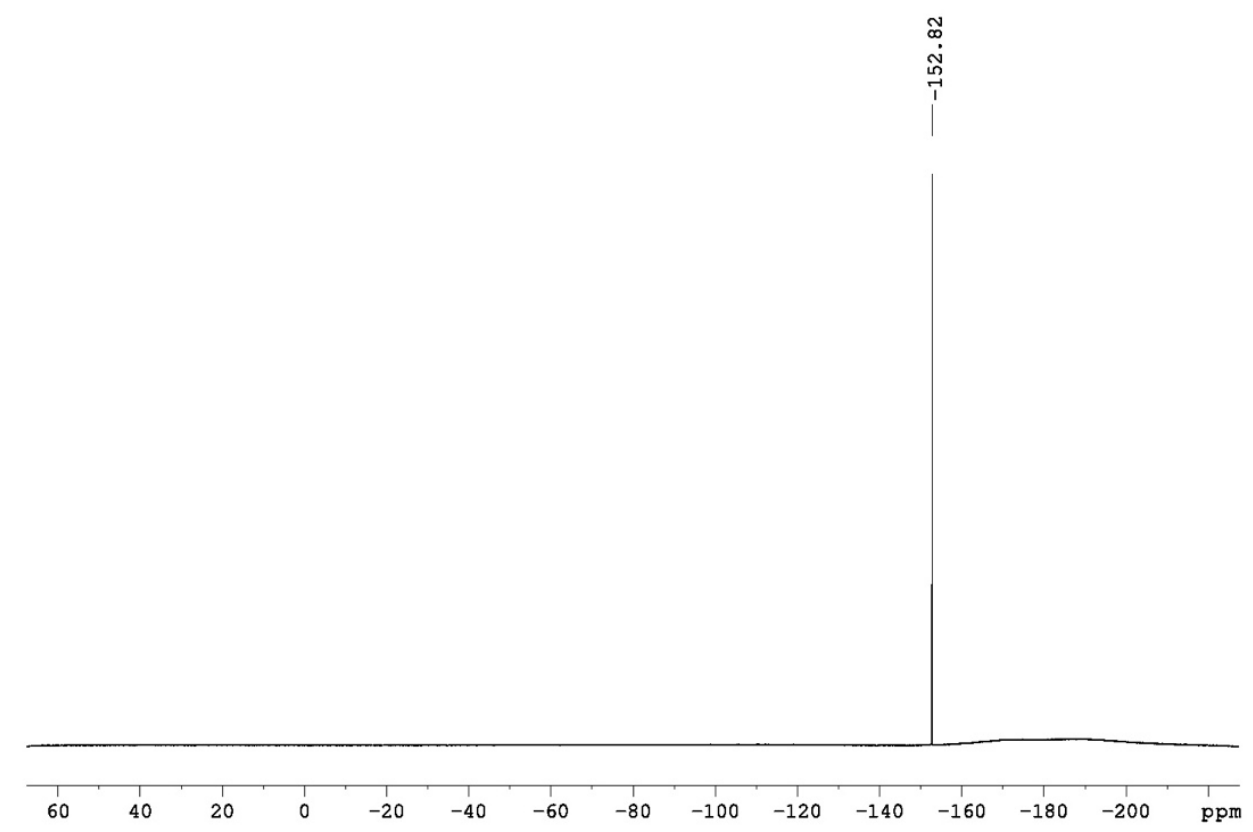

Figure S8. $\quad{ }^{19}$ F-NMR Spectra of Fe3. 


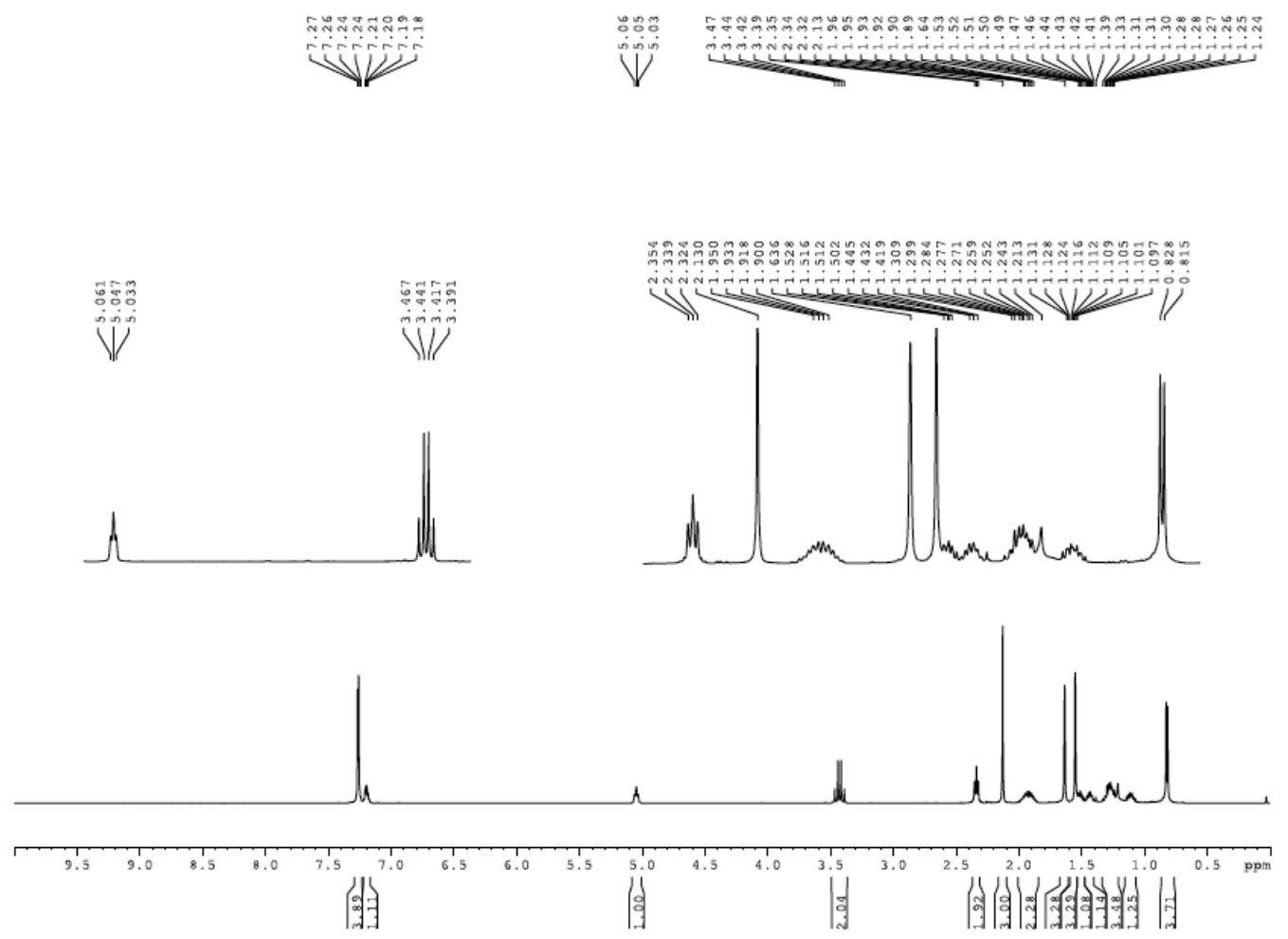

Figure S9. $\quad{ }^{1}$ H-NMR Spectra of 3.
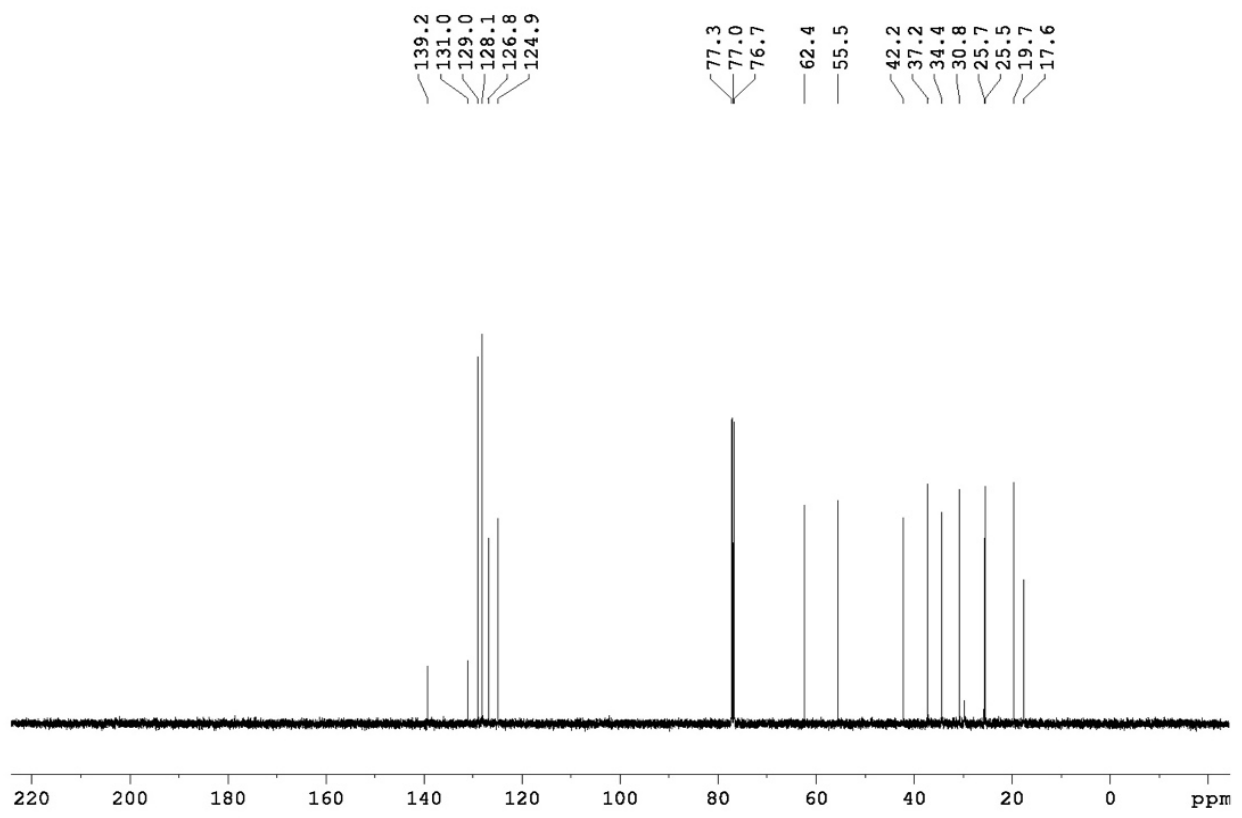

Figure S10. ${ }^{13} \mathrm{C}-\mathrm{NMR}$ Spectra of 3 . 

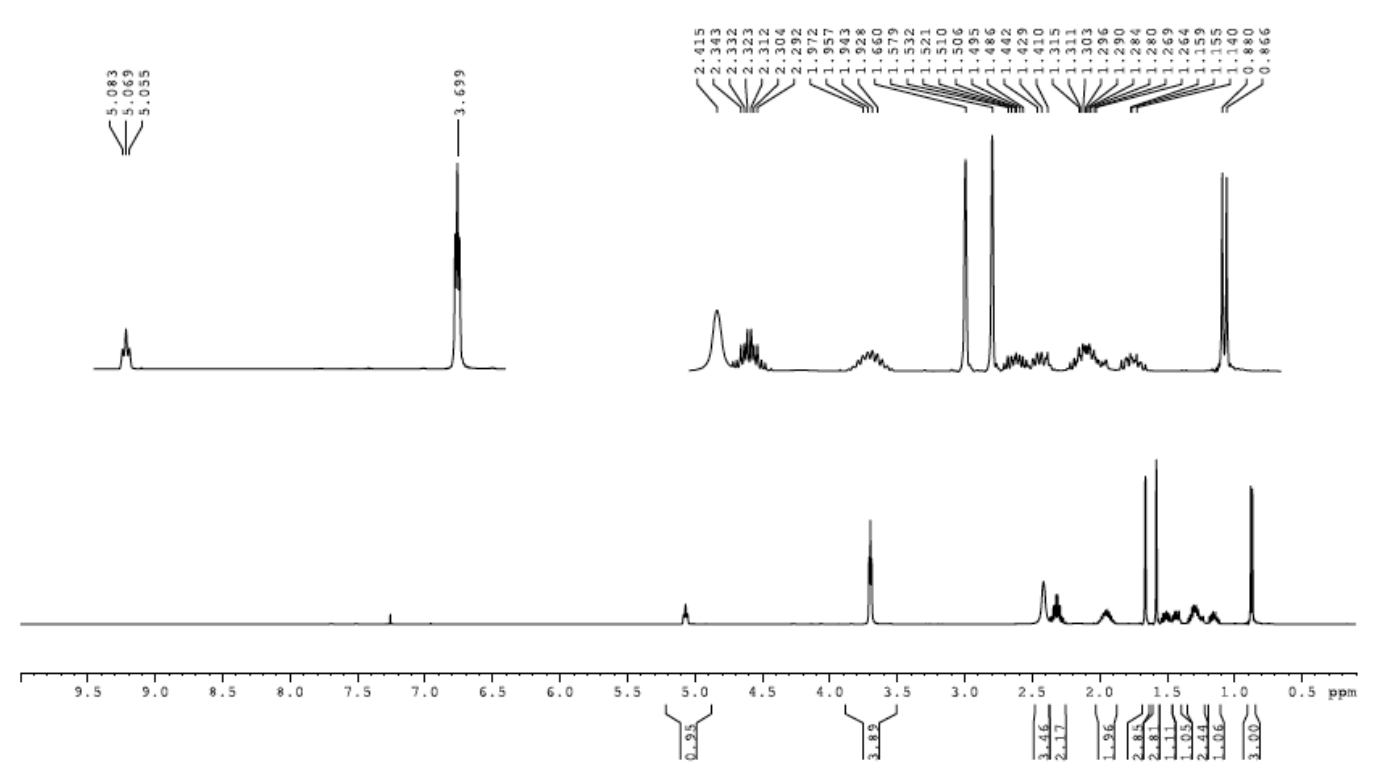

Figure S11. $\quad{ }^{1} H-N M R$ Spectra of 4.

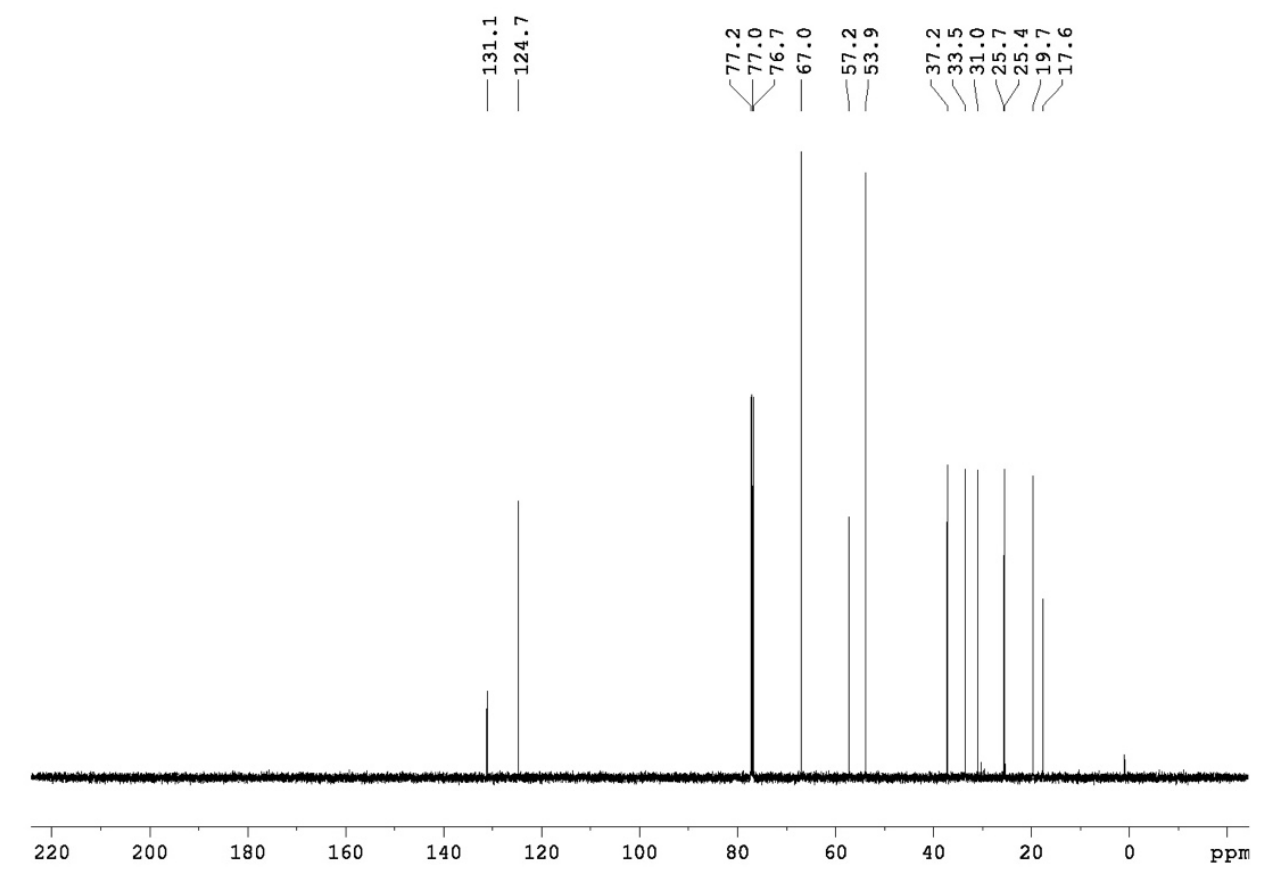

Figure S12. ${ }^{13}$ C-NMR Spectra of 4. 


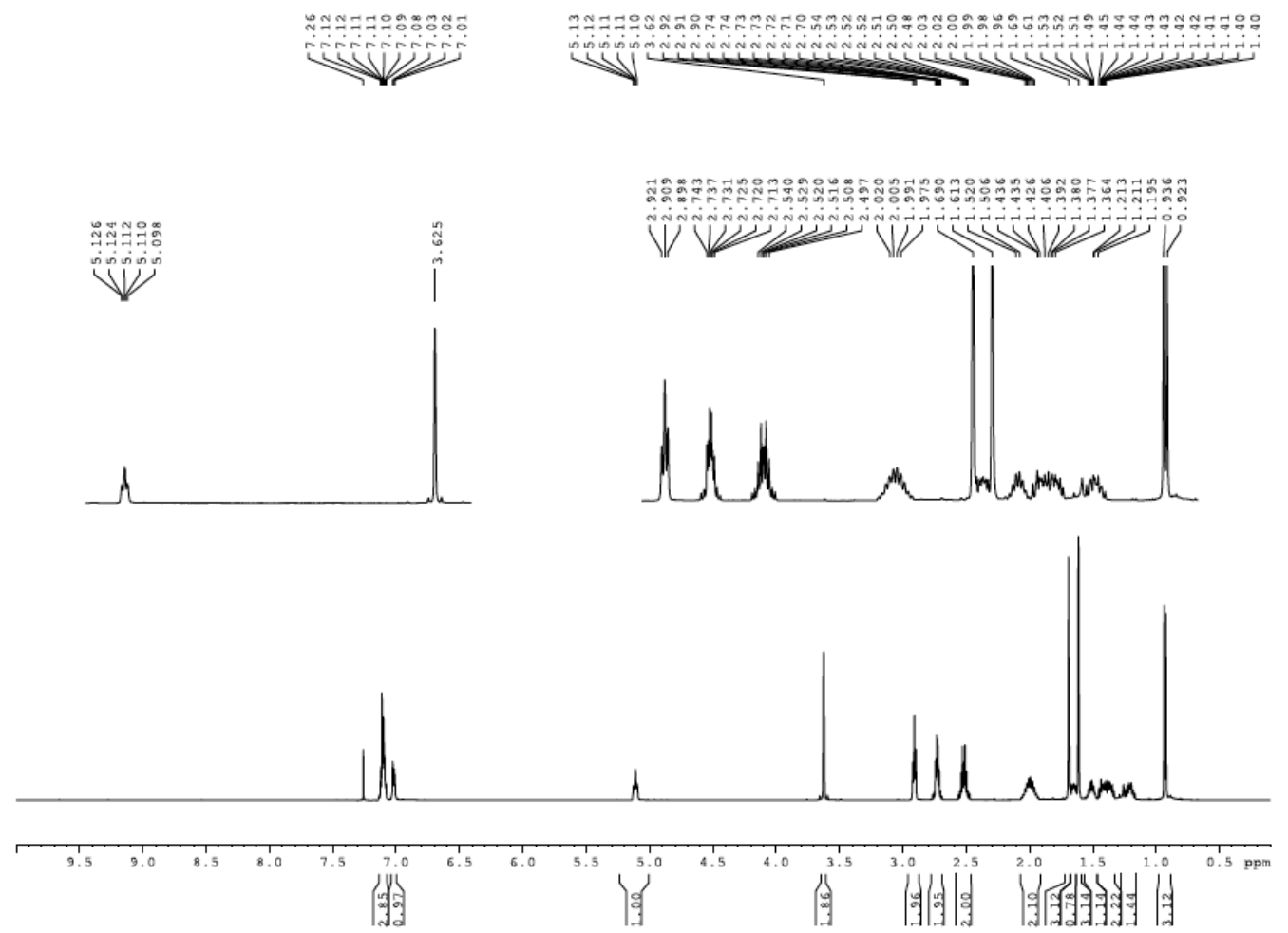

Figure S13. ${ }^{1}$ H-NMR Spectra of 5.

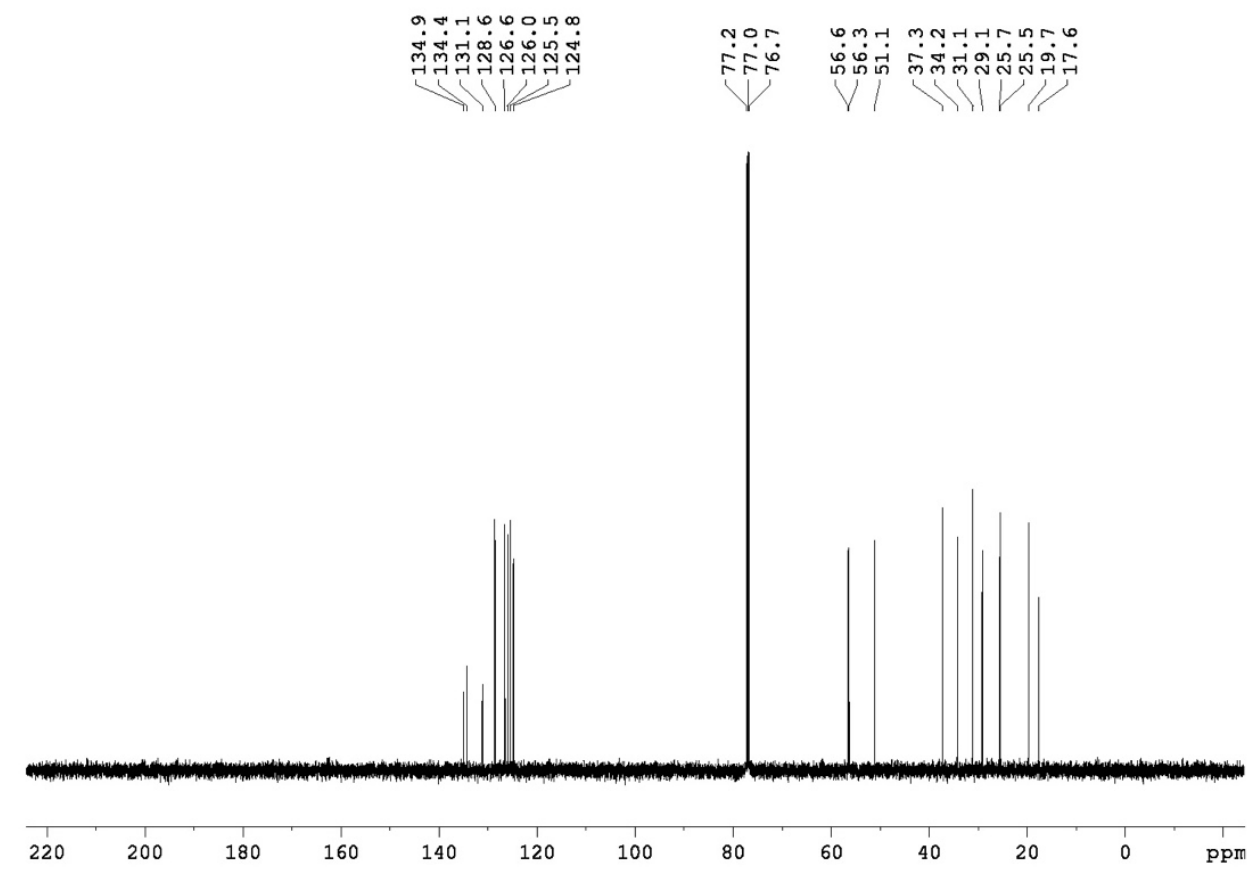

Figure S14. ${ }^{13}$ C-NMR Spectra of 5 . 


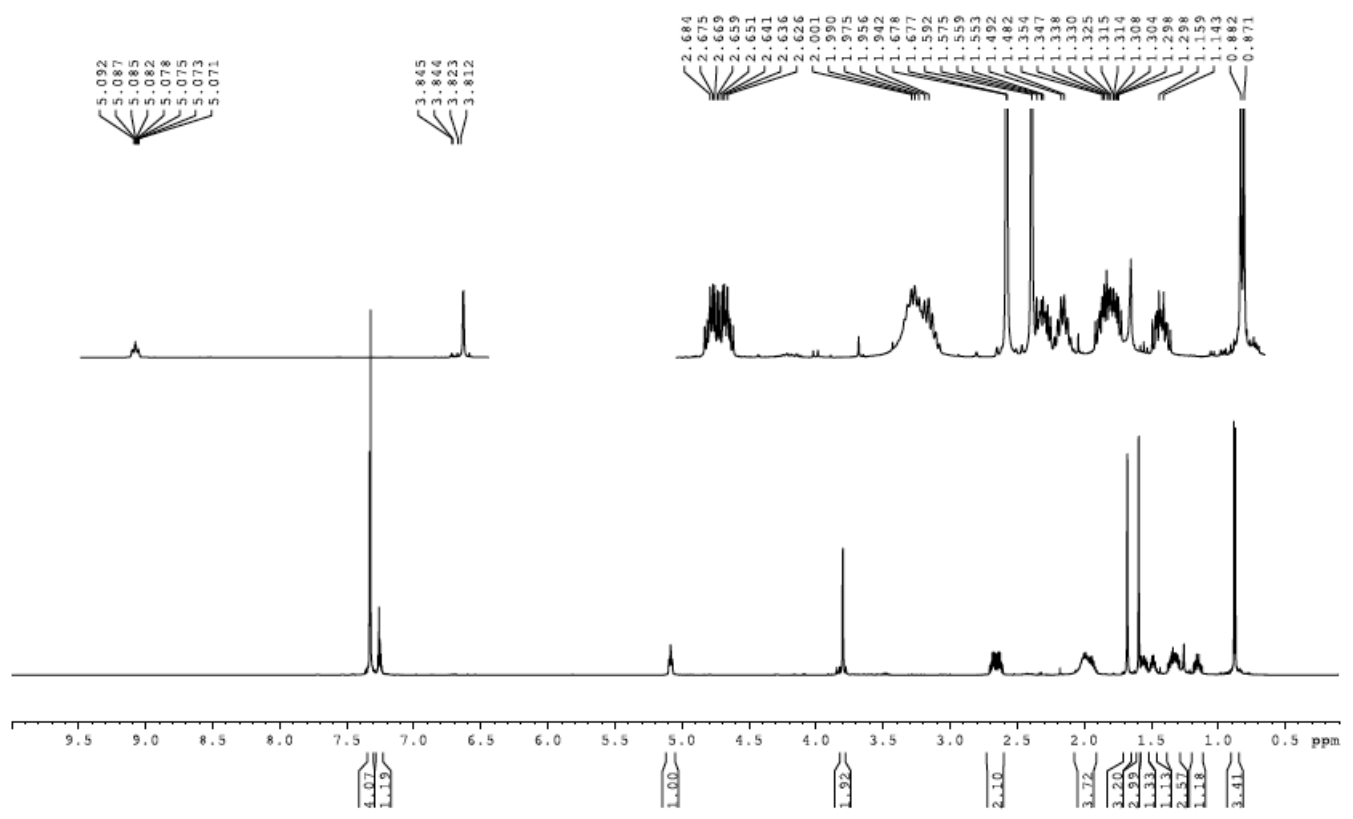

Figure S15. ${ }^{1}$ H-NMR Spectra of 6.

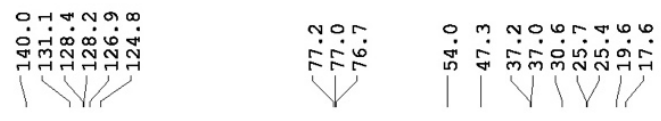

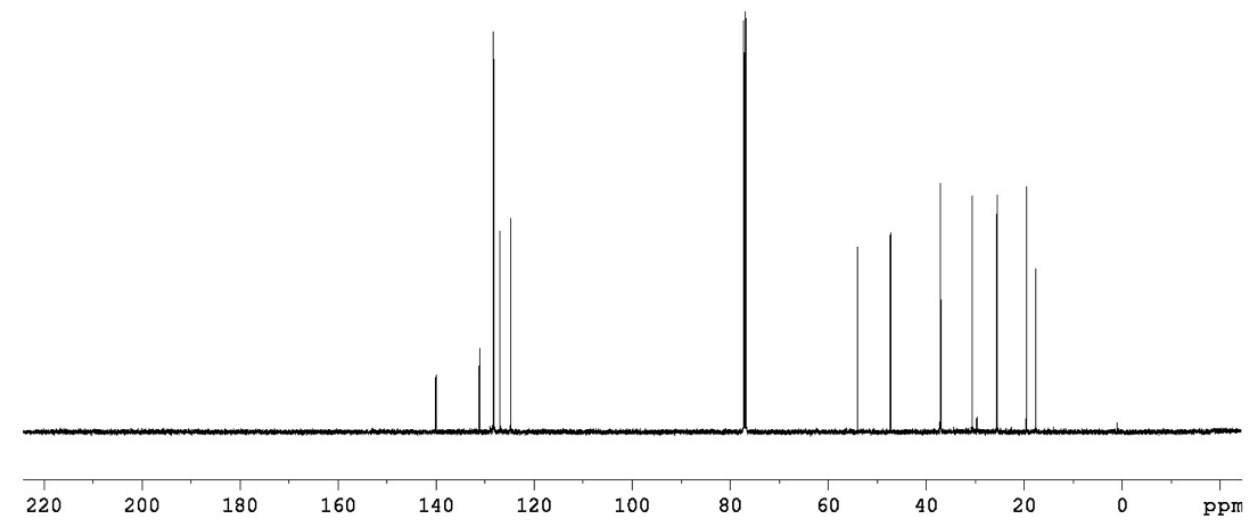

Figure S16. ${ }^{13}$ C-NMR Spectra of 6. 


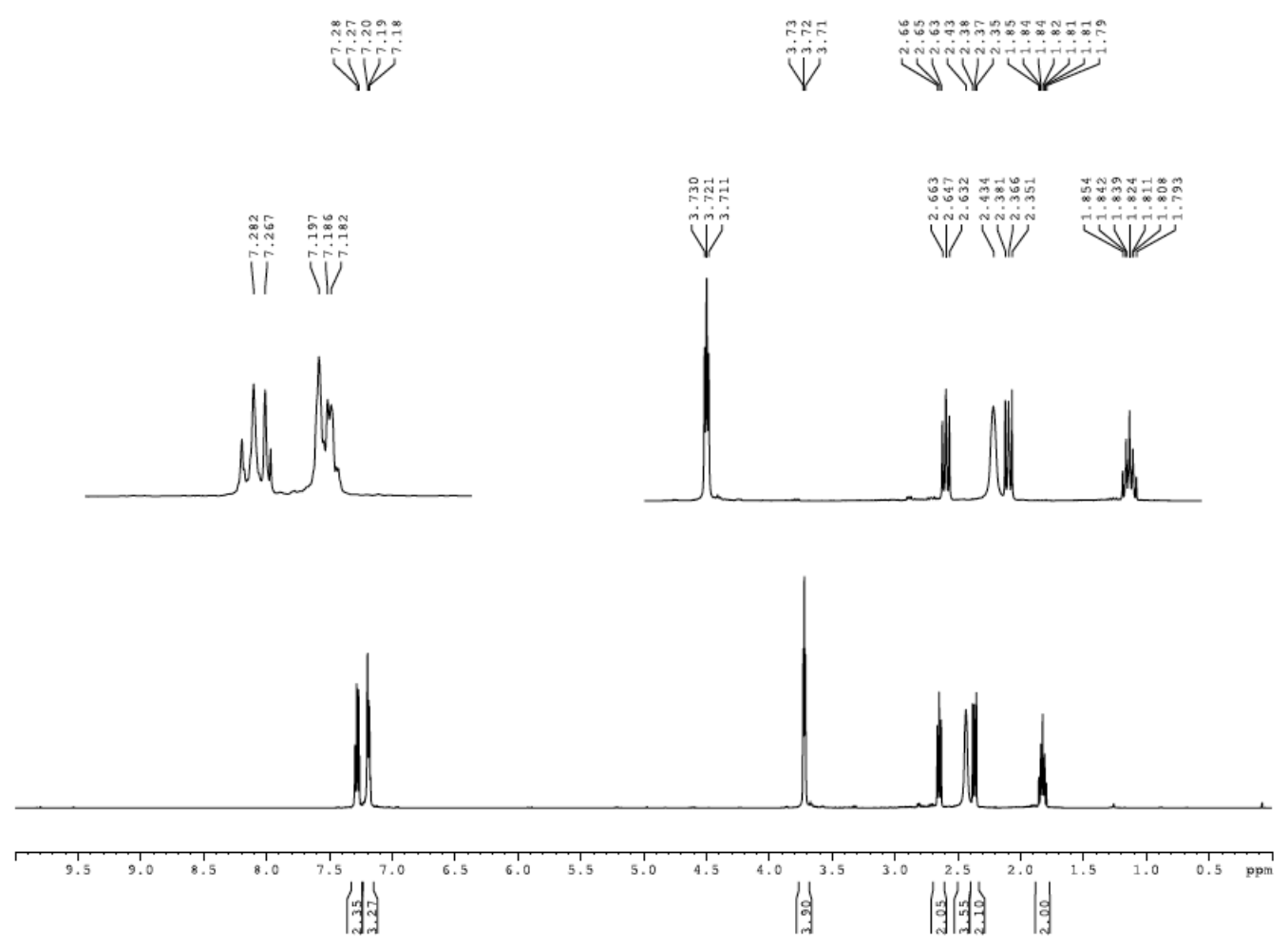

Figure S17. ${ }^{1}$ H-NMR Spectra of 7.
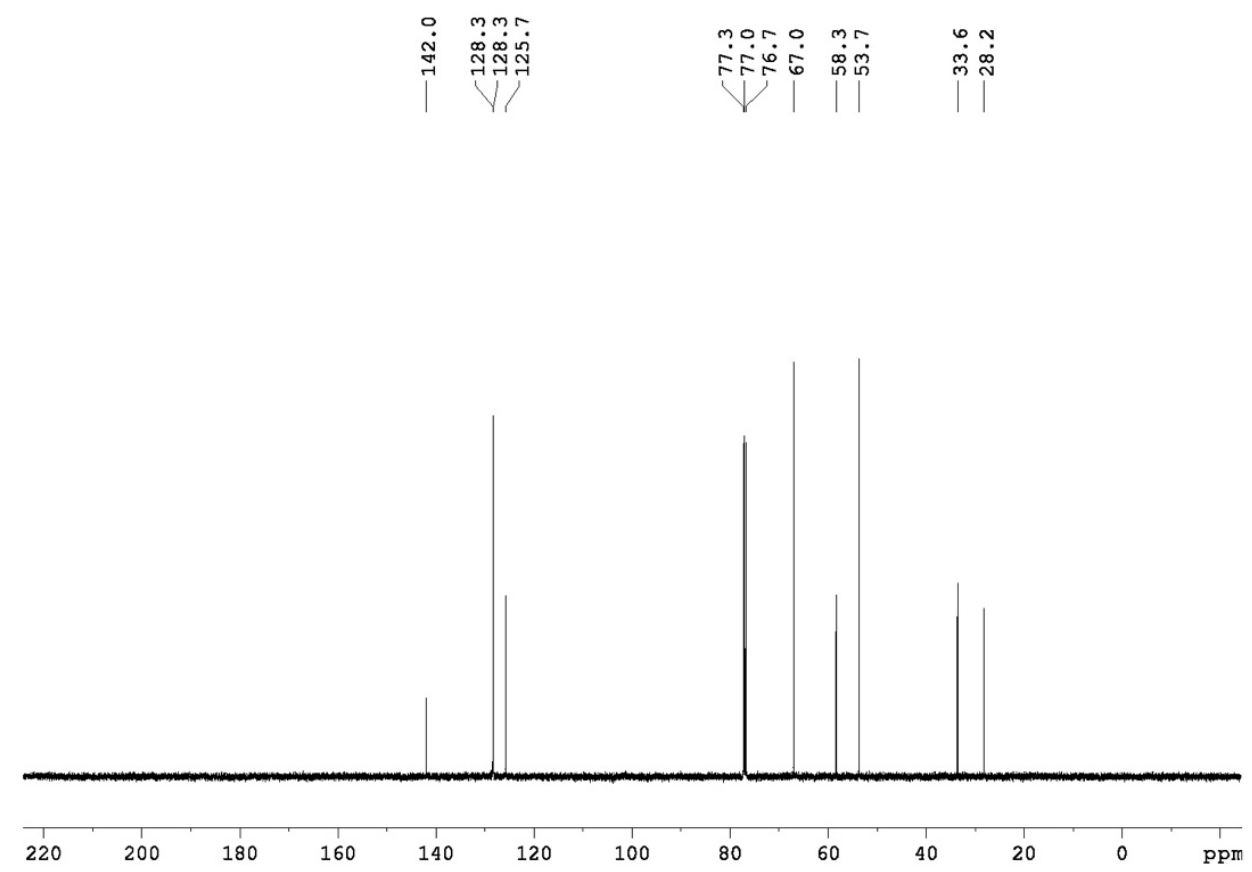

Figure S18. ${ }^{13} \mathrm{C}-\mathrm{NMR}$ Spectra of 7. 


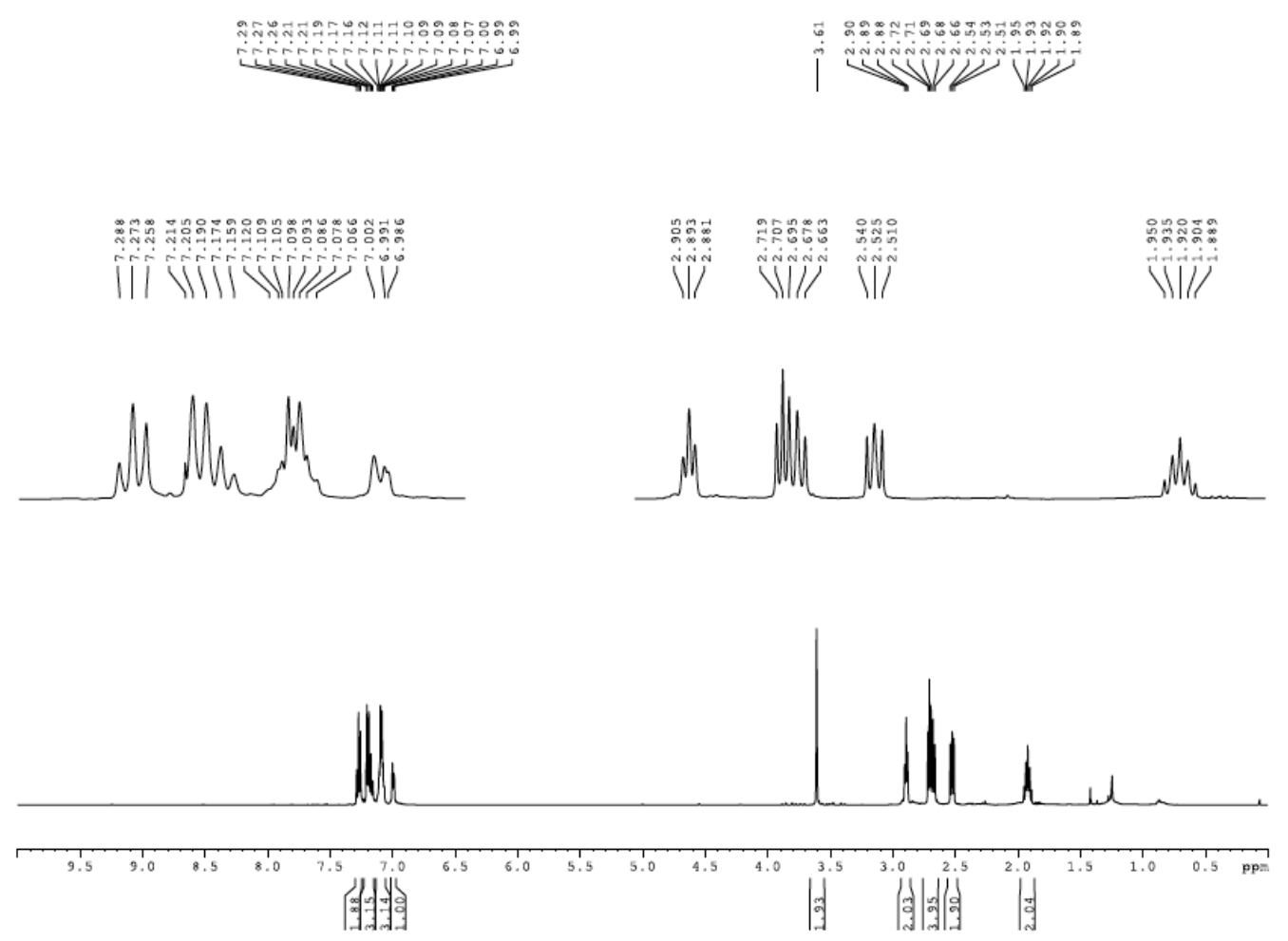

Figure S19. ${ }^{1}$ H-NMR Spectra of 8 .
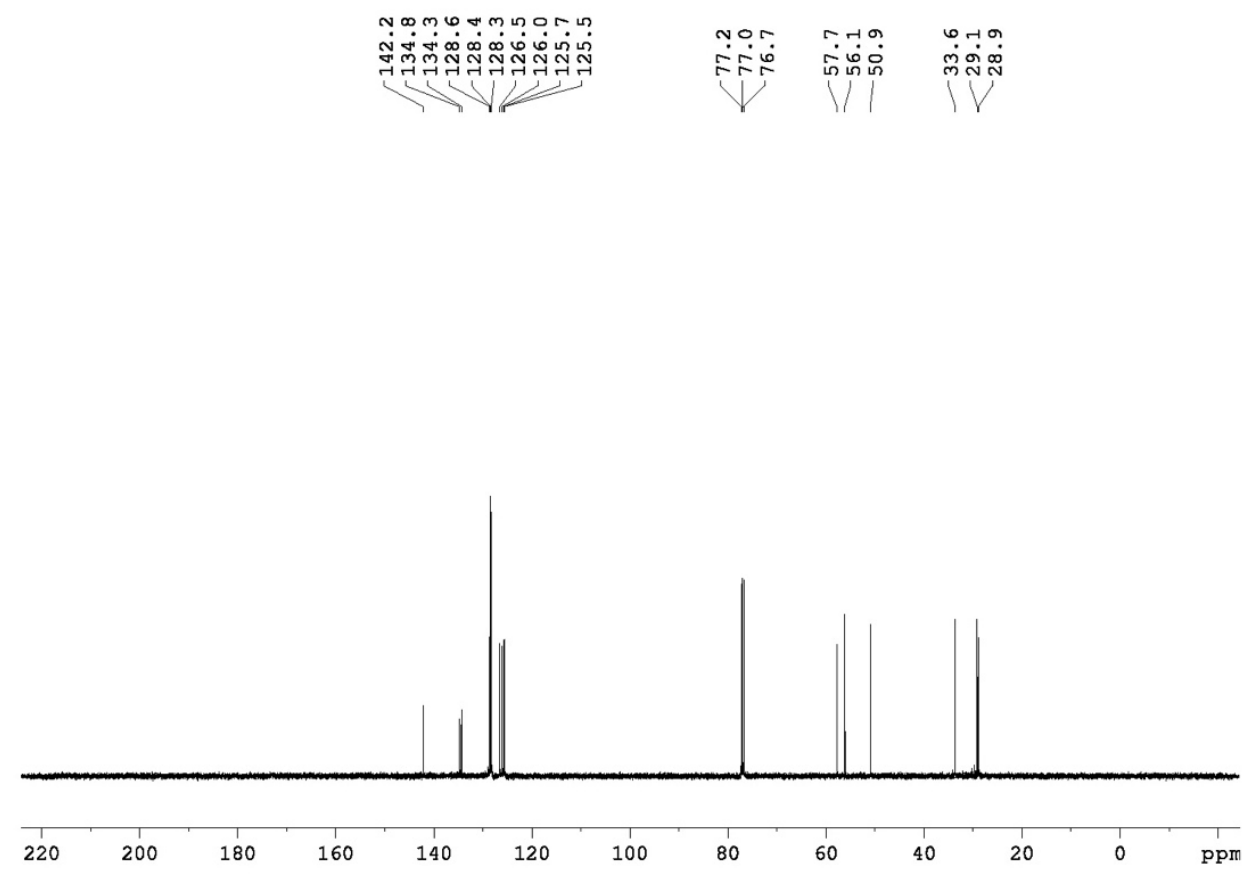

Figure S20. ${ }^{13} \mathrm{C}-\mathrm{NMR}$ Spectra of 8. 


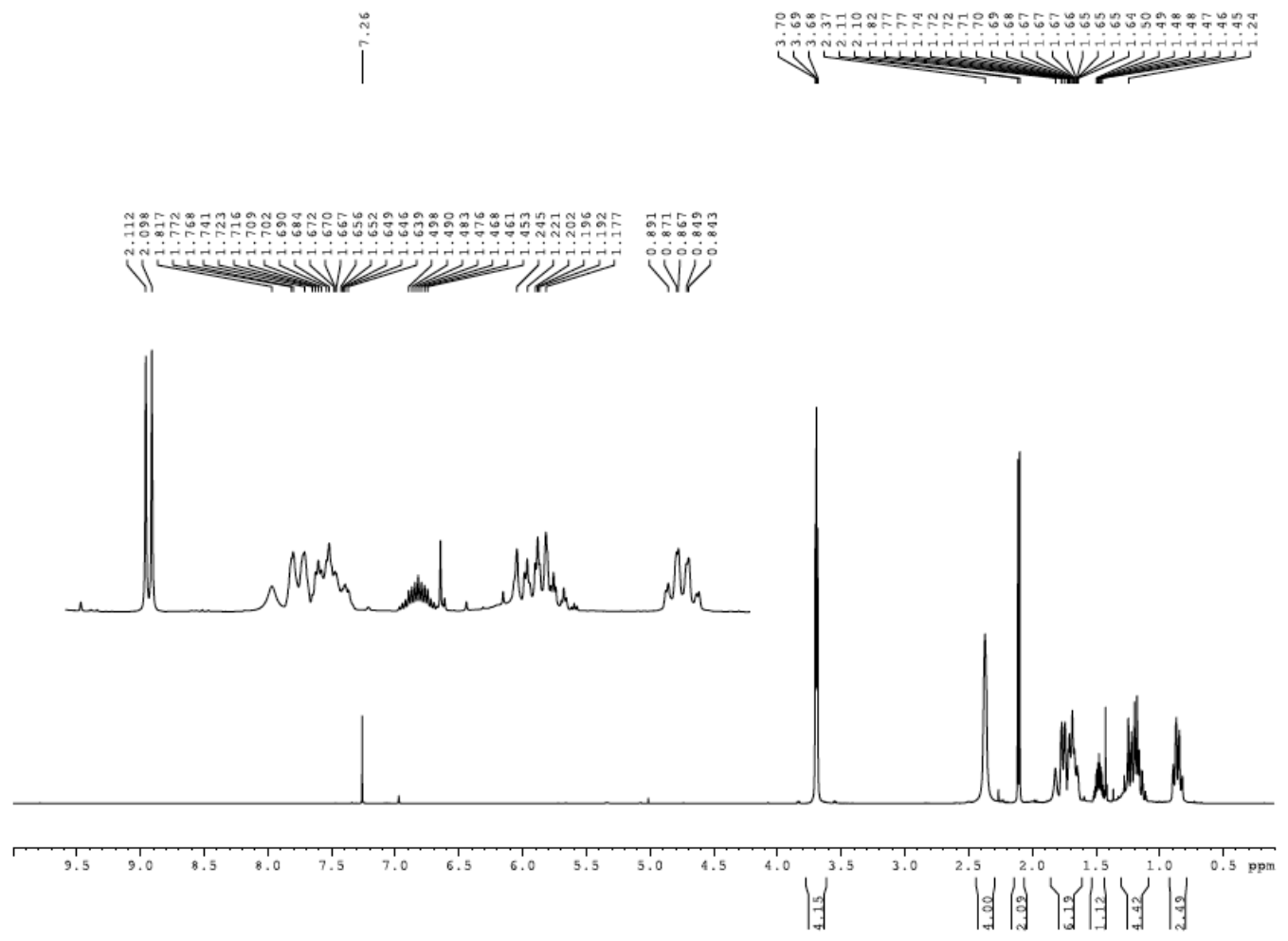

Figure S21. ${ }^{1}$ H-NMR Spectra of 9.

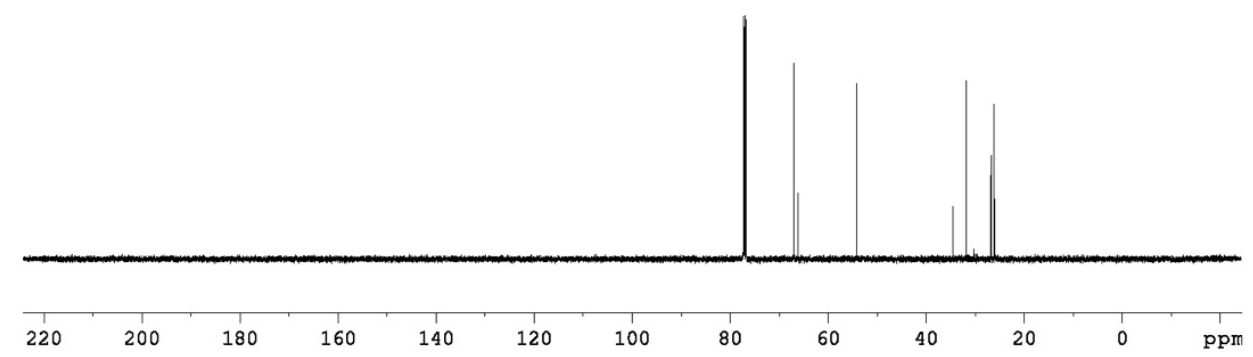

Figure S22. ${ }^{13}$ C-NMR Spectra of 9. 


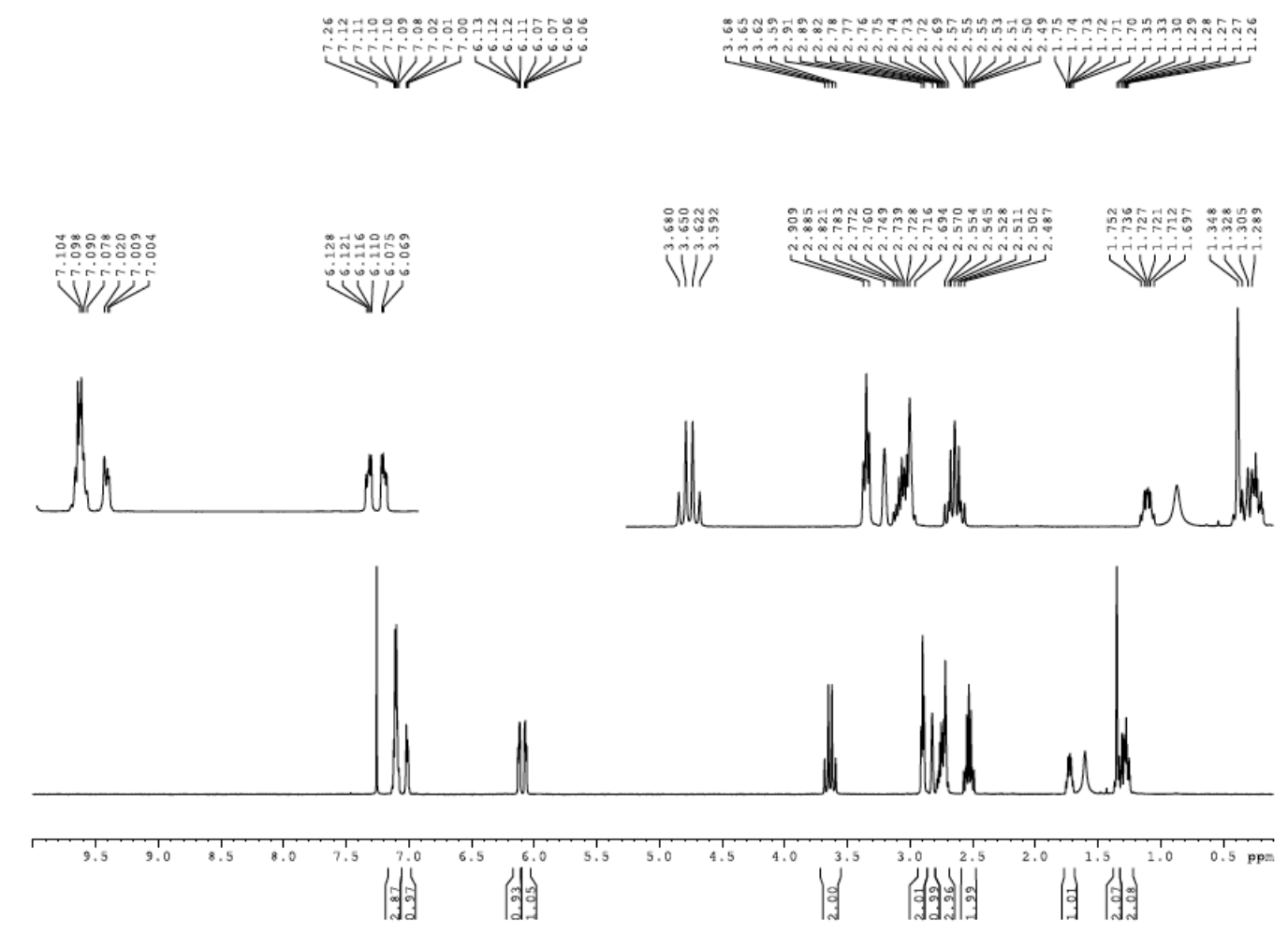

Figure S23. ${ }^{1}$ H-NMR Spectra of 10-Dia 1.

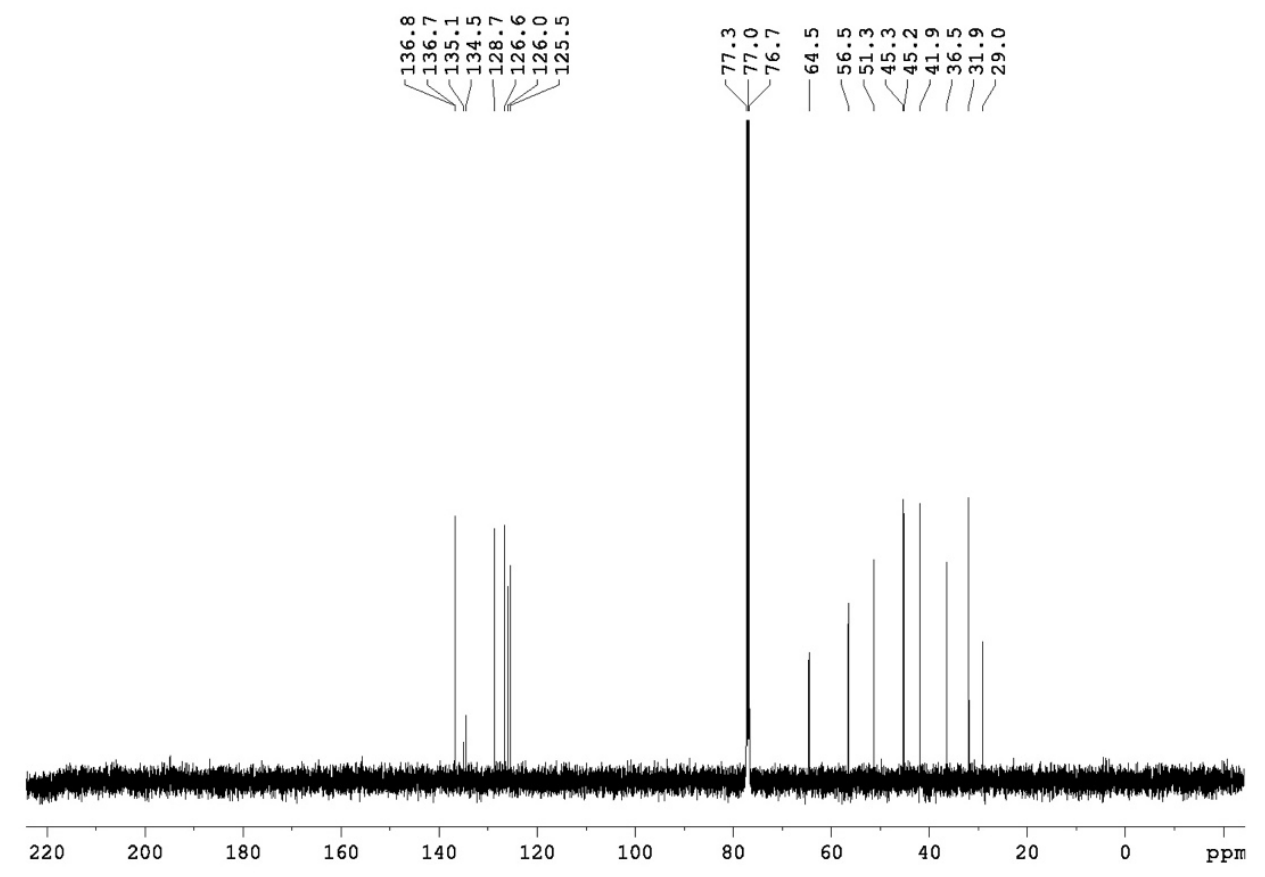

Figure S24. ${ }^{13} \mathrm{C}-\mathrm{NMR}$ Spectra of 10-Dia 1. 


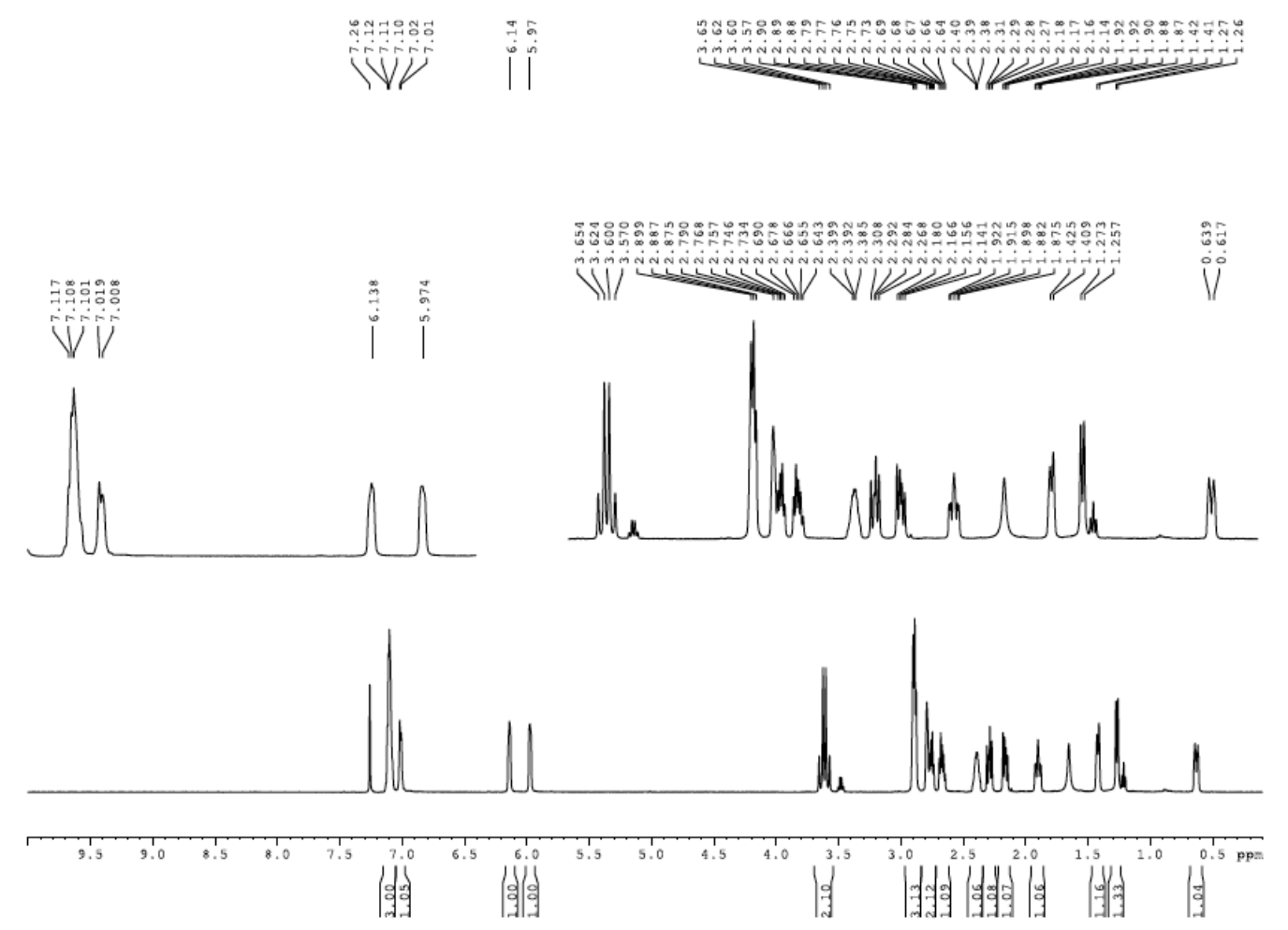

Figure S25. ${ }^{1}$ H-NMR Spectra of 10-Dia 2.

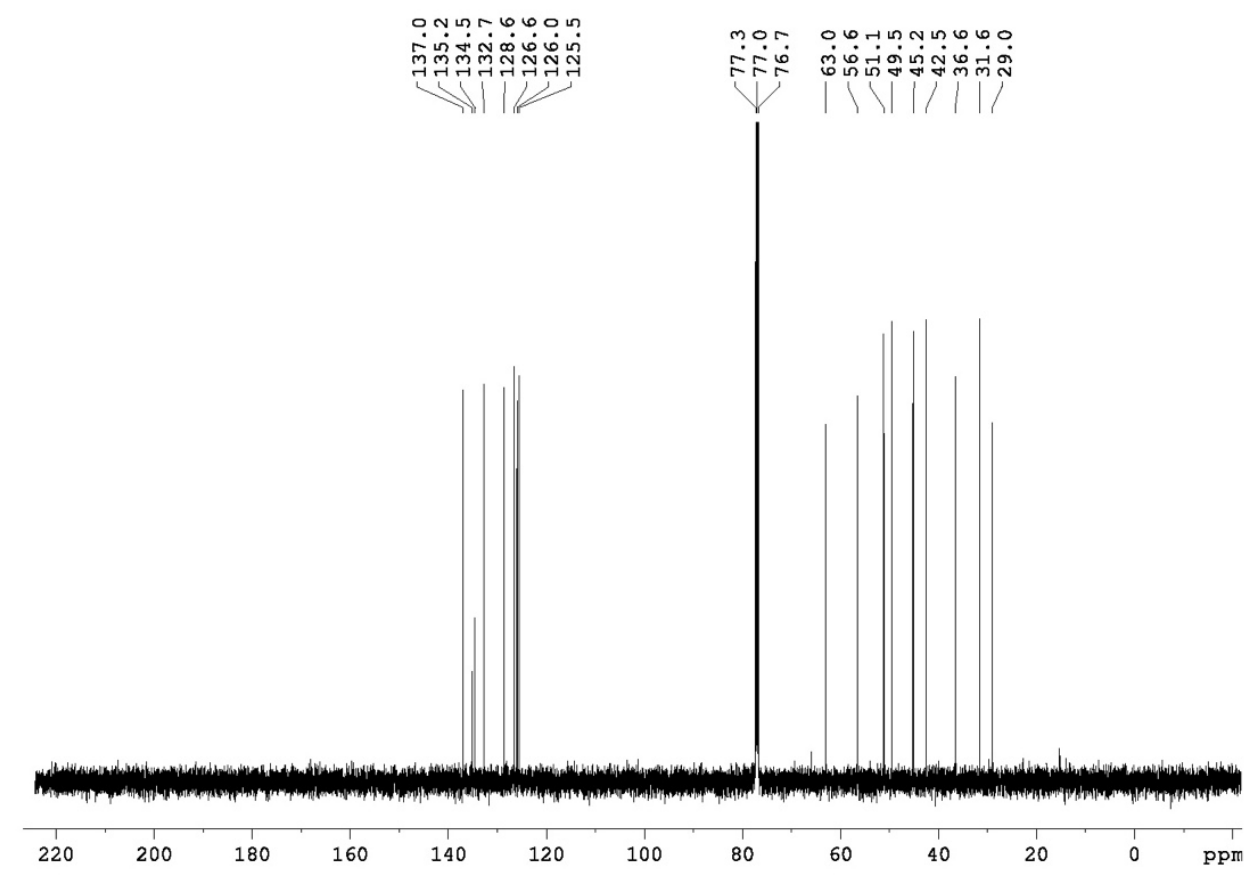

Figure S26. ${ }^{13}$ C-NMR Spectra of 10-Dia 2. 


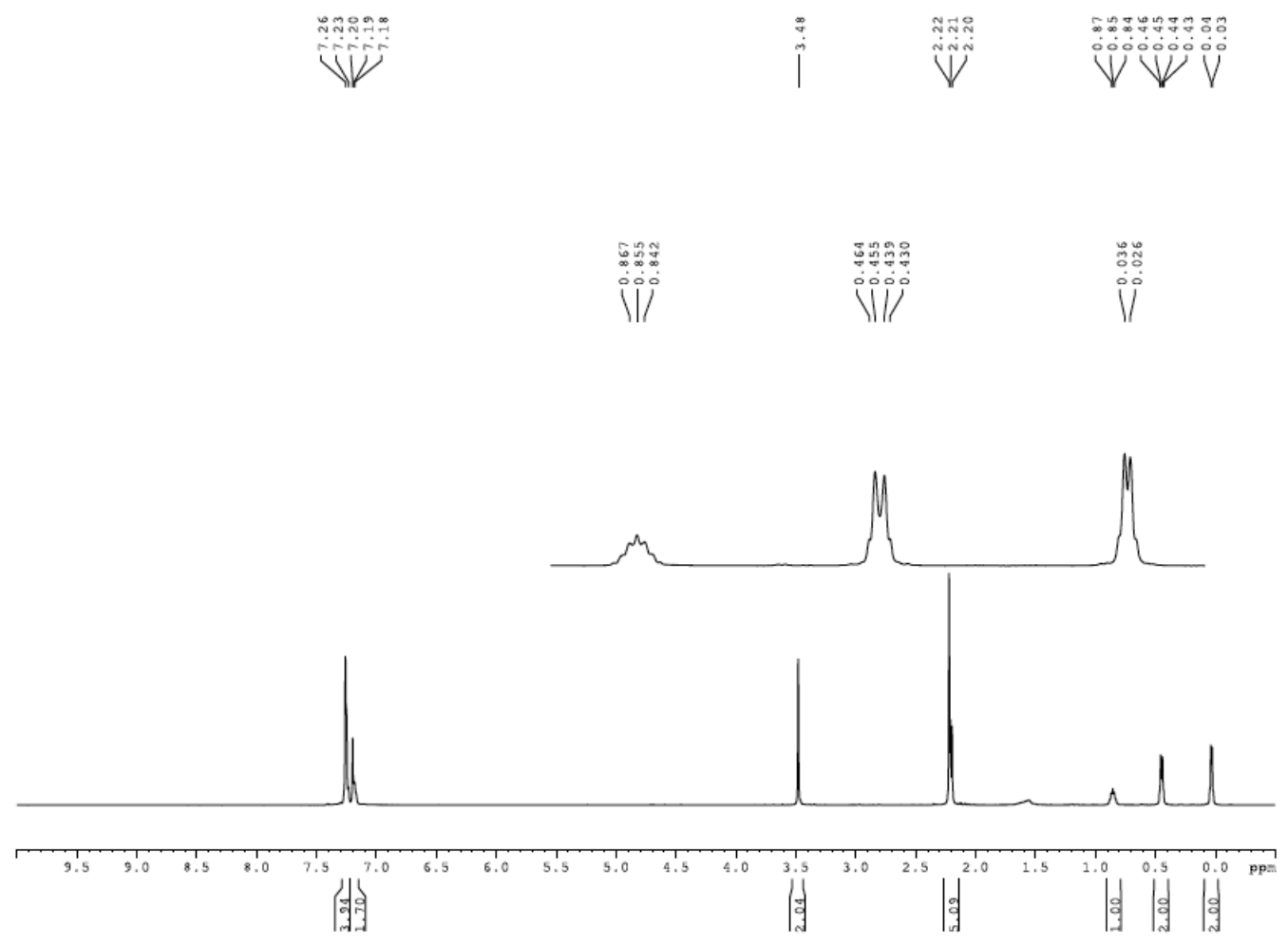

Figure S27. ${ }^{1}$ H-NMR Spectra of 11.

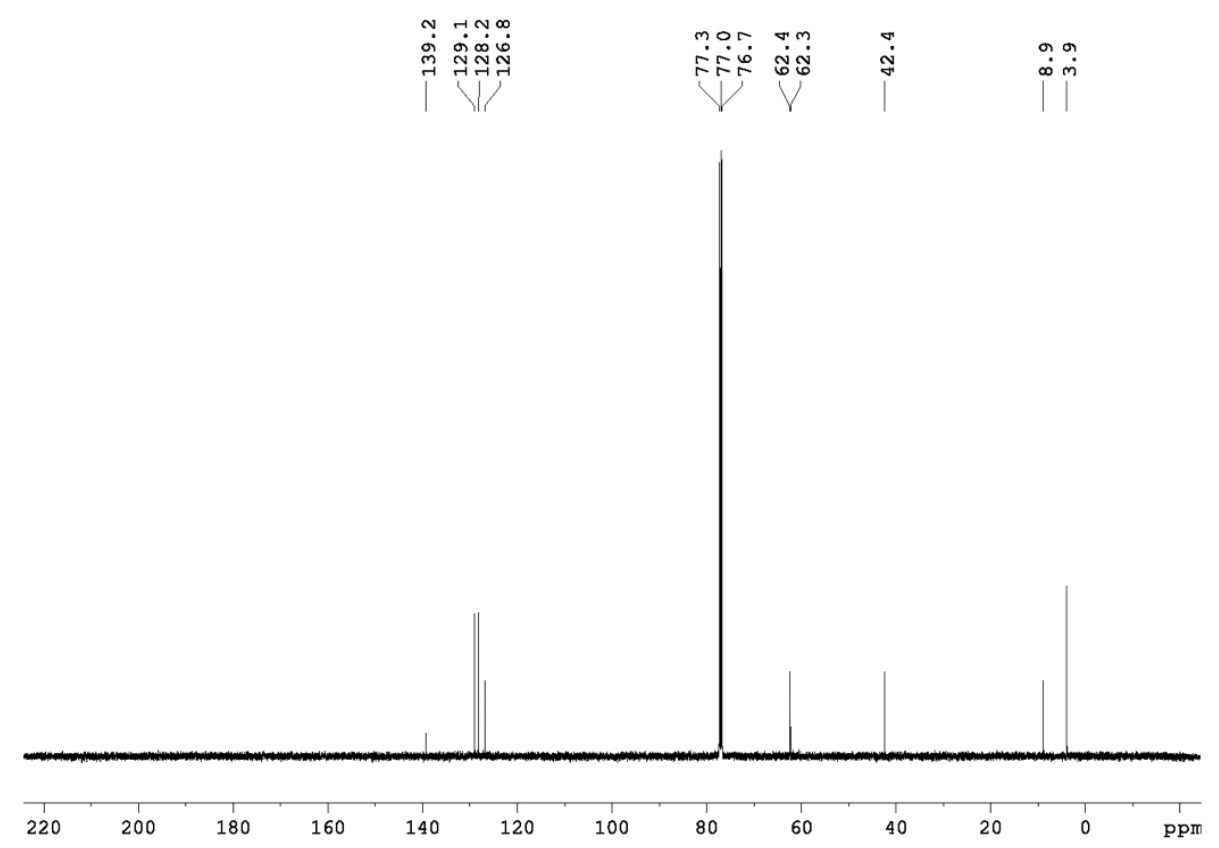

Figure S28. $\quad{ }^{13} \mathrm{C}-\mathrm{NMR}$ Spectra of $\mathbf{1 1}$. 


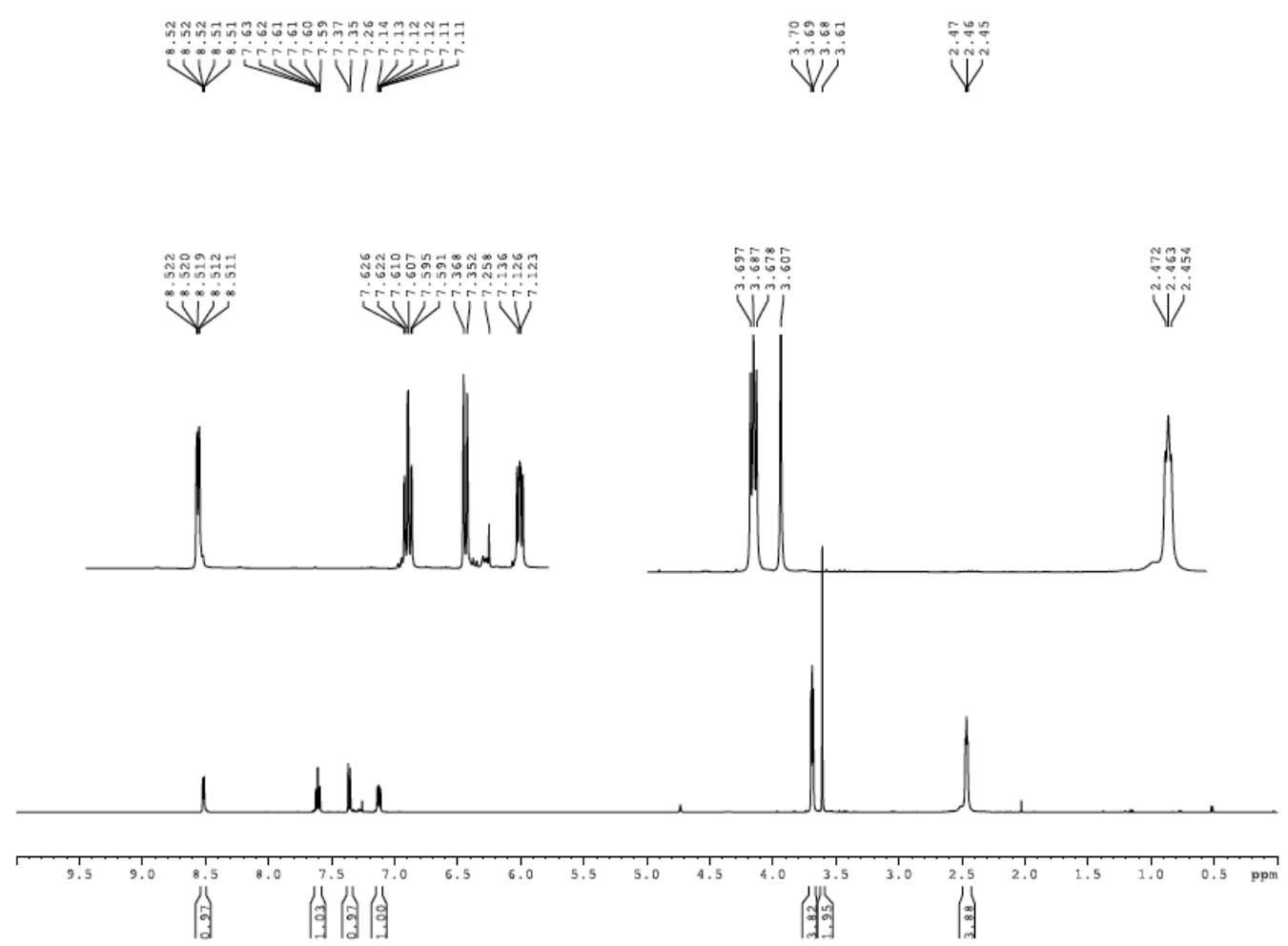

Figure S29. $\quad{ }^{1} \mathrm{H}-\mathrm{NMR}$ Spectra of $\mathbf{1 2}$.
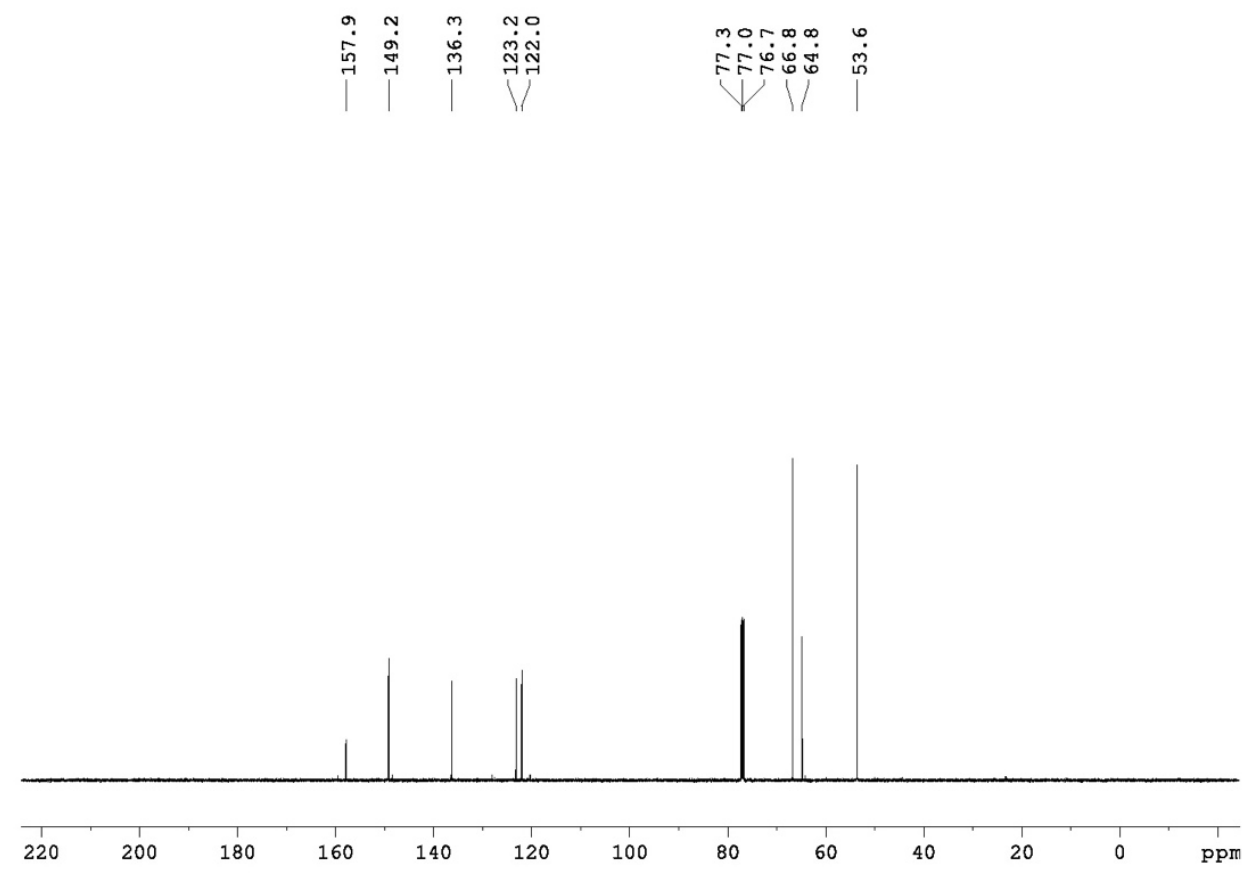

Figure S30. ${ }^{13} \mathrm{C}-\mathrm{NMR}$ Spectra of $\mathbf{1 2}$. 


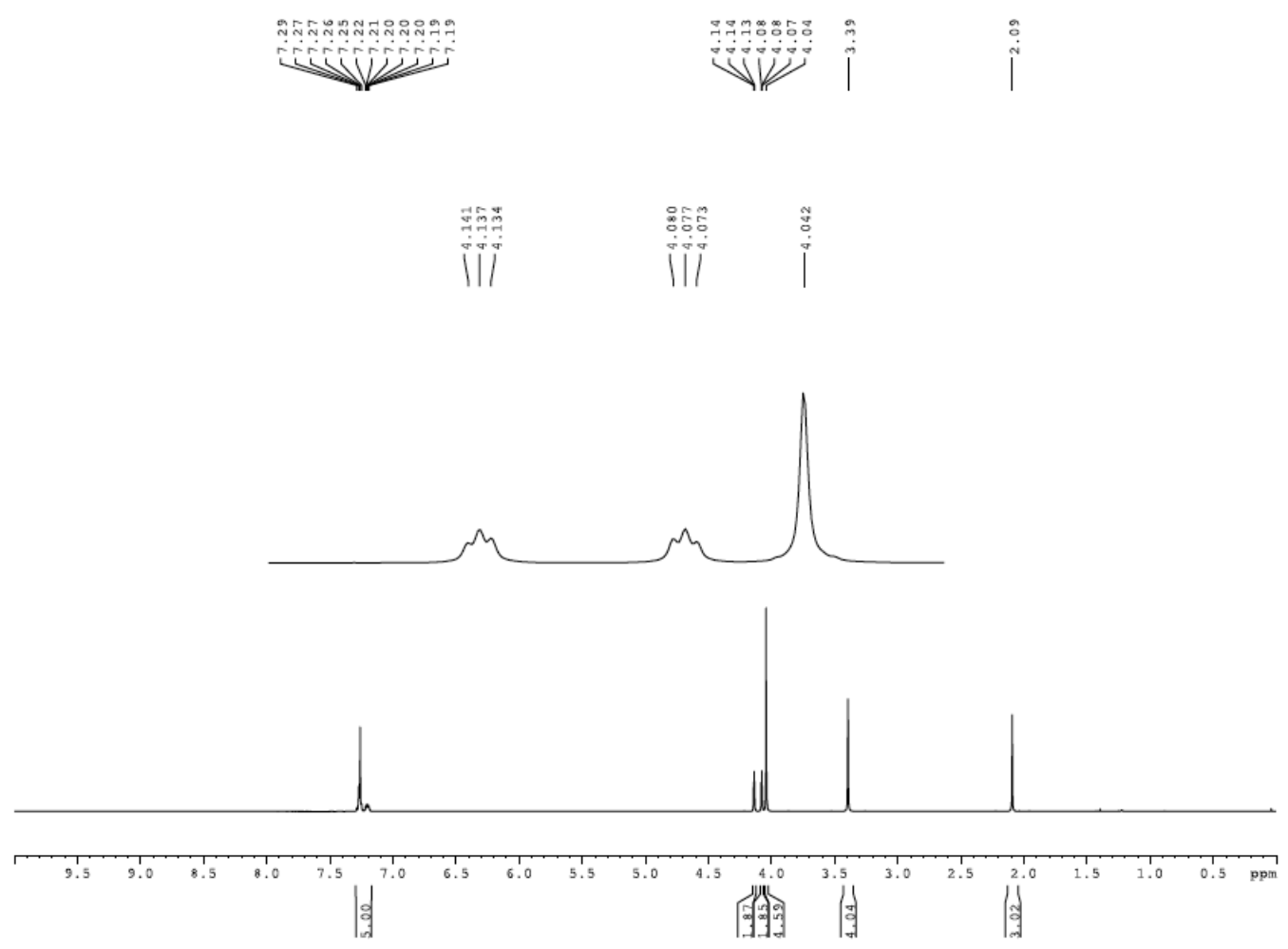

Figure S31. ${ }^{1}$ H-NMR Spectra of 13.

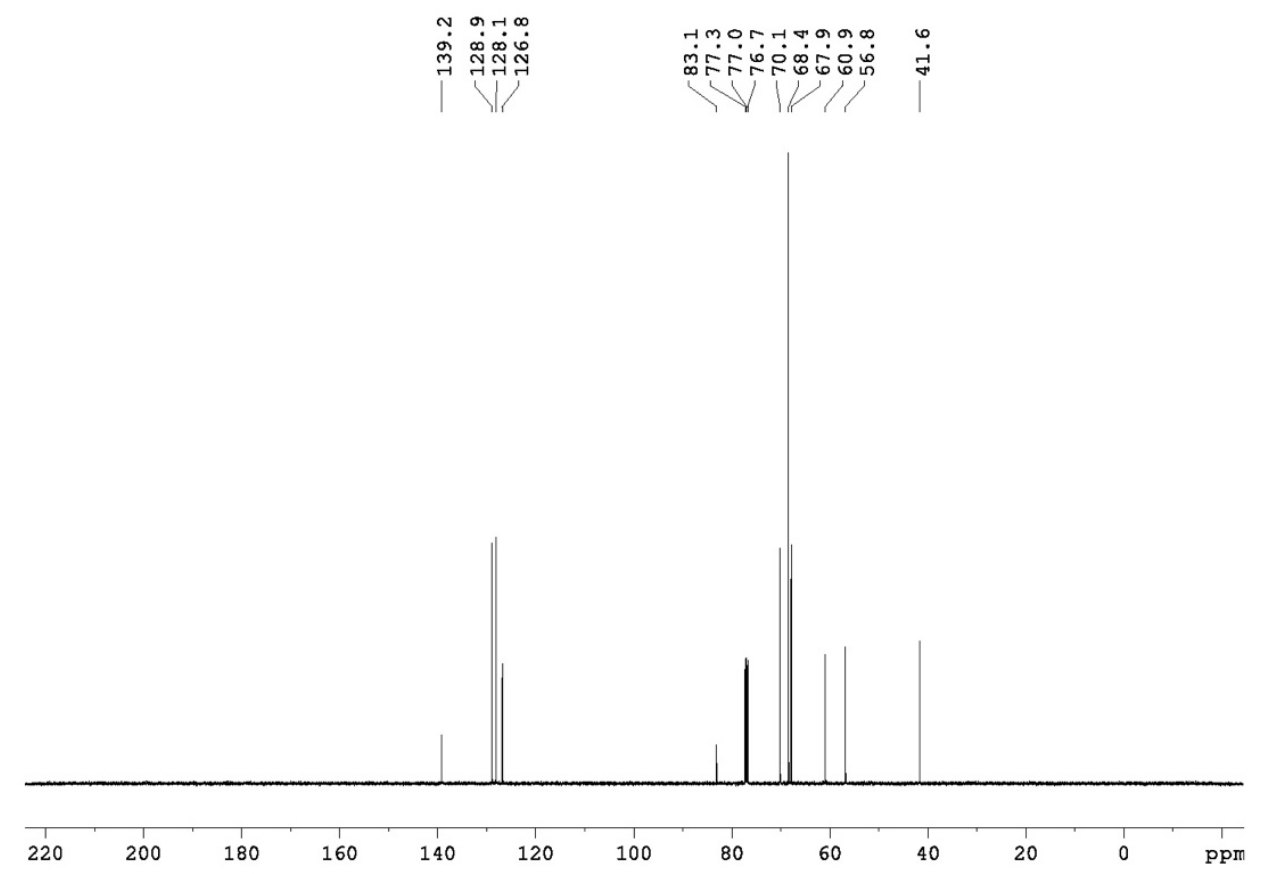

Figure S32. ${ }^{13} \mathrm{C}-\mathrm{NMR}$ Spectra of $\mathbf{1 3}$. 


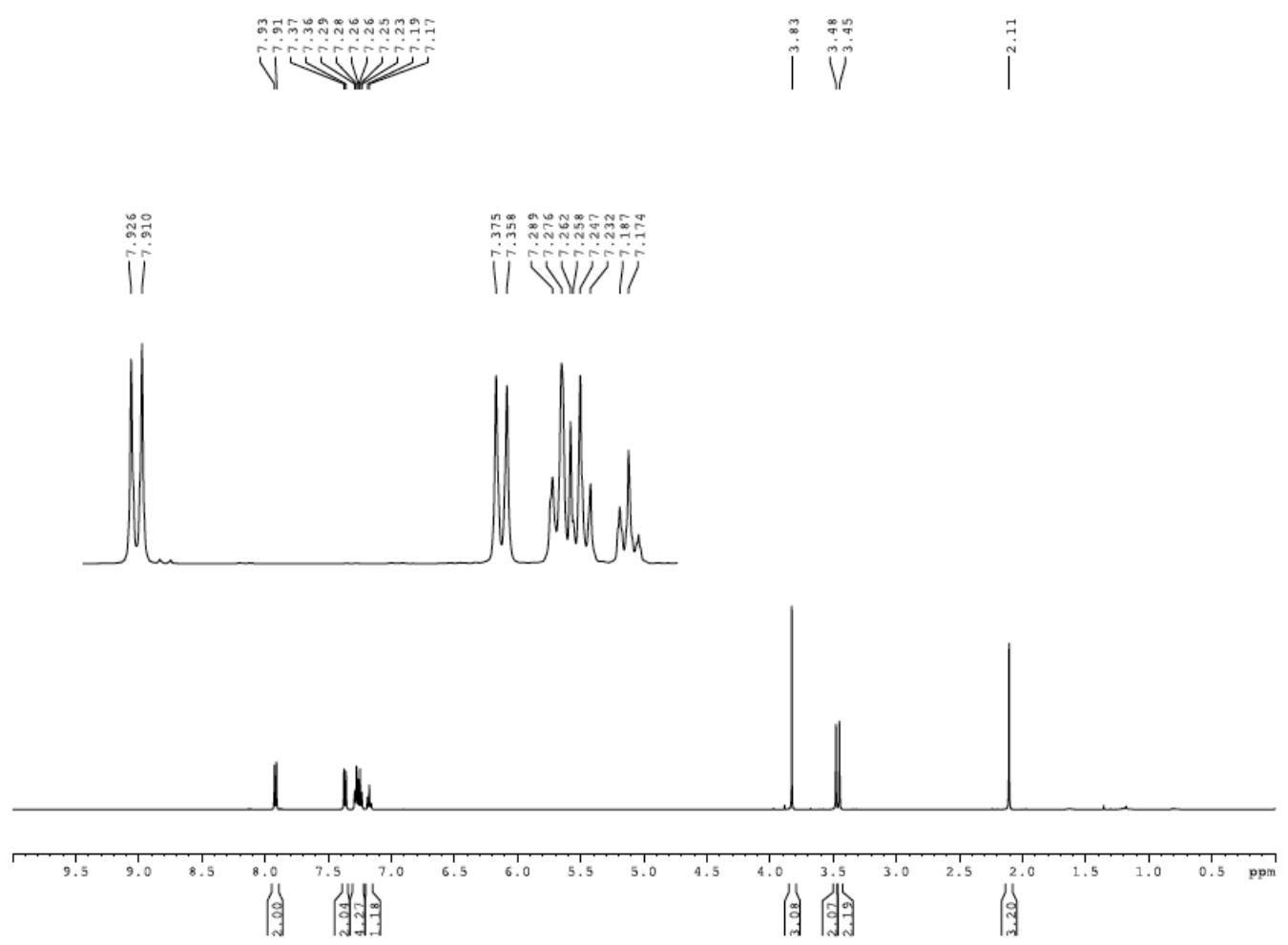

Figure S33. $\quad{ }^{1}$ H-NMR Spectra of 14.

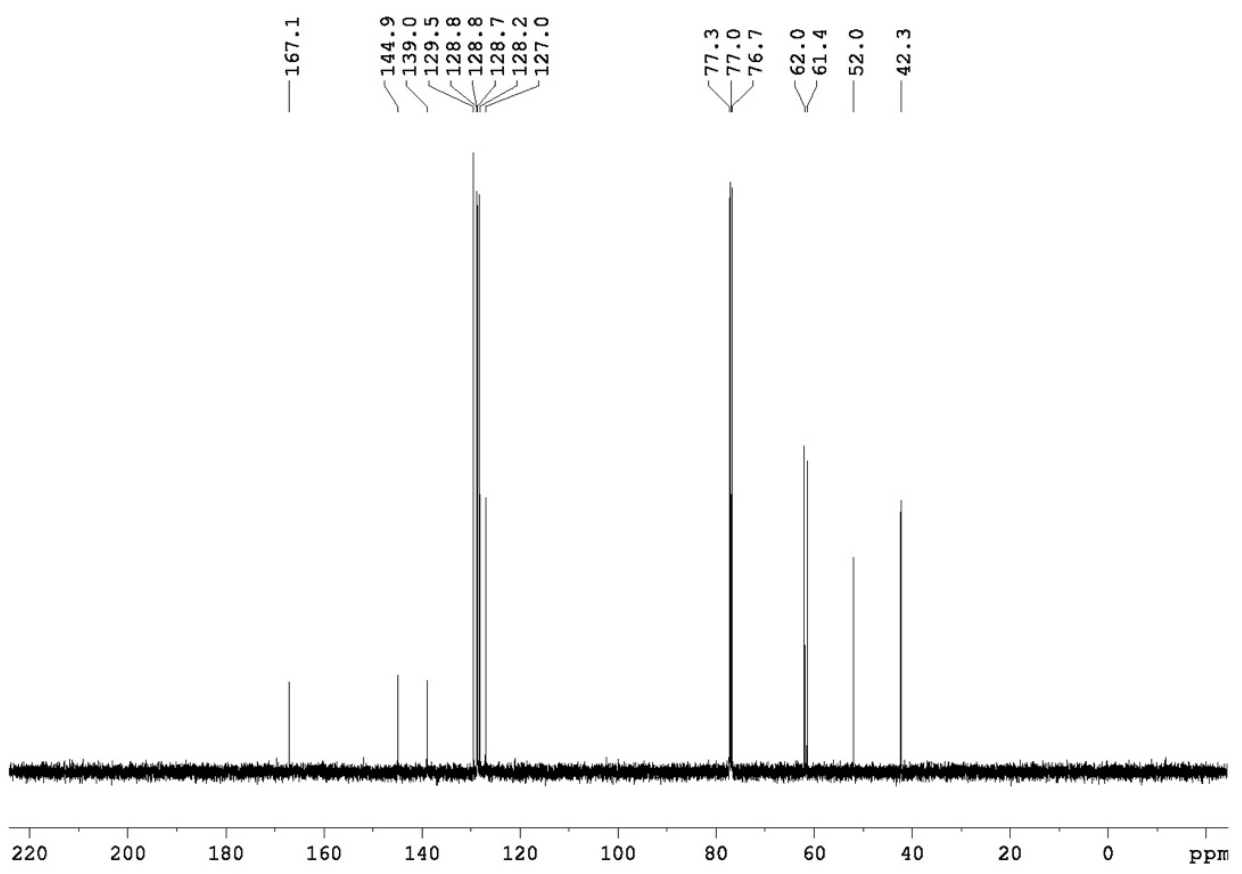

Figure S34. ${ }^{13}$ C-NMR Spectra of 14. 


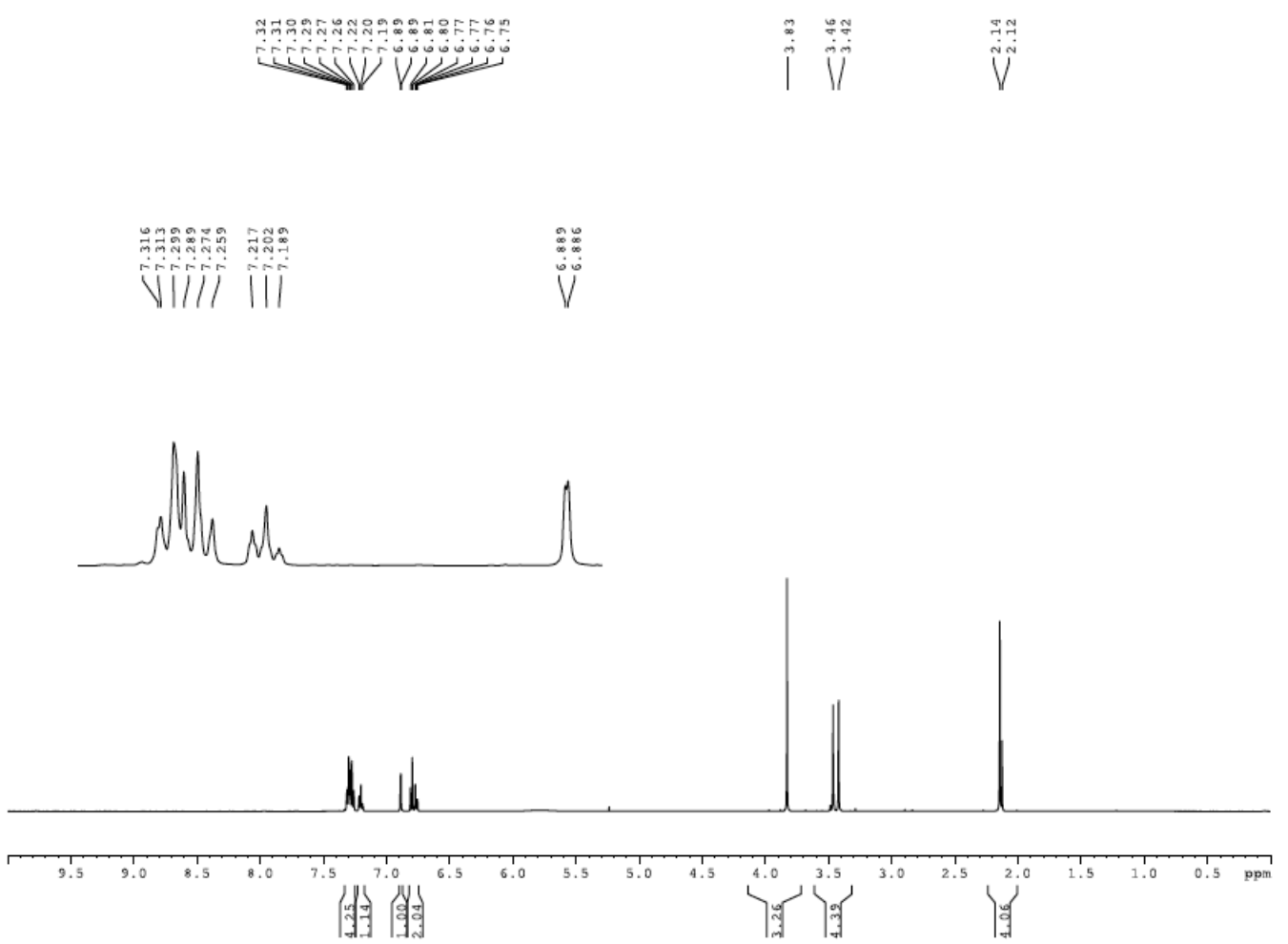

Figure S35. ${ }^{1} \mathrm{H}-\mathrm{NMR}$ Spectra of $\mathbf{1 5}$.
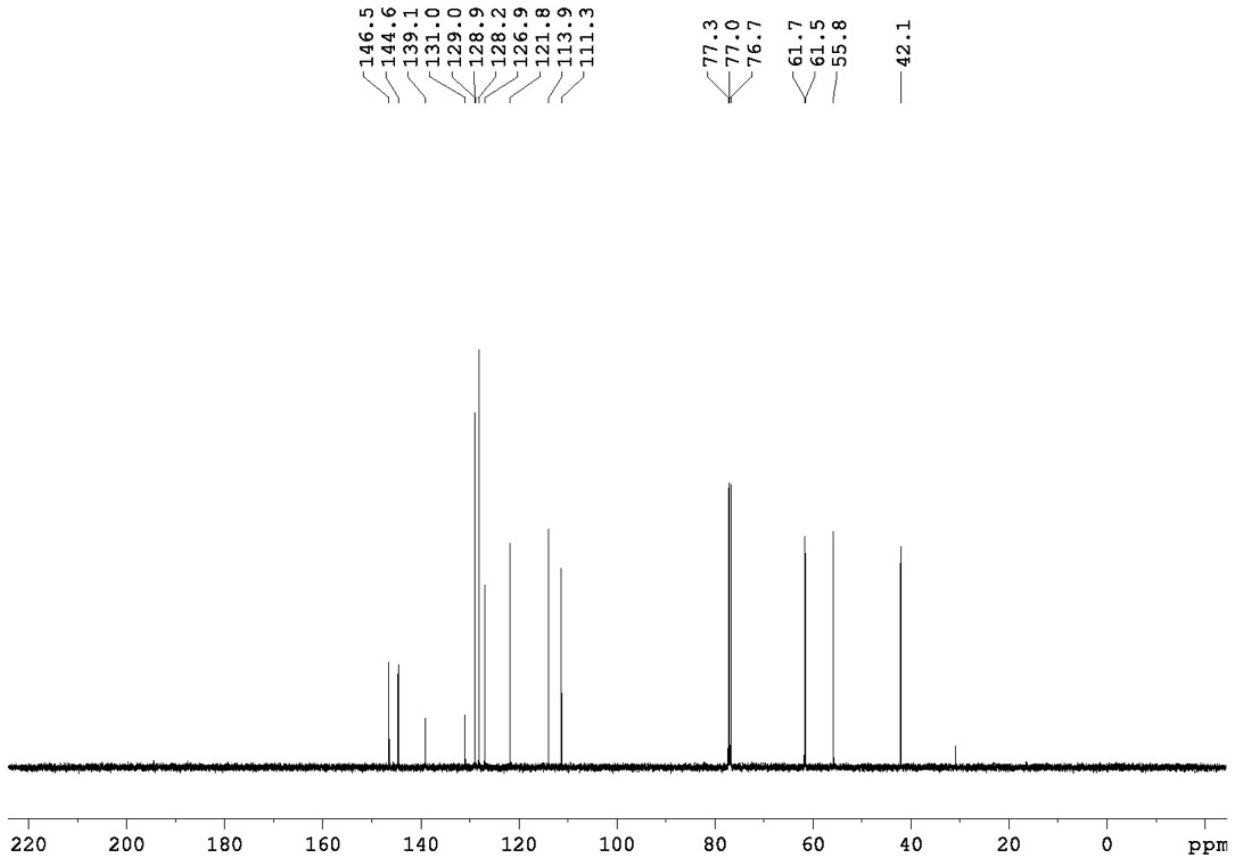

Figure S36. $\quad{ }^{13} \mathrm{C}-\mathrm{NMR}$ Spectra of $\mathbf{1 5}$. 


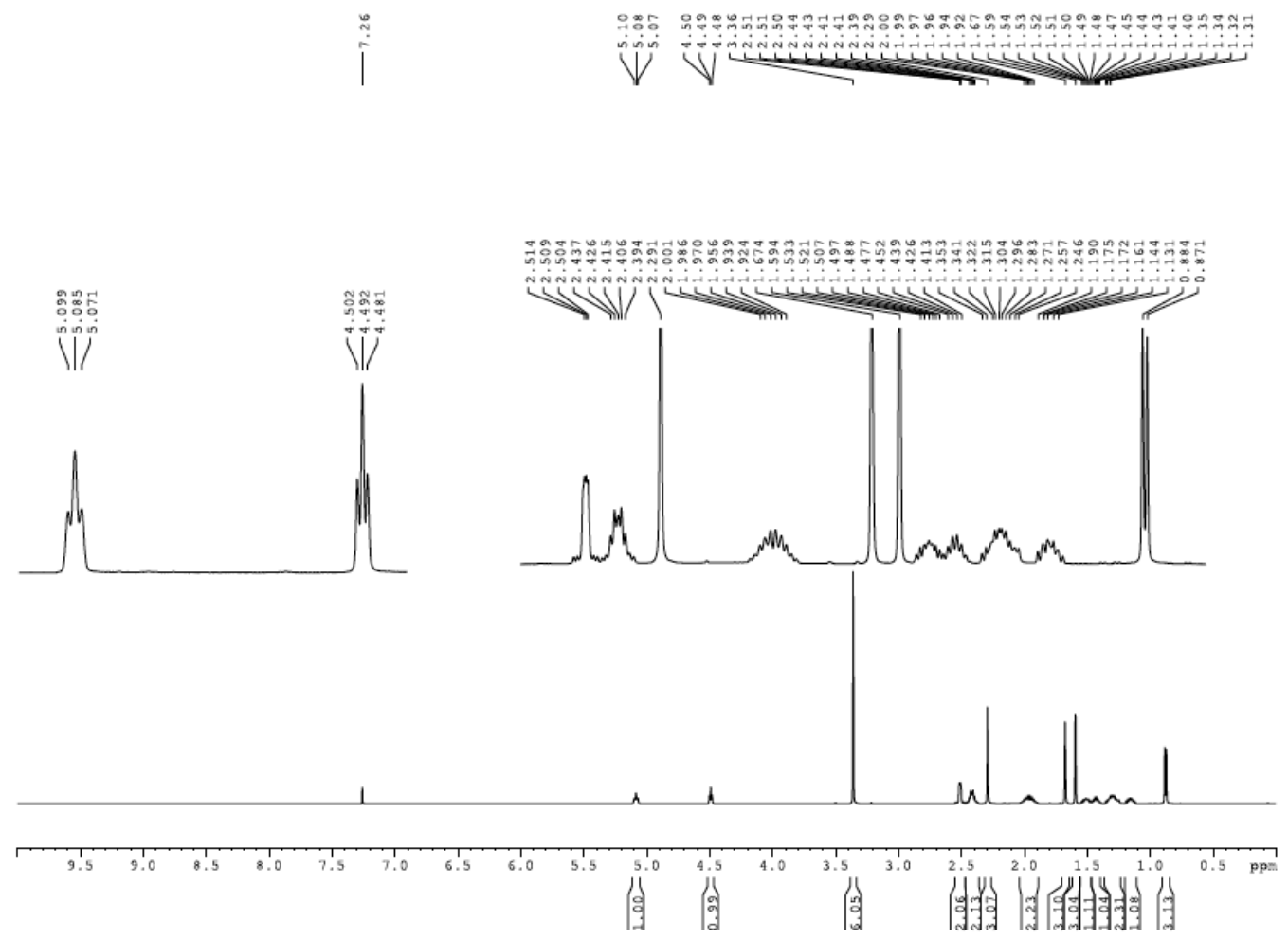

Figure S37. ${ }^{1} \mathrm{H}-\mathrm{NMR}$ Spectra of $\mathbf{1 6}$.

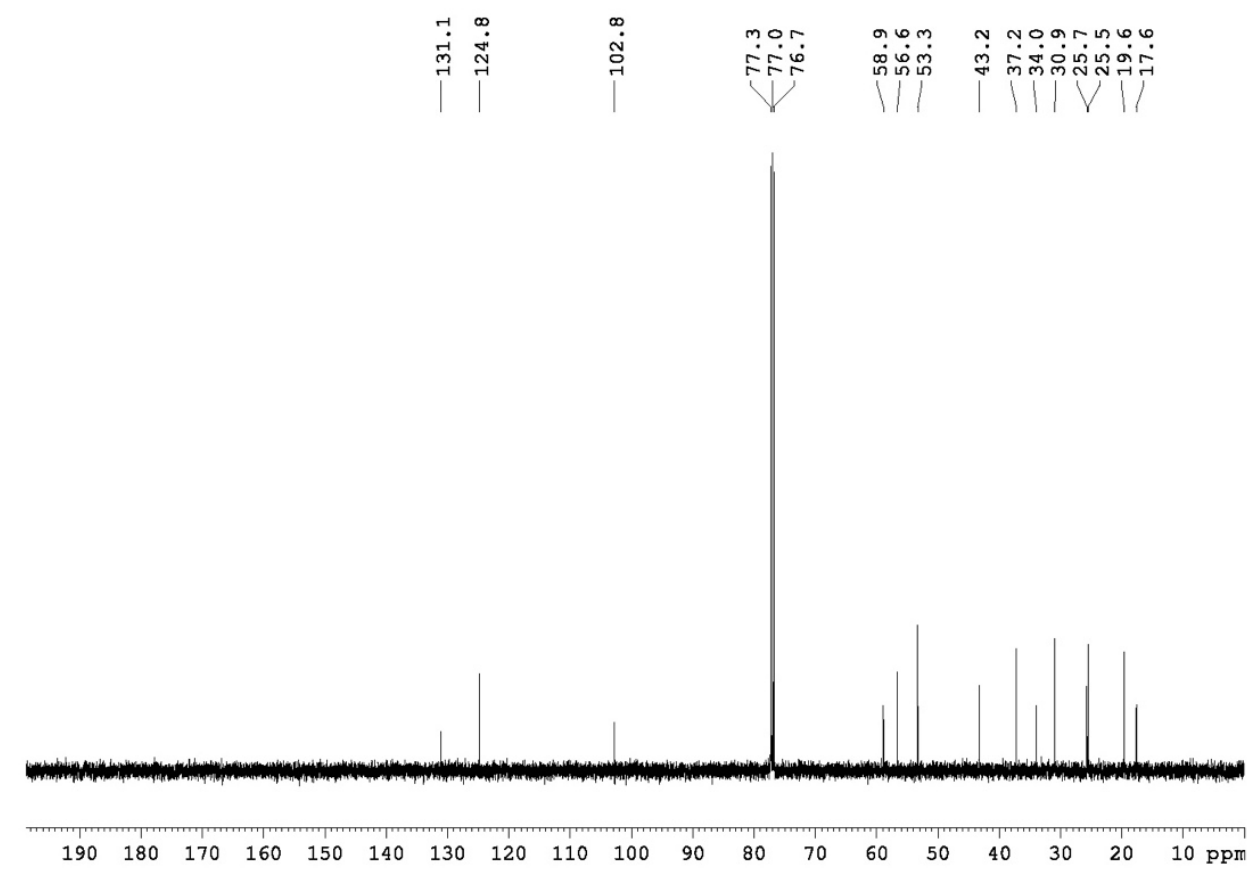

Figure S38. $\quad{ }^{13}$ C-NMR Spectra of $\mathbf{1 6}$. 


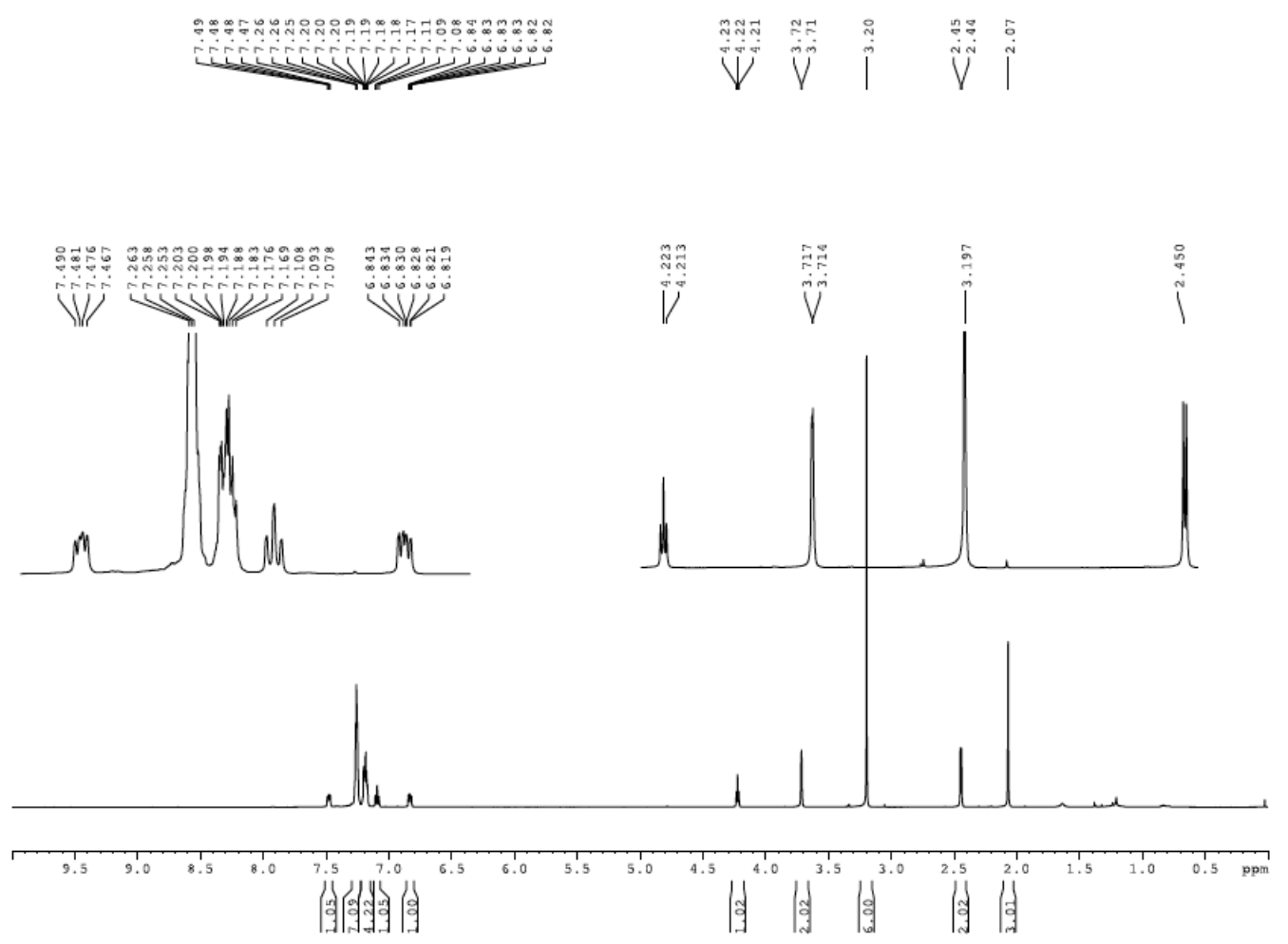

Figure S39. $\quad{ }^{1} \mathrm{H}-\mathrm{NMR}$ Spectra of 17.

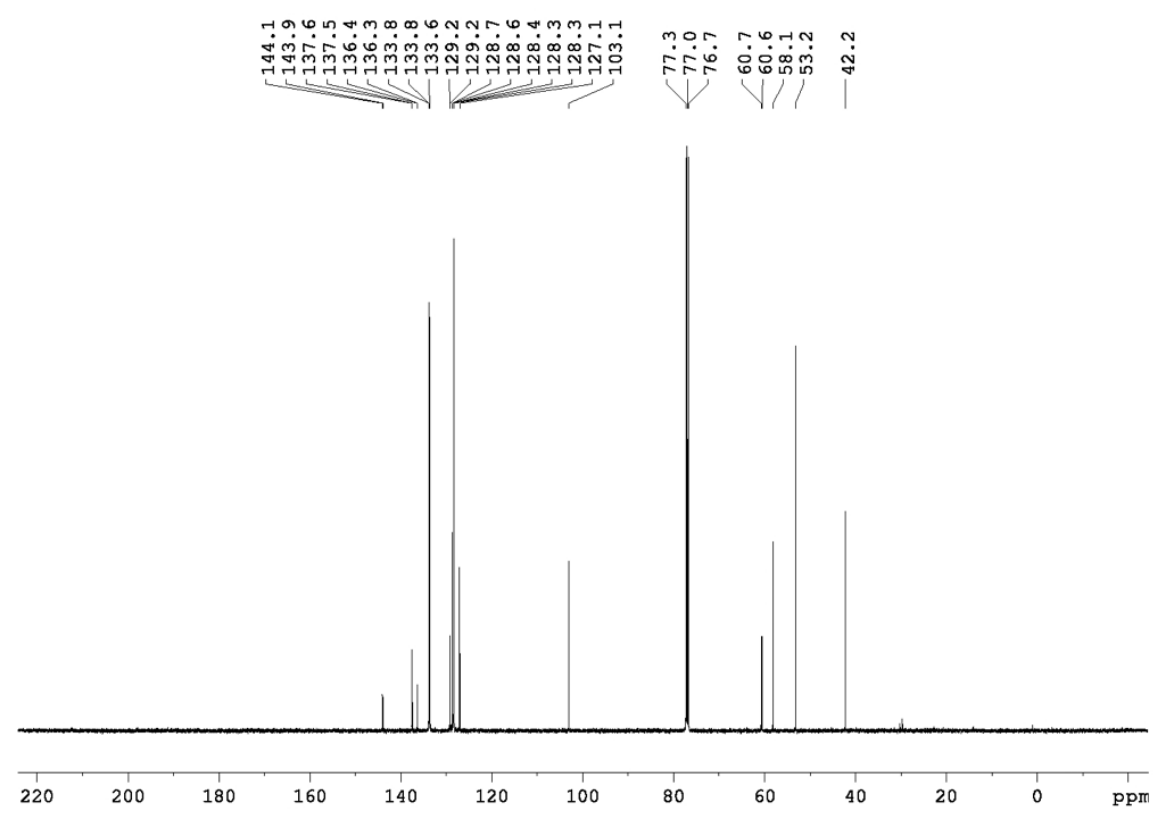

Figure S40. ${ }^{13} \mathrm{C}-\mathrm{NMR}$ Spectra of $\mathbf{1 7}$. 


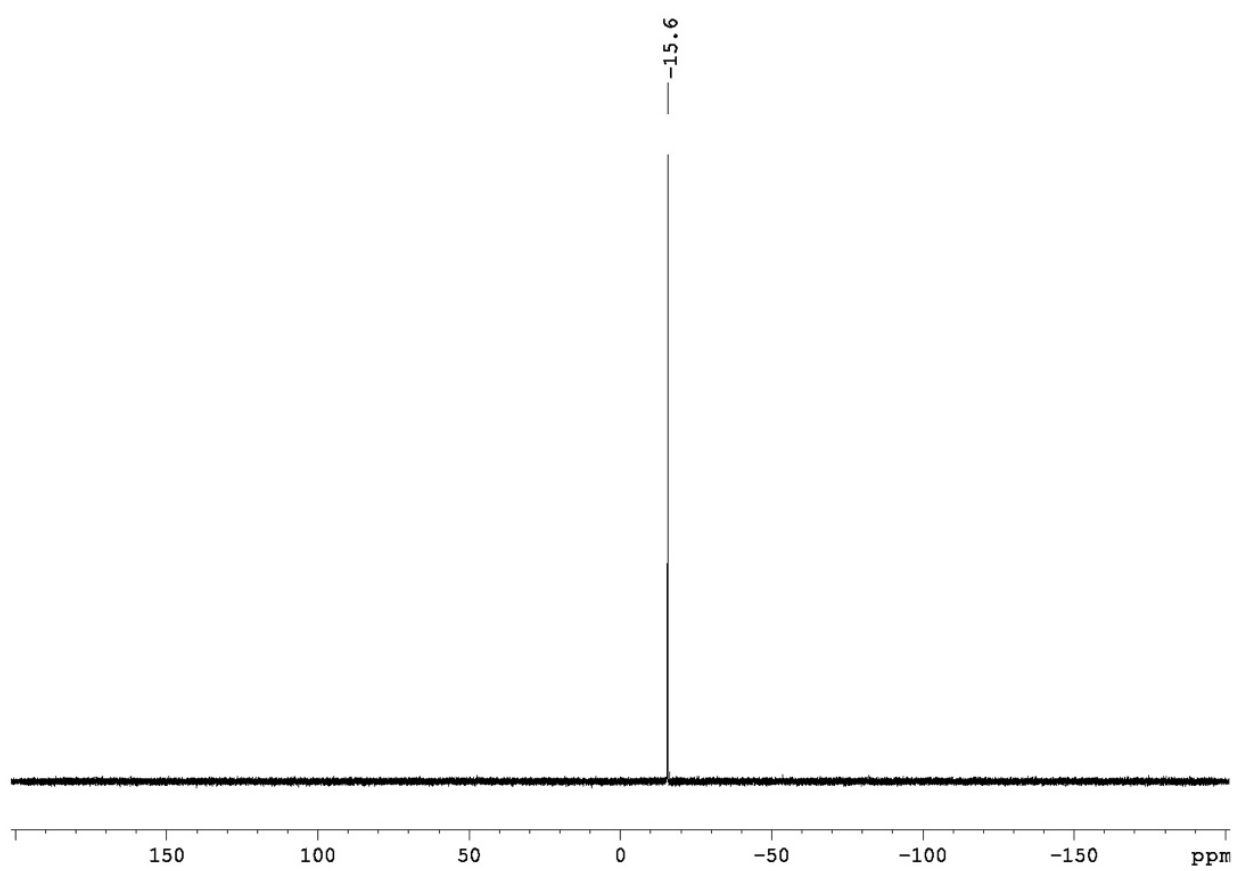

Figure S41. ${ }^{31} \mathrm{P}-\mathrm{NMR}$ Spectra of $\mathbf{1 7 .}$

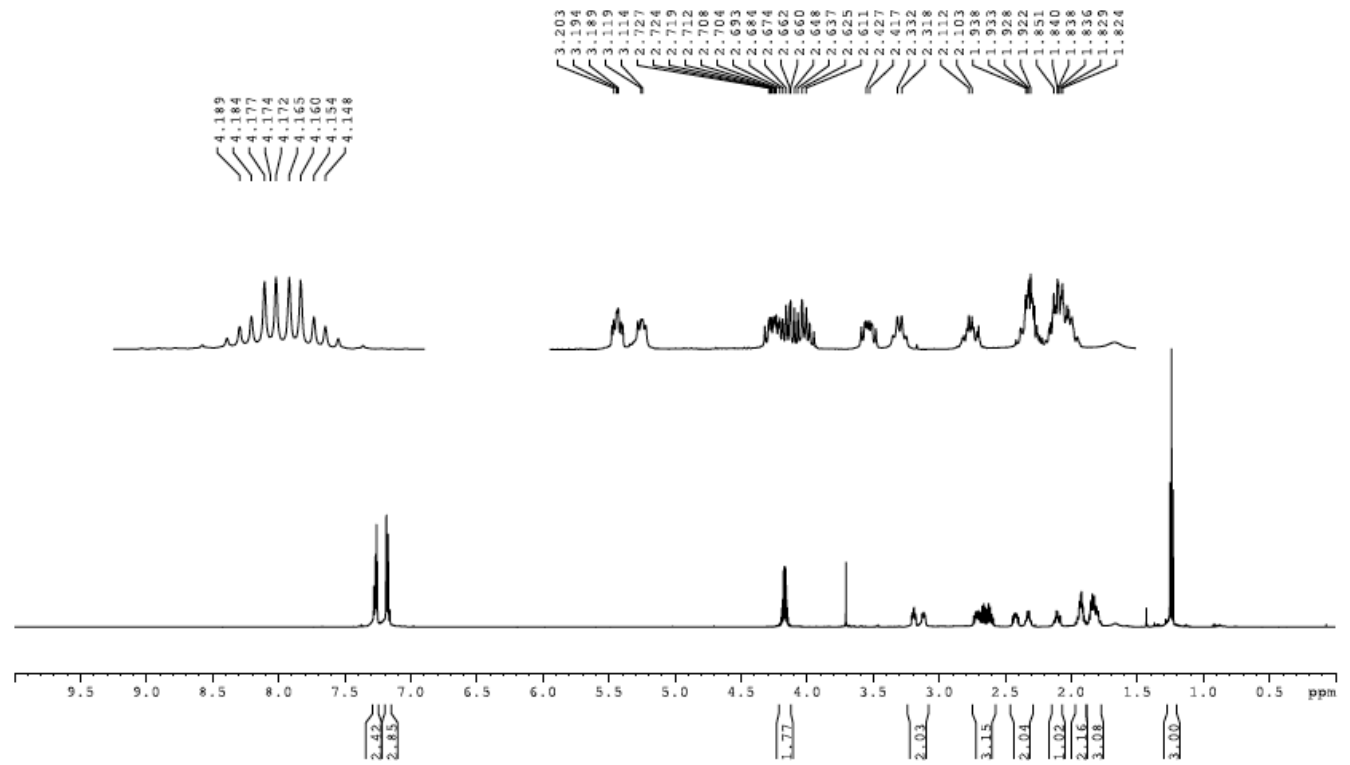

Figure S42. $\quad{ }^{1} \mathrm{H}-\mathrm{NMR}$ Spectra of 18. 


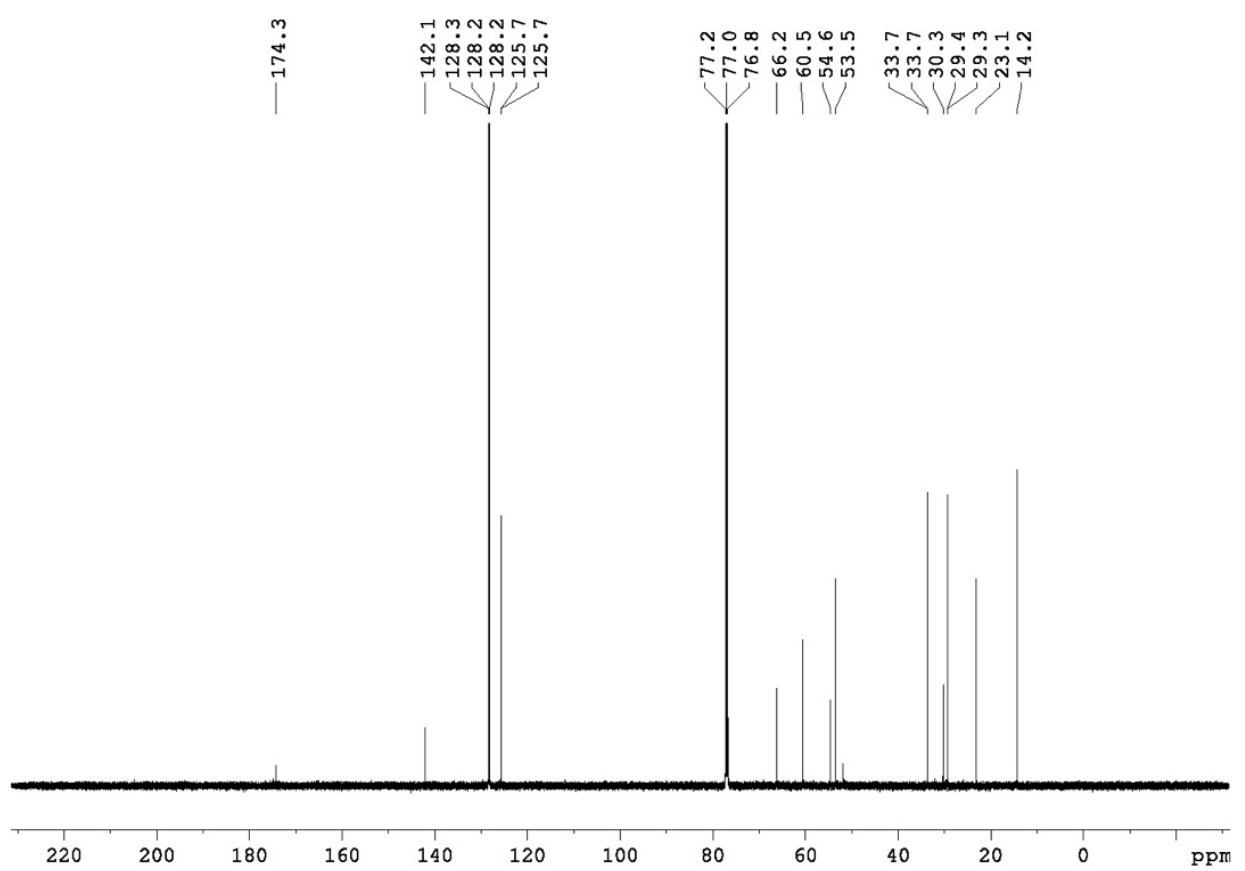

Figure S43. ${ }^{13} \mathrm{C}-\mathrm{NMR}$ Spectra of $\mathbf{1 8}$.

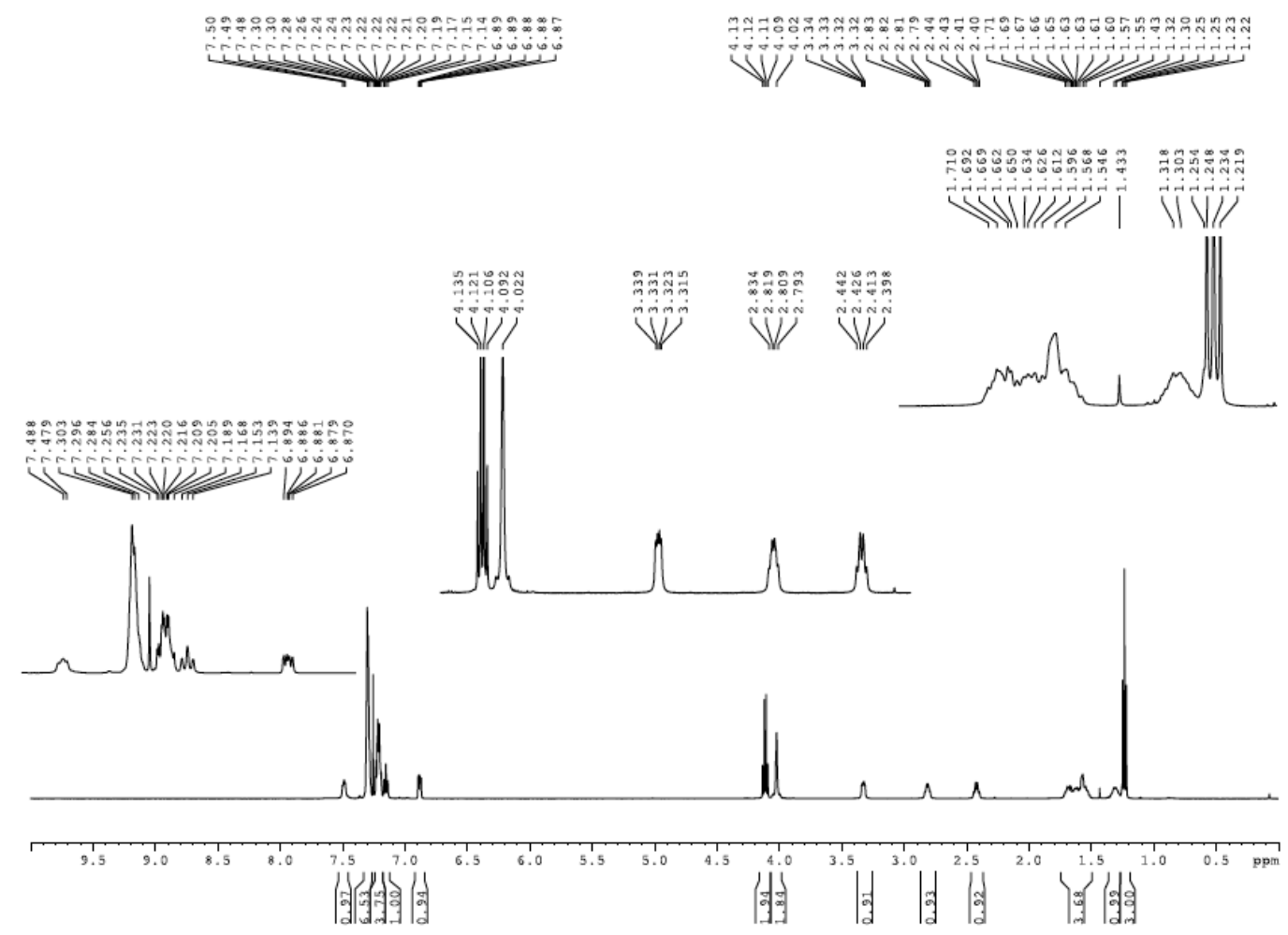

Figure S44. $\quad{ }^{1}$ H-NMR Spectra of 19. 


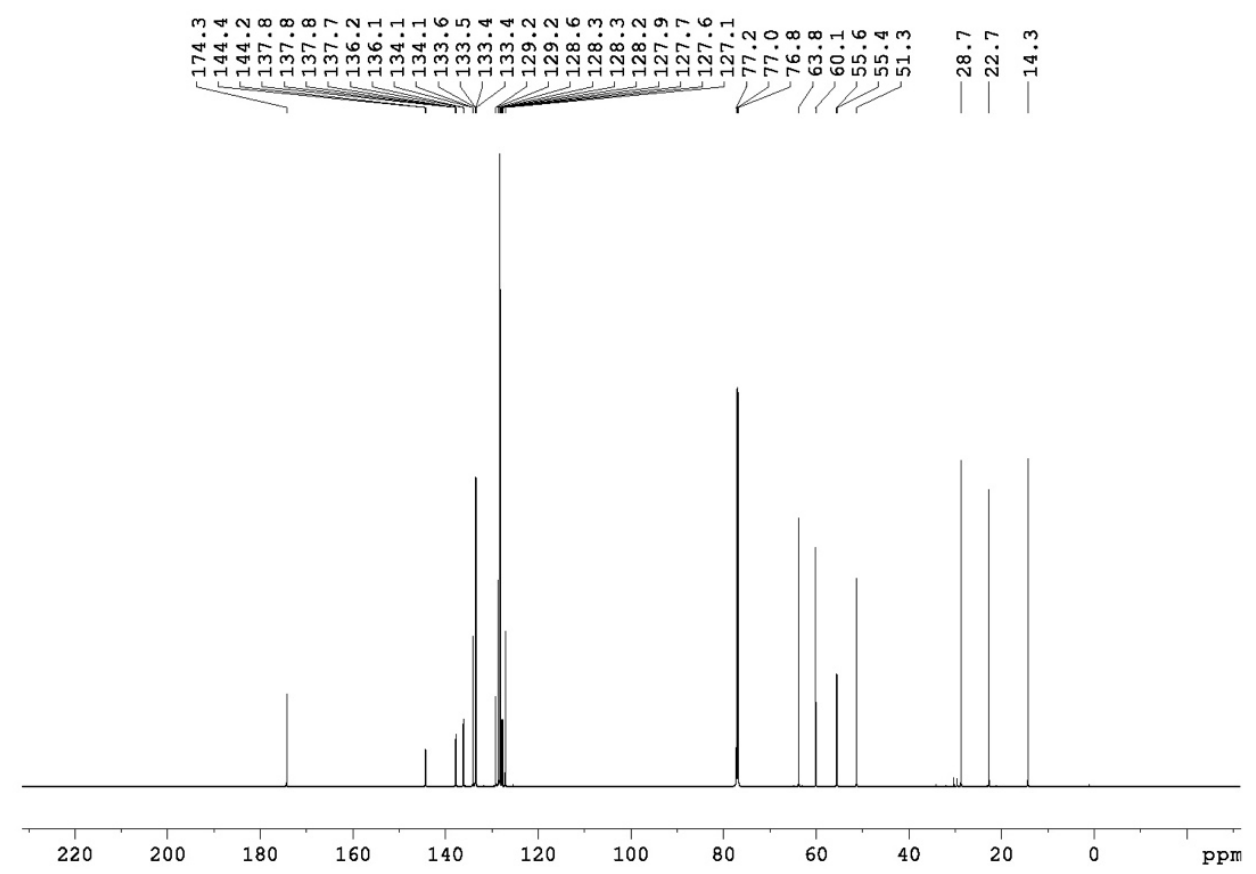

Figure S45. ${ }^{13} \mathrm{C}-\mathrm{NMR}$ Spectra of 19.

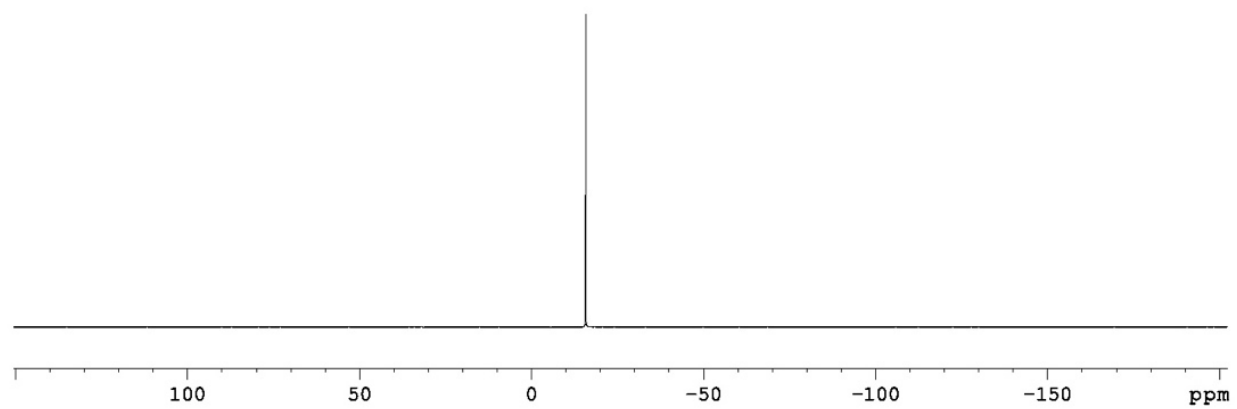

Figure S46. $\quad{ }^{31} \mathrm{P}-\mathrm{NMR}$ Spectra of 19. 


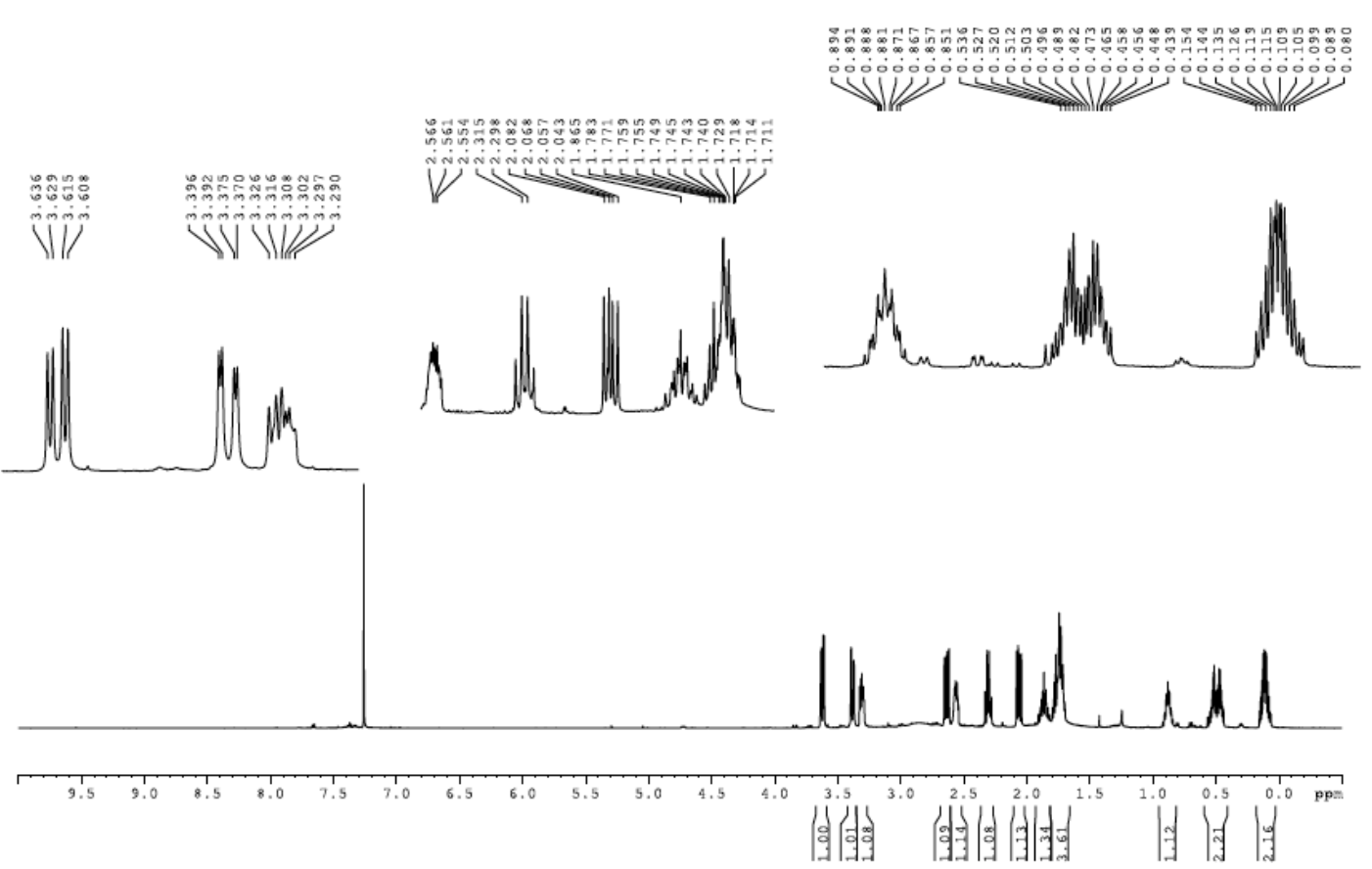

Figure S47. ${ }^{1} \mathrm{H}-\mathrm{NMR}$ Spectra of 20.

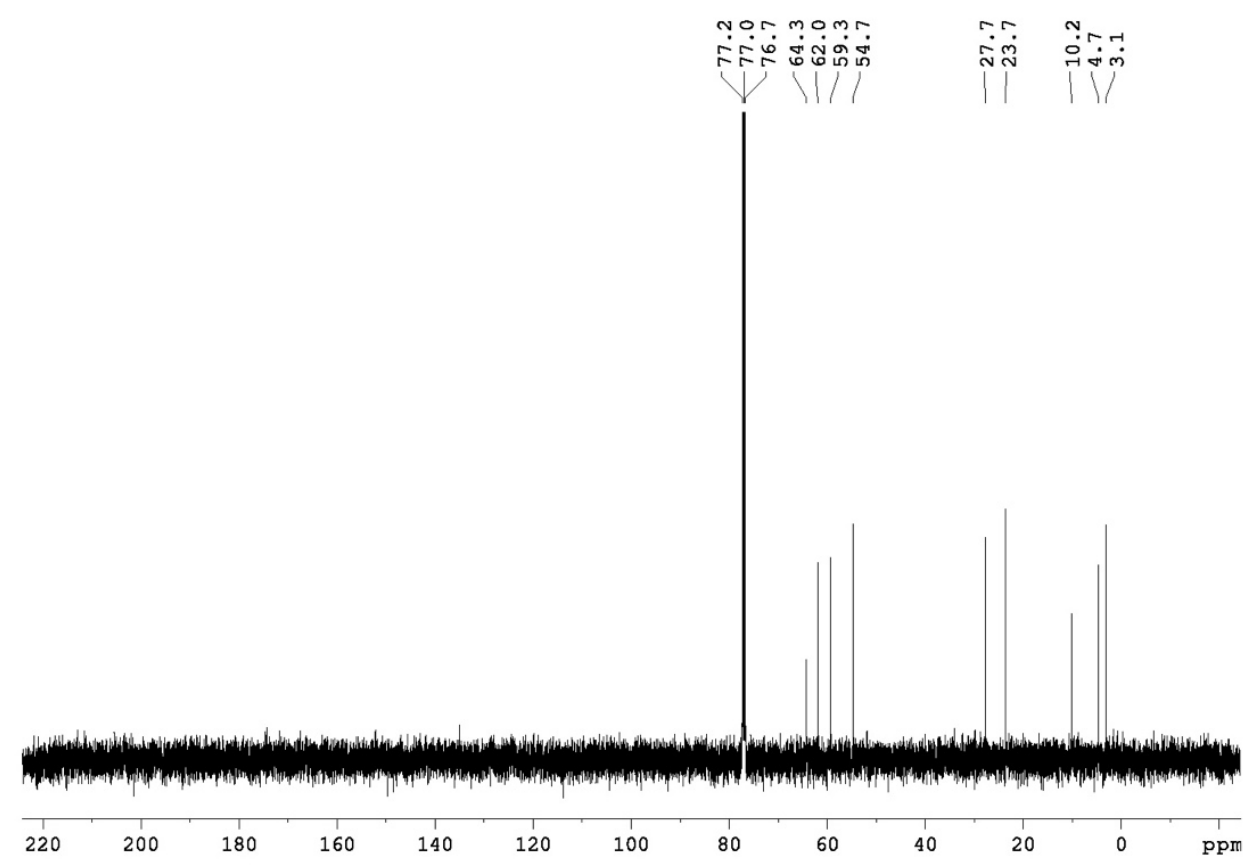

Figure S48. ${ }^{13}$ C-NMR Spectra of 20. 

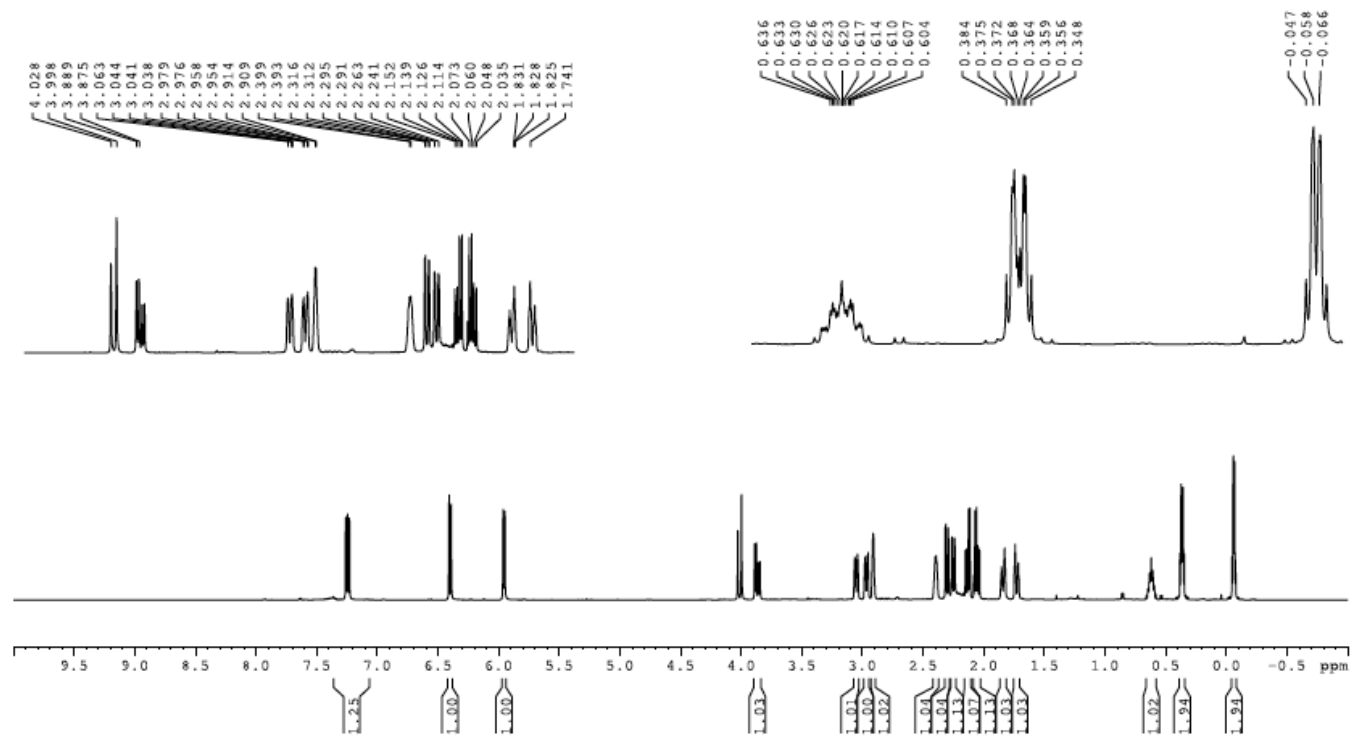

Figure S49. ${ }^{1}$ H-NMR Spectra of 21.

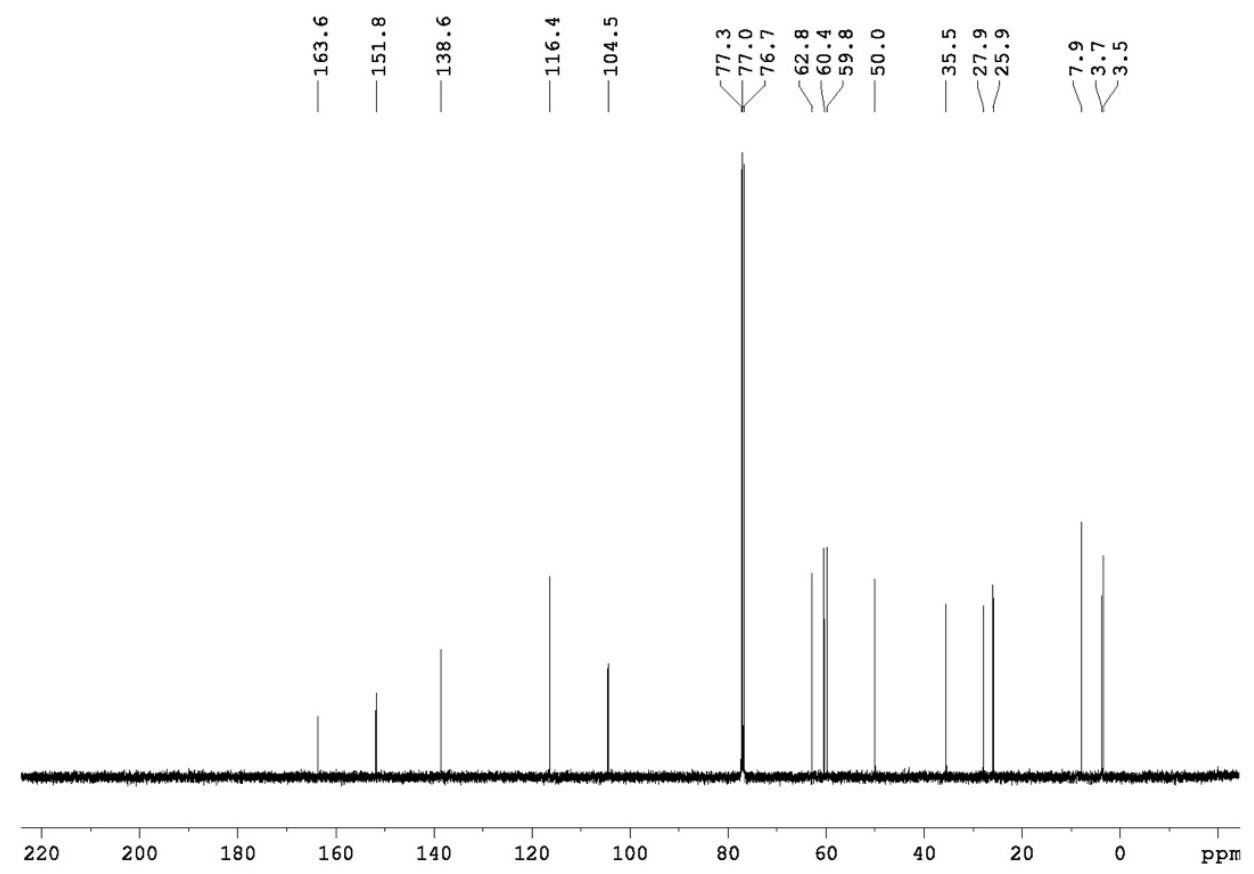

Figure S50. ${ }^{13}$ C-NMR Spectra of 21. 


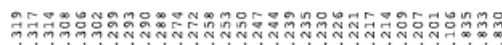
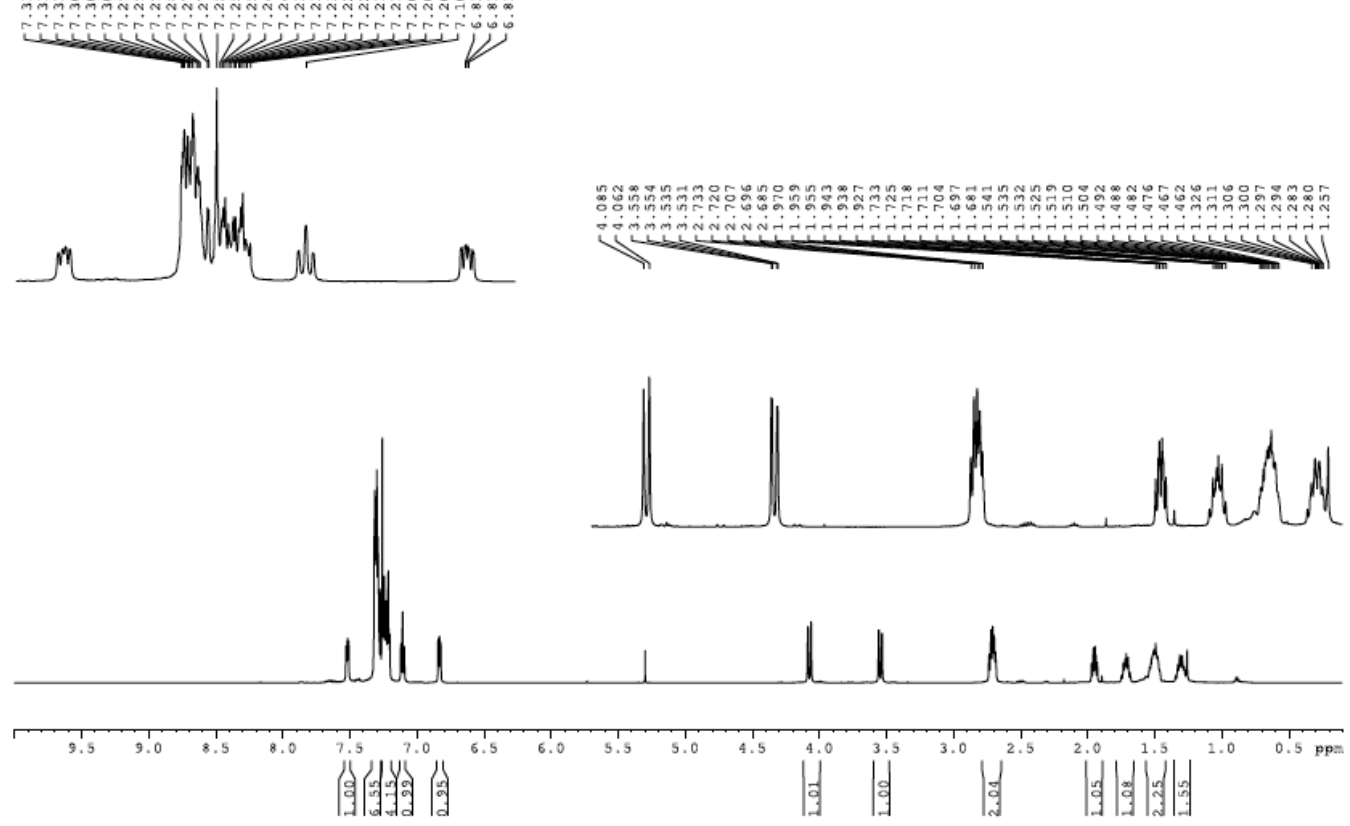

Figure S51. ${ }^{1}$ H-NMR Spectra of 22

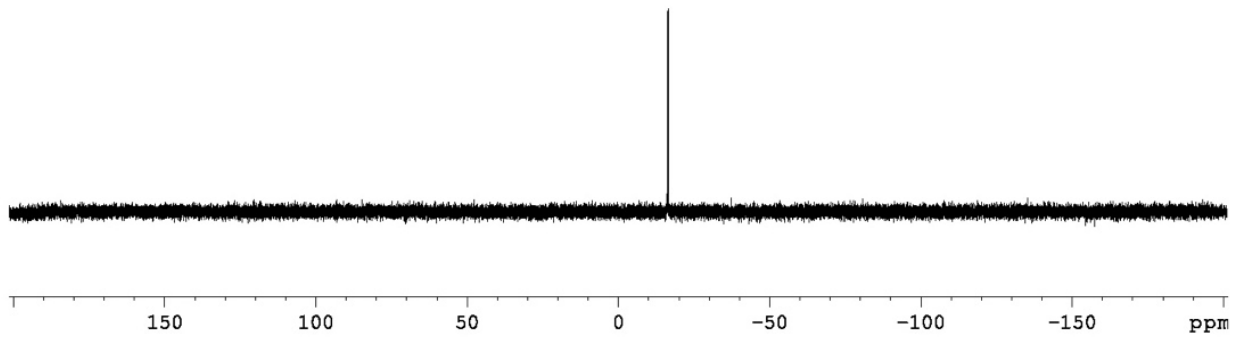

Figure S52. ${ }^{31} \mathrm{P}-\mathrm{NMR}$ Spectra of 22 


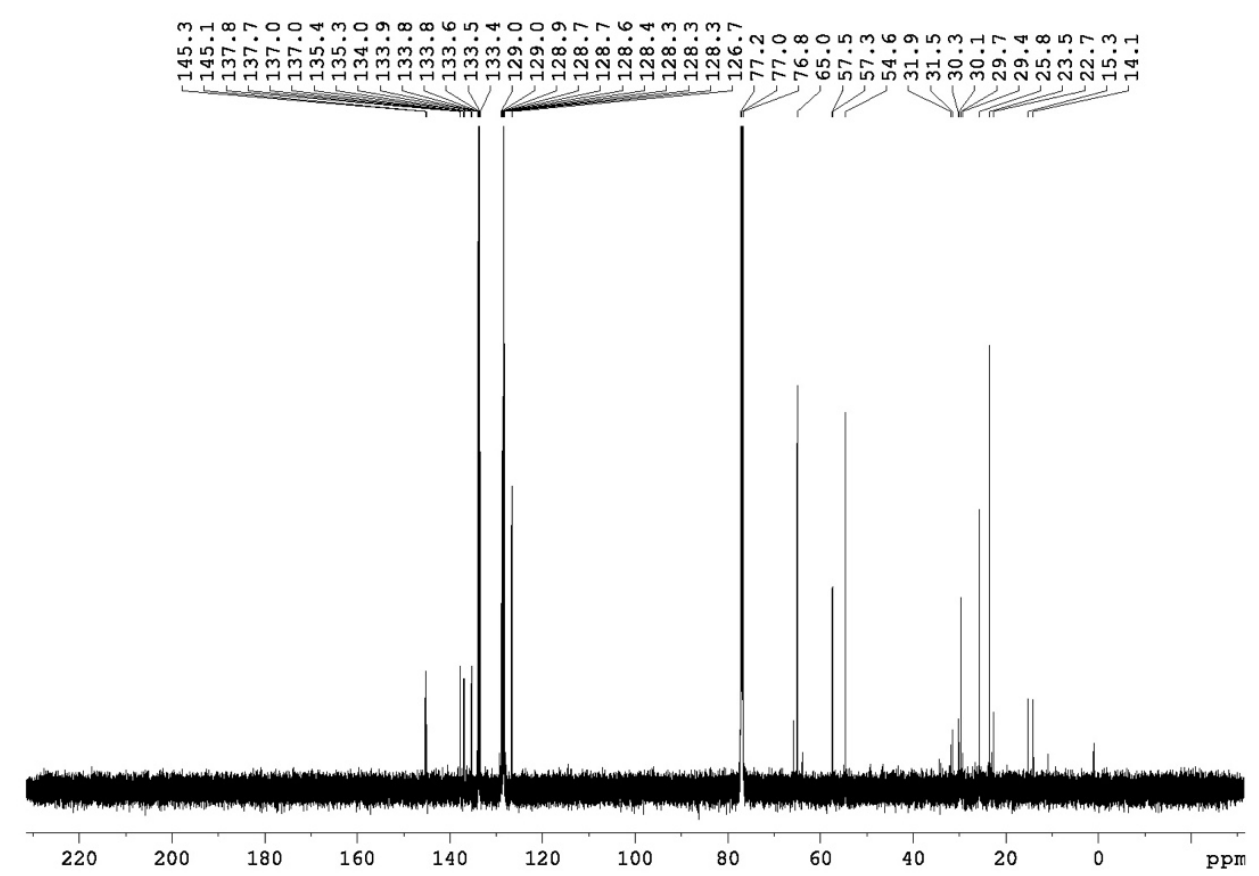

Figure S53. ${ }^{13}$ C-NMR Spectra of 22

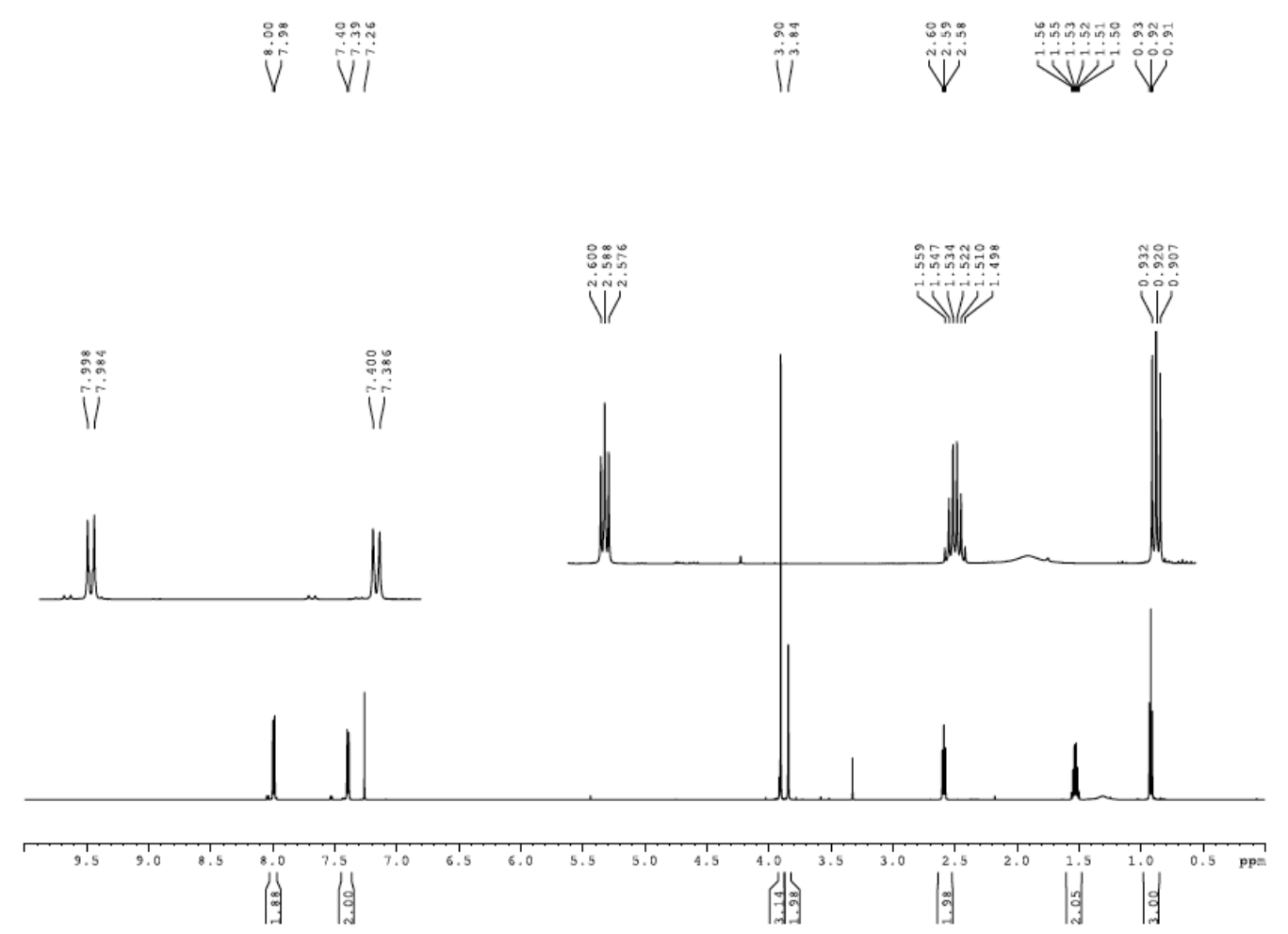

Figure S54. ${ }^{1}$ H-NMR Spectra of 23 


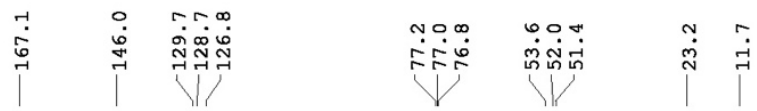

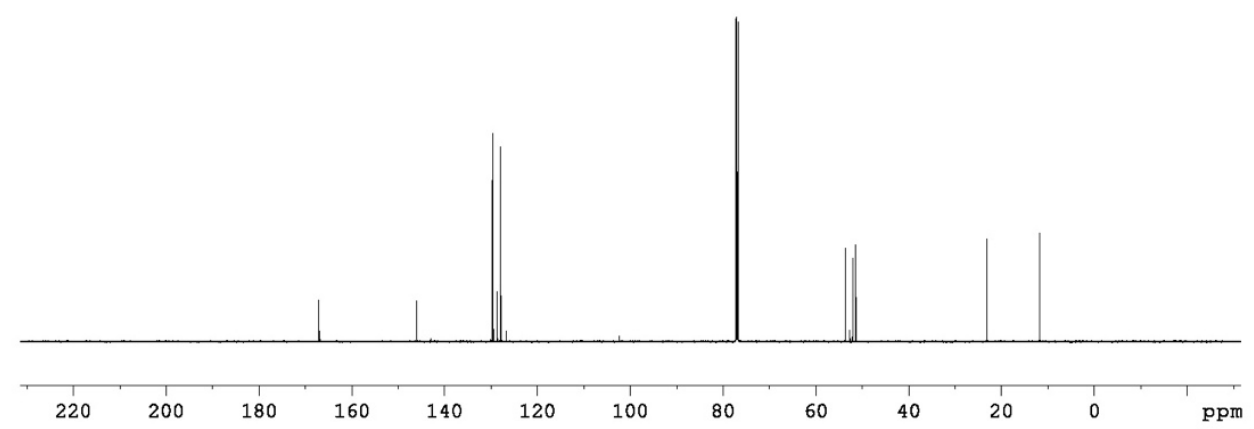

Figure S55. ${ }^{15} \mathrm{C}$-NMR Spectra of 23.
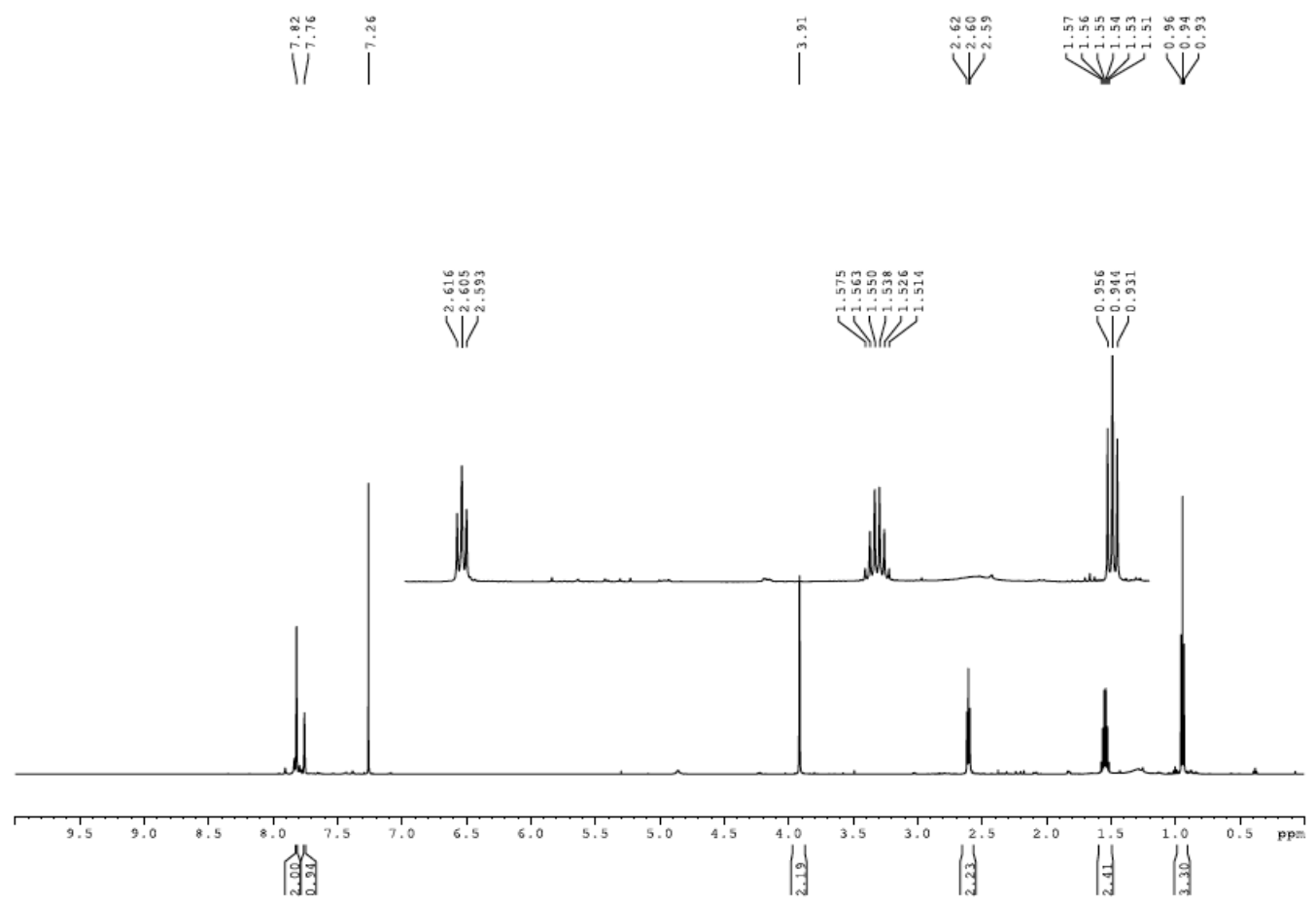

Figure S56. $\quad{ }^{1}$ H-NMR Spectra of 24 


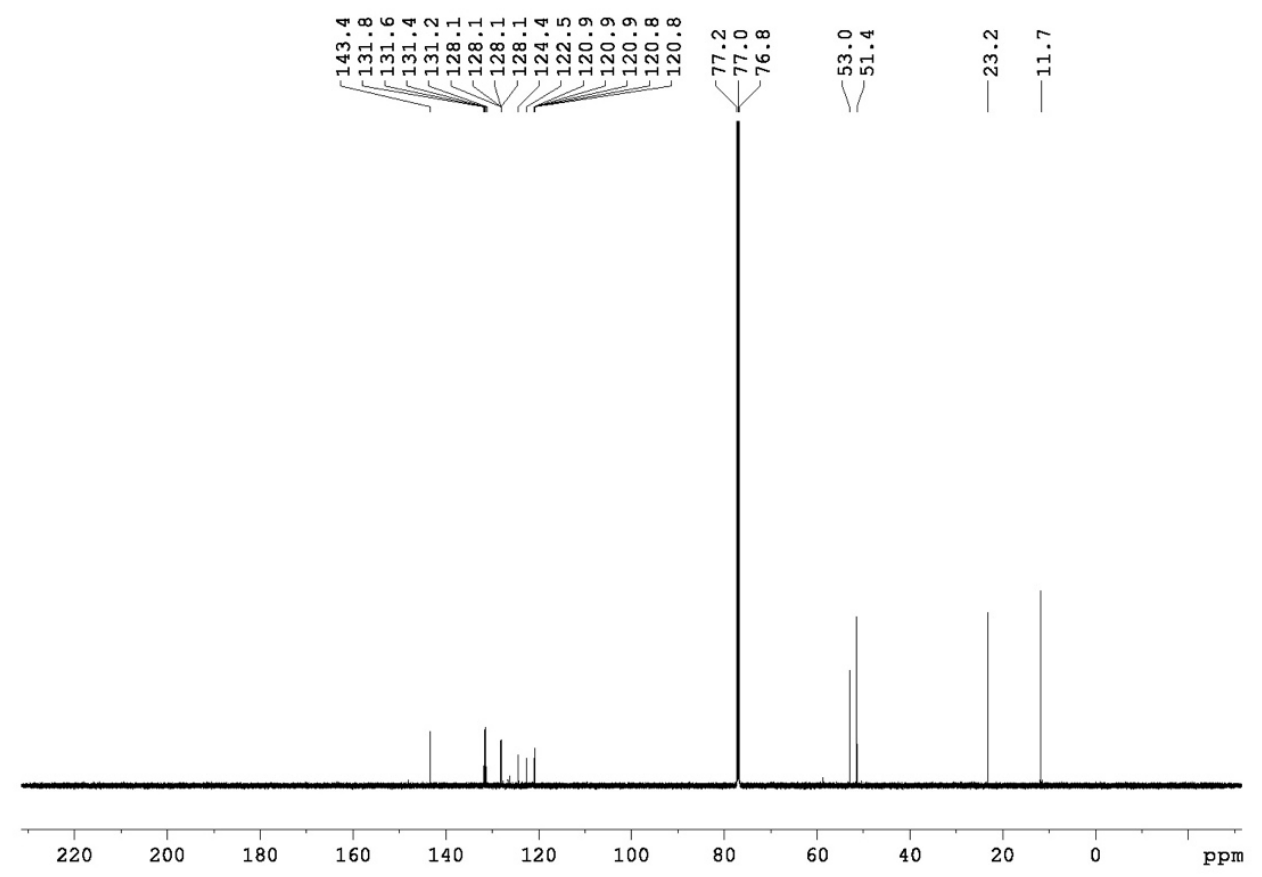

Figure S57. ${ }^{10} \mathrm{C}-\mathrm{NMR}$ Spectra of 24.

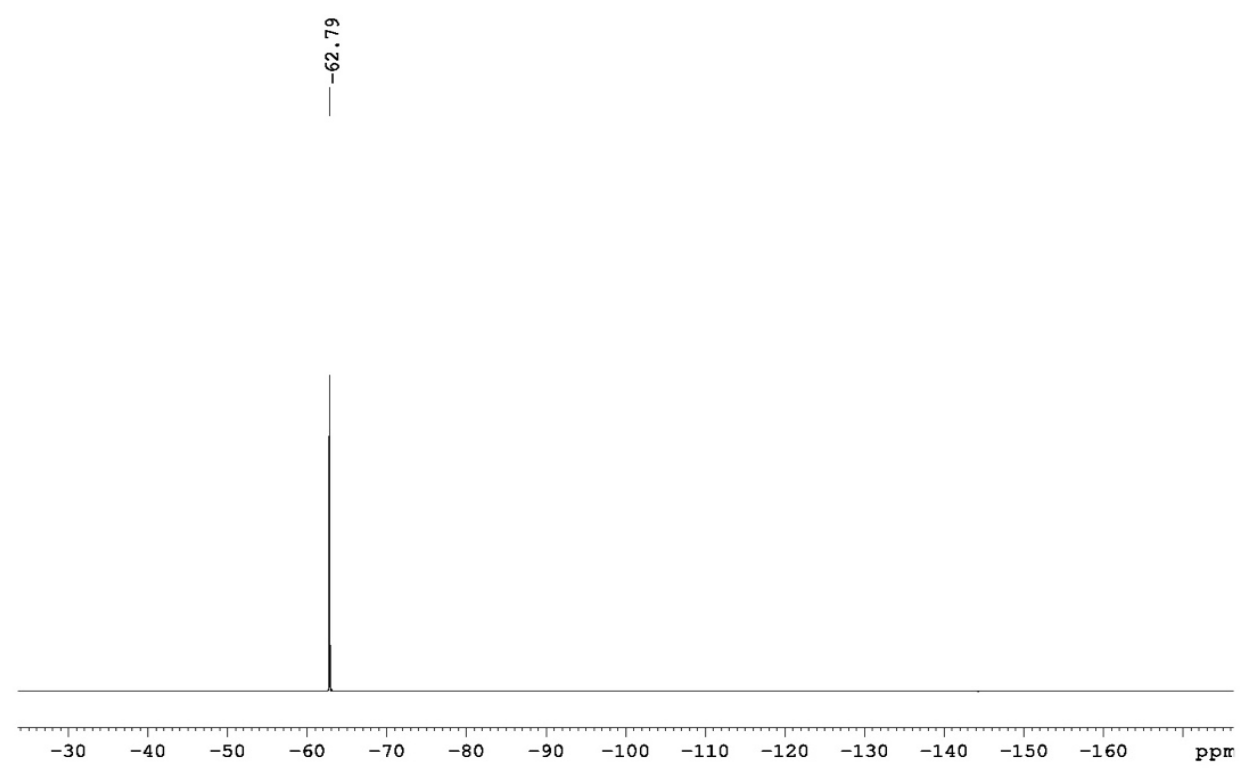

Figure S58. ${ }^{19}$ F-NMR Spectra of 24 


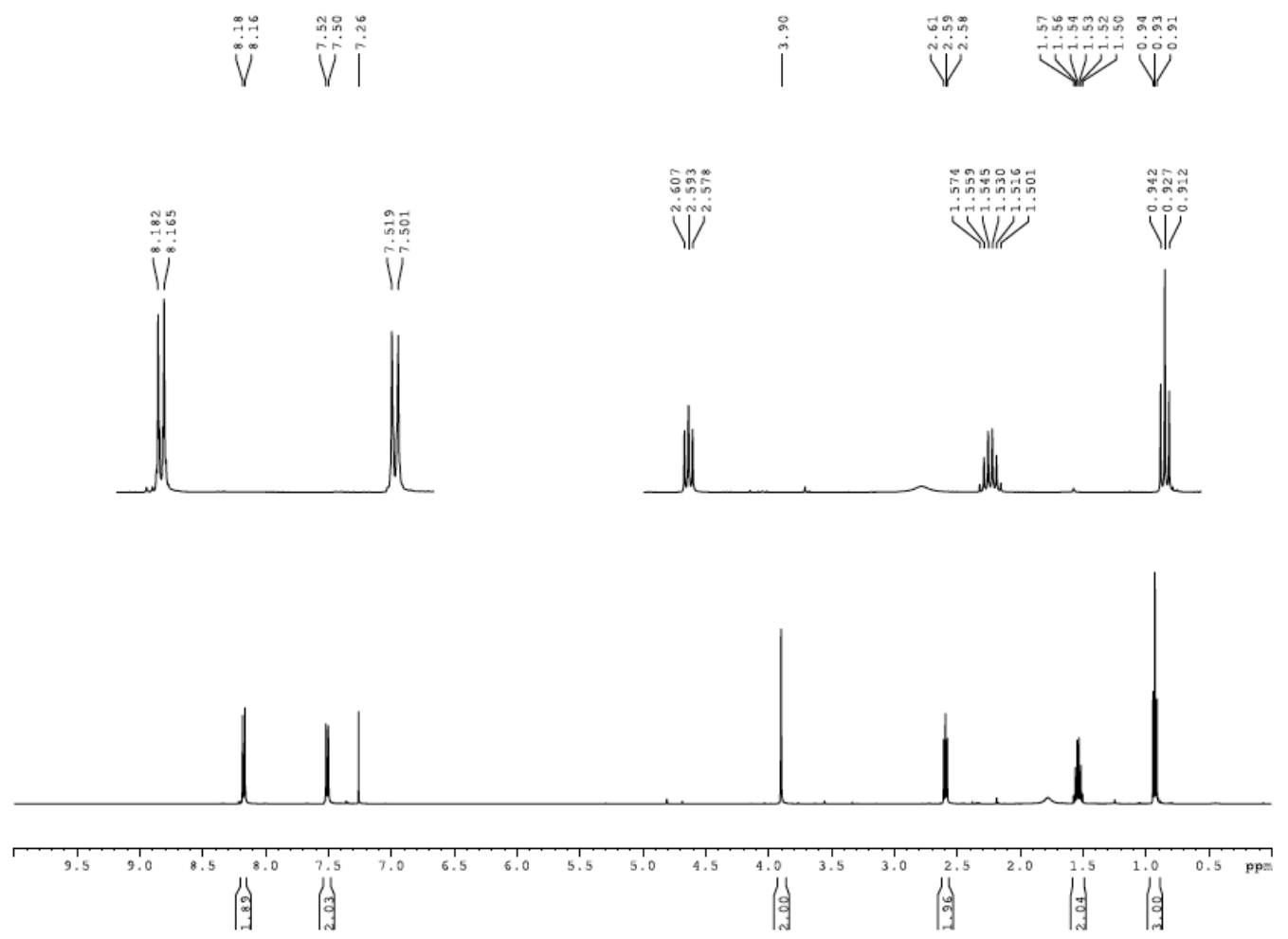

Figure S59. ${ }^{1}$ H-NMR Spectra of 25
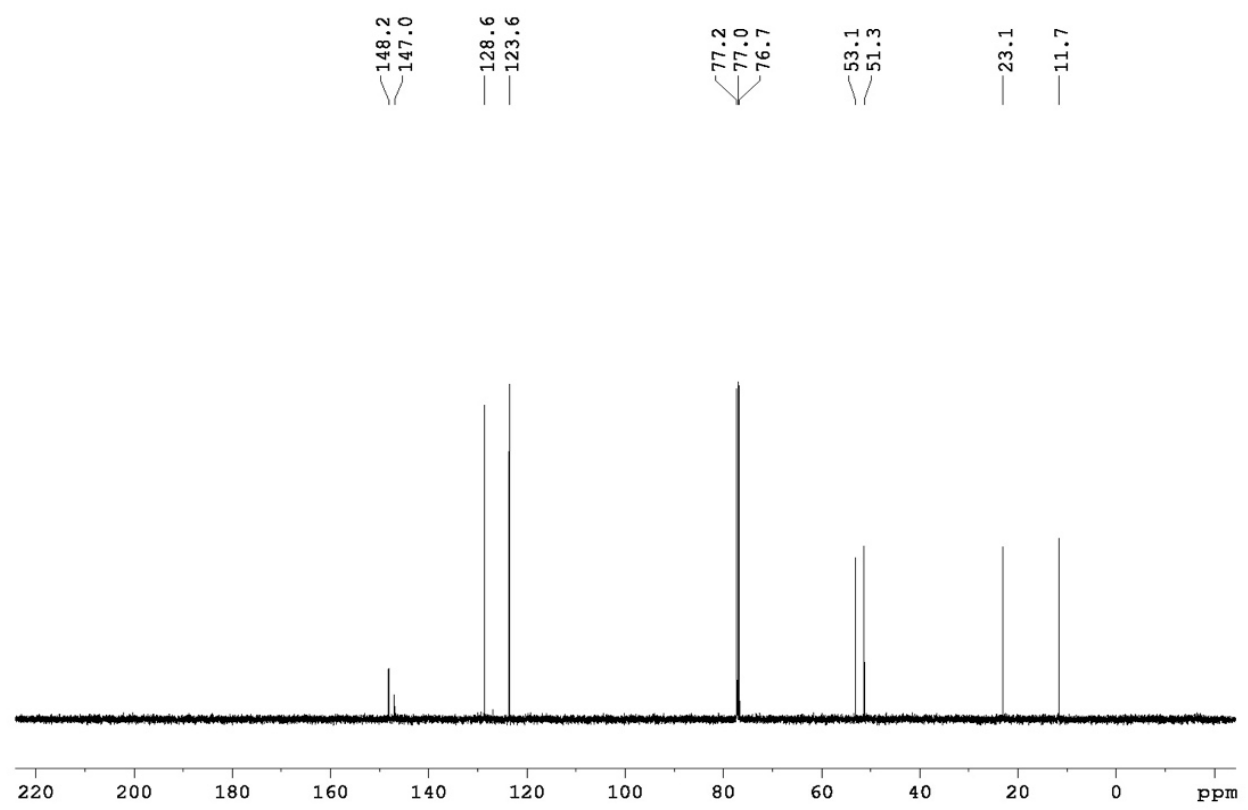

Figure S60. ${ }^{13} \mathrm{C}-\mathrm{NMR}$ Spectra of $\mathbf{2 5}$. 


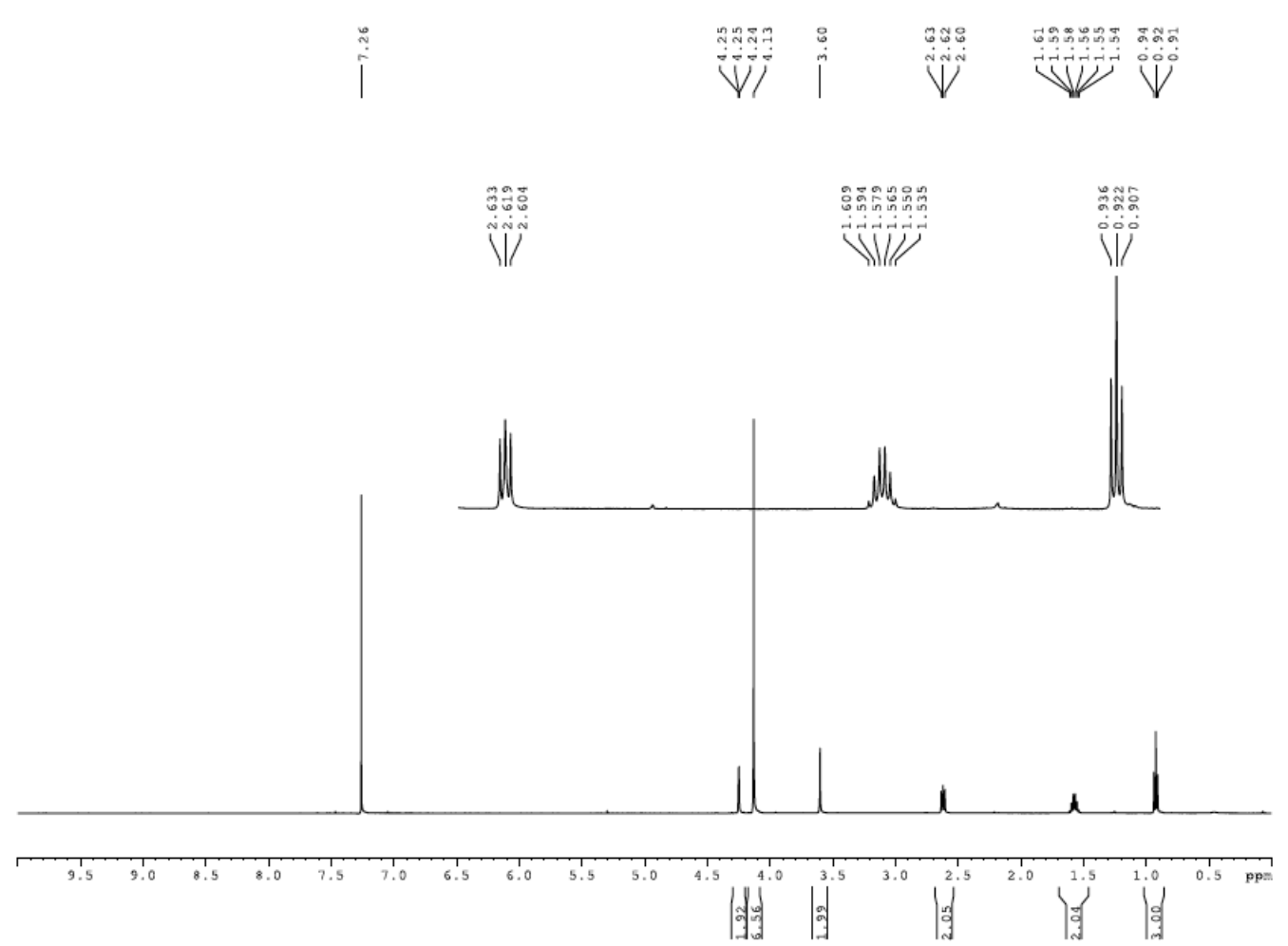

Figure S61. ${ }^{1} H-N M R$ Spectra of 26

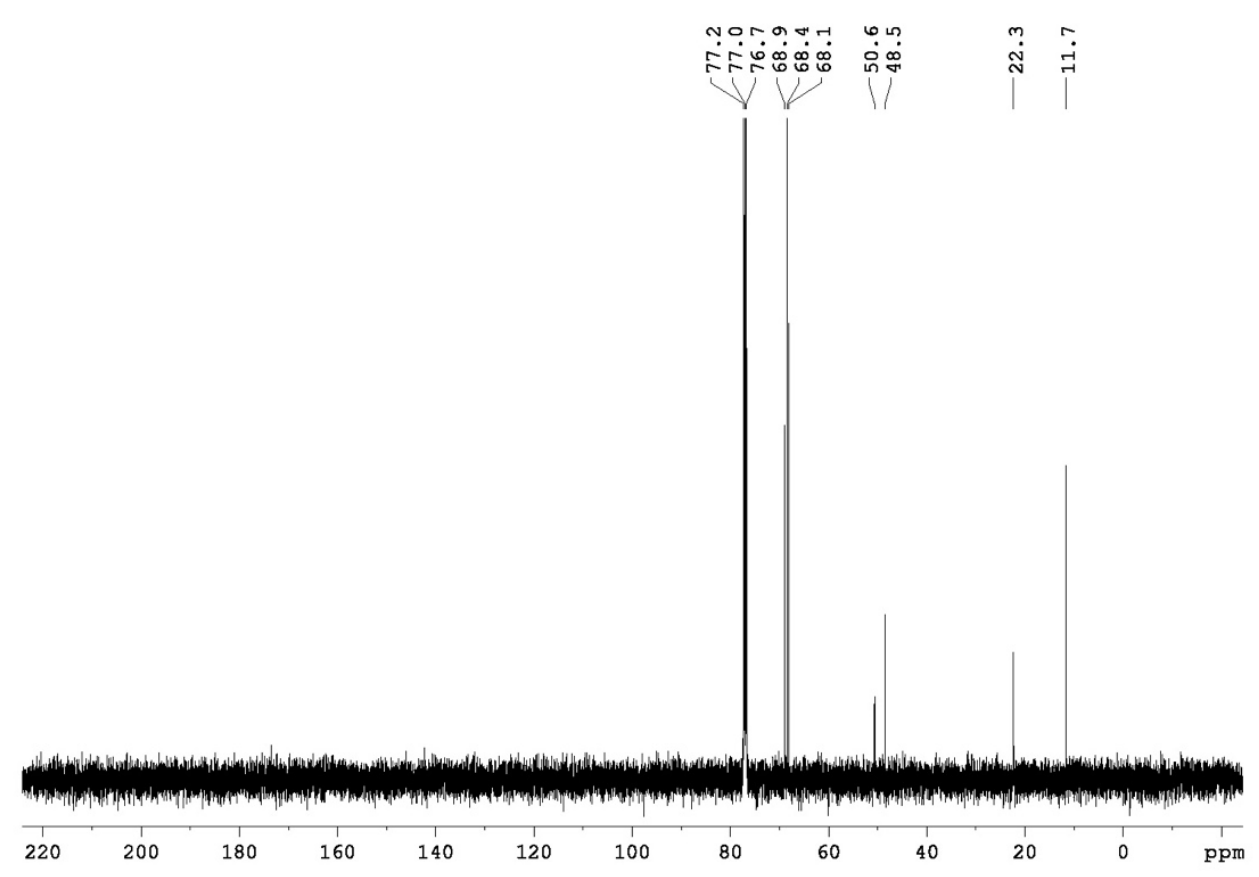

Figure S62. $\quad{ }^{13} \mathrm{C}-\mathrm{NMR}$ Spectra of 26. 


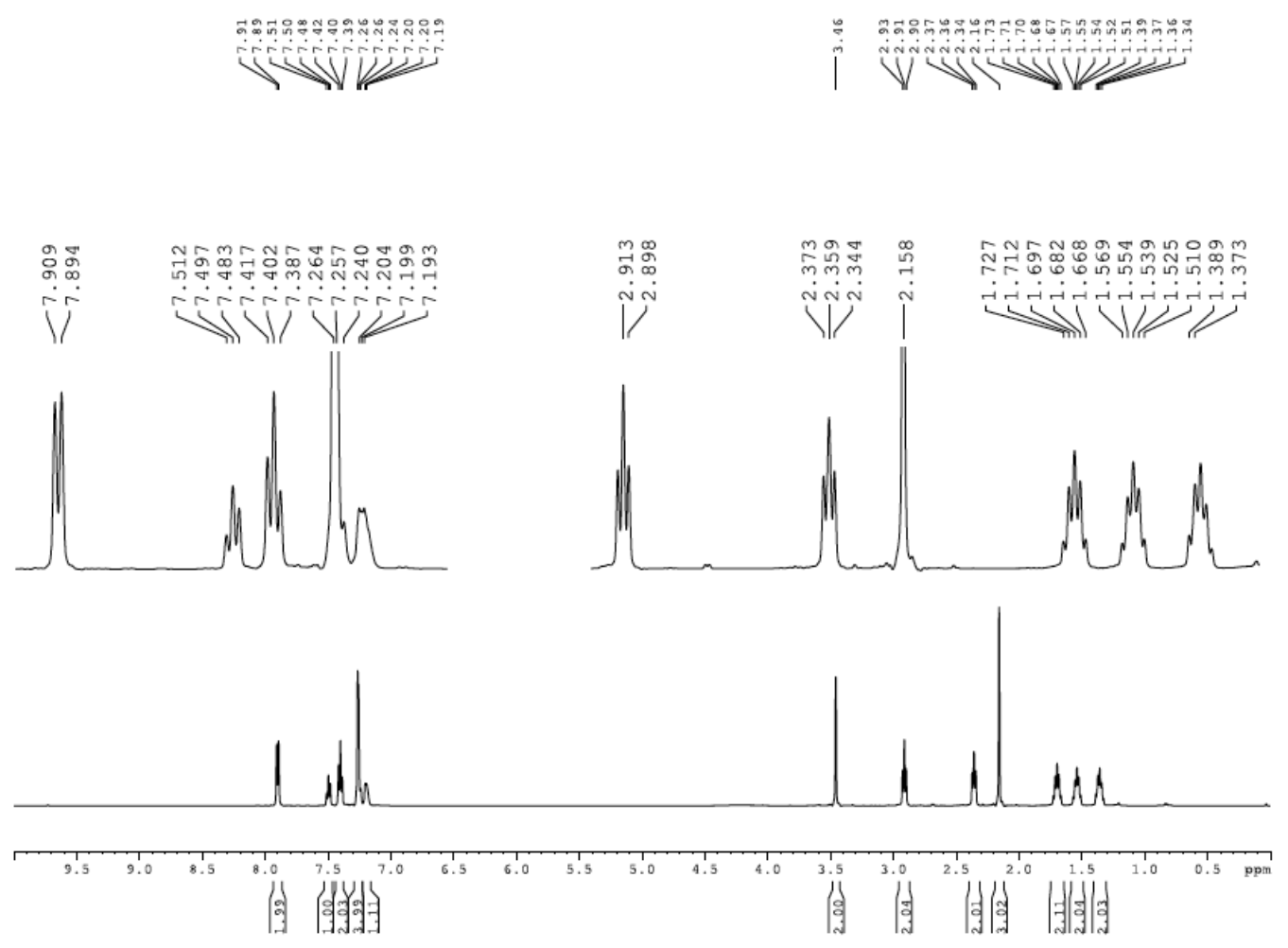

Figure S63. ${ }^{1}$ H-NMR Spectra of 27.

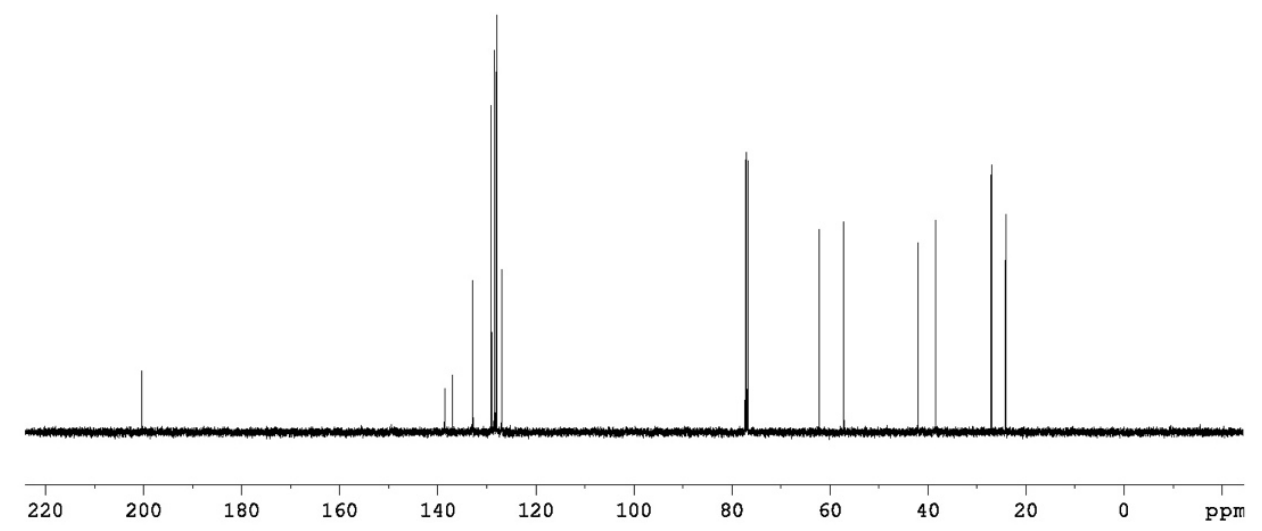

Figure S64. ${ }^{13}$ C-NMR Spectra of 27. 


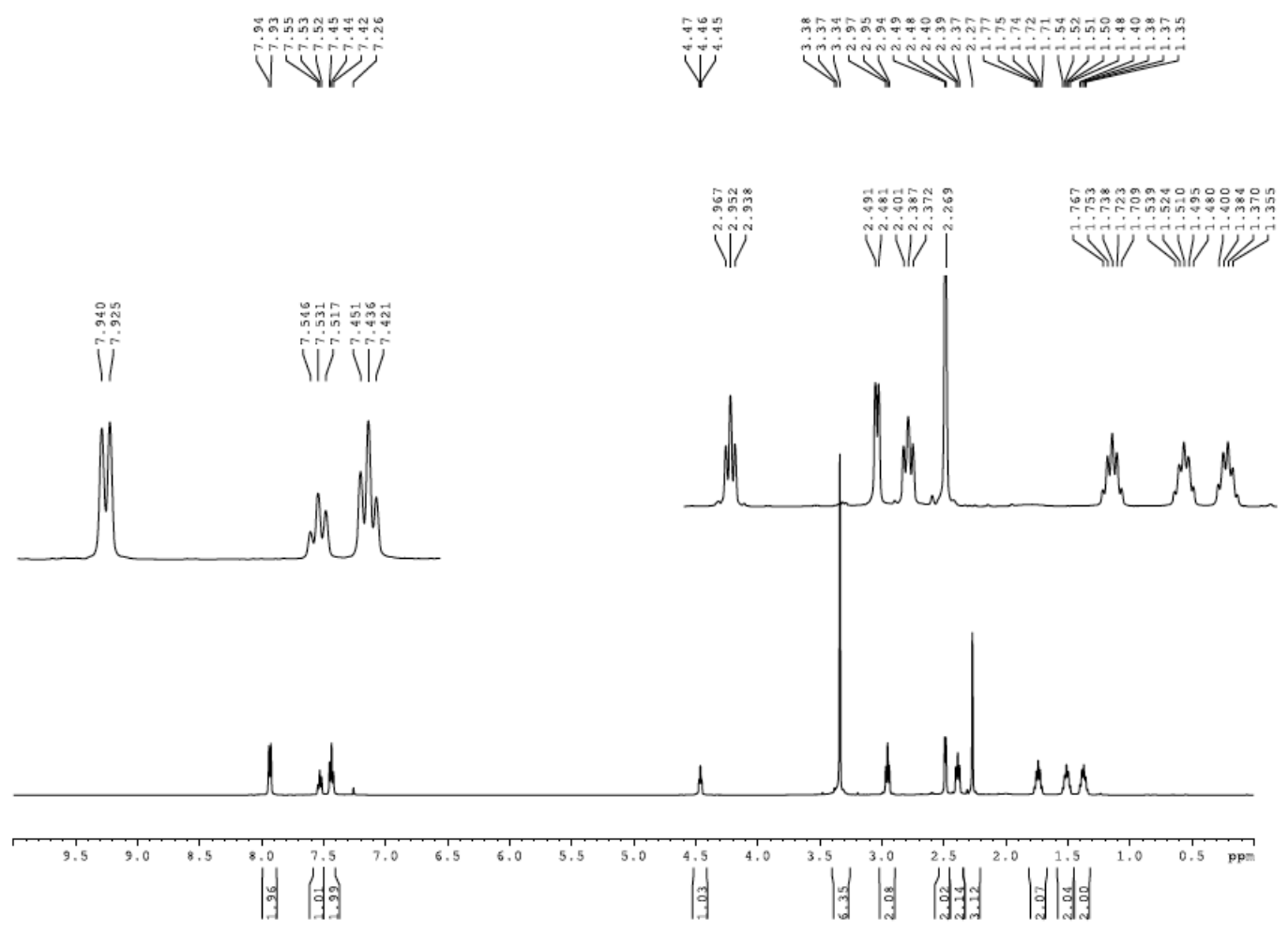

Figure S65. ${ }^{1}$ H-NMR Spectra of 28.

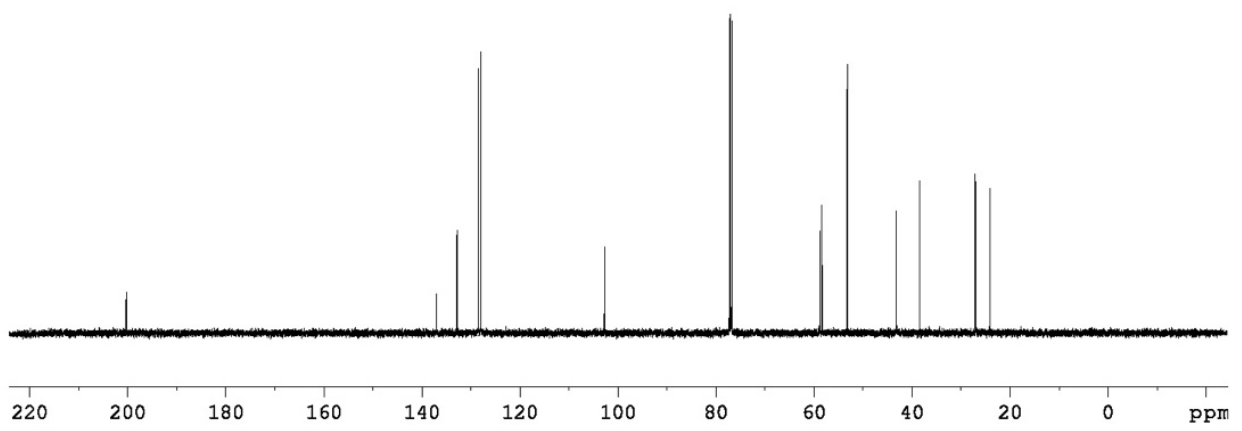

Figure S66. $\quad{ }^{13} \mathrm{C}-\mathrm{NMR}$ Spectra of 28. 


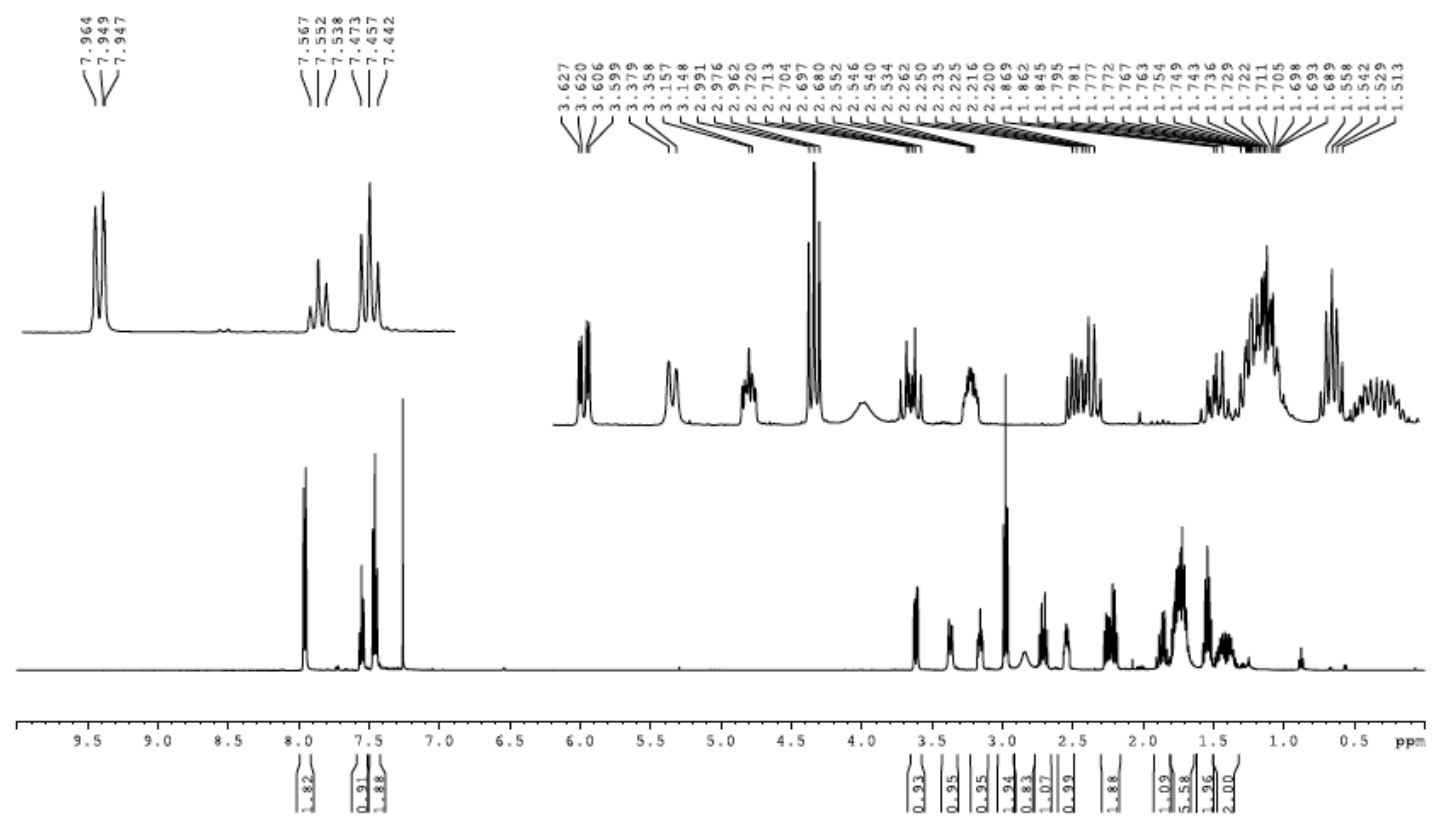

Figure S67. ${ }^{1}$ H-NMR Spectra of 29.

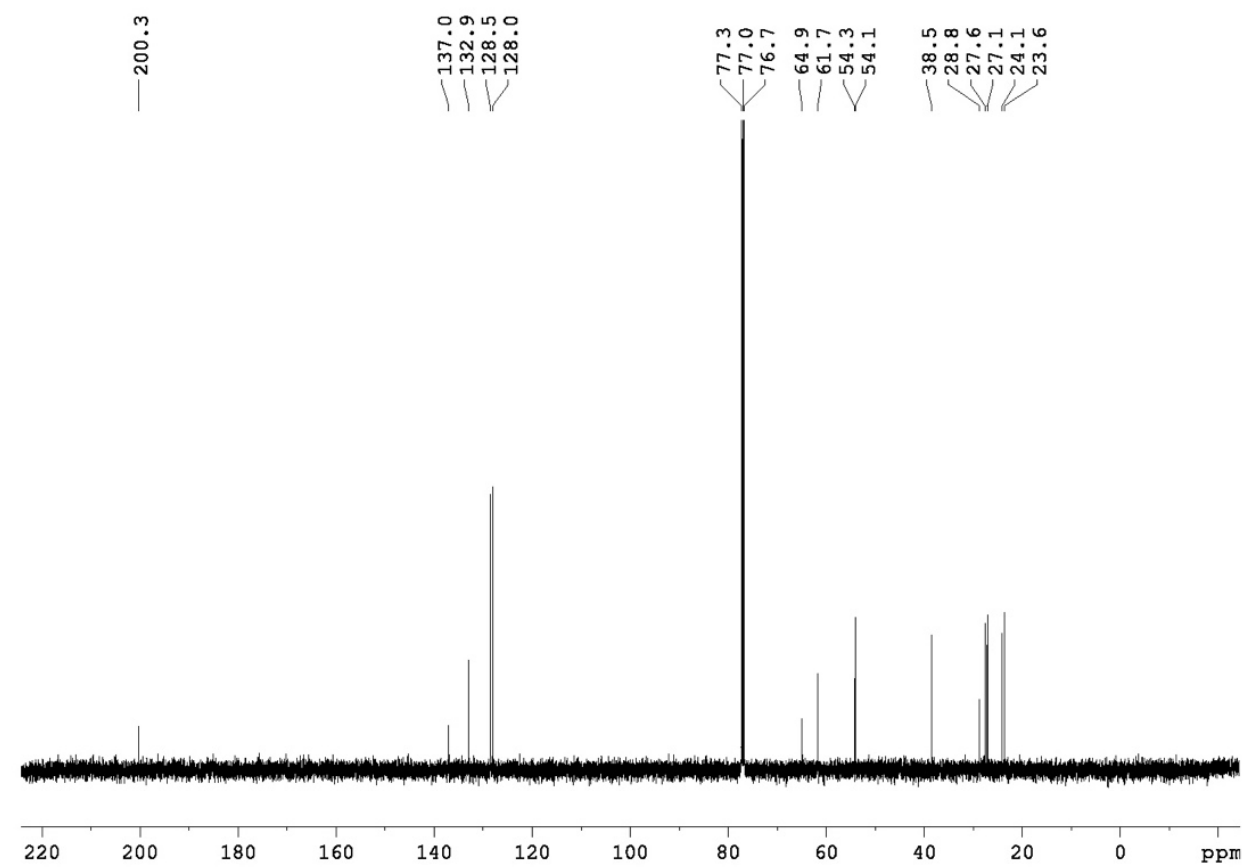

Figure S68. ${ }^{13}$ C-NMR Spectra of 29. 


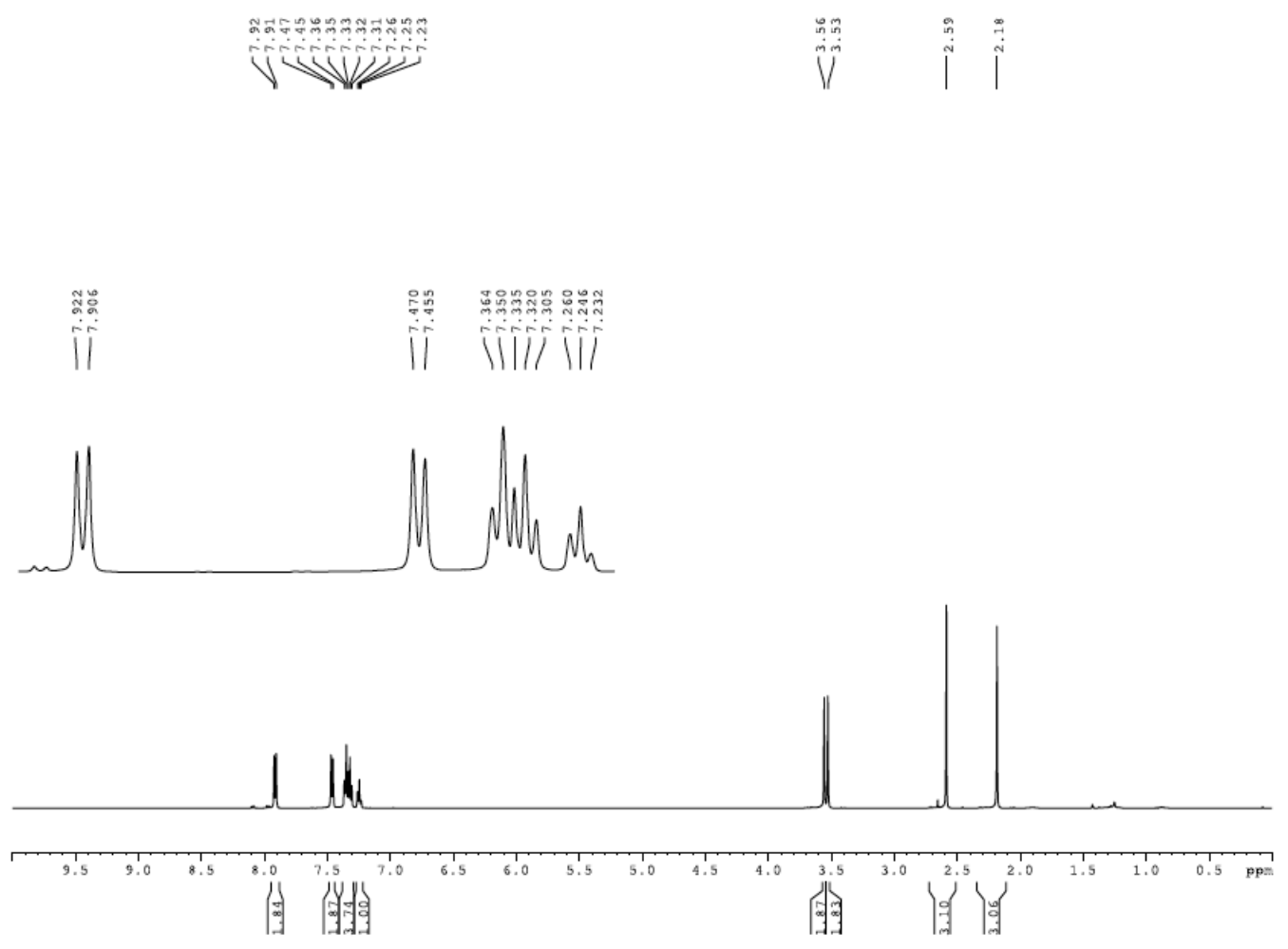

Figure S69. ${ }^{1}$ H-NMR Spectra of $\mathbf{3 0}$.

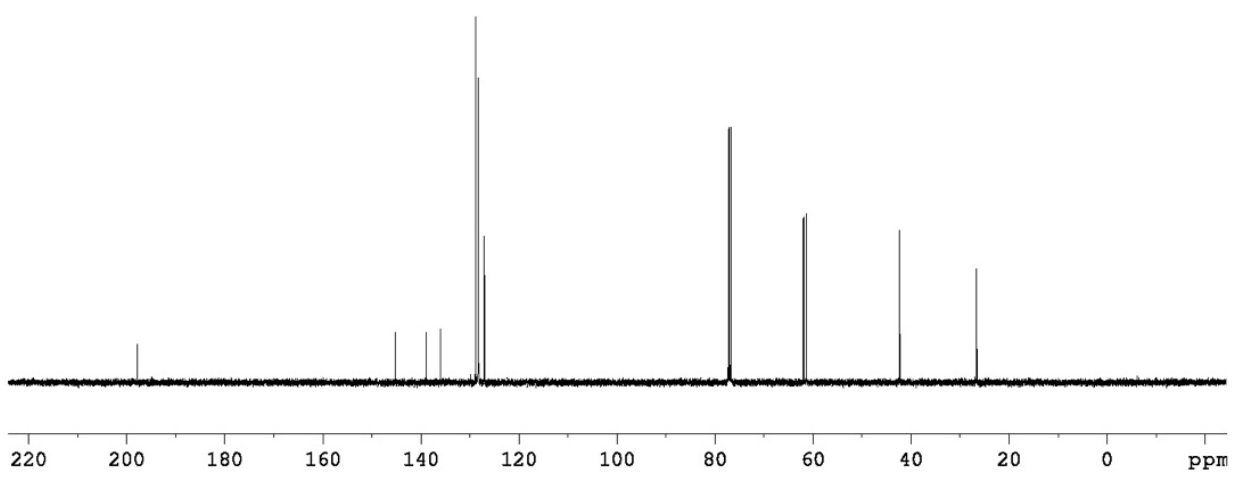

Figure S70. ${ }^{13} \mathrm{C}-\mathrm{NMR}$ Spectra of $\mathbf{3 0}$. 


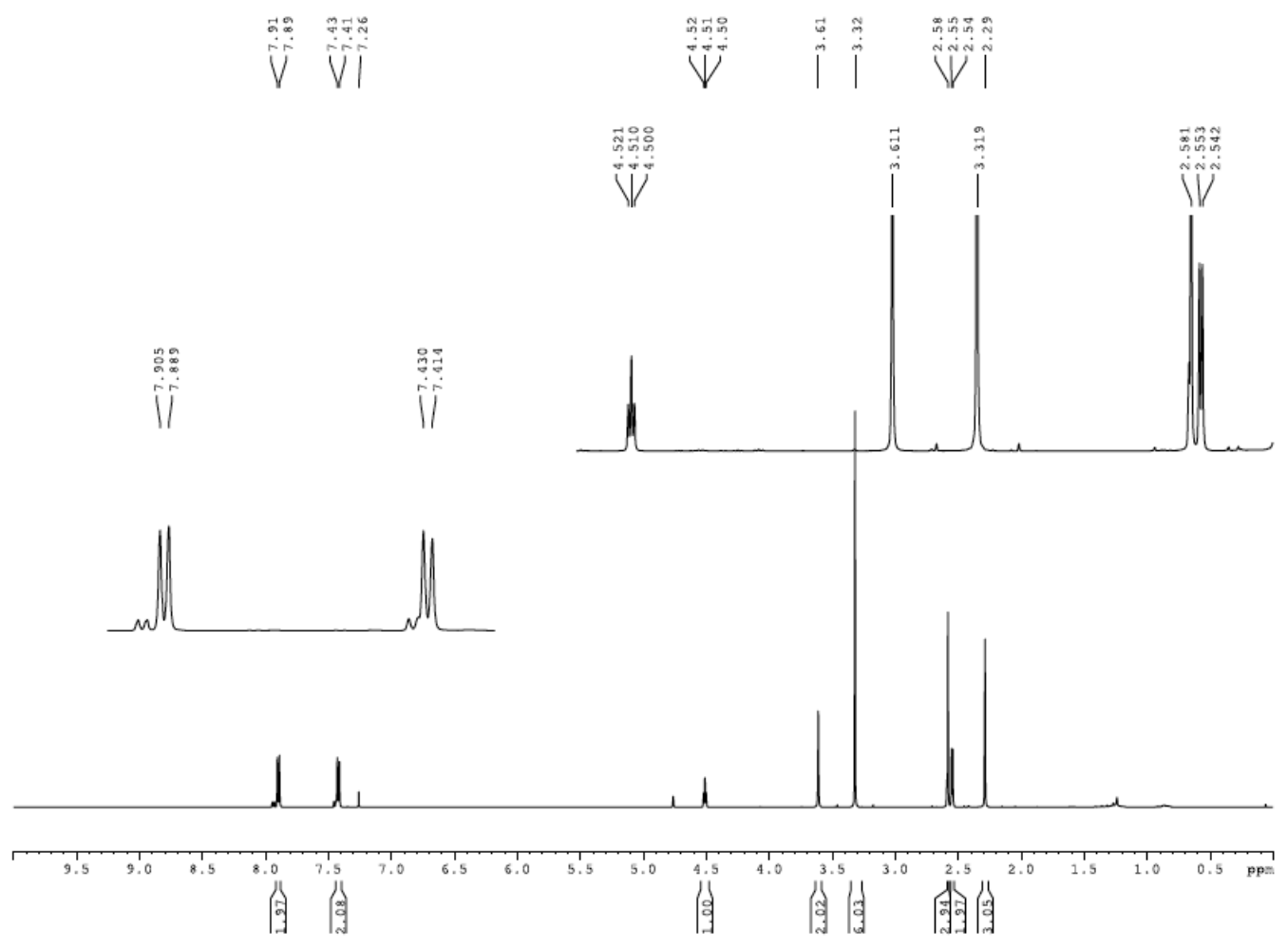

Figure S71. ${ }^{1}$ H-NMR Spectra of 31 .

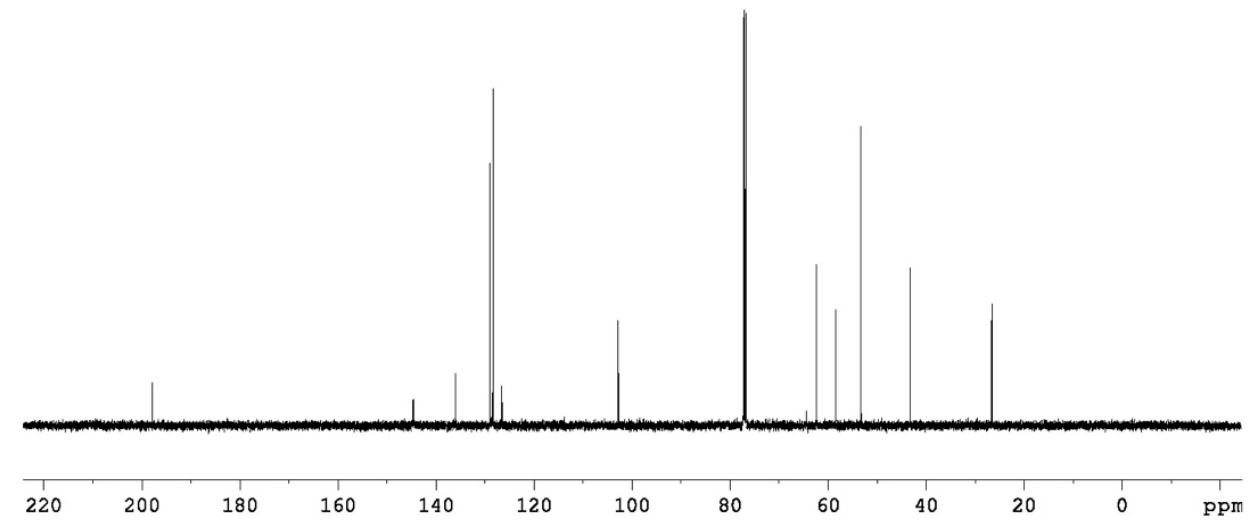

Figure S72. ${ }^{13} \mathrm{C}-\mathrm{NMR}$ Spectra of $\mathbf{3 1}$. 


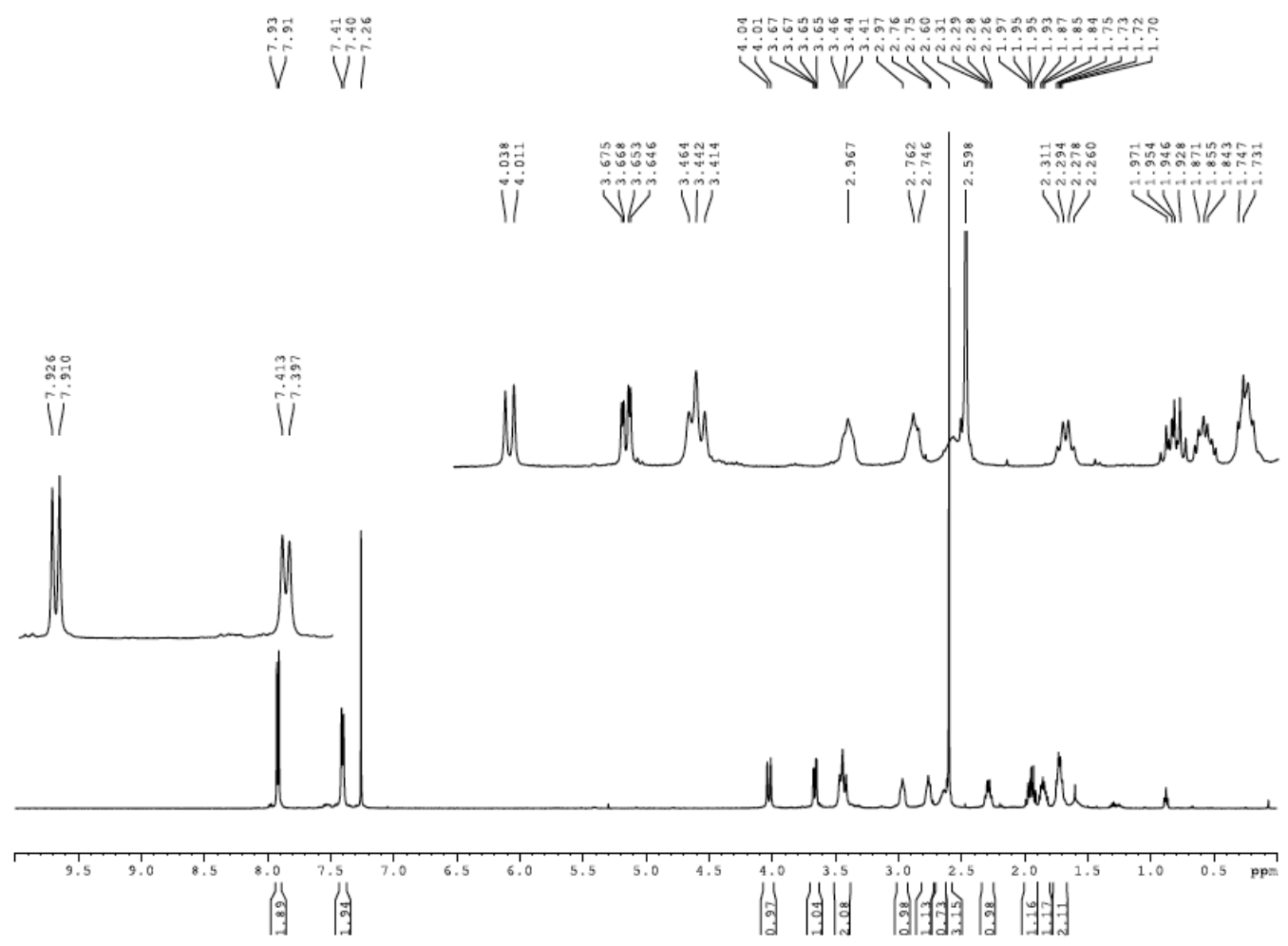

Figure S73. ${ }^{1} \mathrm{H}-\mathrm{NMR}$ Spectra of 32 .

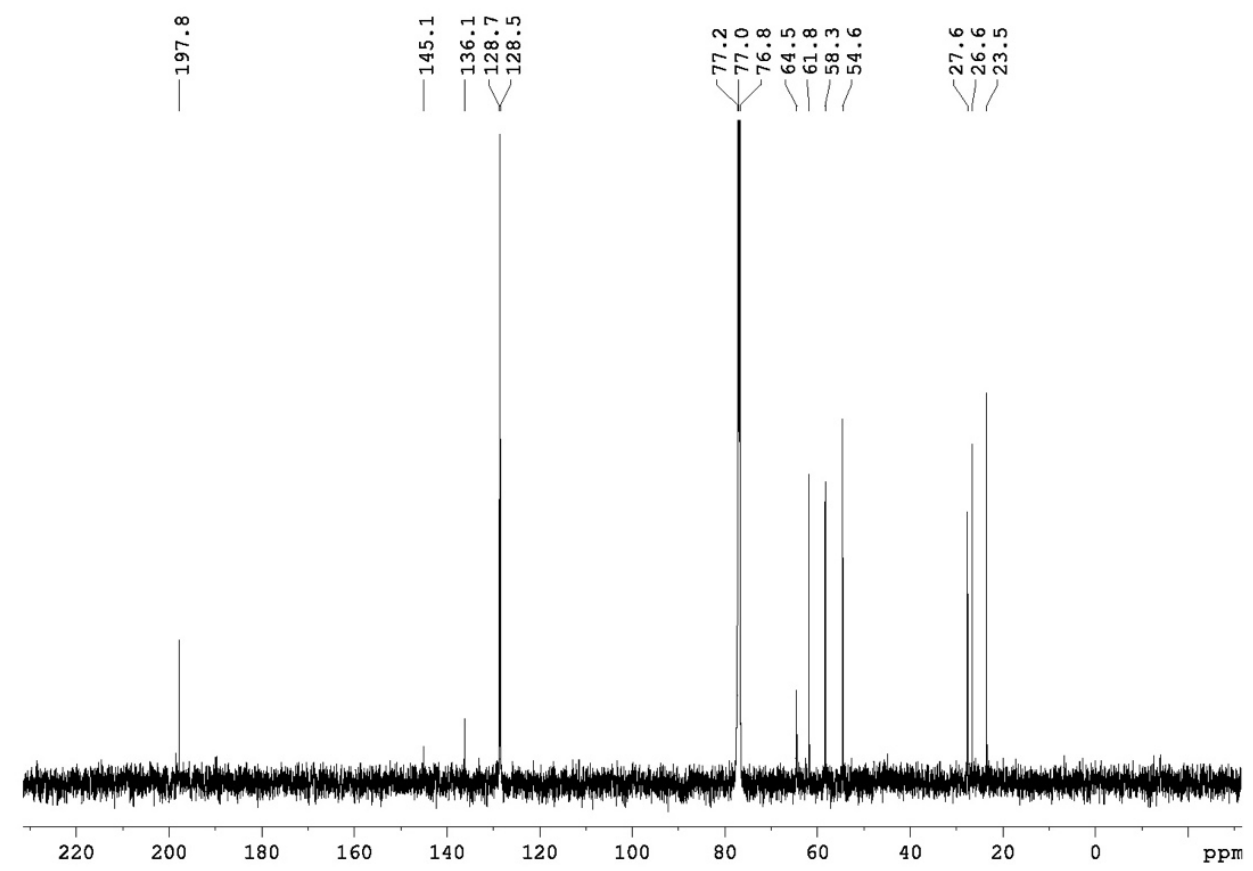

Figure S74. ${ }^{13} \mathrm{C}-\mathrm{NMR}$ Spectra of 32. 

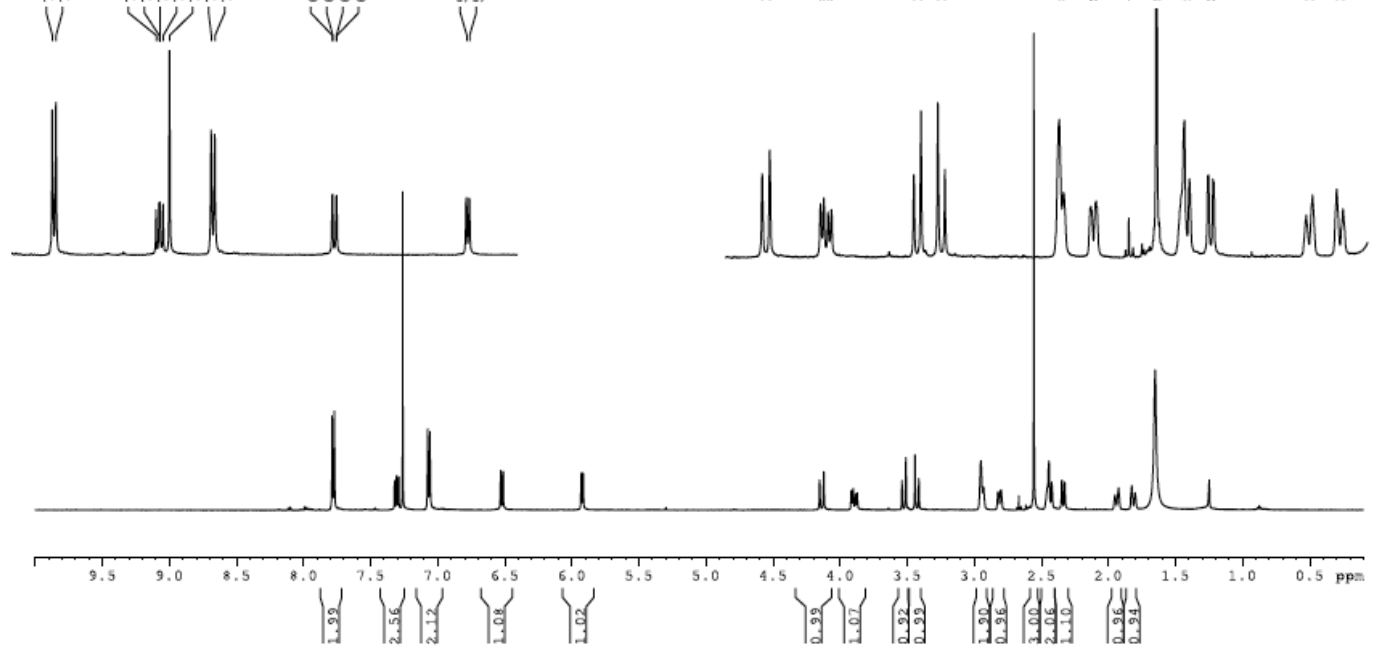

Figure S75. ${ }^{1} \mathrm{H}-\mathrm{NMR}$ Spectra of 33

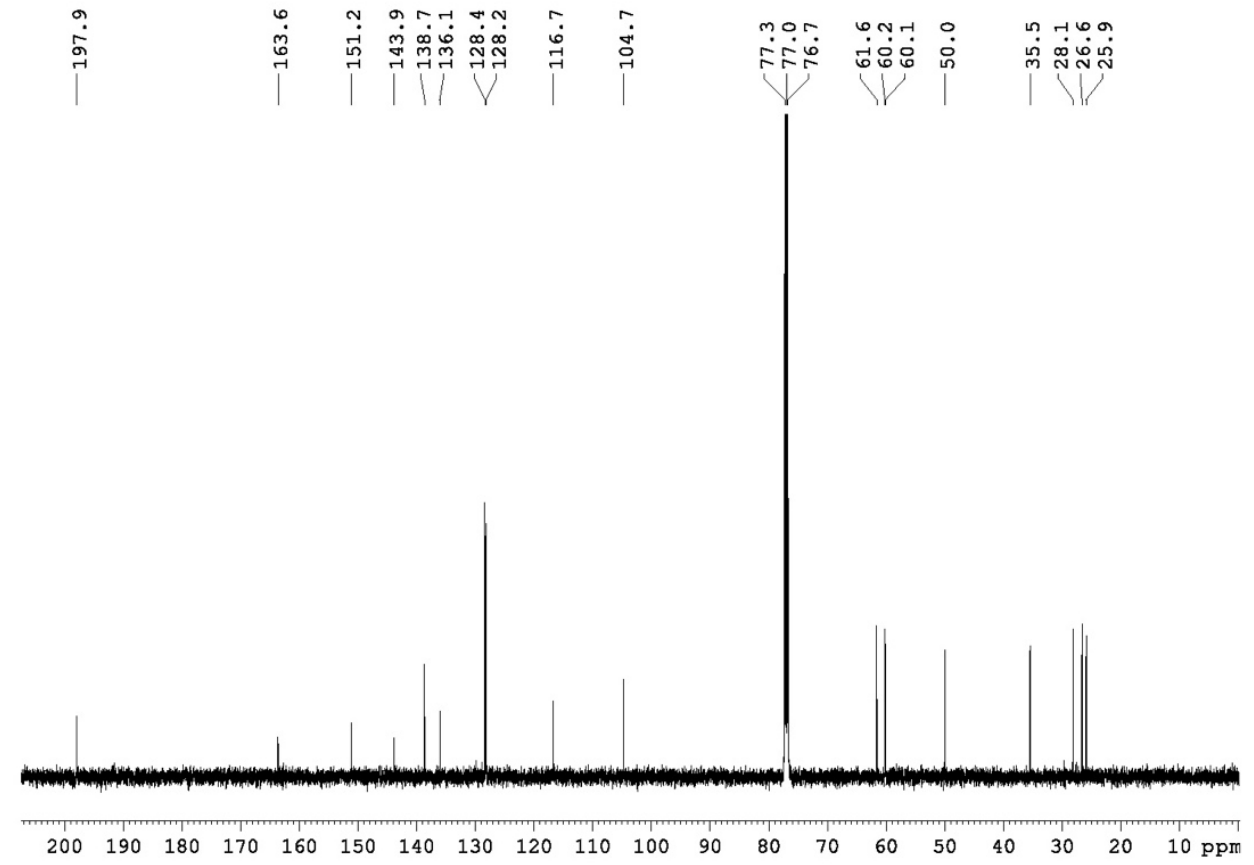

Figure S76. ${ }^{13} \mathrm{C}-\mathrm{NMR}$ Spectra of $\mathbf{3 3}$. 


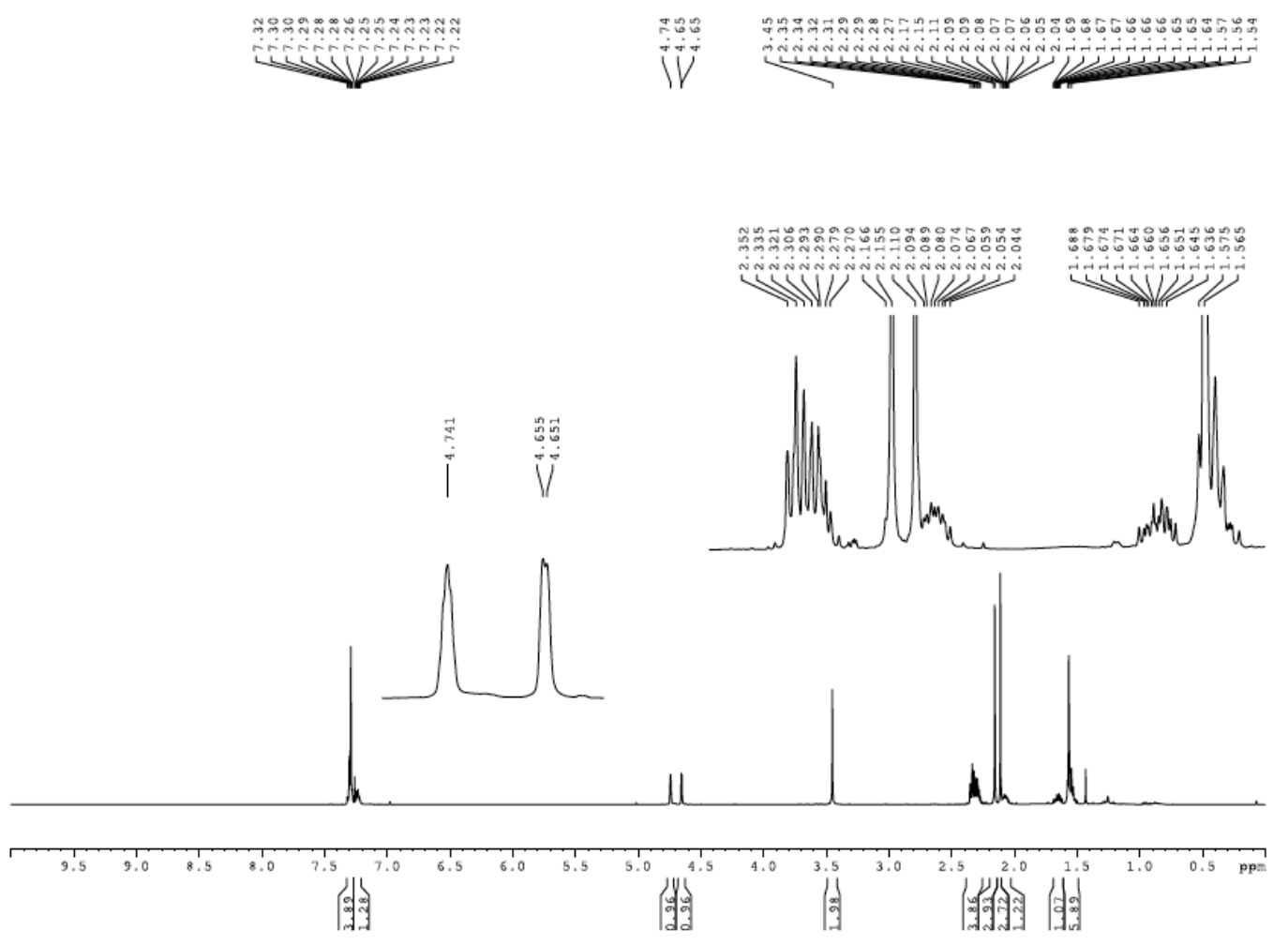

Figure S77. ${ }^{1}$ H-NMR Spectra of 34 .

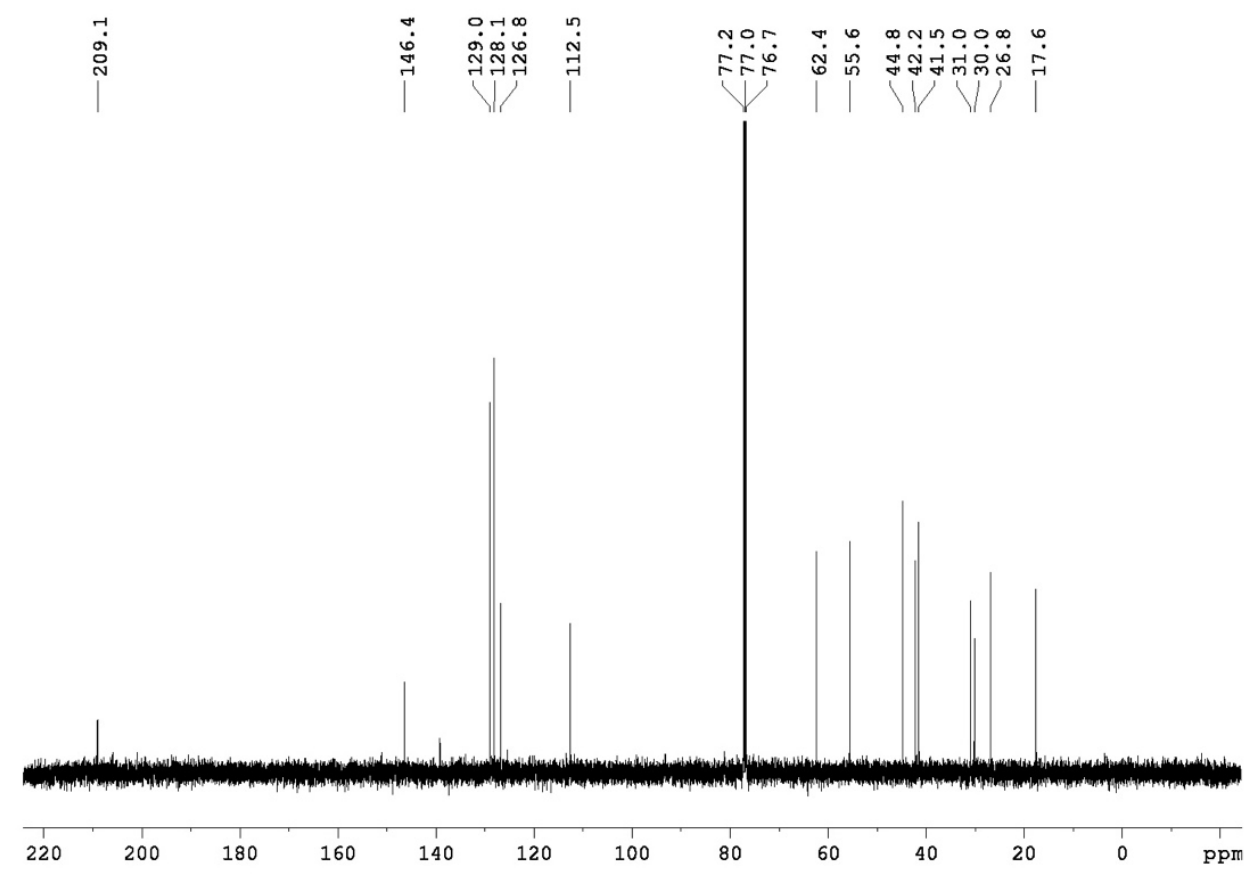

Figure S78. ${ }^{13}$ C-NMR Spectra of $\mathbf{3 4}$. 

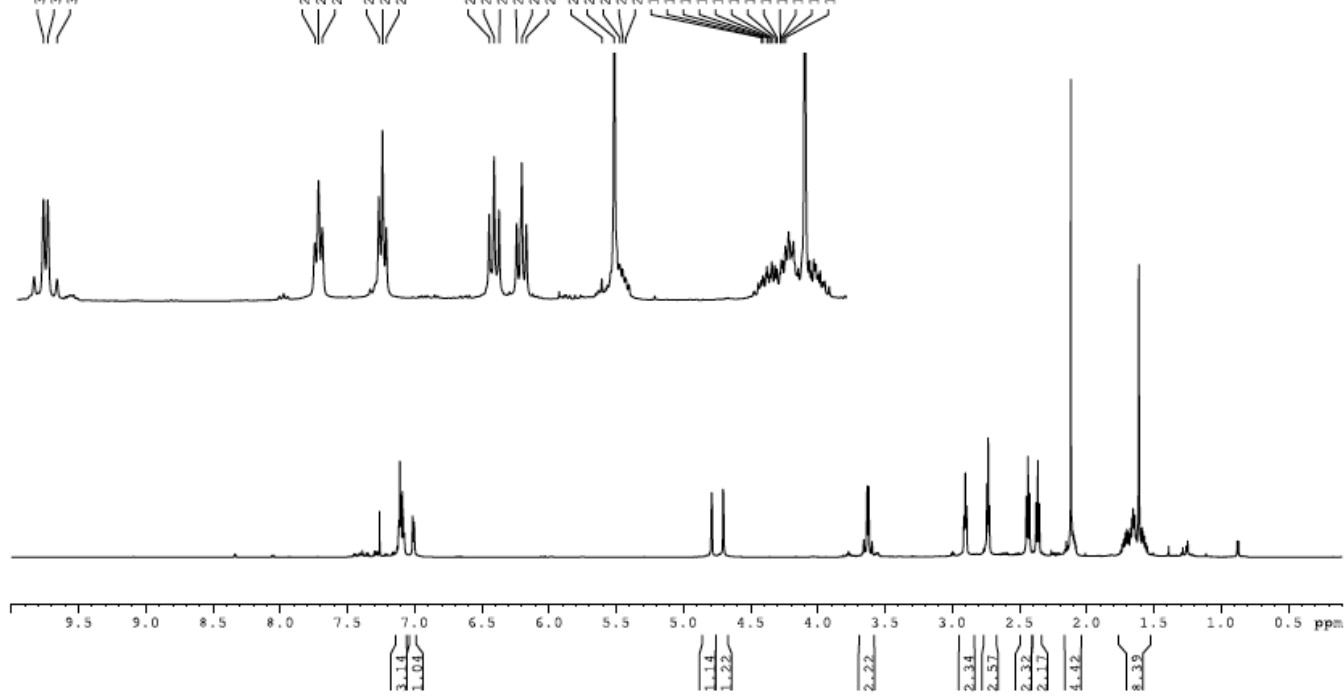

Figure S79. ${ }^{1}$ H-NMR Spectra of 35 .

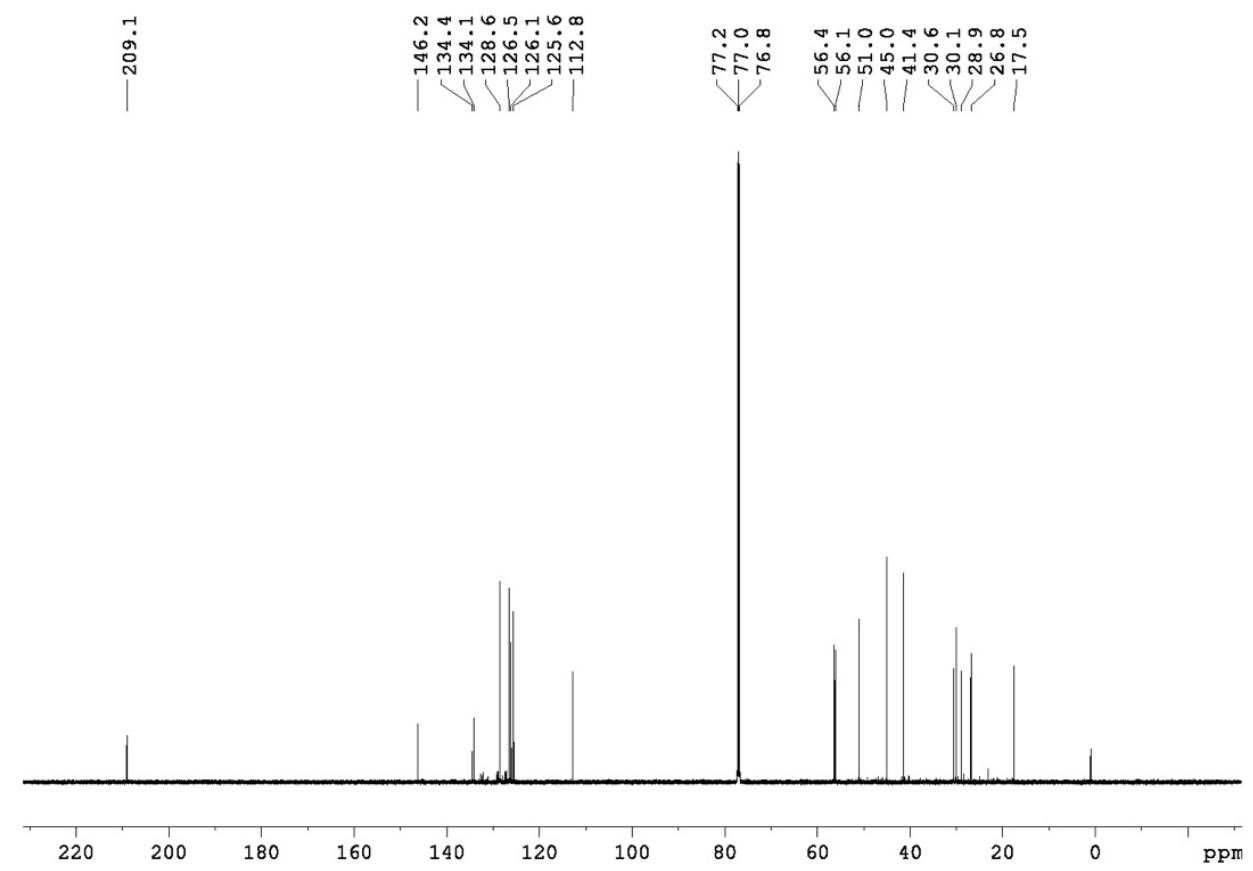

Figure S80. ${ }^{13}$ C-NMR Spectra of $\mathbf{3 5}$. 


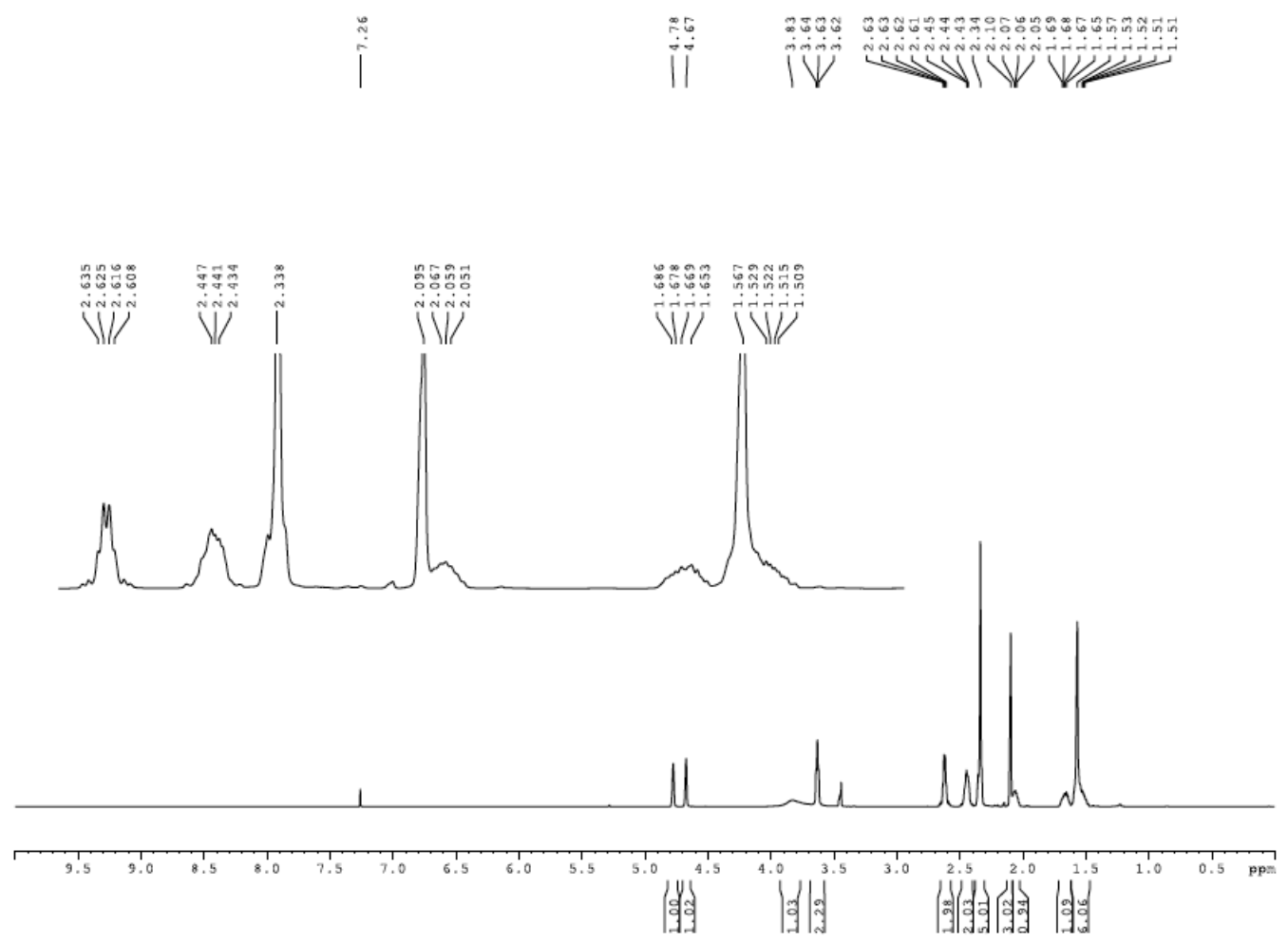

Figure S81. ${ }^{1}$ H-NMR Spectra of 36.

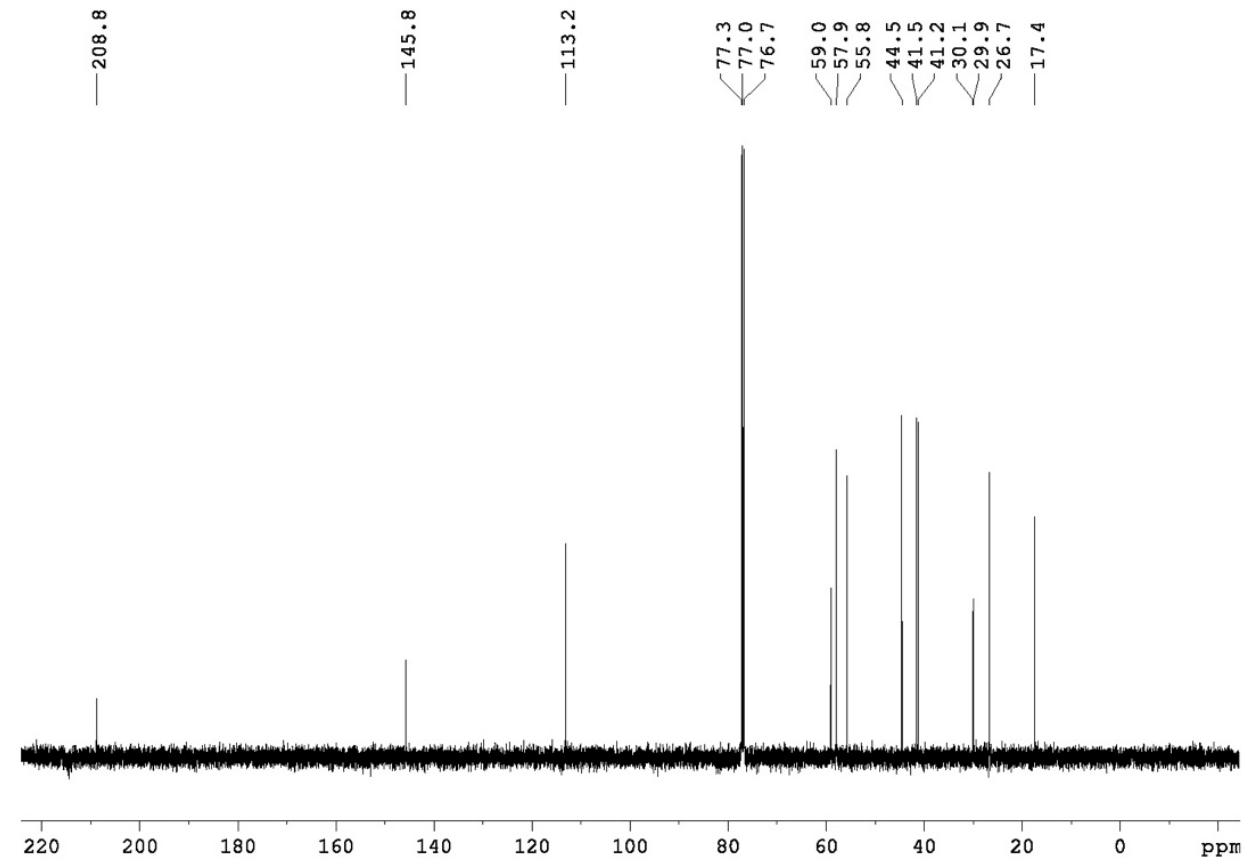

Figure S82. $\quad{ }^{13} \mathrm{C}-\mathrm{NMR}$ Spectra of $\mathbf{3 6}$. 


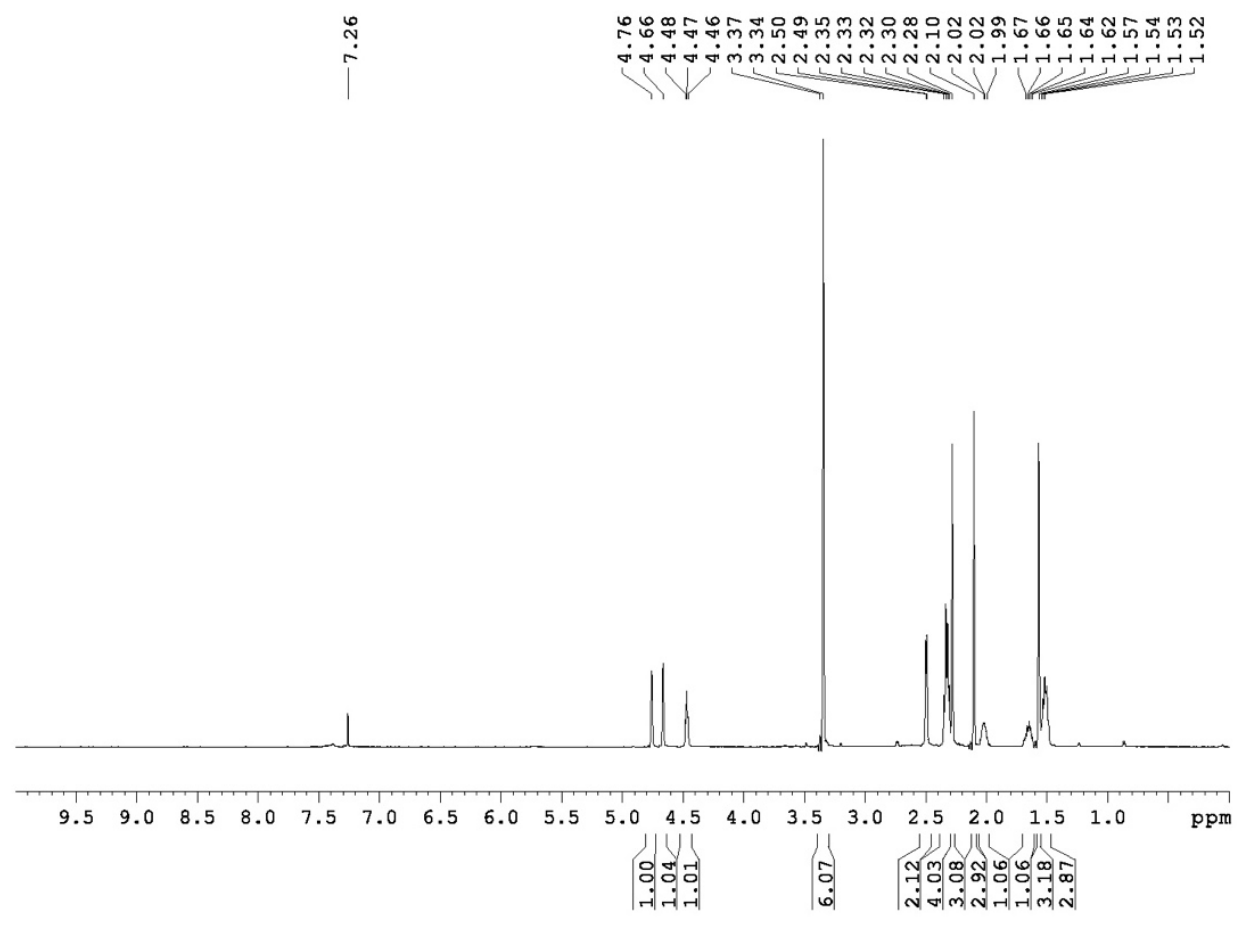

Figure S83. ${ }^{1} \mathrm{H}-\mathrm{NMR}$ Spectra of 37.

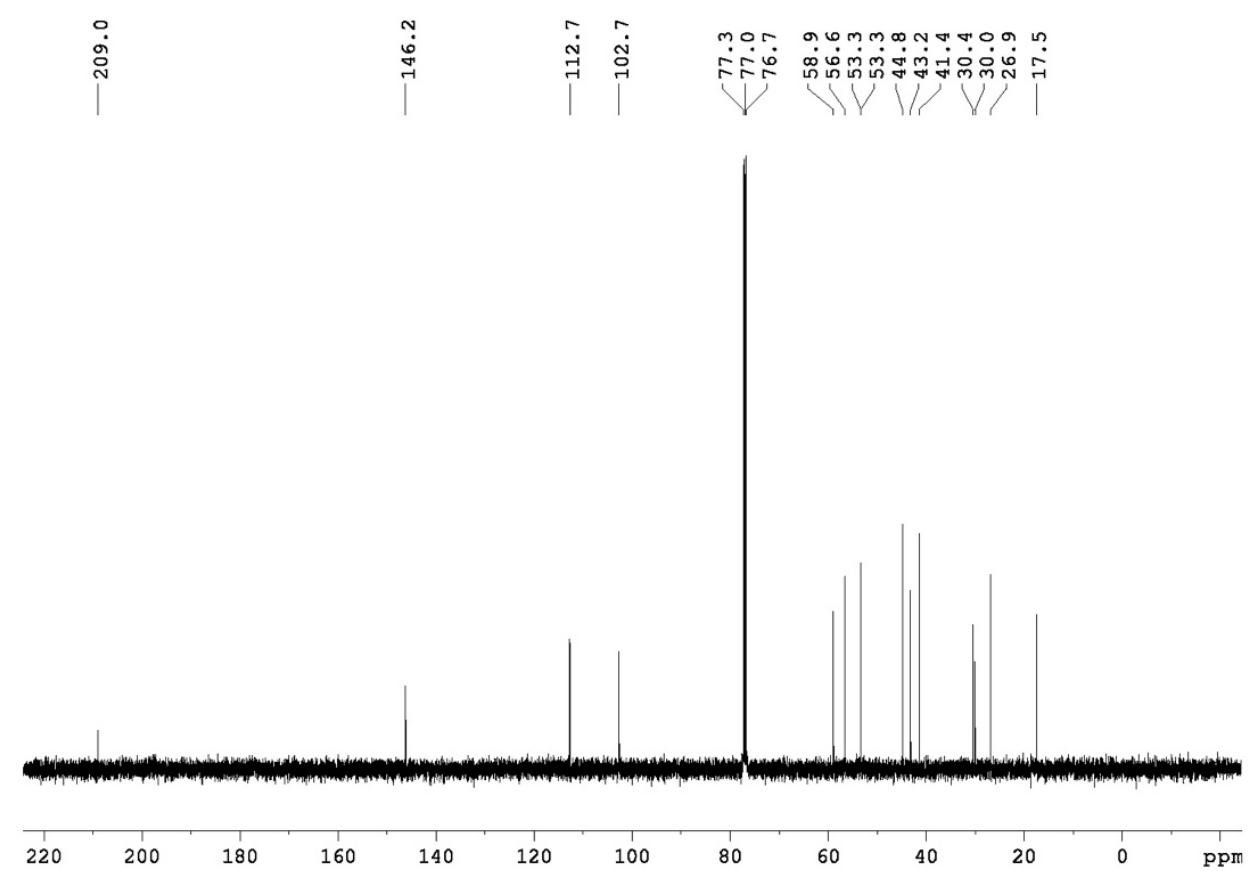

Figure S84. ${ }^{13} \mathrm{C}-\mathrm{NMR}$ Spectra of 37. 


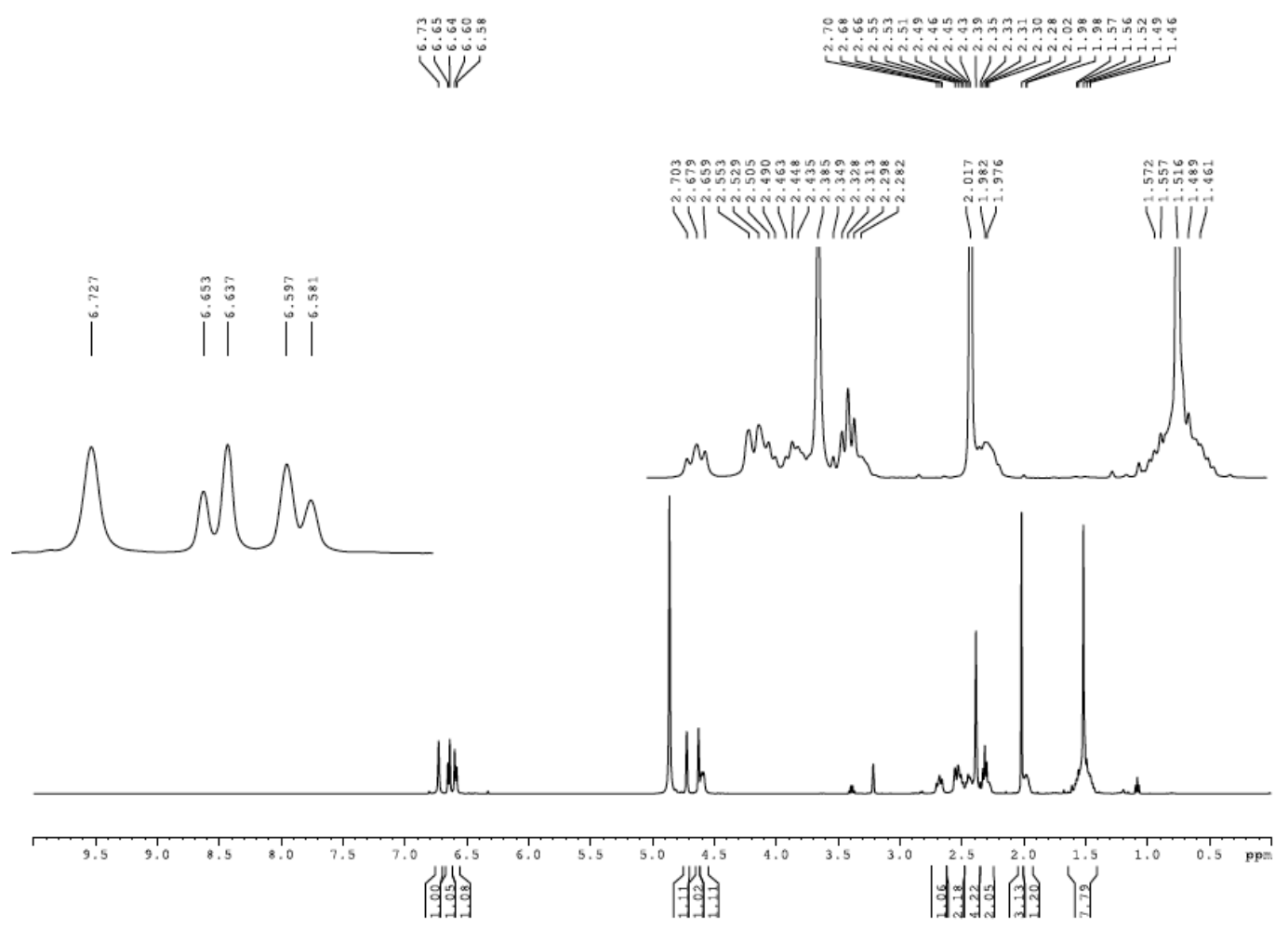

Figure S85. ${ }^{1}$ H-NMR Spectra of 38 .

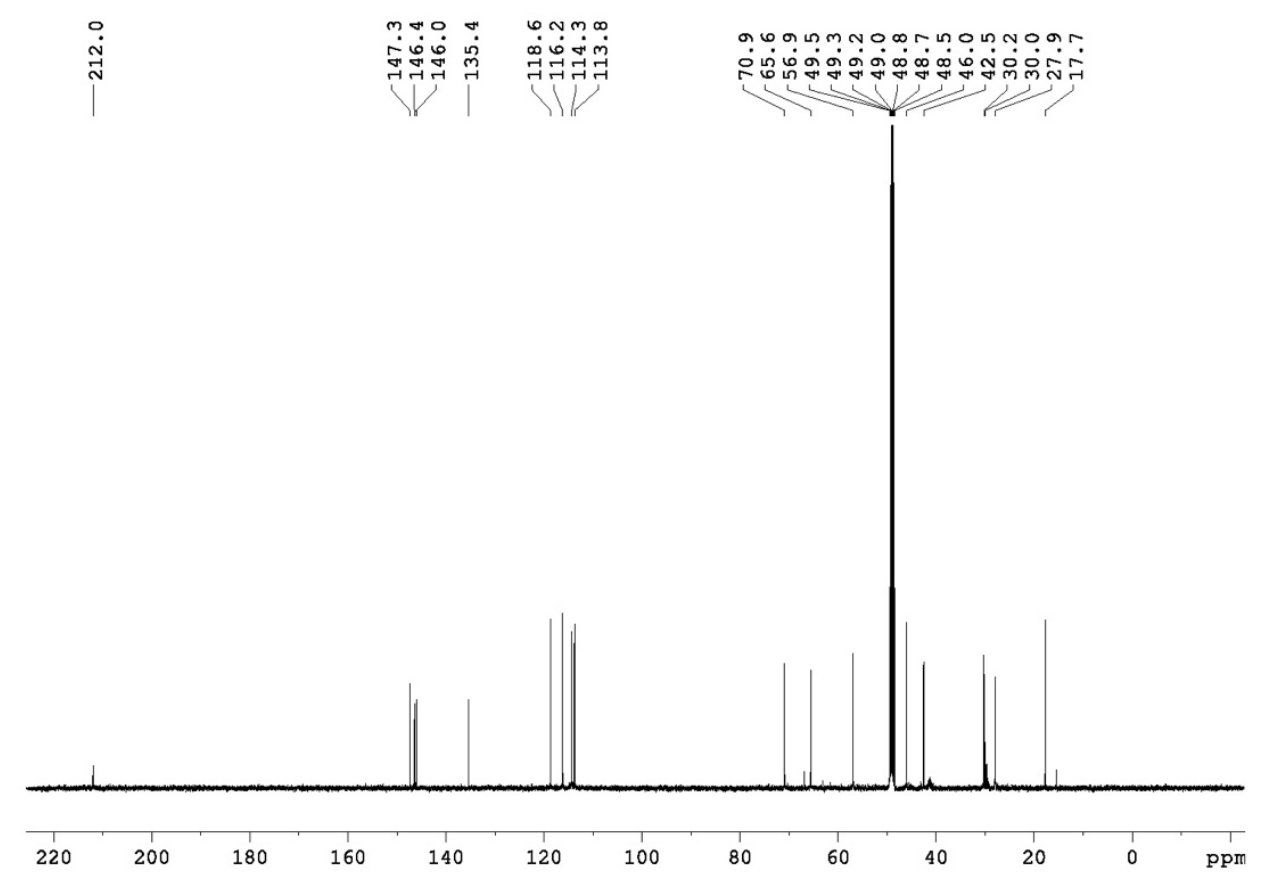

Figure S86. ${ }^{13} \mathrm{C}-\mathrm{NMR}$ Spectra of $\mathbf{3 8}$. 


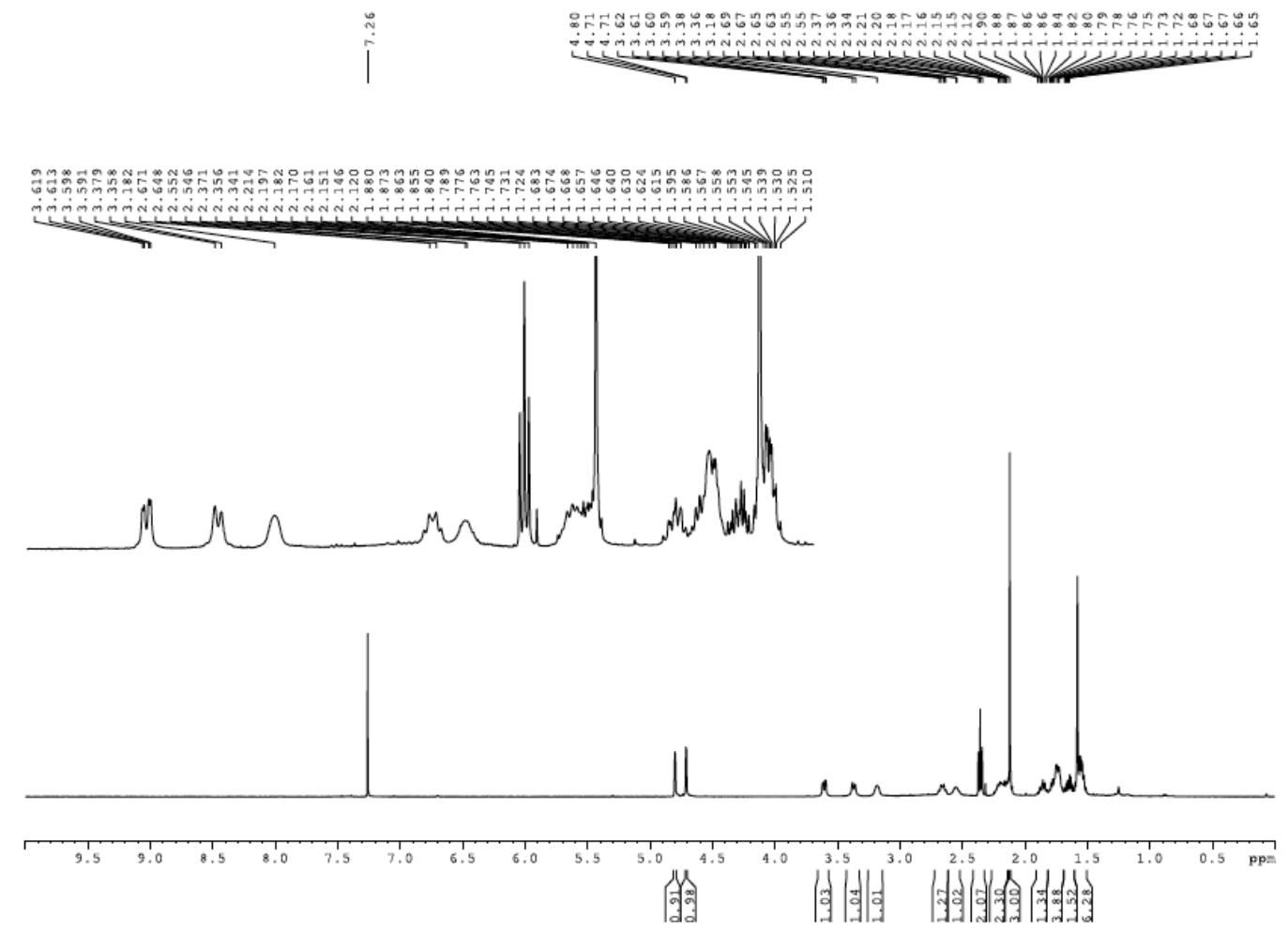

Figure S87. ${ }^{1}$ H-NMR Spectra of 39.

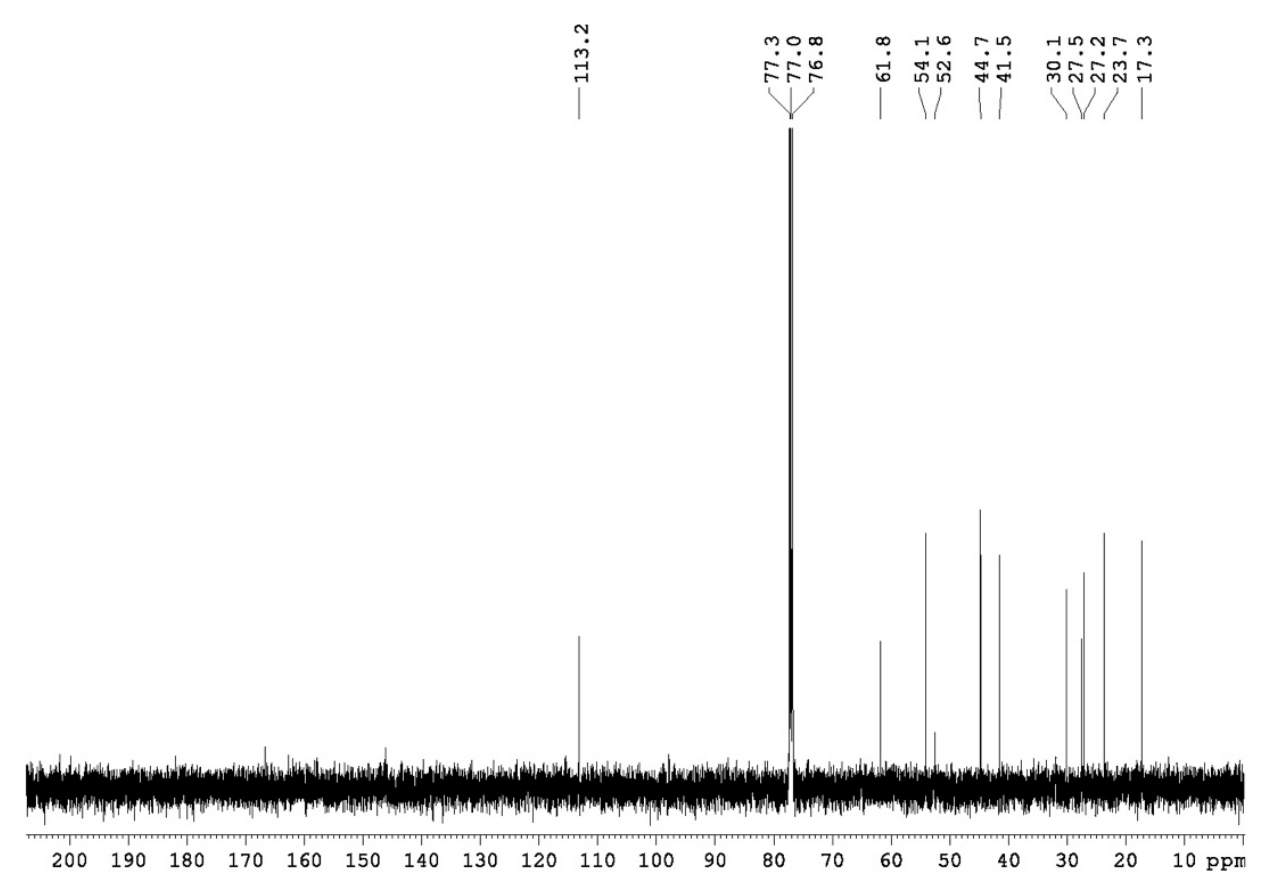

Figure S88. ${ }^{13}$ C-NMR Spectra of 39 
में

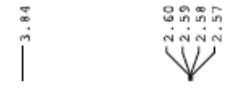

证
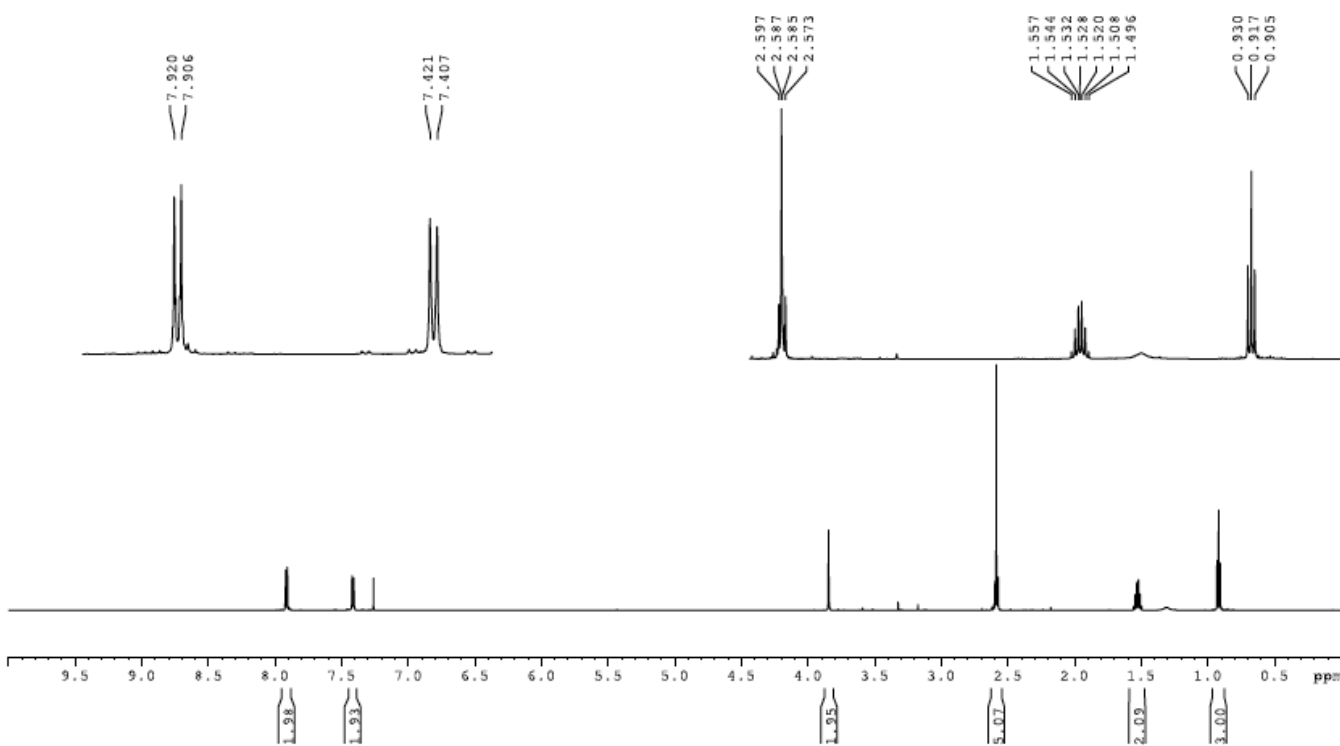

Figure S89. ${ }^{1} H-N M R$ Spectra of $\mathbf{4 0}$.

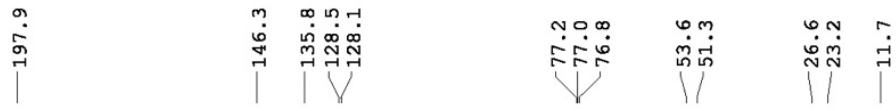

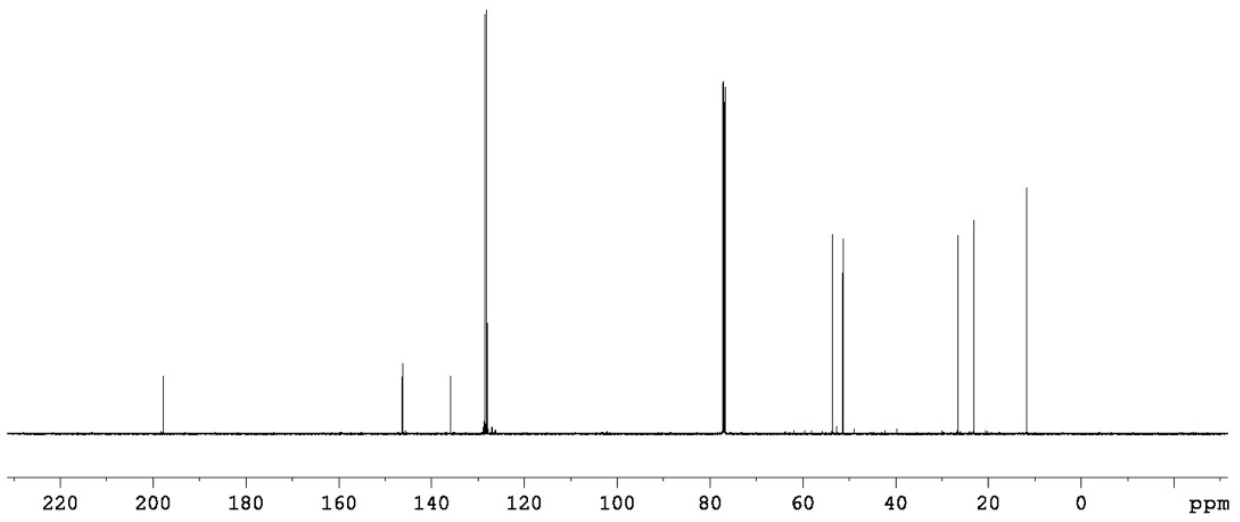

Figure S90. ${ }^{13} \mathrm{C}-\mathrm{NMR}$ Spectra of $\mathbf{4 0}$. 


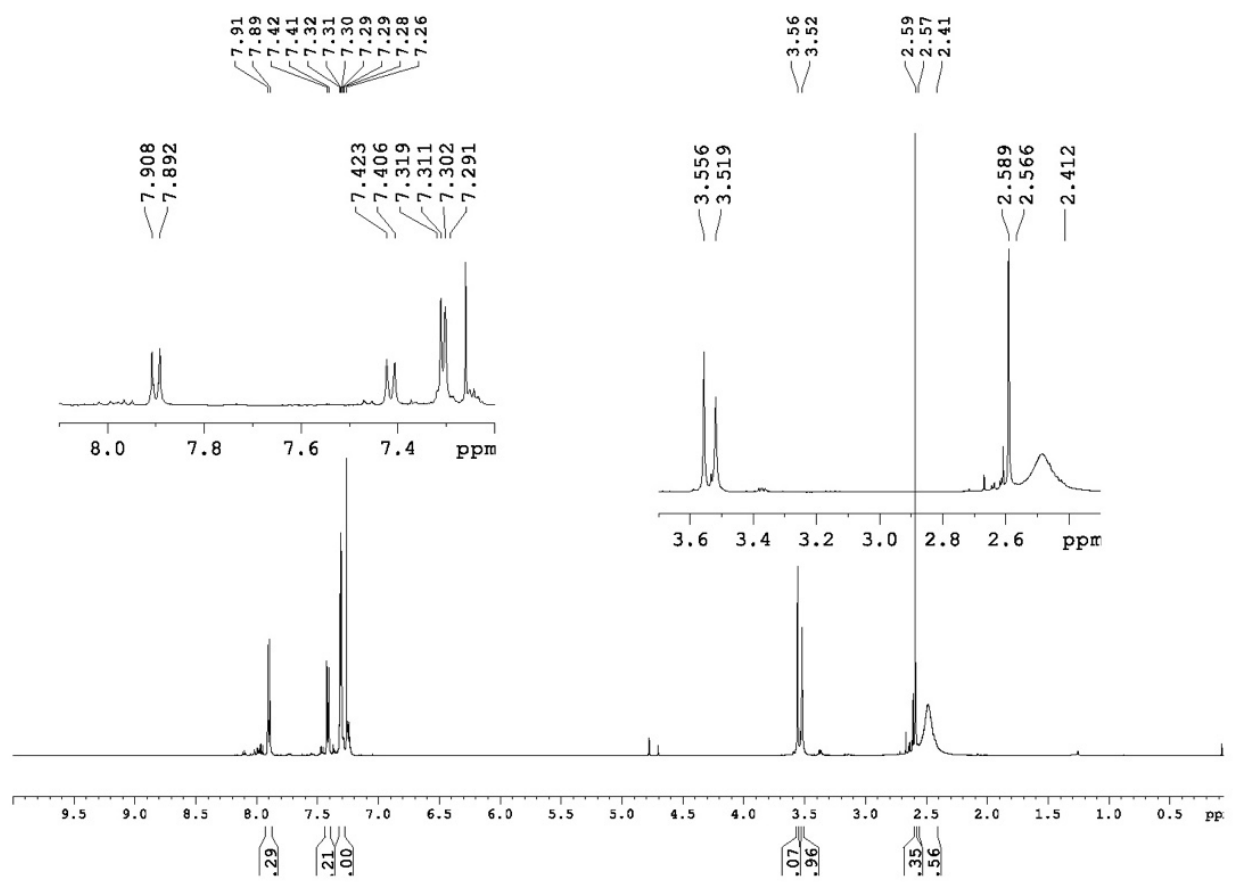

Figure S91. $\quad{ }^{1} H-N M R$ Spectra of 41.

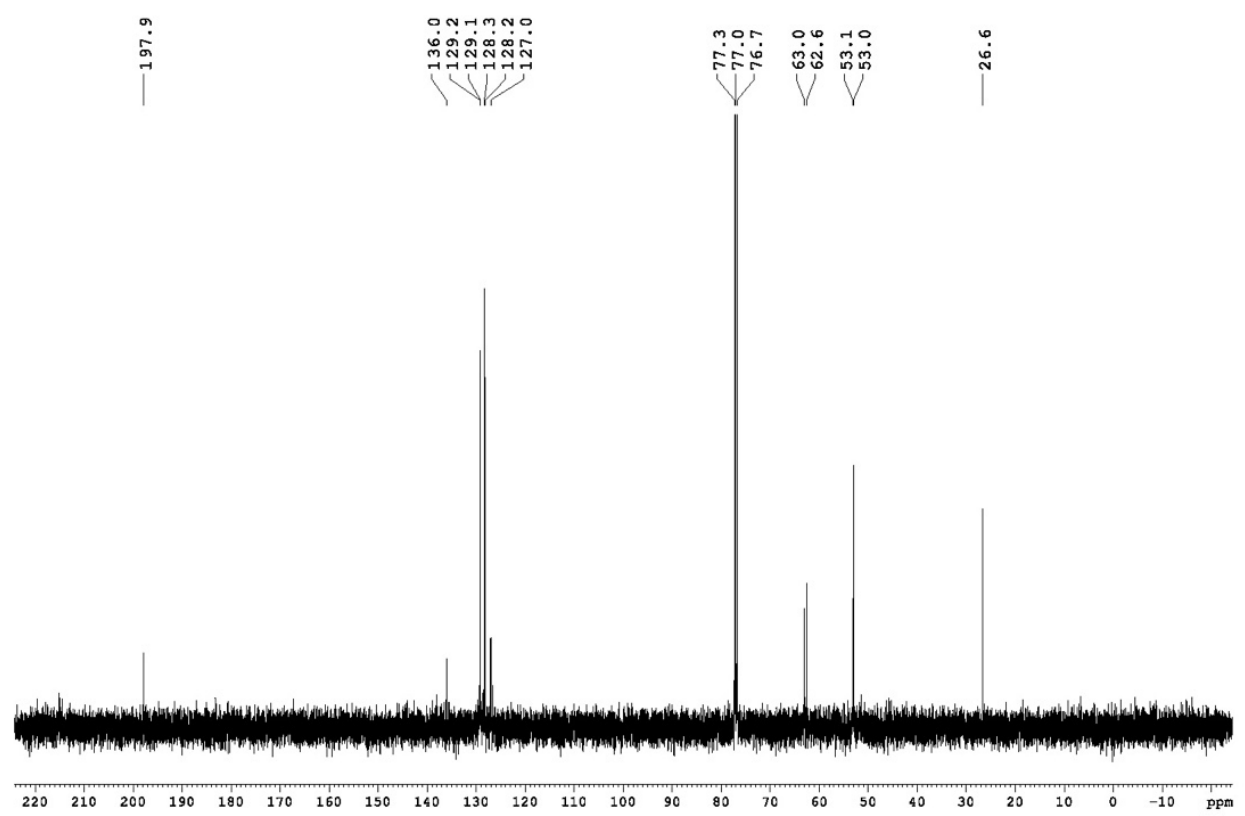

Figure S92. ${ }^{13} \mathrm{C}-\mathrm{NMR}$ Spectra of 41. 


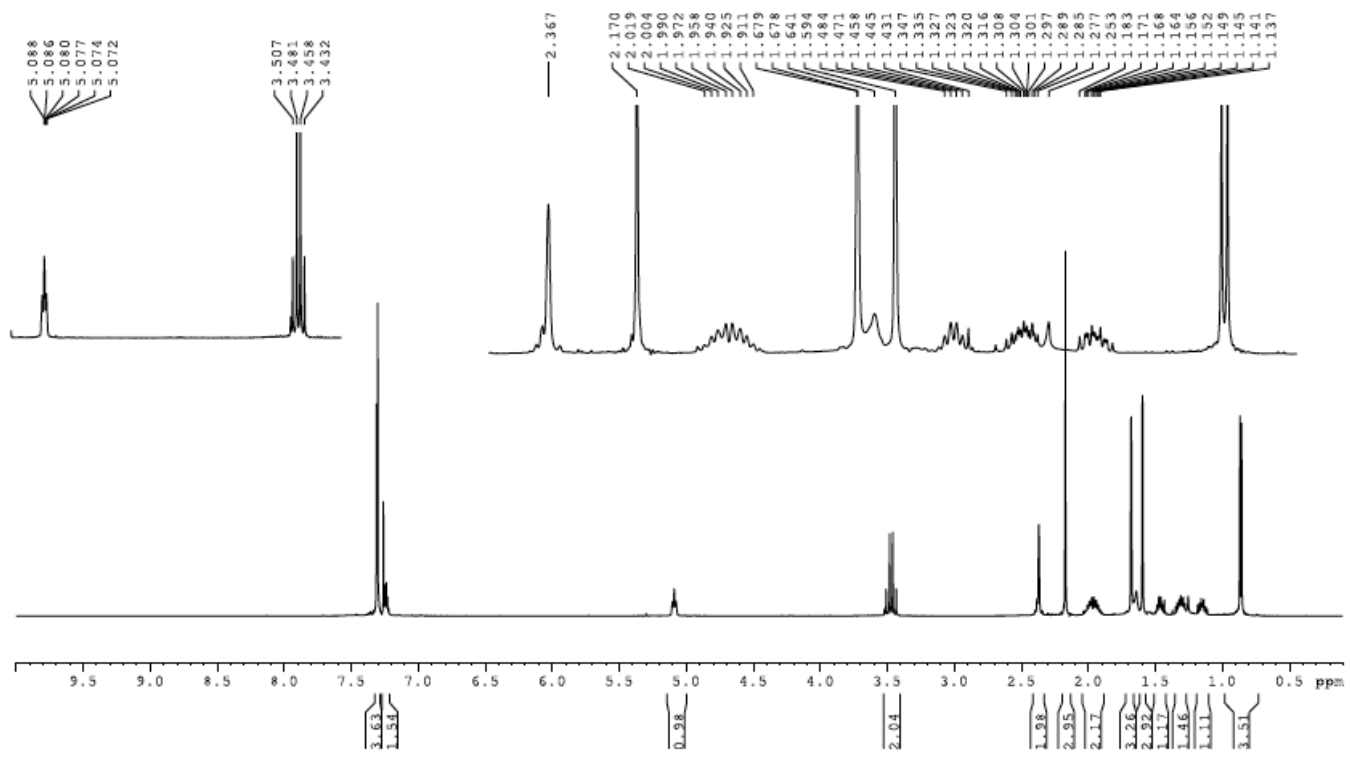

Figure S93. ${ }^{1}$ H-NMR Spectra of 3-D ${ }_{2}$.

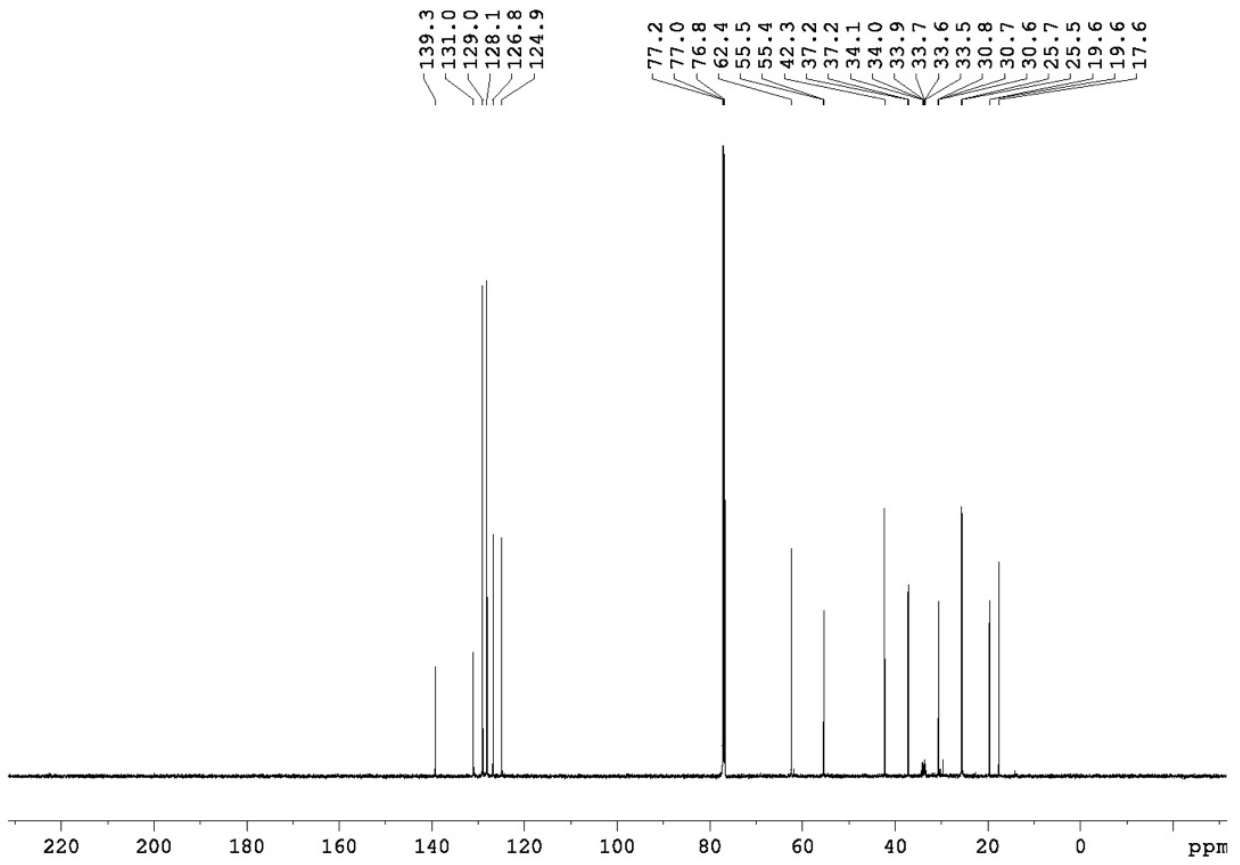

Figure S94. ${ }^{13}$ C-NMR Spectra of $3-\mathbf{D}_{2}$. 


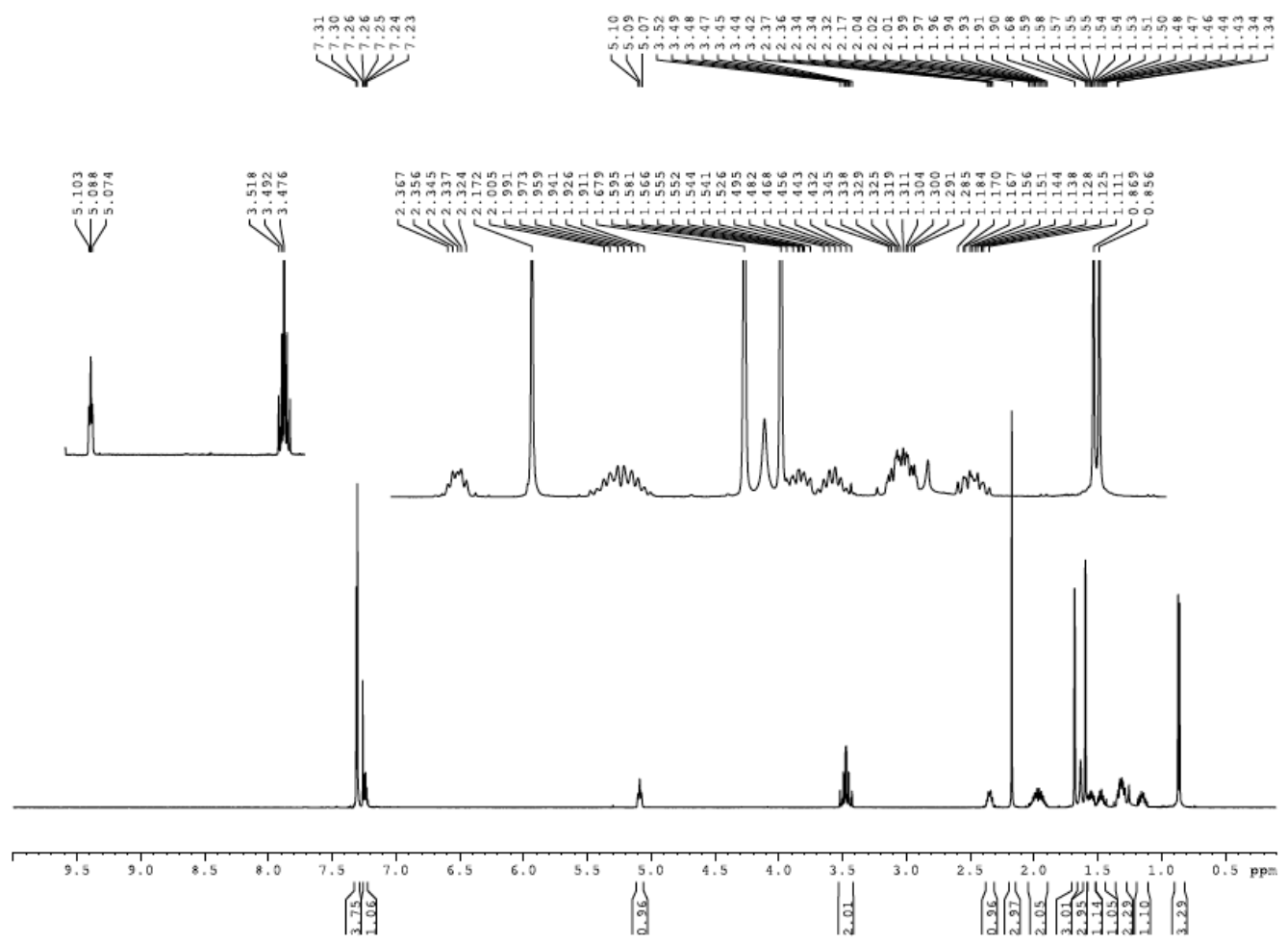

Figure S95. ${ }^{1} \mathrm{H}-\mathrm{NMR}$ Spectra of 3-D .

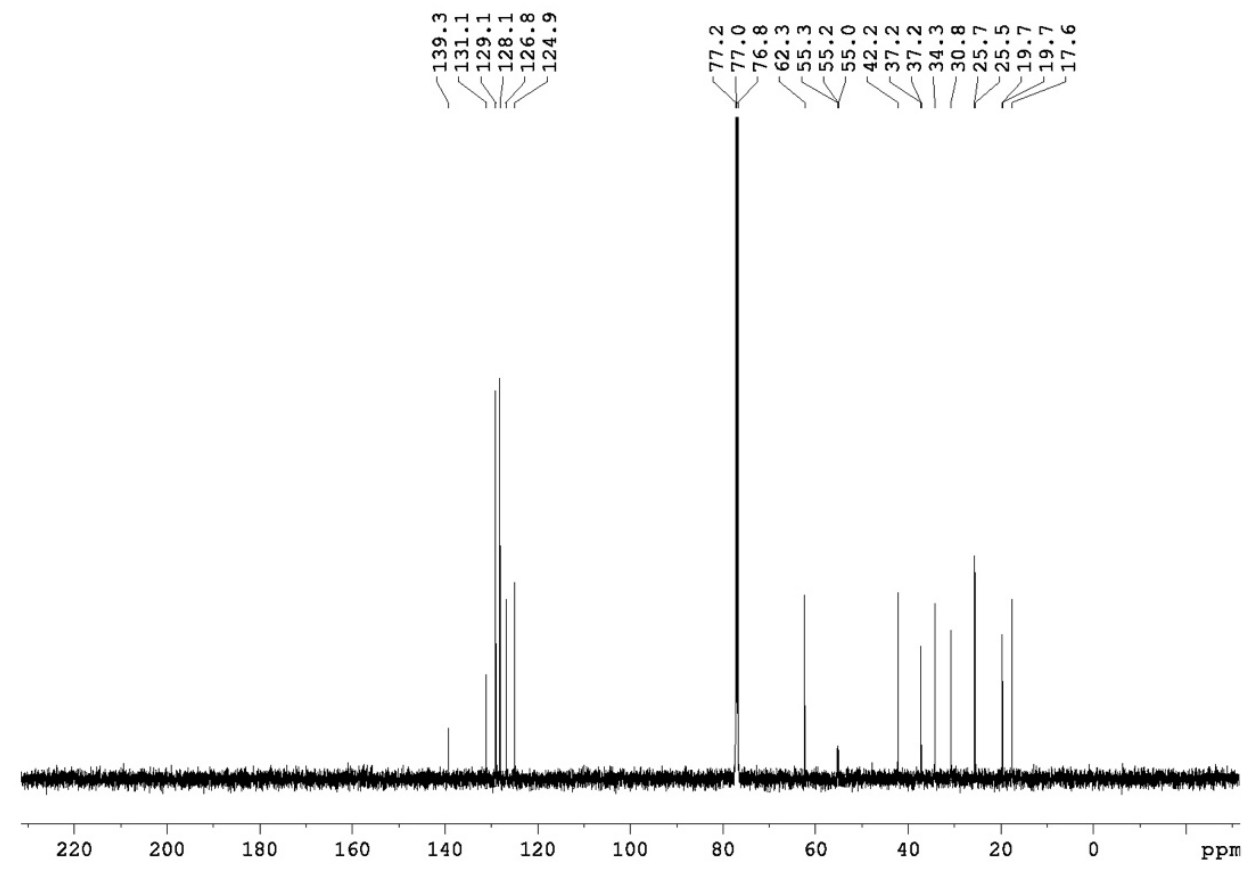

Figure S96. ${ }^{13} \mathrm{C}-\mathrm{NMR}$ Spectra of 3-D . 


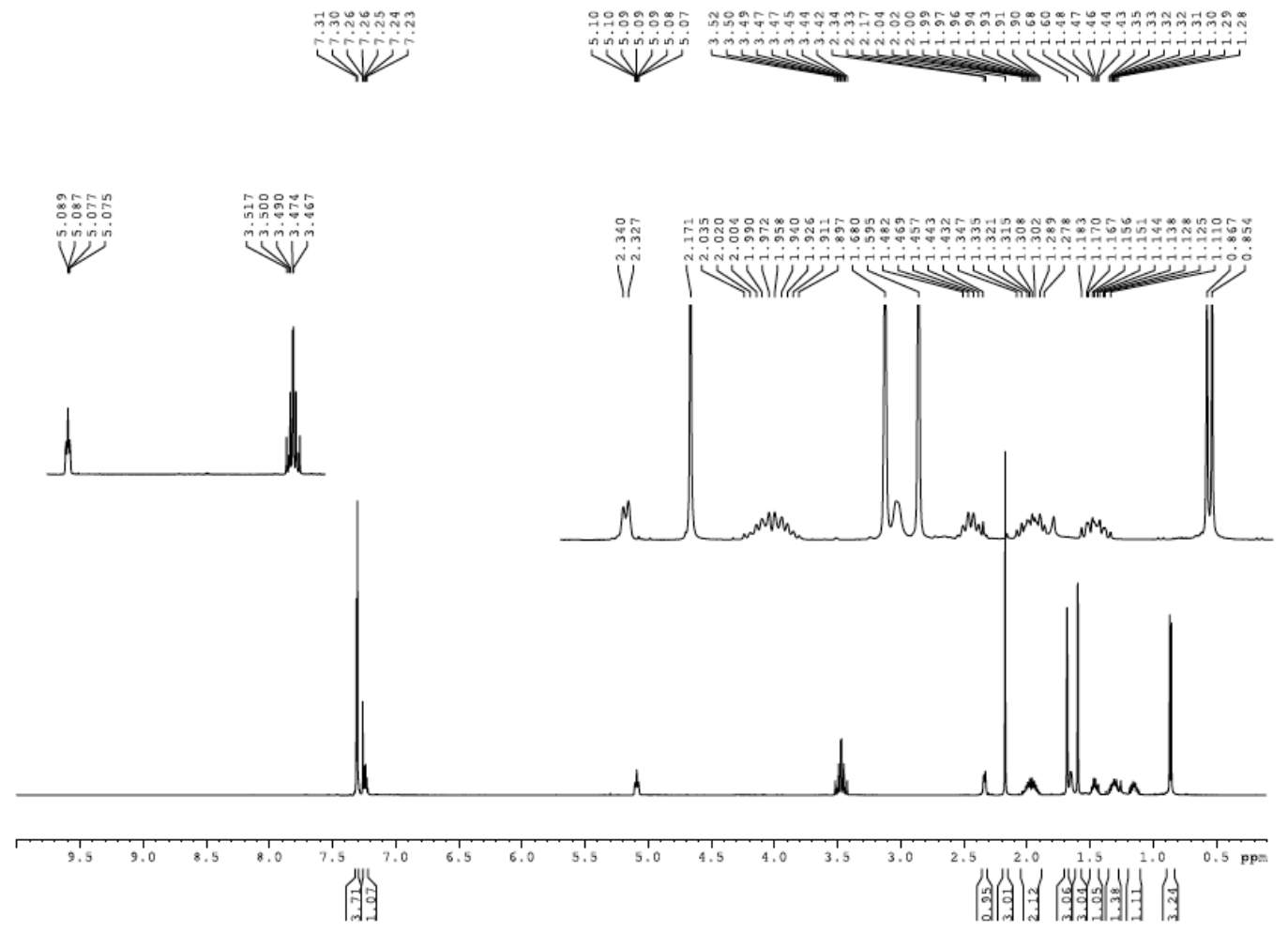

Figure S97. ${ }^{1} \mathrm{H}-\mathrm{NMR}$ Spectra of $\mathbf{3}-\mathbf{D}_{\mathbf{3}}$.

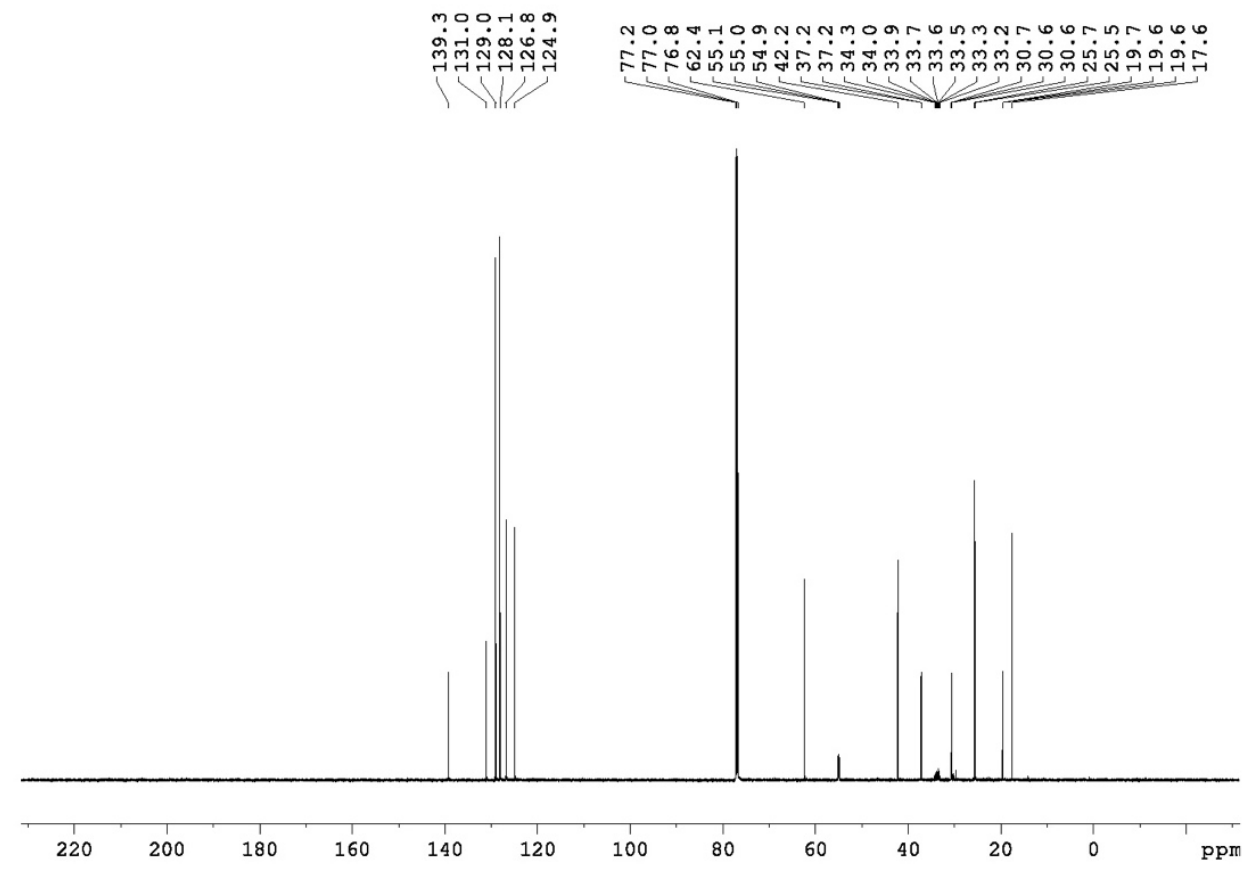

Figure S98. ${ }^{13} \mathrm{C}-\mathrm{NMR}$ Spectra of $\mathbf{3}-\mathbf{D}_{\mathbf{3}}$. 

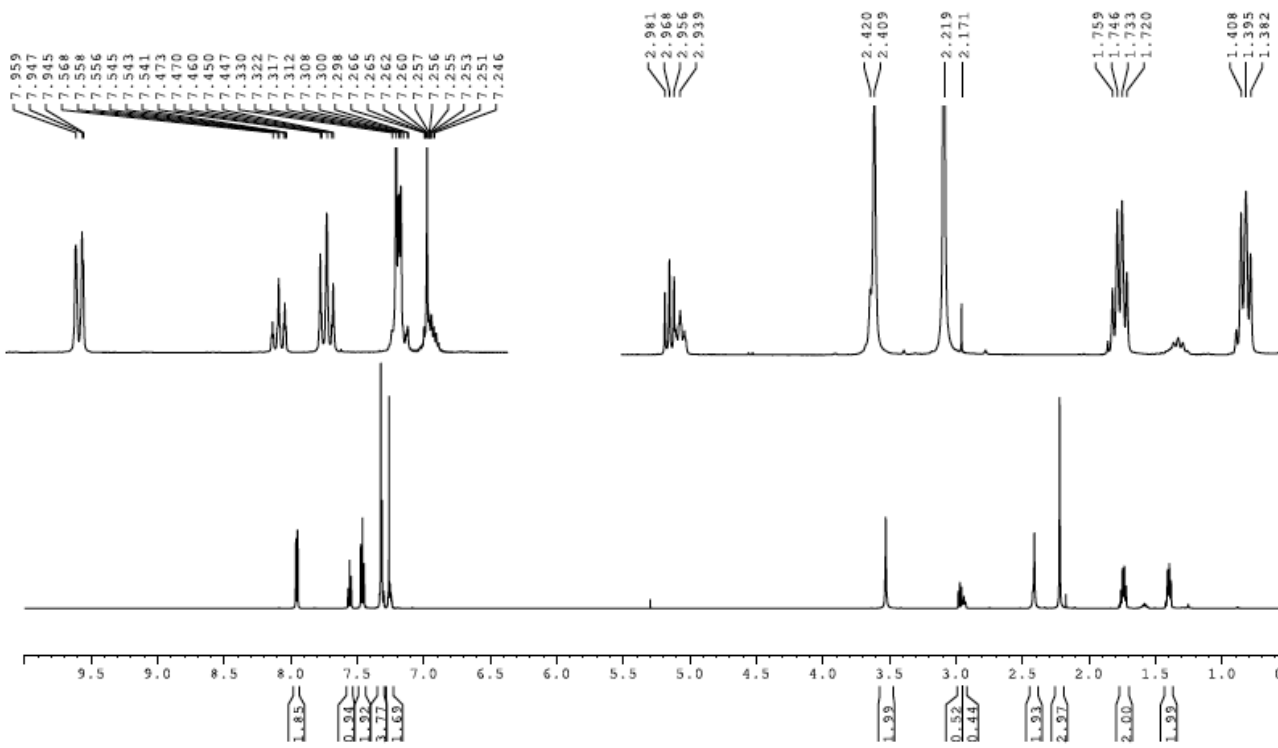

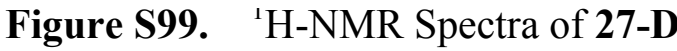

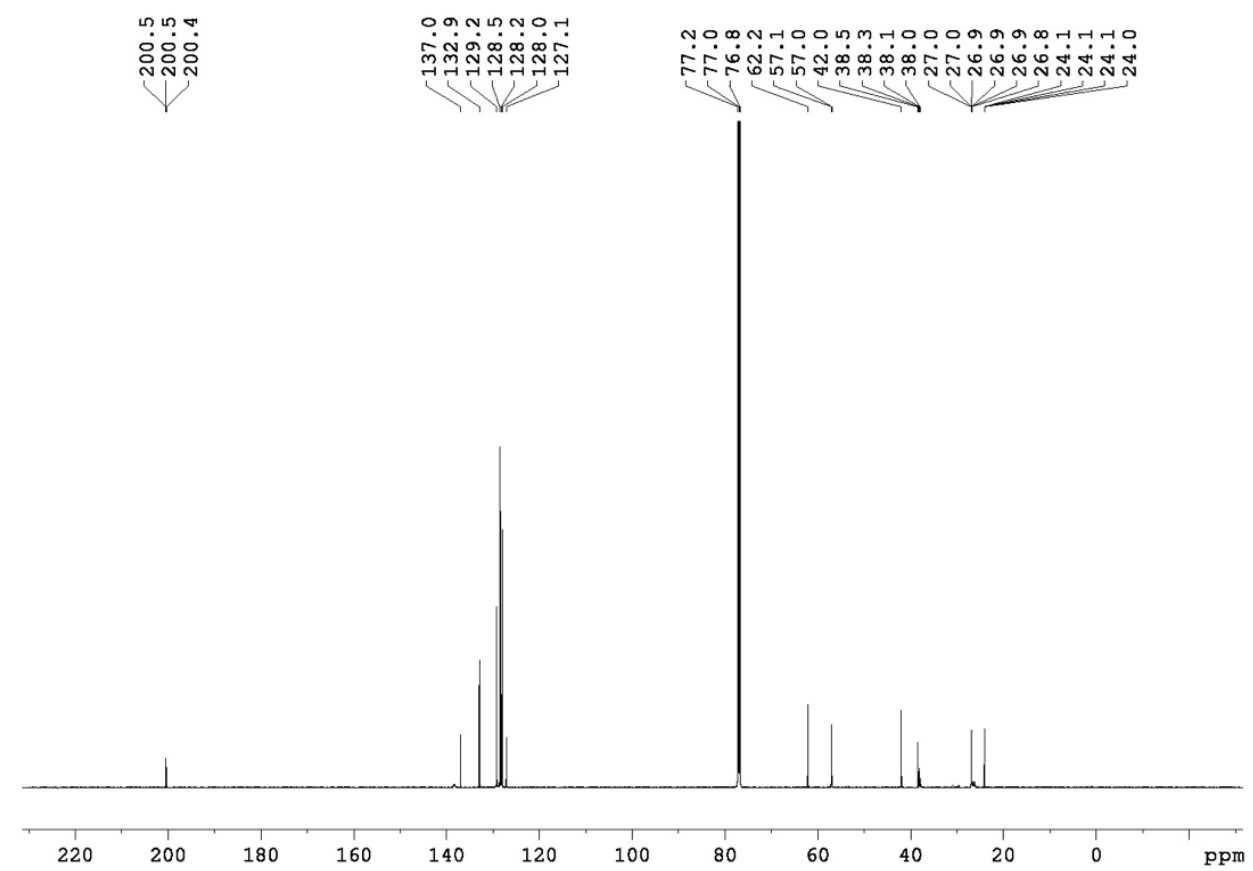

Figure S100. ${ }^{13}$ C-NMR Spectra of 27-D 


\section{Cristallographic data of $\mathrm{Fe} 3$}

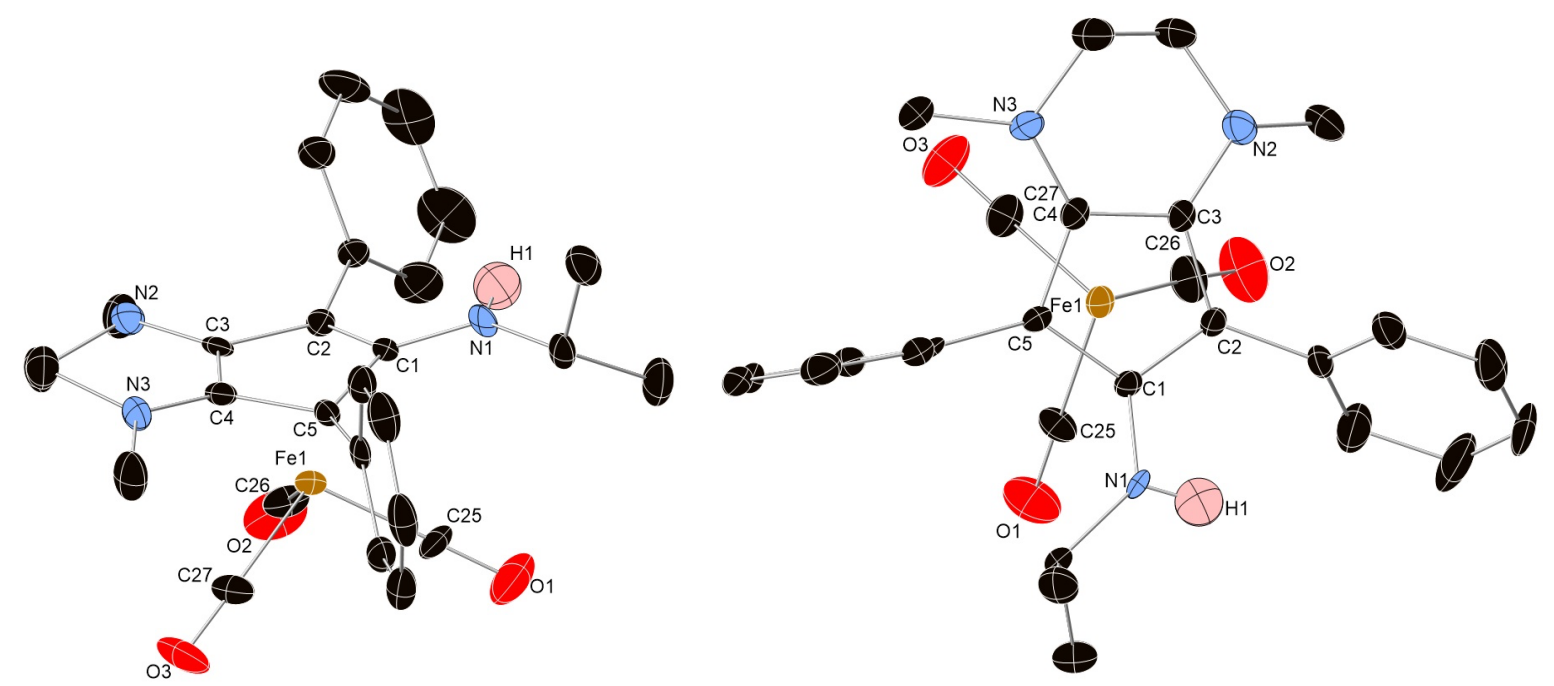

Figure S101. Thermal ellipsoid representations (50\% probability) of complex Fe3. Hydrogen atoms, except for the $\mathrm{NH} i \mathrm{Pr}$ group, and $\mathrm{BF}_{4}$ anion were omitted for clarity.

\begin{tabular}{|c|c|}
\hline & $\mathrm{Fe} 3$ \\
\hline Formula & $\mathrm{C}_{27} \mathrm{H}_{28} \mathrm{BF}_{4} \mathrm{FeN}_{3} \mathrm{O}_{3}$ \\
\hline M/g.mol-1 & 585.18 \\
\hline Crystal system & Triclinic \\
\hline Space group & P1 \\
\hline $\mathrm{a} / \AA$ & $8.8011(4)$ \\
\hline $\mathrm{b} / \AA$ & $16.3251(7)$ \\
\hline c/ $\AA$ & $21.7086(10)$ \\
\hline$\alpha / \circ$ & $104.967(2)$ \\
\hline$\beta / \circ$ & $99.429(2)$ \\
\hline $\mathrm{Y} /{ }^{\circ}$ & $98.308(2)$ \\
\hline $\mathrm{V} / \AA_{3}$ & $2914.9(2)$ \\
\hline Z & 4 \\
\hline pcalcd / g.cm ${ }^{-3}$ & 1.333 \\
\hline$\lambda\left(\mathrm{Mo} \mathrm{K}_{\alpha}\right) / \mathrm{mm}^{-1}$ & 0.71073 \\
\hline$\mu / \mathrm{mm}^{-1}$ & 0.575 \\
\hline $\mathrm{T} / \mathrm{K}$ & $150(2)$ \\
\hline No of reflections & 11360 \\
\hline No of unique reflections & 9225 \\
\hline $\mathrm{R}_{\text {int }}$ & 0.0381 \\
\hline GOF & 1.099 \\
\hline
\end{tabular}




\section{Computational details and DFT calculations}

DFT static calculations were performed with the Gausian09 set of programs, ${ }^{1}$ using the BP86 functional of Becke and Perdew. ${ }^{2}$ The electronic configuration of the molecular systems was described with the double- $\zeta$ basis set with polarization of Ahlrichs for main-group atoms (SVP keyword in Gaussian), ${ }^{3}$ using the SDD ECP on Fe. ${ }^{4}$ The geometry optimizations were performed without symmetry constraints, and analytical frequency calculations performed the characterization of the located stationary points. These frequencies were used to calculate unscaled zero-point energies (ZPEs) as well as thermal corrections and entropy effects at 298 $K$. Energies were obtained by single-point calculations on the optimized geometries with the M06 functional ${ }^{5}$ and the triple- $\zeta$ basis set cc-pVTZ, which is a dunning's correlation consistent basis set which has redundant function removed and has been rotated in order to increase computational efficiency, ${ }^{6}$ using the SDD ECP on Fe. And estimating solvent effects with the polarizable continuous solvation model (PCM) as implemented in Gaussian09, using ethanol as solvent. The reported free energies in this work include energies obtained at the M06/cc-pVTZ sdd level of theory corrected with zero-point energies, thermal corrections and entropy effects evaluated at $298 \mathrm{~K}$, achieved at the BP86/SVP $\sim$ sdd level.

\footnotetext{
${ }^{1}$ Frisch, M. J.; Trucks, G. W.; Schlegel, H. B.; Scuseria, G. E.; Robb, M. A.; Cheeseman, J. R.; Scalmani, G.; Barone, V.; Petersson, G. A.; Nakatsuji, H.; Li, X.; Caricato, M.; Marenich, A.; Bloino, J.; Janesko, B. G.; Gomperts, R.; Mennucci, B.; Hratchian, H. P.; Ortiz, J. V.; Izmaylov, A. F.; Sonnenberg, J. L.; Williams-Young, D.; Ding, F.; Lipparini, F.; Egidi, F.; Goings, J.; Peng, B.; Petrone, A.; Henderson, T.; Ranasinghe, D.; Zakrzewski, V. G.; Gao, J.; Rega, N.; Zheng, G.; Liang, W.; Hada, M.; Ehara, M.; Toyota, K.; Fukuda, R.; Hasegawa, J.; Ishida, M.; Nakajima, T.; Honda, Y.; Kitao, O. Nakai, H.; Vreven, T.; Throssell, K.; Montgomery, J. A.; Peralta, J. E.; Ogliaro, F.; Bearpark, M.; Heyd, J. J.; Brothers, E.; Kudin, K. N.; Staroverov, V. N.; Keith, T.; Kobayashi, R.; Normand, J.; Raghavachari, K.; Rendell, A.; Burant, J. C.; Iyengar, S. S.; Tomasi, J.; Cossi, M.; Millam, J.; Klene, M.; Adamo, C.; Cammi, R.; Ochterski, J. W.; Martin, R. L.; Morokuma, K.; Farkas, O.; Foresman, J. B.; Fox, D. J. Gaussian 09, Revision E.01. Gaussian, Inc., Wallingford CT, 2016.

2 (a) Becke, A. Density-Functional Exchange-Energy Approximation with Correct Asymptotic Behavior. Phys. Rev. A 1988, 38 , 3098-3100. (b) Perdew, J. P. Density-Functional Approximation for the Correlation Energy of the Inhomogeneous Electron Gas. Phys. Rev. B 1986, 33, 8822-8824. (c) Perdew, J. P. Erratum: Density-Functional Approximation for the Correlation Energy of the Inhomogeneous Electron Gas. Phys. Rev. B 1986, 34, 7406-7406.

${ }^{3}$ Schäfer, S.; Horn, H.; Ahlrichs, R. Fully Optimized Contracted Gaussian Basis Sets for Atoms Li to Kr. J. Chem. Phys. 1992, 97, 2571-2577.

${ }^{4}$ (a) Haeusermann, U.; Dolg, M.; Stoll, H.; Preuss, H. Accuracy of Energy-Adjusted Quasirelativistic ab initio Pseudopotentials. Mol. Phys. 1993, 78, 1211-1224. (b) Küchle, W.; Dolg, M.; Stoll, H.; Preuss, H. Energy Adjusted Pseudopotentials for the Actinides. Parameter Sets and Test Calculations for Thorium and Thorium Monoxide. J. Chem. Phys. 1994, 100, 7535-7542. (c) Leininger, T.; Nicklass, A.; Stoll, H.; Dolg, M.; Schwerdtfeger, P. The Accuracy of the Pseudopotential Approximation. A Comparison of Various Core Sizes for Indium Pseudopotentials in Calculations for Spectroscopic Constants of InH, InF, and InCl. J. Chem. Phys. 1996, 105, 1052-1059.

${ }^{5}$ (a) Zhao, Y.; Truhlar, D. G. The M06 Suite of Density Functionals for Main Group Thermochemistry, Thermochemical Kinetics, Noncovalent Interactions, Excited States, and Transition Elements: Two New Functionals and Systematic Testing of Four M06Class Functionals and 12 Other Functionals. Theor. Chem. Acc. 2008, 120, 215-241. (b) Zhao, Y.; Truhlar, D. G. A New Local Density Functional for Main-Group Thermochemistry, Transition Metal Bonding, Thermochemical Kinetics, and Noncovalent Interactions. J. Chem. Phys. 2006, 125, 194101-194118.

${ }^{6}$ Kendall, R. A.; Dunning Jr., T. H.; Harrison, R. J. Electron Affinities of the First row Atoms Revisited Systematic Basis Sets and Wave Functions. J. Chem. Phys. 1992, 96, 6796-6806.

(a) Barone, V.; Cossi, M. Quantum Calculation of Molecular Energies and Energy Gradients in Solution by a Conductor Solvent Model. J. Phys. Chem. A 1988, 102, 1995-2001. (b) Tomasi, J.; Persico, M. Molecular Interactions in Solution: An Overview of Methods Based on Continuous Distributions of the Solvent. Chem. Rev. 1994, 94, 2027-2094.
} 
Table S1. 3D view and $x y z$ coordinate data sets and absolute energies in a.u. for DFT optimized complex Fe1-I.

\begin{tabular}{|c|c|c|c|c|}
\hline $\begin{array}{lc}\text { Zero-point correction }= & \begin{array}{c}0.378678 \text { (Hartree/Particle) } \\
\text { Thermal correction to Energy }=\end{array} \\
\text { Thermal correction to Enthalpy= } & 0.408101 \\
\text { Thermal correction to Gibbs Free Energy= } & 0.317305 \\
\text { Sum of electronic and zero-point Energies }= & -1459.771539 \\
\text { Sum of electronic and thermal Energies }= & -1459.742116 \\
\text { Sum of electronic and thermal Enthalpies }= & -1459.741172 \\
\text { Sum of electronic and thermal Free Energies }= & -1459.832912 \\
& \\
\text { Solvent }=-1460.5043787 & \end{array}$ & $\begin{array}{l}\text { Ce } \\
\text { C } \\
\text { C } \\
\text { C } \\
\text { H } \\
\text { C } \\
\text { C } \\
\text { C } \\
\text { H } \\
\text { H } \\
\text { C } \\
\text { C } \\
\text { H } \\
\text { H } \\
\text { C } \\
\text { C } \\
\text { C } \\
\text { C } \\
\text { C } \\
\text { H } \\
\text { C } \\
\text { H } \\
\text { C } \\
\text { H } \\
\text { H } \\
\text { C } \\
\text { H } \\
\text { C } \\
\text { H } \\
\text { C } \\
\text { C } \\
\text { H } \\
\text { C } \\
\text { H } \\
\text { C } \\
\text { H } \\
\text { C } \\
\text { O } \\
\text { O } \\
\text { O } \\
\text { O } \\
\text { N } \\
\text { N }\end{array}$ & 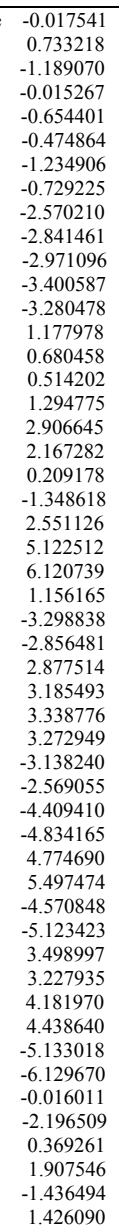 & 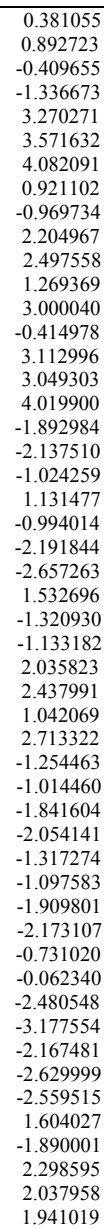 & 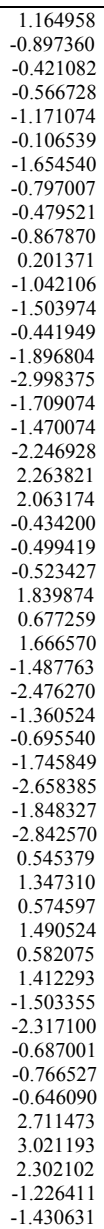 \\
\hline
\end{tabular}


Table S2. 3D view and $x y z$ coordinate data sets and absolute energies in a.u. for DFT optimized complex Fe1-I-II.

\begin{tabular}{|c|c|c|c|}
\hline $\begin{array}{lc}\text { Zero-point correction }= & 0.501676 \text { (Hartree/Particle) } \\
\text { Thermal correction to Energy }= & 0.537211 \\
\text { Thermal correction to Enthalpy= } & 0.435455 \\
\text { Thermal correction to Gibbs Free Energy= } & -1709.084249 \\
\text { Sum of electronic and zero-point Energies= } & -1709.048713 \\
\text { Sum of electronic and thermal Energies= } & -1709.047769 \\
\text { Sum of electronic and thermal Enthalpies }= & -1709.150470 \\
\text { Sum of electronic and thermal Free Energies }= & -155\end{array}$ & 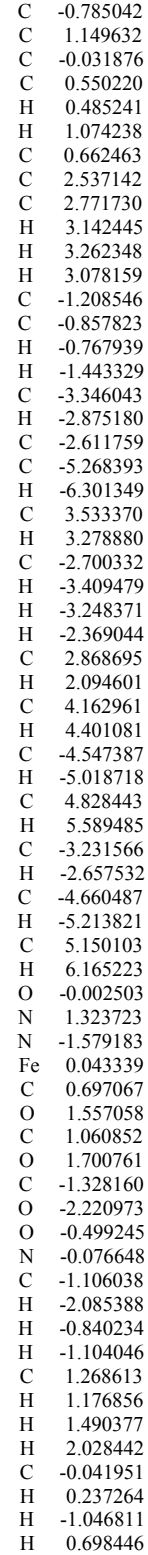 & 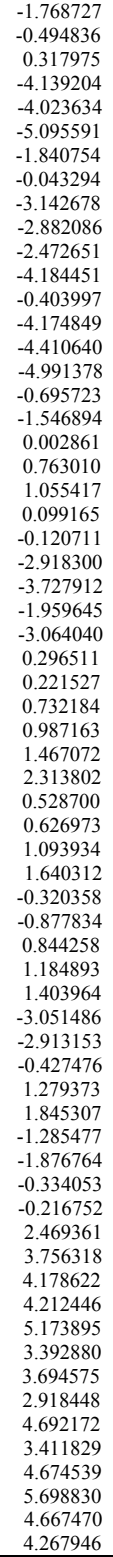 & 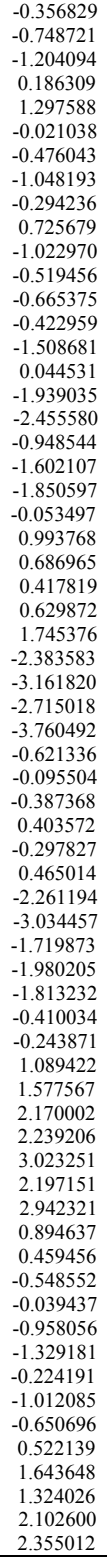 \\
\hline
\end{tabular}


Table S3. 3D view and $x y z$ coordinate data sets and absolute energies in a.u. for DFT optimized complex Fe1-II.

\begin{tabular}{|c|c|c|c|c|}
\hline $\begin{array}{lc}\text { Zero-point correction }= & 0.370262 \text { (Hartree/Particle) } \\
\text { Thermal correction to Energy= } & 0.397352 \\
\text { Thermal correction to Enthalpy= } & 0.398296 \\
\text { Thermal correction to Gibbs Free Energy= } & 0.312247 \\
\text { Sum of electronic and zero-point Energies= } & -1346.491876 \\
\text { Sum of electronic and thermal Energies }= & -1346.464787 \\
\text { Sum of electronic and thermal Enthalpies= } & -1346.463843 \\
\text { Sum of electronic and thermal Free Energies }= & -1346.549892\end{array}$ & $\begin{array}{l}\text { Fe } \\
\text { C } \\
\text { C } \\
\text { C } \\
\text { C } \\
\text { H } \\
\text { H } \\
\text { C } \\
\text { C } \\
\text { C } \\
\text { H } \\
\text { H } \\
\text { H } \\
\text { C } \\
\text { C } \\
\text { H } \\
\text { H } \\
\text { C } \\
\text { H } \\
\text { C } \\
\text { C } \\
\text { C } \\
\text { H } \\
\text { C } \\
\text { C } \\
\text { H } \\
\text { C } \\
\text { H } \\
\text { H } \\
\text { H } \\
\text { C } \\
\text { H } \\
\text { C } \\
\text { H } \\
\text { C } \\
\text { H } \\
\text { C } \\
\text { H } \\
\text { C } \\
\text { H } \\
\text { C } \\
\text { H } \\
\text { C } \\
\text { H } \\
\text { O } \\
\text { O } \\
\text { O } \\
\text { N } \\
\text { N }\end{array}$ & 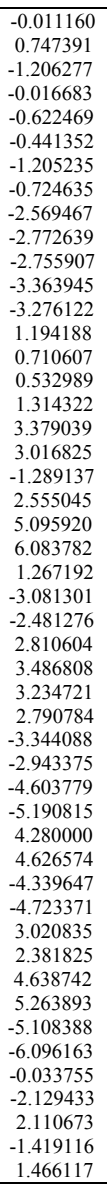 & 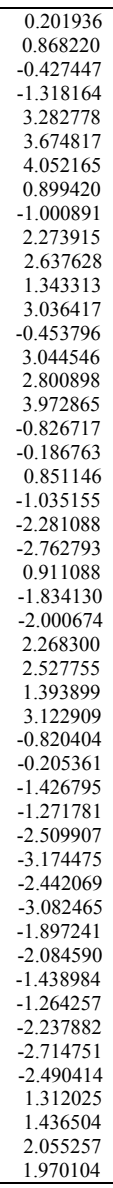 & 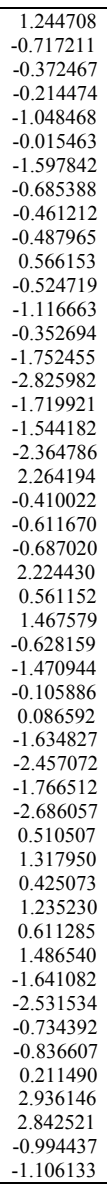 \\
\hline
\end{tabular}


Table S4. 3D view and $x y z$ coordinate data sets and absolute energies in a.u. for DFT optimized complex Fe1-II-III.

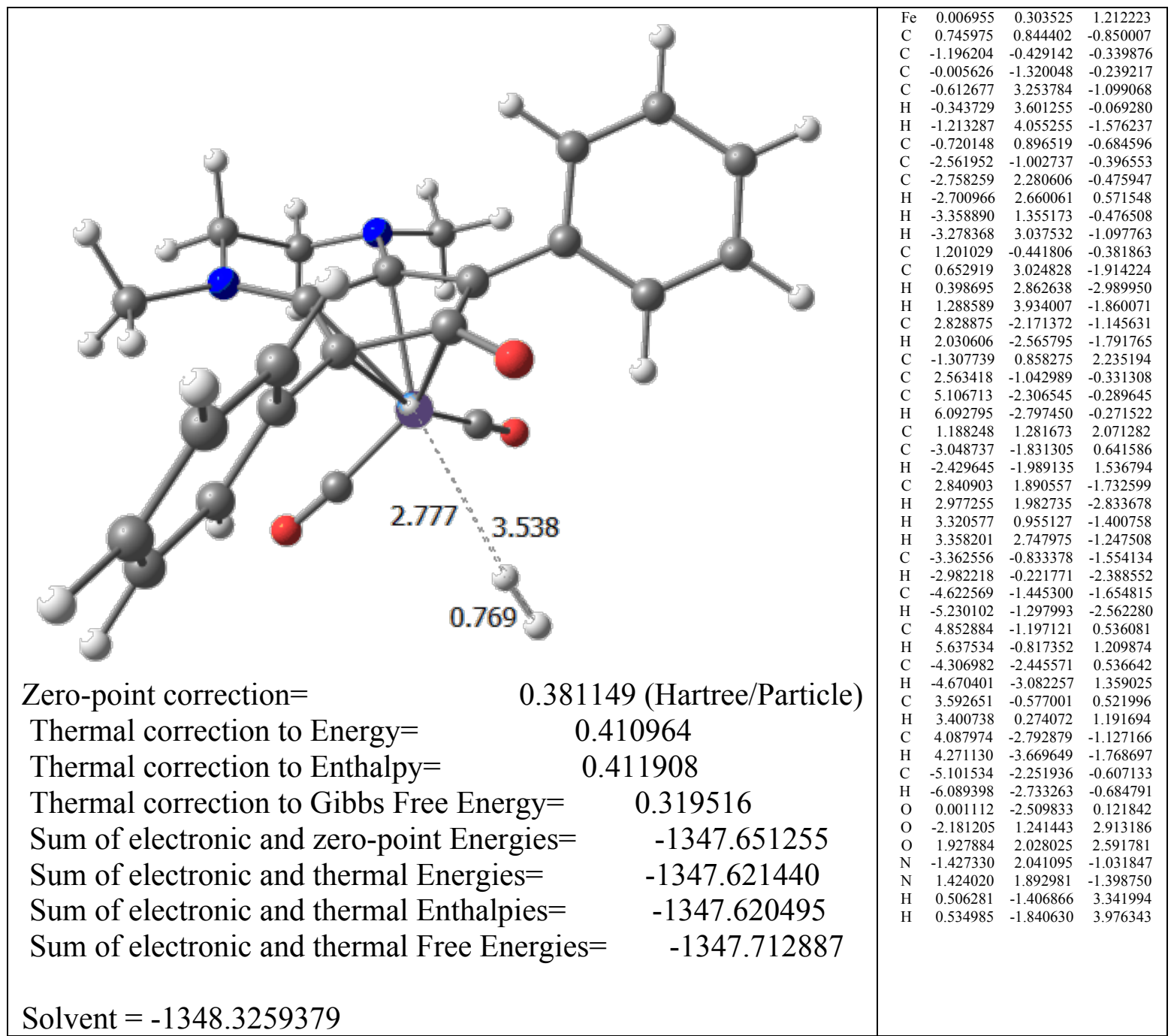


Table S5. 3D view and $x y z$ coordinate data sets and absolute energies in a.u. for DFT optimized complex Fe1-III.

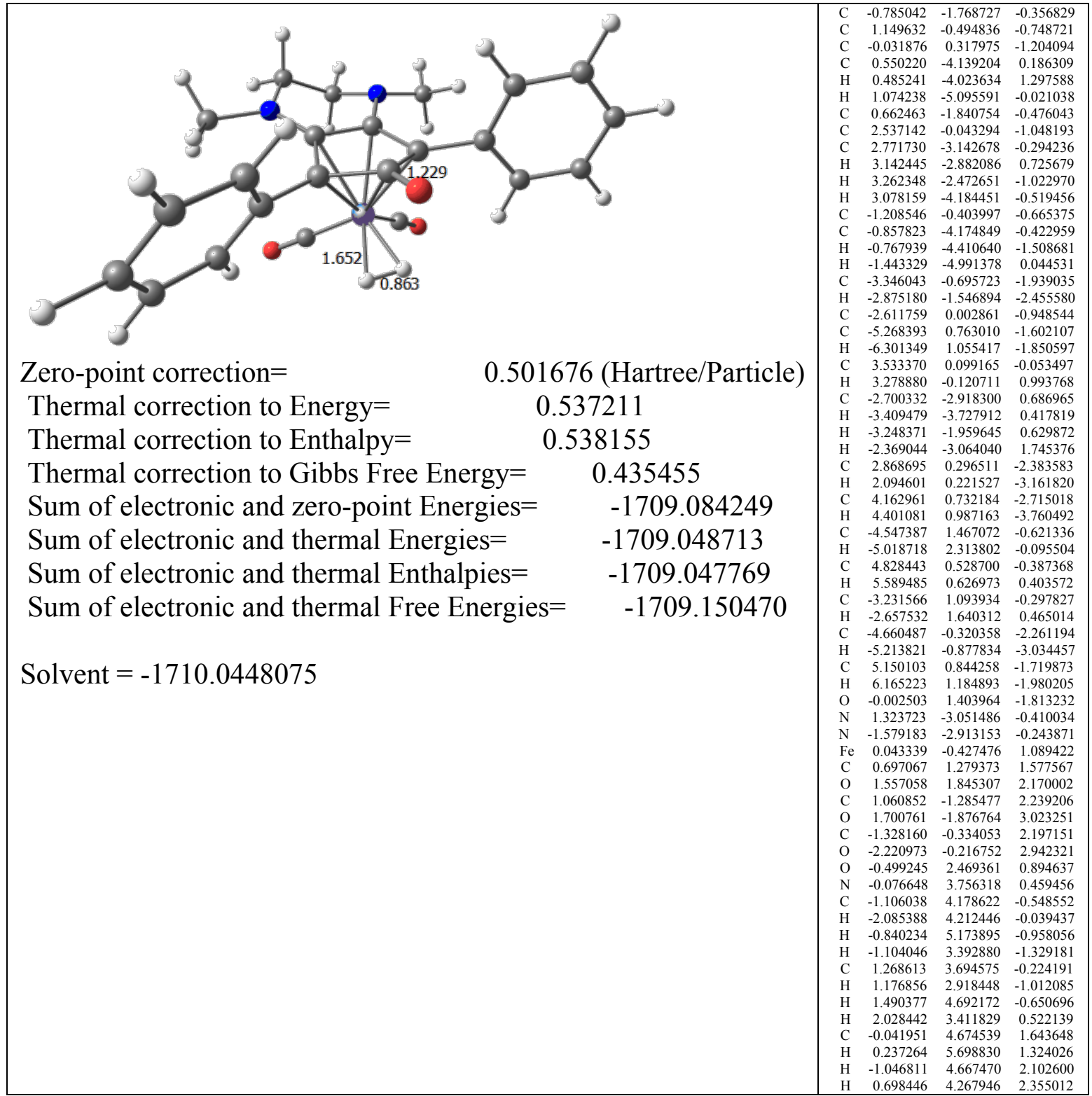


Table S6. 3D view and $x y z$ coordinate data sets and absolute energies in a.u. for DFT optimized complex Fe1-III-IV.

\begin{tabular}{|c|c|c|c|c|}
\hline $\begin{array}{lc}\text { Zero-point correction }= & 0.382983 \text { (Hartree/Particle) } \\
\text { Thermal correction to Energy= } & 0.410287 \\
\text { Thermal correction to Enthalpy= } & 0.411231 \\
\text { Thermal correction to Gibbs Free Energy= } & 0.324481 \\
\text { Sum of electronic and zero-point Energies }= & -1347.633118 \\
\text { Sum of electronic and thermal Energies }= & -1347.605814 \\
\text { Sum of electronic and thermal Enthalpies }= & -1347.604870 \\
\text { Sum of electronic and thermal Free Energies }= & -1347.691620\end{array}$ & $\begin{array}{l}\mathrm{C} \\
\mathrm{C} \\
\mathrm{H} \\
\mathrm{H} \\
\mathrm{H} \\
\mathrm{C} \\
\mathrm{C} \\
\mathrm{C} \\
\mathrm{H} \\
\mathrm{C}\end{array}$ & 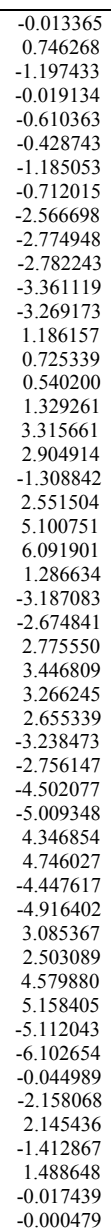 & 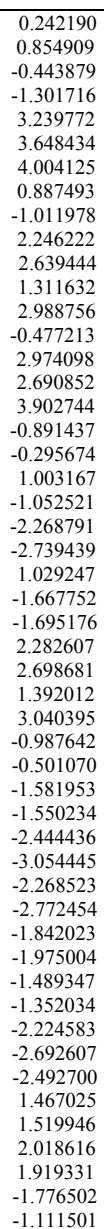 & 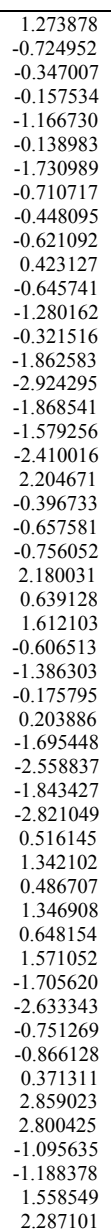 \\
\hline
\end{tabular}


Table S7. 3D view and $x y z$ coordinate data sets and absolute energies in a.u. for DFT optimized complex Fe1-III-IV+1EtOH.

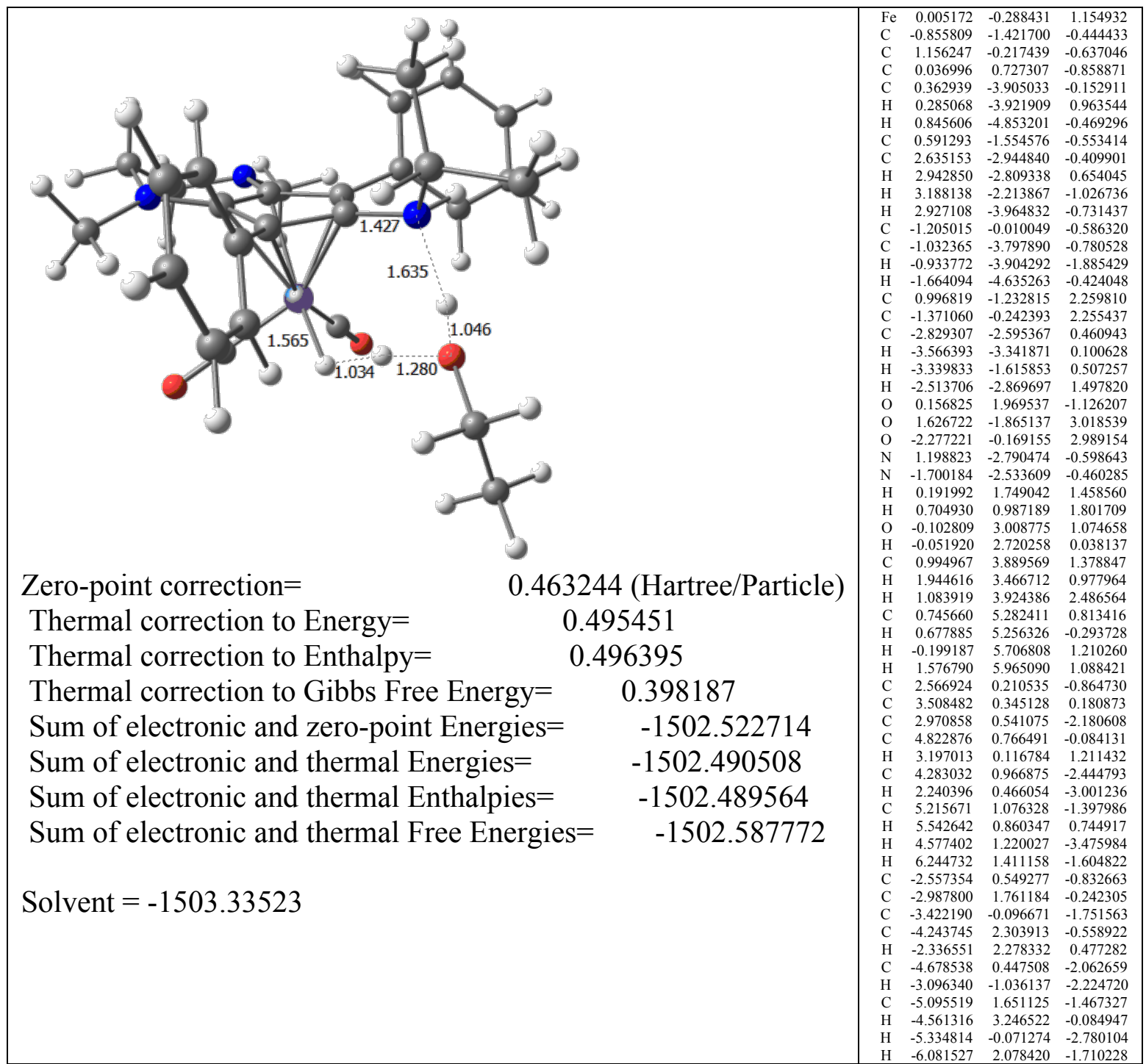


Table S8. 3D view and $x y z$ coordinate data sets and absolute energies in a.u. for DFT optimized complex Fe1-III-IV+2EtOH.

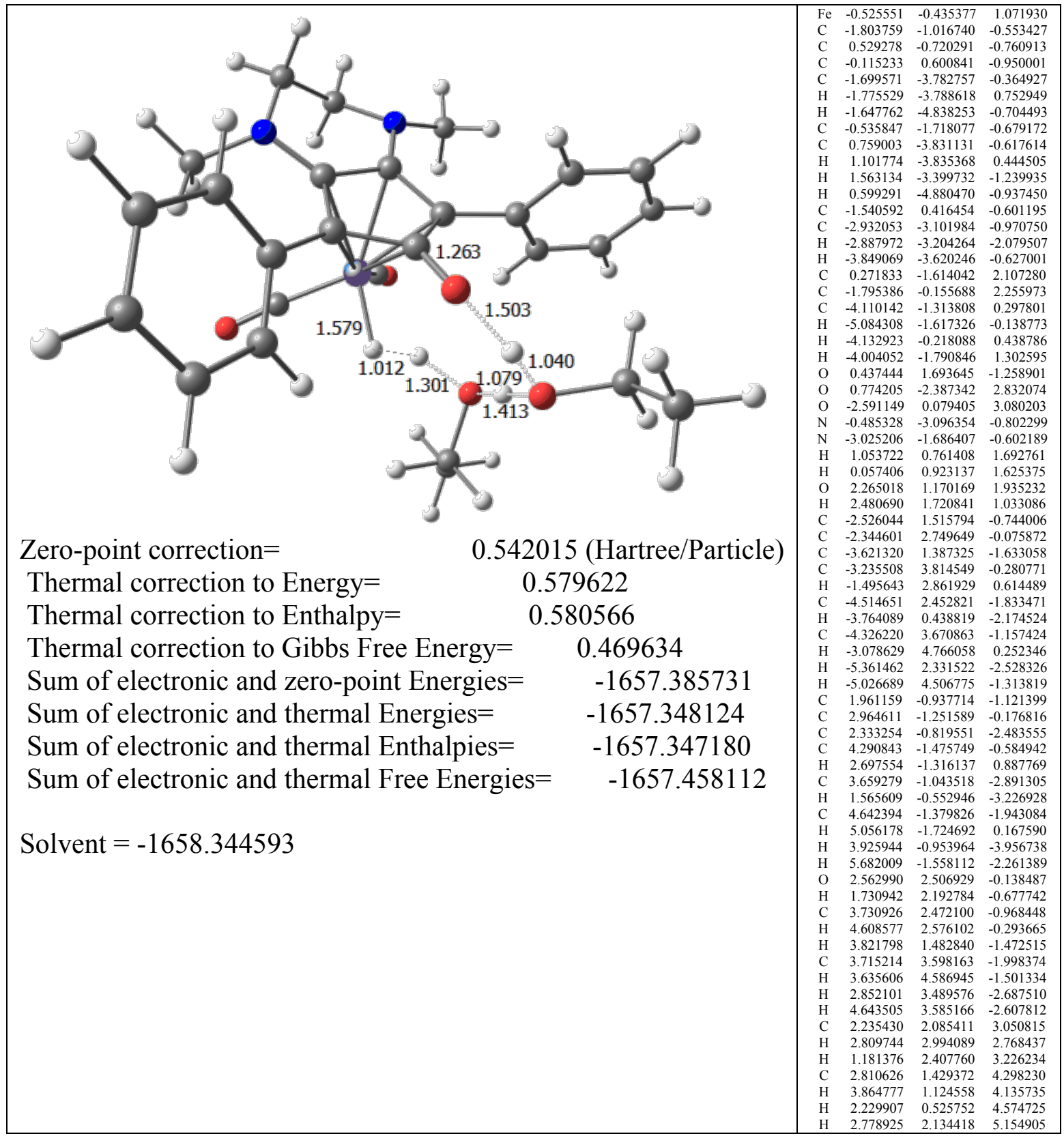


Table S9. 3D view and $x y z$ coordinate data sets and absolute energies in a.u. for DFT optimized complex Fe1-IV.

\begin{tabular}{|c|c|c|c|}
\hline $\begin{array}{lc}\text { Zero-point correction }= & 0.389531 \text { (Hartree/Particle) } \\
\text { Thermal correction to Energy= } & 0.416899 \\
\text { Thermal correction to Enthalpy= } & 0.417843 \\
\text { Thermal correction to Gibbs Free Energy= } & 0.331495 \\
\text { Sum of electronic and zero-point Energies }= & -1347.676350 \\
\text { Sum of electronic and thermal Energies }= & -1347.648983 \\
\text { Sum of electronic and thermal Enthalpies }= & -1347.648039 \\
\text { Sum of electronic and thermal Free Energies }= & -1347.734386\end{array}$ & 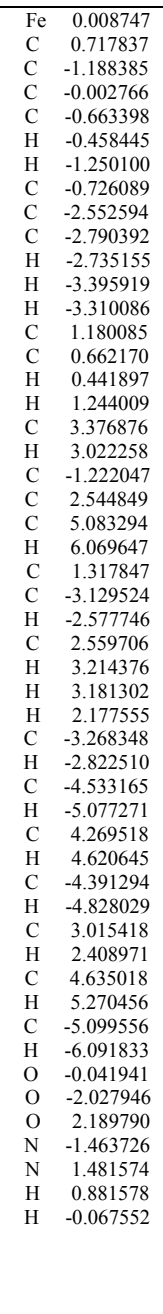 & 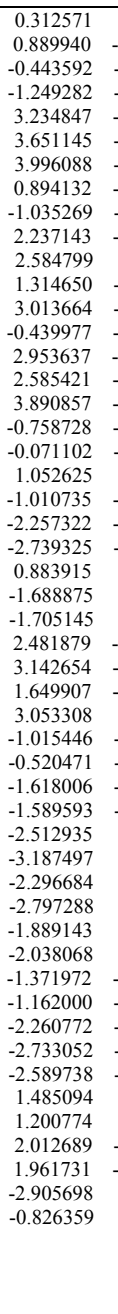 & 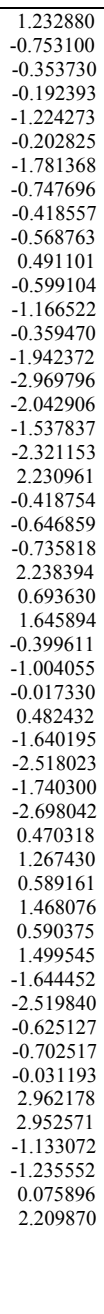 \\
\hline
\end{tabular}


Table S10. 3D view and $x y z$ coordinate data sets and absolute energies in a.u. for DFT optimized complex Fe1-V.

\begin{tabular}{|c|c|c|c|c|}
\hline $\begin{array}{lc}\text { Zero-point correction }= & 0.590381 \text { (Hartree/Particle) } \\
\text { Thermal correction to Energy= } & 0.630647 \\
\text { Thermal correction to Enthalpy= } & 0.631592 \\
\text { Thermal correction to Gibbs Free Energy }= & 0.511501 \\
\text { Sum of electronic and zero-point Energies }= & -1790.783921 \\
\text { Sum of electronic and thermal Energies }= & -1790.743654 \\
\text { Sum of electronic and thermal Enthalpies }= & -1790.742709 \\
\text { Sum of electronic and thermal Free Energies }= & -1790.862800\end{array}$ & $\begin{array}{l}\mathrm{H} \\
\mathrm{C} \\
\mathrm{H} \\
\mathrm{C} \\
\mathrm{H} \\
\mathrm{C} \\
\mathrm{H} \\
\mathrm{C} \\
\mathrm{H} \\
\mathrm{O} \\
\mathrm{O} \\
\mathrm{N} \\
\mathrm{N} \\
\mathrm{O} \\
\mathrm{H} \\
\mathrm{H} \\
\mathrm{C} \\
\mathrm{N} \\
\mathrm{C} \\
\mathrm{H} \\
\mathrm{H} \\
\mathrm{C} \\
\mathrm{C} \\
\mathrm{C} \\
\mathrm{C} \\
\mathrm{C}\end{array}$ & 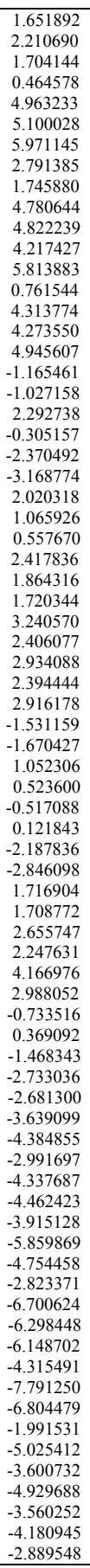 & 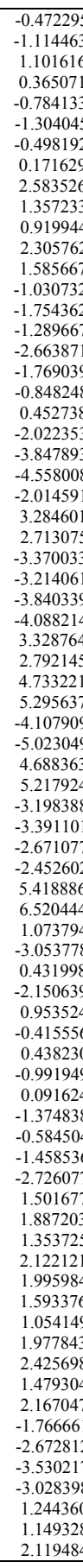 & 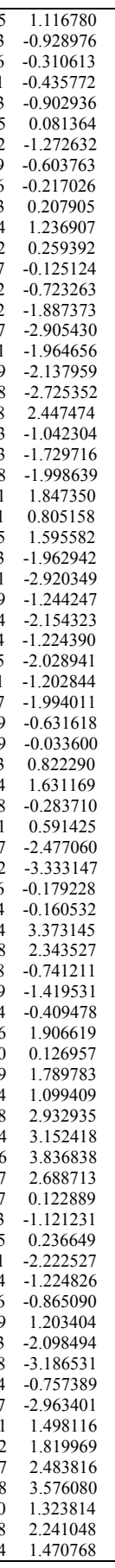 \\
\hline
\end{tabular}


Table S11. 3D view and $x y z$ coordinate data sets and absolute energies in a.u. for DFT optimized complex Fe1-V-VI.

\begin{tabular}{|c|c|c|c|c|}
\hline $\begin{array}{lc}\text { Zero-point correction }= & 0.587384 \text { (Hartree/Particle) } \\
\text { Thermal correction to Energy= } & 0.626891 \\
\text { Thermal correction to Enthalpy= } & 0.627835 \\
\text { Thermal correction to Gibbs Free Energy= } & 0.510883 \\
\text { Sum of electronic and zero-point Energies }= & -1790.780971 \\
\text { Sum of electronic and thermal Energies= } & -1790.741464 \\
\text { Sum of electronic and thermal Enthalpies= } & -1790.740520 \\
\text { Sum of electronic and thermal Free Energies }= & -1790.857472\end{array}$ & $\begin{array}{l}\text { Fe } \\
\text { C } \\
\text { C } \\
\text { C } \\
\text { C } \\
\text { H } \\
\text { H } \\
\text { C } \\
\text { C } \\
\text { C } \\
\text { H } \\
\text { H } \\
\text { H } \\
\text { C } \\
\text { C } \\
\text { H } \\
\text { H } \\
\text { C } \\
\text { H } \\
\text { C } \\
\text { C } \\
\text { C } \\
\text { H } \\
\text { C } \\
\text { C } \\
\text { H } \\
\text { C } \\
\text { H } \\
\text { H } \\
\text { H } \\
\text { C } \\
\text { H } \\
\text { C } \\
\text { H } \\
\text { C } \\
\text { H } \\
\text { C } \\
\text { H } \\
\text { C } \\
\text { H } \\
\text { C } \\
\text { H } \\
\text { C } \\
\text { H } \\
\text { O } \\
\text { O } \\
\text { N } \\
\text { N } \\
\text { O } \\
\text { H } \\
\text { H } \\
\text { C } \\
\text { N } \\
\text { C } \\
\text { H } \\
\text { H } \\
\text { C } \\
\text { C } \\
\text { C } \\
\text { C } \\
\text { C } \\
\text { H } \\
\text { C } \\
\text { H } \\
\text { C } \\
\text { H } \\
\text { H } \\
\text { H } \\
\text { H } \\
\text { H } \\
\text { H } \\
\text { H } \\
\text { C } \\
\text { H } \\
\text { H } \\
\end{array}$ & 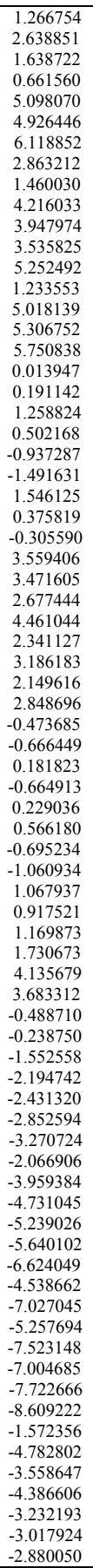 & 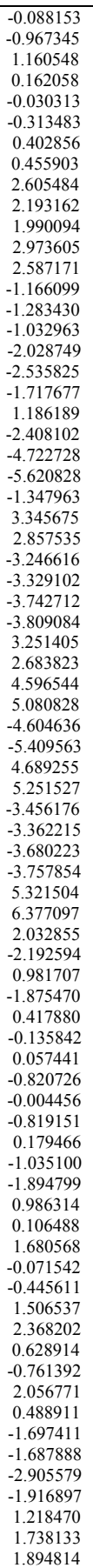 & 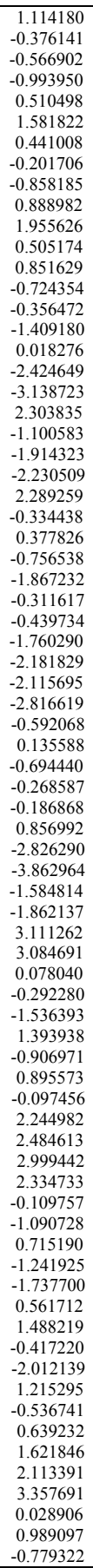 \\
\hline
\end{tabular}


Table S12. 3D view and $x y z$ coordinate data sets and absolute energies in a.u. for DFT optimized complex Fe1-VI.

\begin{tabular}{|c|c|c|c|c|}
\hline $\begin{array}{lc}\text { Zero-point correction }= & 0.594152 \text { (Hartree/Particle) } \\
\text { Thermal correction to Energy= } & 0.634139 \\
\text { Thermal correction to Enthalpy= } & 0.635083 \\
\text { Thermal correction to Gibbs Free Energy= } & 0.517746 \\
\text { Sum of electronic and zero-point Energies }= & -1790.797894 \\
\text { Sum of electronic and thermal Energies }= & -1790.757907 \\
\text { Sum of electronic and thermal Enthalpies }= & -1790.756963 \\
\text { Sum of electronic and thermal Free Energies }= & -1790.874300\end{array}$ & $\begin{array}{l}\mathrm{C} \\
\mathrm{H} \\
\mathrm{C} \\
\mathrm{C} \\
\mathrm{H} \\
\mathrm{C} \\
\mathrm{H} \\
\mathrm{H} \\
\mathrm{H} \\
\mathrm{C} \\
\mathrm{H} \\
\mathrm{C} \\
\mathrm{H} \\
\mathrm{C} \\
\mathrm{H} \\
\mathrm{C} \\
\mathrm{H} \\
\mathrm{C} \\
\mathrm{H} \\
\mathrm{C} \\
\mathrm{H} \\
\mathrm{C} \\
\mathrm{H} \\
\mathrm{O} \\
\mathrm{O} \\
\mathrm{N} \\
\mathrm{N} \\
\mathrm{O}\end{array}$ & 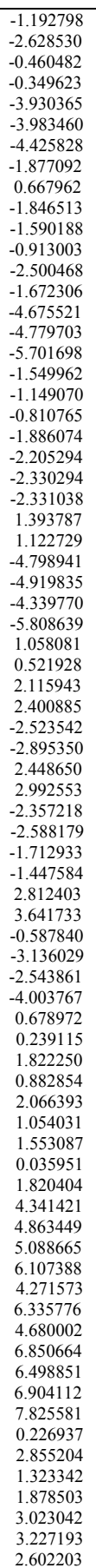 & 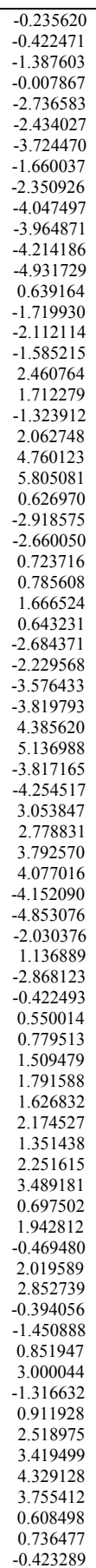 & 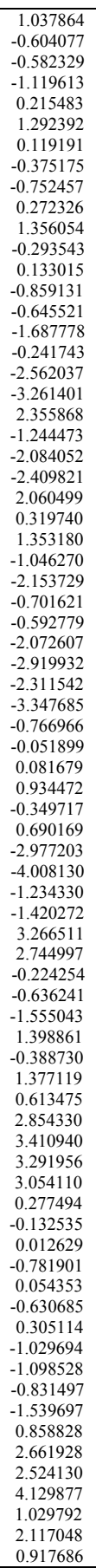 \\
\hline
\end{tabular}


Table S13. 3D view and $x y z$ coordinate data sets and absolute energies in a.u. for DFT optimized complex Fe1-III--H.

\begin{tabular}{|c|c|c|c|c|}
\hline 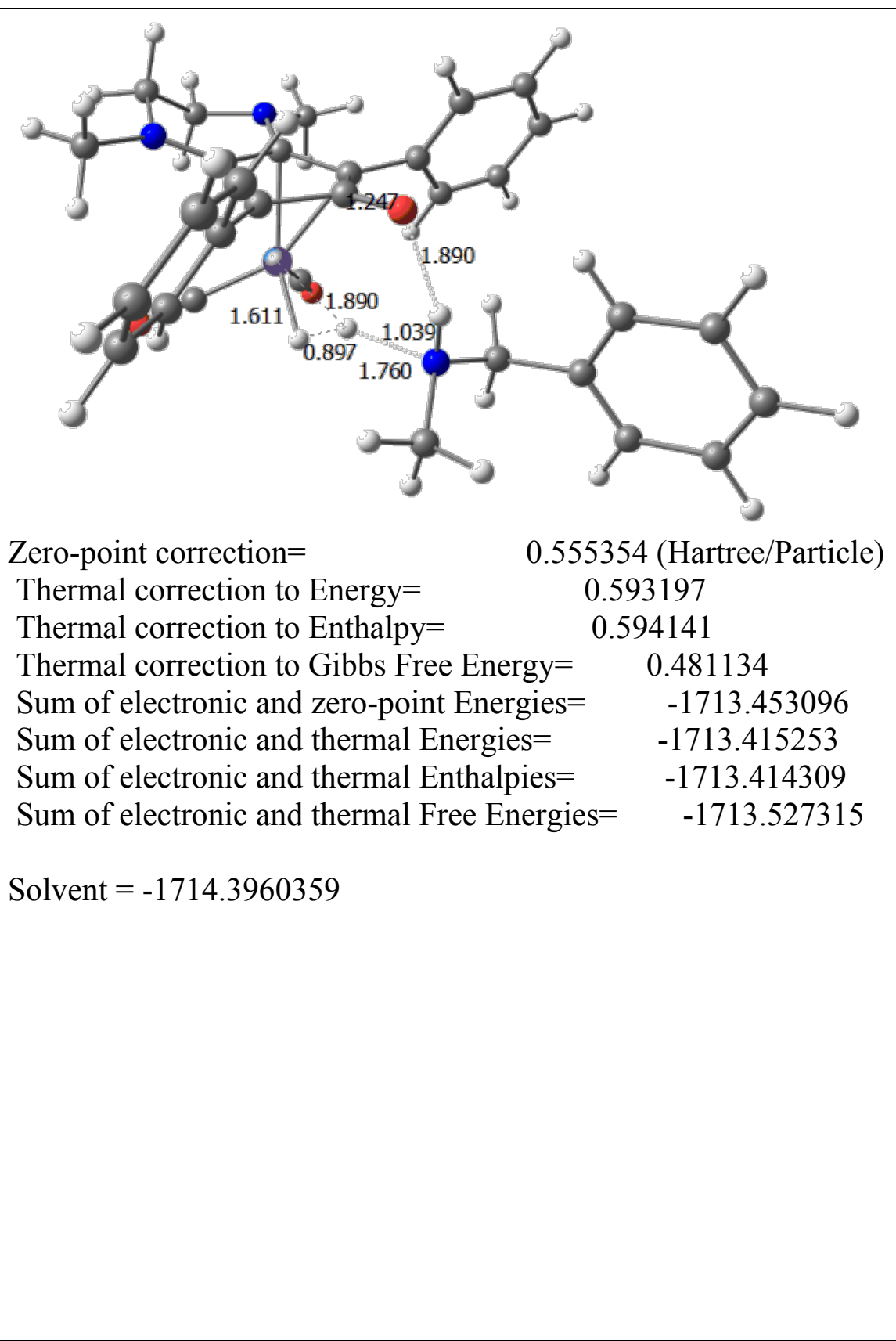 & $\begin{array}{l}H \\
\mathrm{C} \\
\mathrm{C} \\
\mathrm{H} \\
\mathrm{C} \\
\mathrm{H} \\
\mathrm{H} \\
\mathrm{H} \\
\mathrm{C} \\
\mathrm{H} \\
\mathrm{H} \\
\mathrm{H} \\
\mathrm{H} \\
\mathrm{C} \\
\mathrm{H} \\
\mathrm{C} \\
\mathrm{H} \\
\mathrm{C} \\
\mathrm{H} \\
\mathrm{C} \\
\mathrm{H} \\
\mathrm{O} \\
\mathrm{O} \\
\mathrm{N} \\
\mathrm{N} \\
\mathrm{H} \\
\mathrm{H} \\
\mathrm{C} \\
\mathrm{N} \\
\mathrm{C} \\
\mathrm{C} \\
\mathrm{C} \\
\mathrm{C} \\
\mathrm{H} \\
\mathrm{C} \\
\mathrm{H} \\
\mathrm{H} \\
\mathrm{H} \\
\mathrm{H} \\
\mathrm{H} \\
\mathrm{H} \\
\mathrm{H} \\
\mathrm{H} \\
\mathrm{H} \\
\mathrm{H} \\
\mathrm{H} \\
\mathrm{O}\end{array}$ & 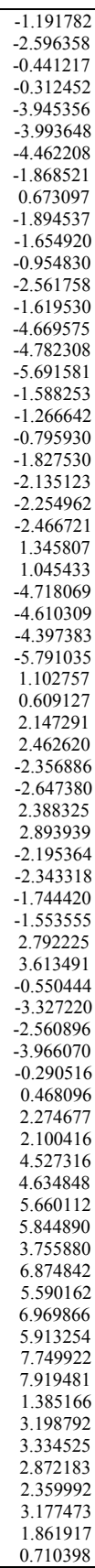 & 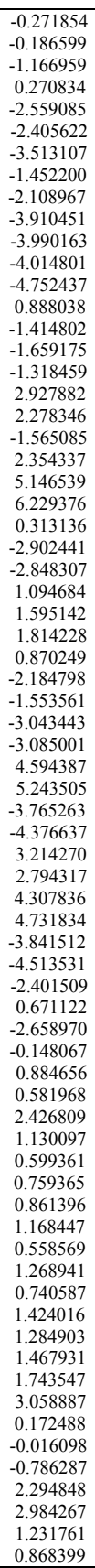 & 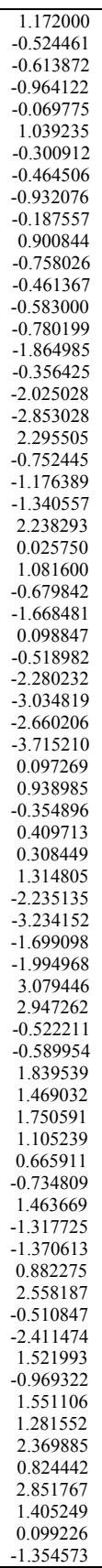 \\
\hline
\end{tabular}


Table S14. 3D view and $x y z$ coordinate data sets and absolute energies in a.u. for DFT optimized complex Fe1-III (without $\mathrm{H}^{+}$).

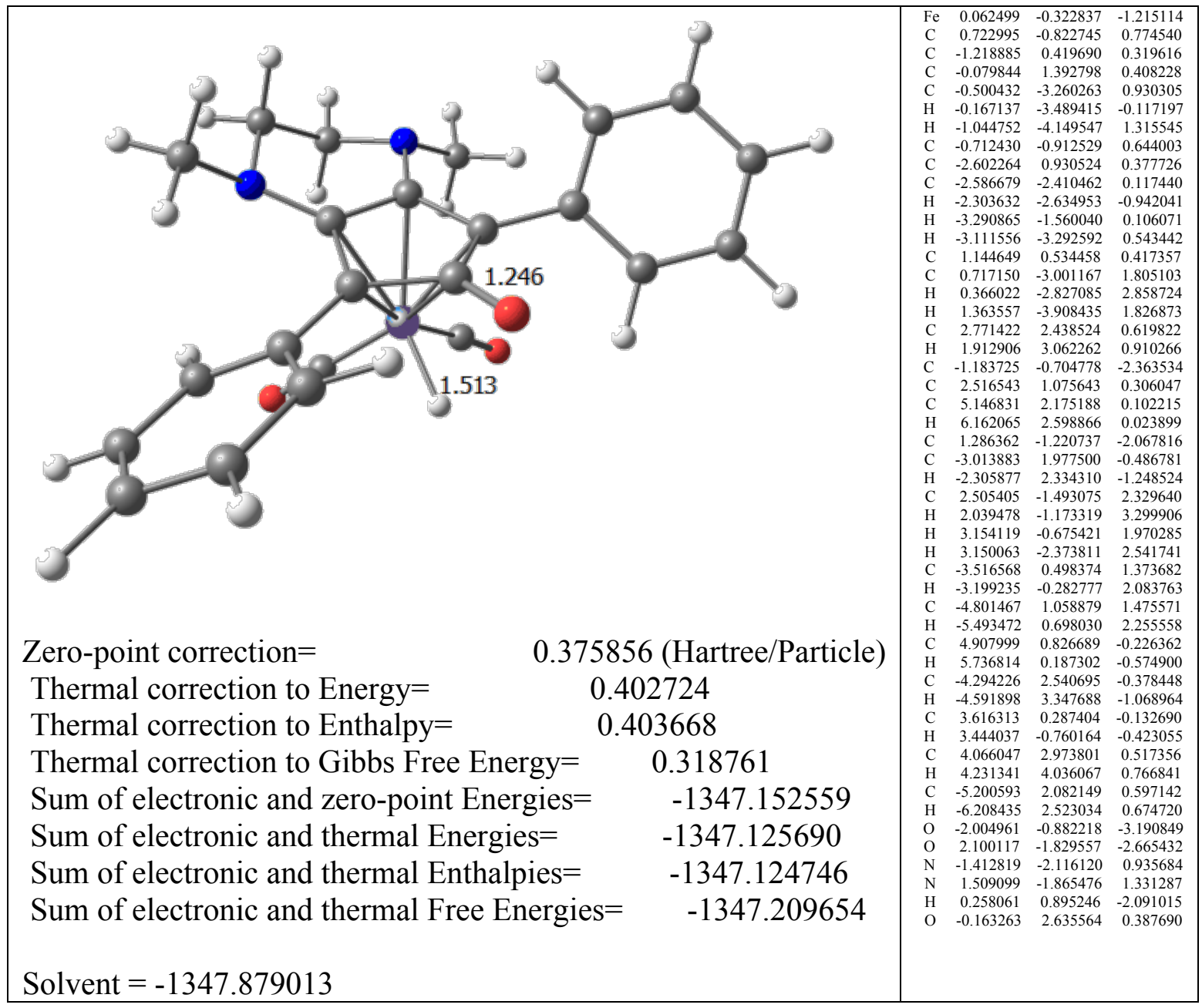


Table S15. 3D view and $x y z$ coordinate data sets and absolute energies in a.u. for DFT optimized complex Fe3-I $\left(\mathrm{BF}_{4}\right)$.

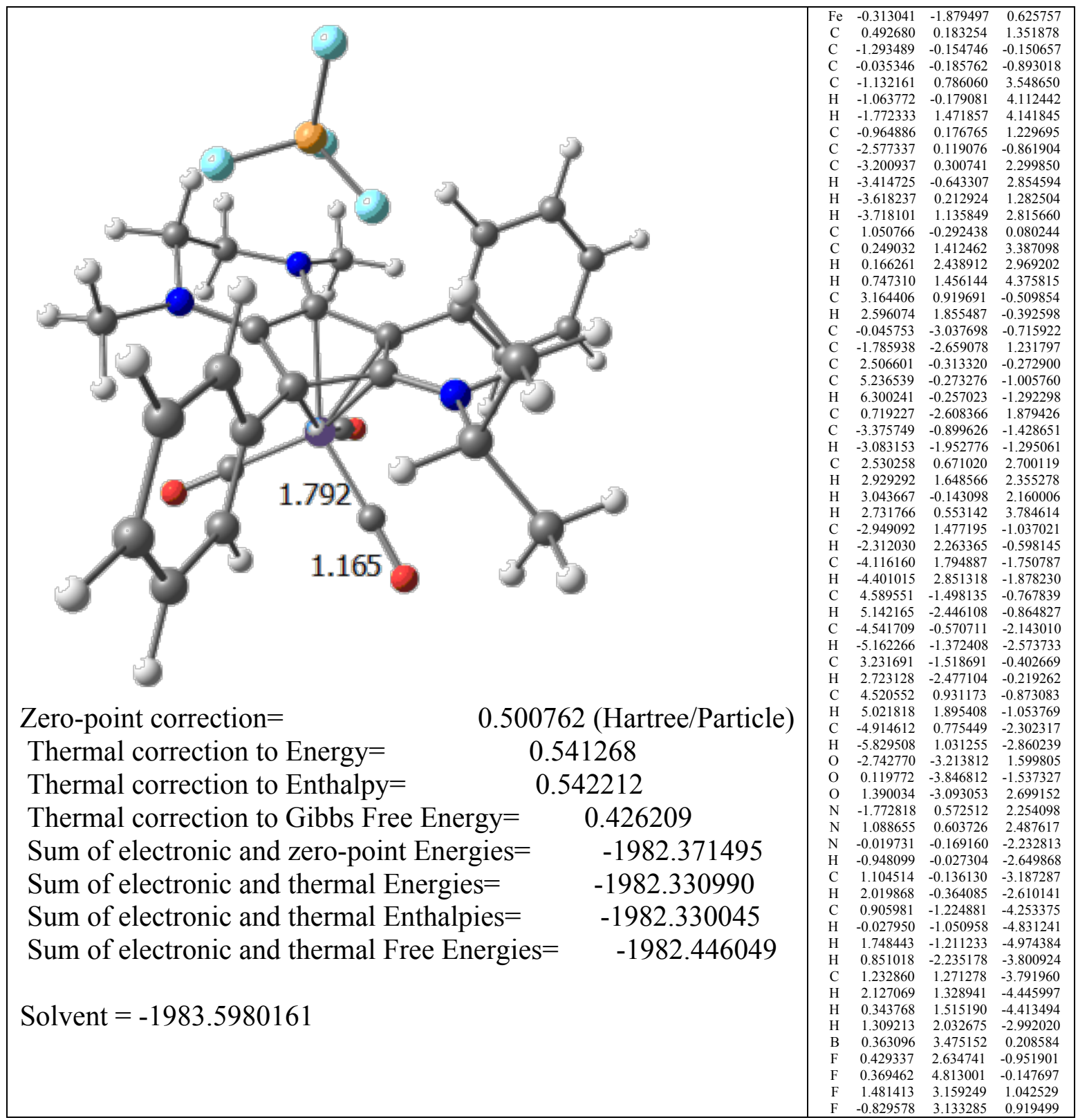


Table S16. 3D view and $x y z$ coordinate data sets and absolute energies in a.u. for DFT optimized complex Fe3-I-II $\left(\mathrm{BF}_{4}\right)$.

\begin{tabular}{|c|c|c|c|c|}
\hline $\begin{array}{lc} & 0.622618 \text { (Hartree/Particle) } \\
\text { Zero-point correction= } & 0.670045 \\
\text { Thermal correction to Energy= } & 0.670989 \\
\text { Thermal correction to Enthalpy= } & 0.539822 \\
\text { Thermal correction to Gibbs Free Energy= } & -2231.676462 \\
\text { Sum of electronic and zero-point Energies }= & -2231.629035 \\
\text { Sum of electronic and thermal Energies }= & -2231.628090 \\
\text { Sum of electronic and thermal Enthalpies }= & -2231.759258 \\
\text { Sum of electronic and thermal Free Energies }= & \\
& \\
\text { Solvent }=-2233.1390707 & \end{array}$ & $\begin{array}{l}\mathrm{C} \\
\mathrm{C} \\
\mathrm{C} \\
\mathrm{H} \\
\mathrm{C} \\
\mathrm{C} \\
\mathrm{H} \\
\mathrm{H} \\
\mathrm{H} \\
\mathrm{C} \\
\mathrm{C} \\
\mathrm{H} \\
\mathrm{H} \\
\mathrm{T}\end{array}$ & 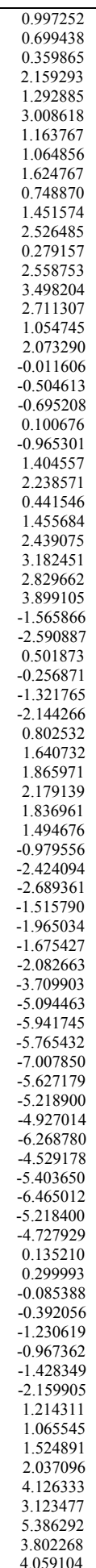 & 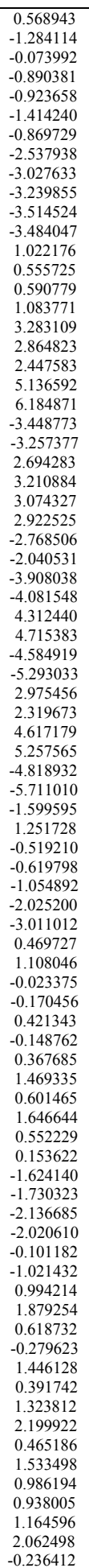 & 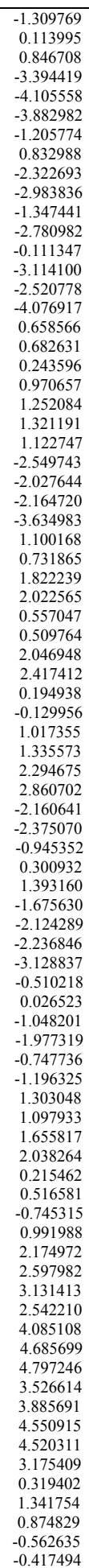 \\
\hline
\end{tabular}


Table S17. $\quad 3 \mathrm{D}$ view and $x y z$ coordinate data sets and absolute energies in a.u. for DFT optimized complex Fe3-II $\left(\mathrm{BF}_{4}\right)$.

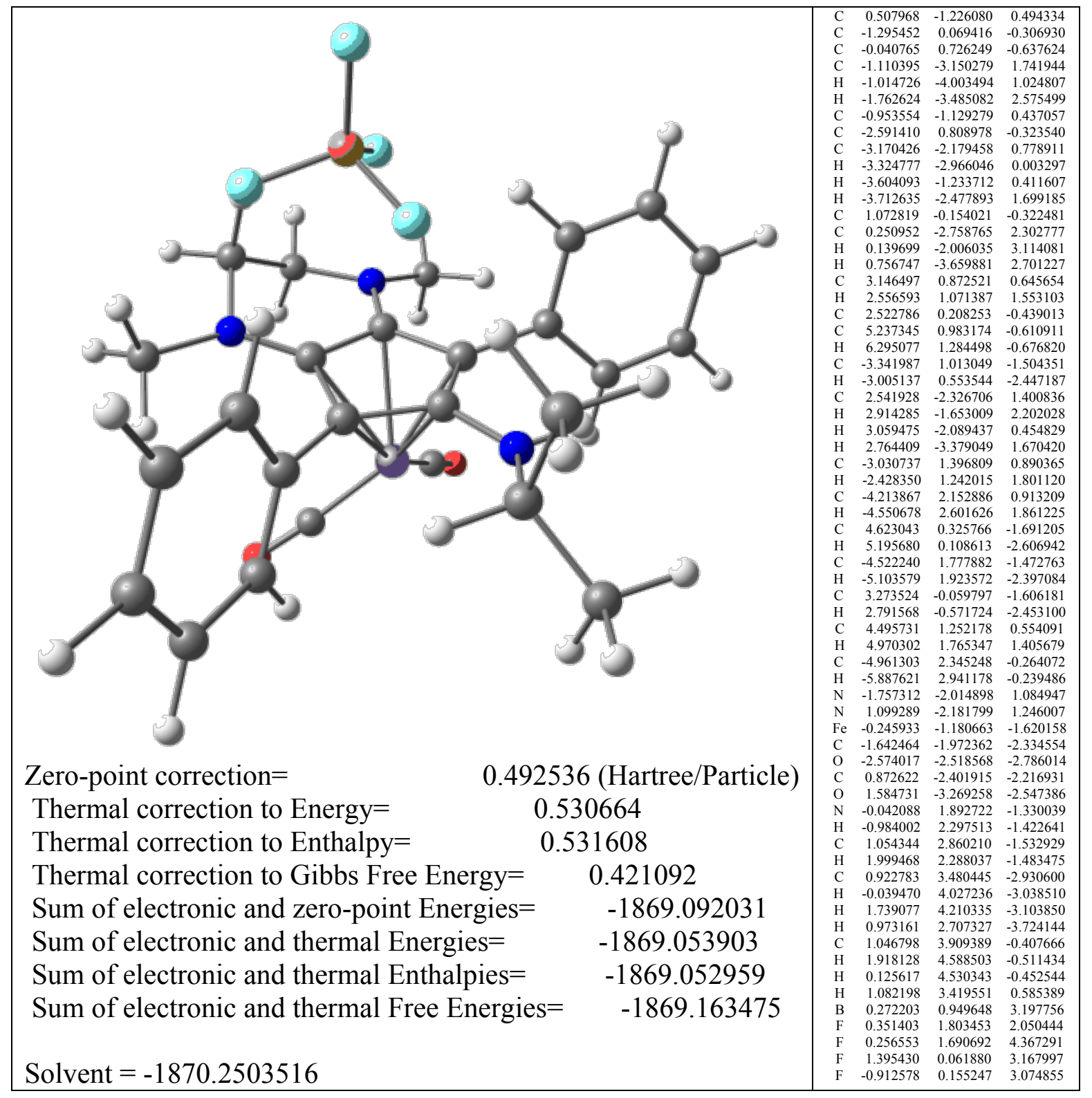


Table S18. 3D view and $x y z$ coordinate data sets and absolute energies in a.u. for DFT optimized complex Fe3-II-III $\left(\mathrm{BF}_{4}\right)$.

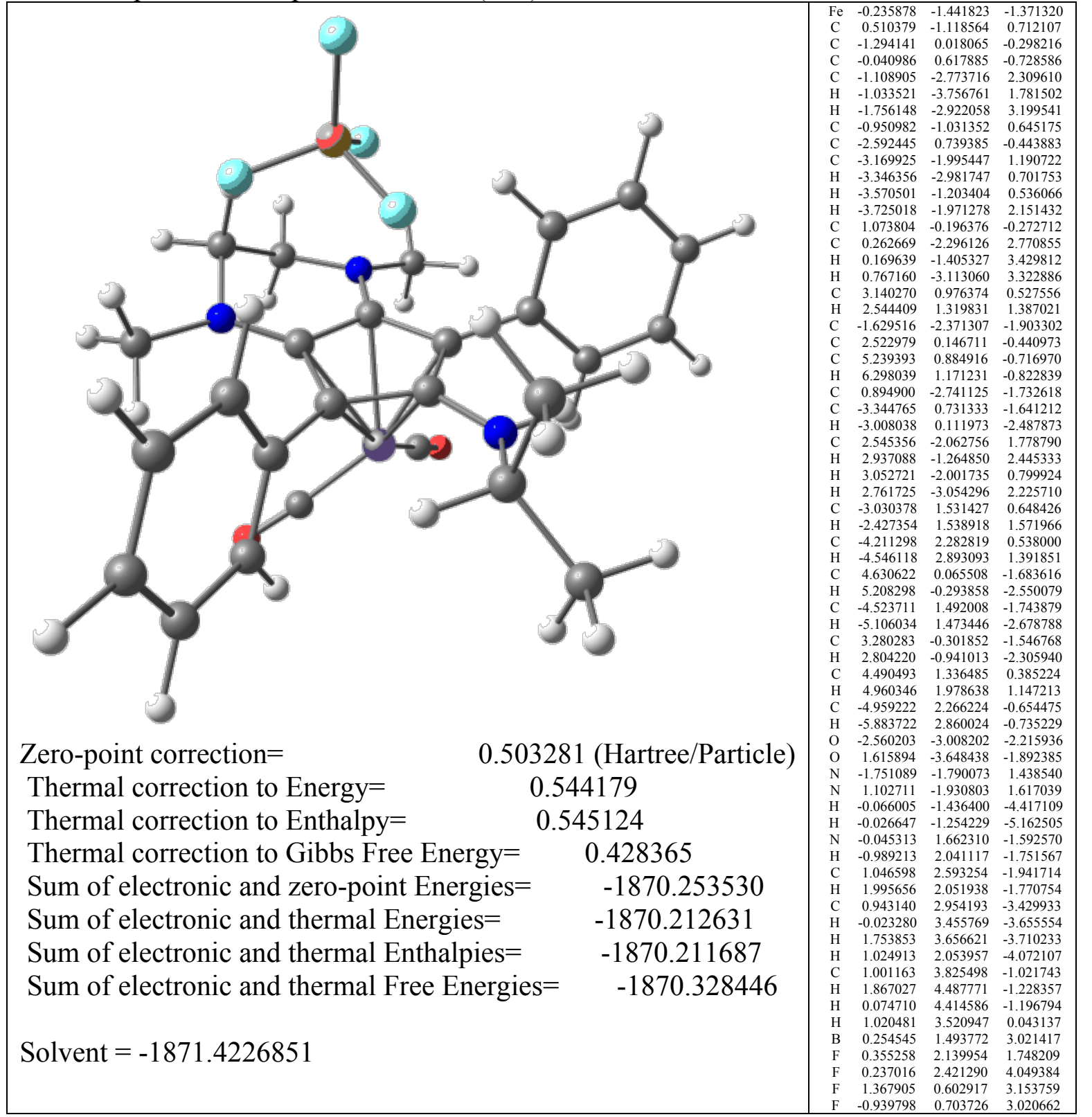


Table S19. $\quad 3 \mathrm{D}$ view and $x y z$ coordinate data sets and absolute energies in a.u. for DFT optimized complex Fe3-III $\left(\mathrm{BF}_{4}\right)$.

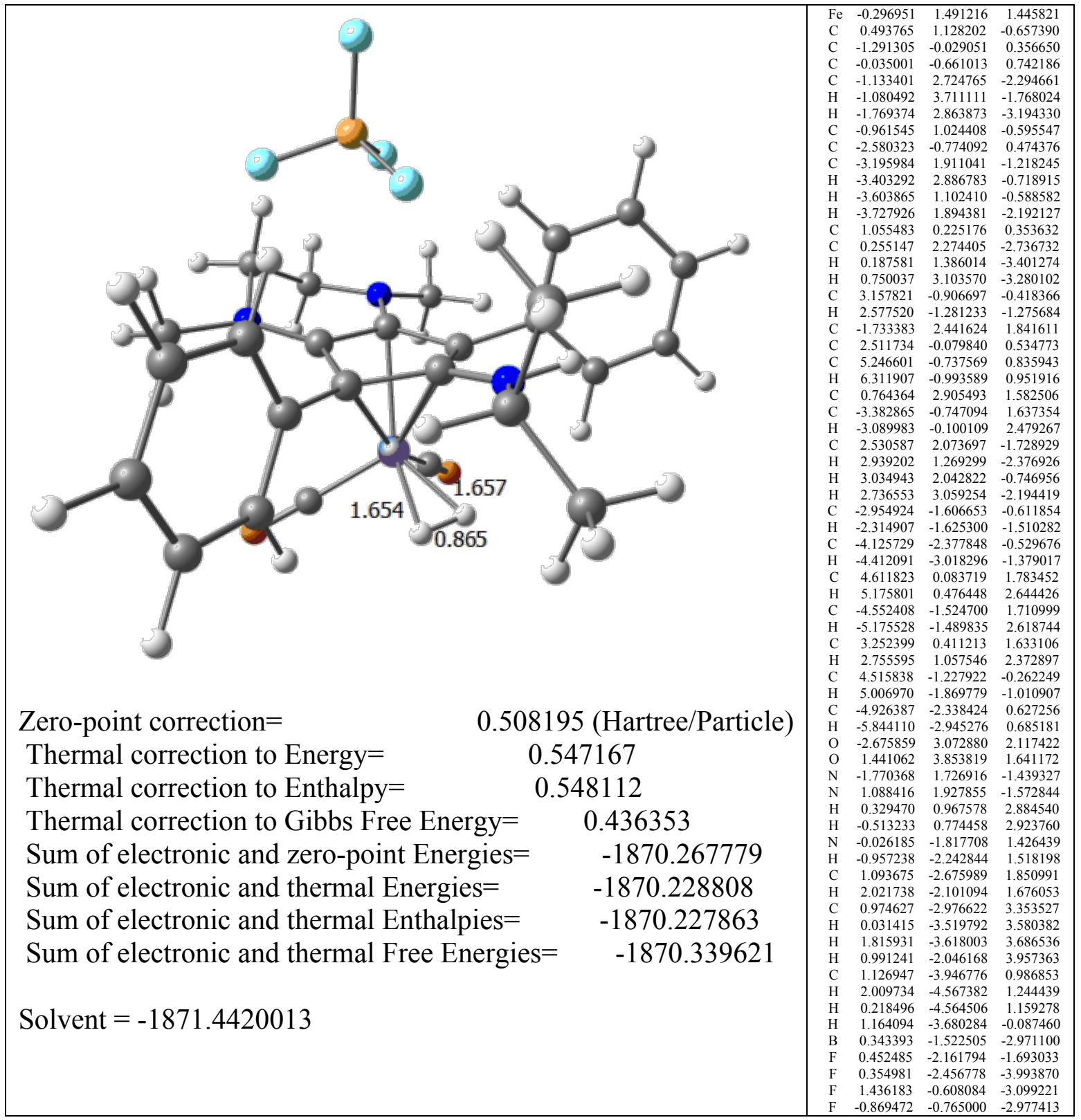


Table S20.3D view and $x y z$ coordinate data sets and absolute energies in a.u. for DFT optimized complex Fe3-III-IV $\left(\mathrm{BF}_{4}\right)$.

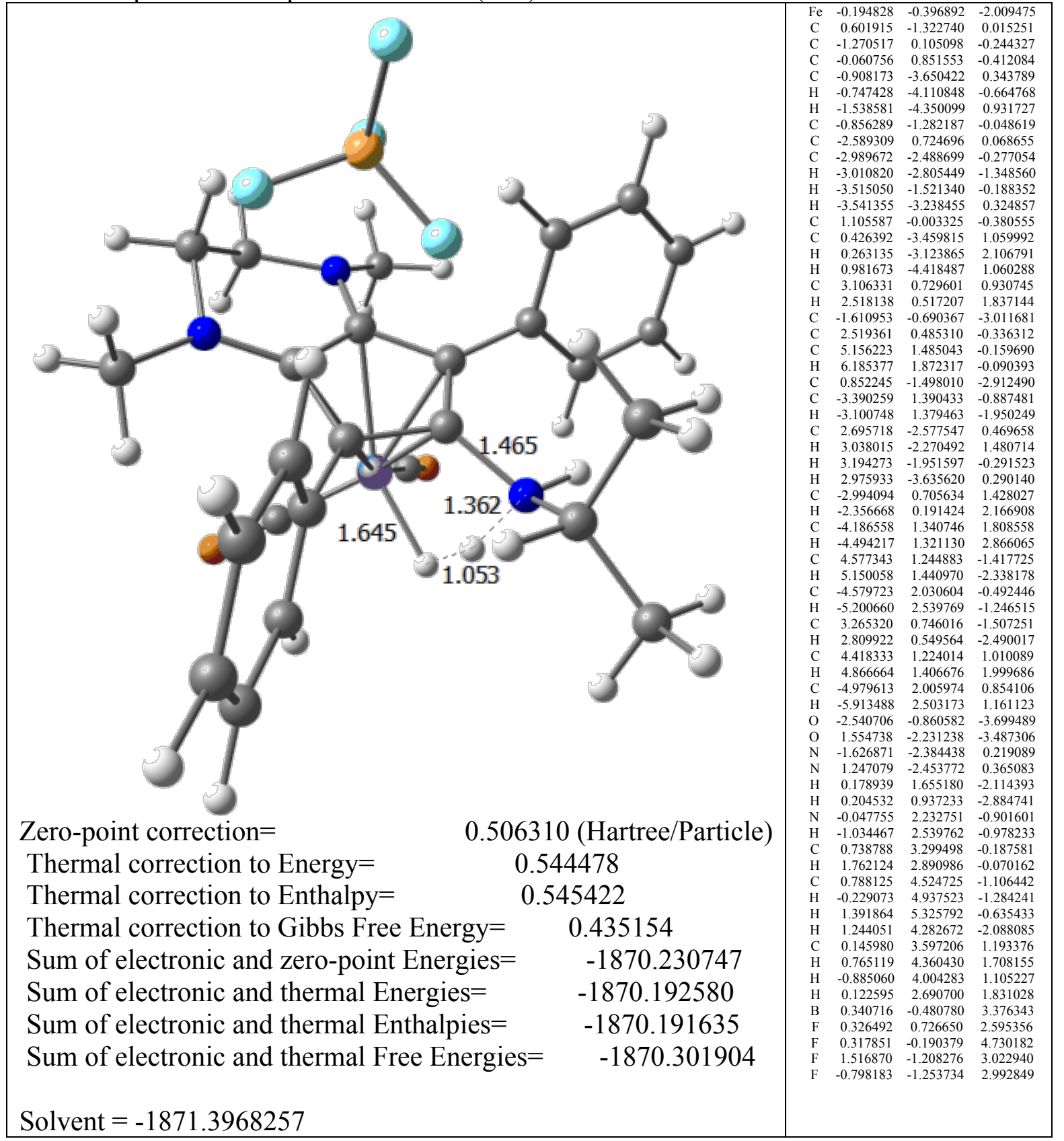


Table S21. 3D view and $x y z$ coordinate data sets and absolute energies in a.u. for DFT optimized complex Fe3-III-IV+EtOH $\left(\mathrm{BF}_{4}\right)$.

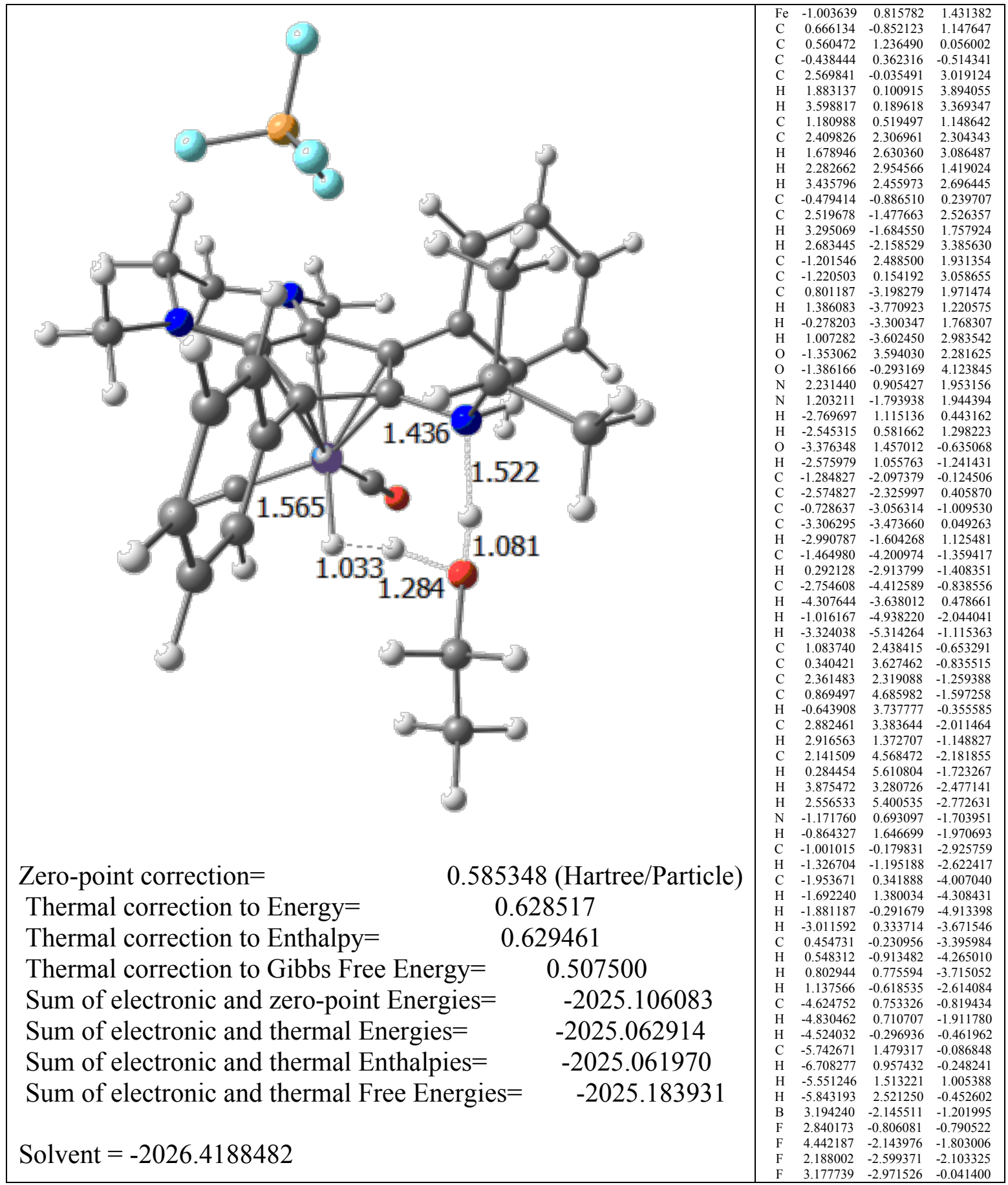


Table S22. 3D view and $x y z$ coordinate data sets and absolute energies in a.u. for DFT optimized complex Fe3-IV $\left(\mathrm{BF}_{4}\right)$.

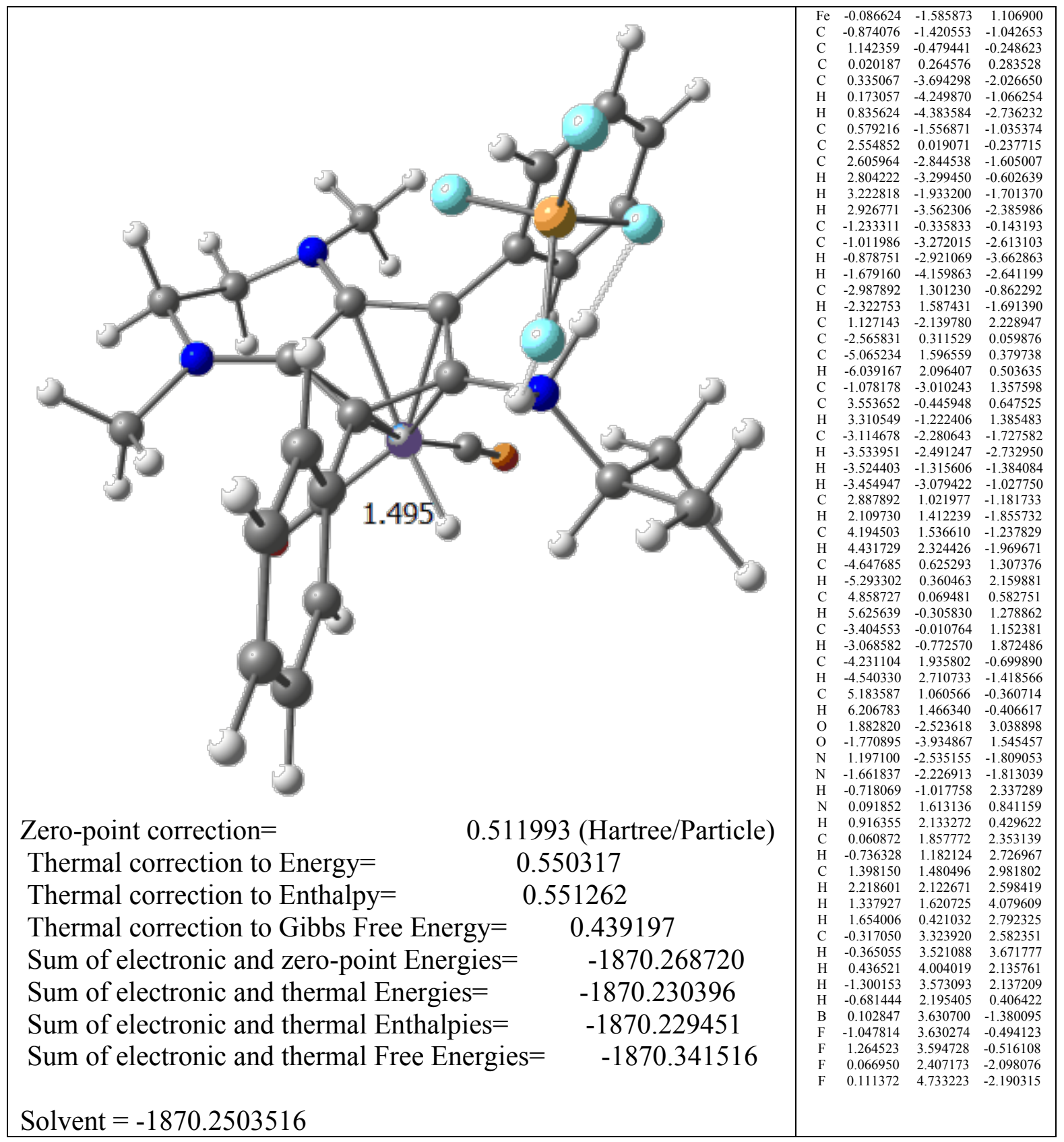


Table S23. 3D view and $x y z$ coordinate data sets and absolute energies in a.u. for DFT optimized complex Fe3-III--H $\left(\mathrm{BF}_{4}\right)$.

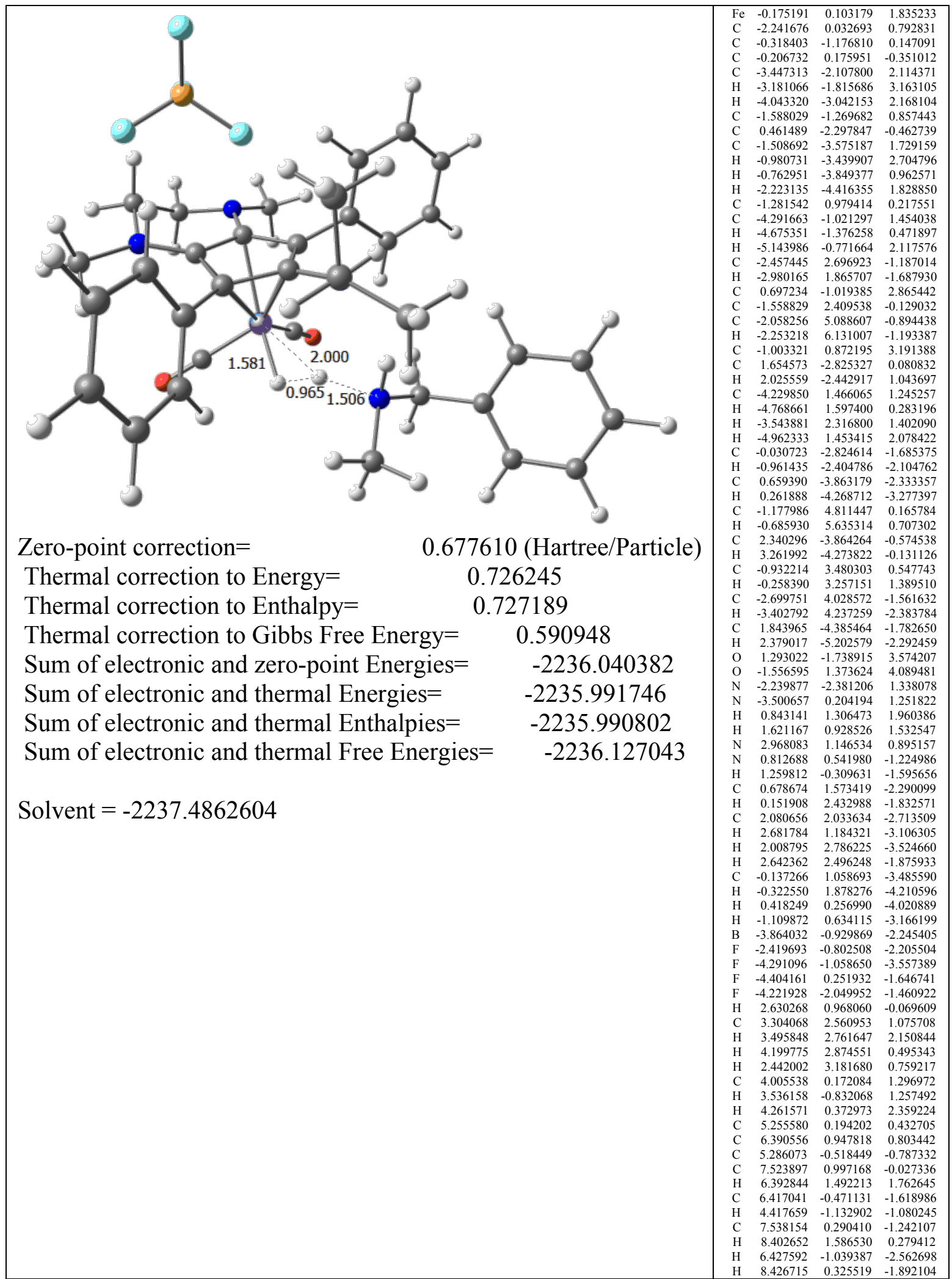


Table S24. 3D view and $x y z$ coordinate data sets and absolute energies in a.u. for DFT optimized complex Fe3-III (without $\left.\mathrm{H}^{+}\right)\left(\mathrm{BF}_{4}\right)$.

\begin{tabular}{|c|c|c|c|}
\hline $\begin{array}{lc}\text { Zero-point correction }= & 0.497258 \text { (Hartree/Particle) } \\
\text { Thermal correction to Energy= } & 0.535692 \\
\text { Thermal correction to Enthalpy= } & 0.536636 \\
\text { Thermal correction to Gibbs Free Energy= } & 0.424477 \\
\text { Sum of electronic and zero-point Energies }= & -1869.773895 \\
\text { Sum of electronic and thermal Energies }= & -1869.735461 \\
\text { Sum of electronic and thermal Enthalpies }= & -1869.734517 \\
\text { Sum of electronic and thermal Free Energies }= & -1869.846676 \\
& \\
\text { Solvent }=-1870.9897227 & \end{array}$ & 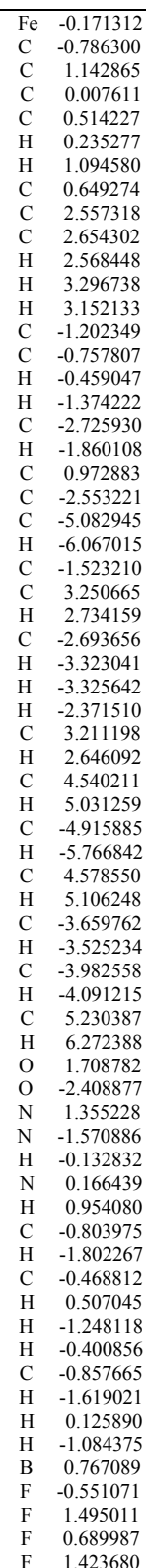 & 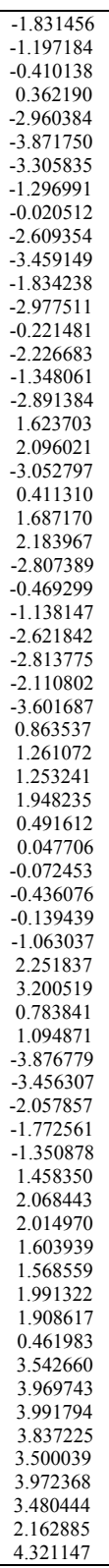 & 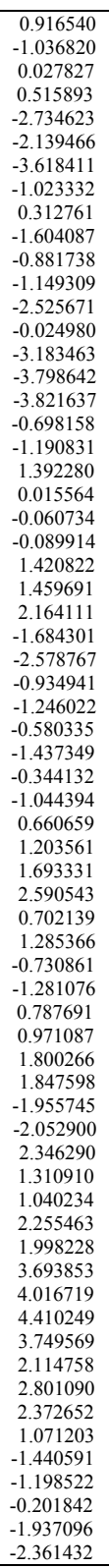 \\
\hline
\end{tabular}


Table S25. 3D view and $x y z$ coordinate data sets and absolute energies in a.u. for DFT optimized complex Fe3-V $\left(\mathrm{BF}_{4}\right)$.

\begin{tabular}{|c|c|c|c|c|}
\hline $\begin{array}{lc}\text { Zero-point correction }= & 0.714021 \text { (Hartree/Particle) } \\
\text { Thermal correction to Energy= } & 0.764950 \\
\text { Thermal correction to Enthalpy= } & 0.765894 \\
\text { Thermal correction to Gibbs Free Energy= } & 0.622770 \\
\text { Sum of electronic and zero-point Energies }= & -2313.361482 \\
\text { Sum of electronic and thermal Energies }= & -2313.310553 \\
\text { Sum of electronic and thermal Enthalpies }= & -2313.309609 \\
\text { Sum of electronic and thermal Free Energies }= & -2313.452733 \\
& \\
\text { Solvent }=-2314.8721606 & \end{array}$ & $\begin{array}{l}\text { Fe } \\
\text { C } \\
\text { C } \\
\text { C } \\
\text { H } \\
\text { C } \\
\text { C } \\
\text { C } \\
\text { H } \\
\text { H } \\
\text { C } \\
\text { C } \\
\text { H } \\
\text { H } \\
\text { C } \\
\text { C } \\
\text { C } \\
\text { C } \\
\text { C } \\
\text { C } \\
\text { H } \\
\text { C } \\
\text { H } \\
\text { H } \\
\text { H } \\
\text { C } \\
\text { C } \\
\text { H } \\
\text { C } \\
\text { H } \\
\text { C } \\
\text { C } \\
\text { H } \\
\text { C } \\
\text { H } \\
\text { C } \\
\text { O } \\
\text { O } \\
\text { N } \\
\text { N } \\
\text { H } \\
\text { C } \\
\text { C } \\
\text { H } \\
\text { H } \\
\text { C } \\
\text { C } \\
\text { C } \\
\text { C } \\
\text { C } \\
\text { H } \\
\text { C } \\
\text { H } \\
\text { H } \\
\text { H } \\
\text { H } \\
\text { H } \\
\text { C } \\
\text { H } \\
\text { H } \\
\text { N } \\
\text { H } \\
\text { H } \\
\text { C } \\
\text { H } \\
\text { H } \\
\text { H } \\
\text { H } \\
\text { H } \\
\text { H } \\
\text { B } \\
\text { F } \\
\text { F } \\
\text { F } \\
\text { H } \\
\end{array}$ & 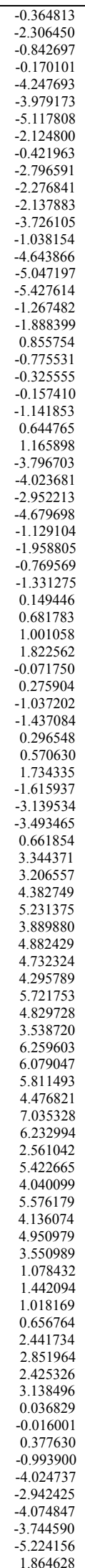 & 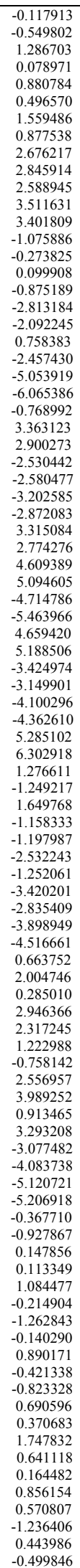 & 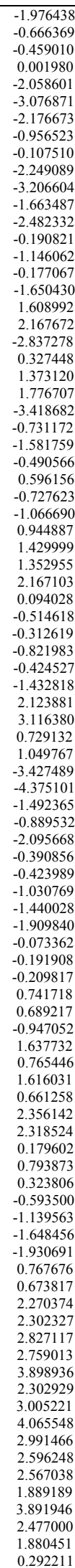 \\
\hline
\end{tabular}


Table S26. 3D view and $x y z$ coordinate data sets and absolute energies in a.u. for DFT optimized complex Fe3-III (without $\left.\mathrm{H}^{+}\right)--$VI $\left(\mathrm{BF}_{4}\right)$.

\begin{tabular}{|c|c|c|c|c|}
\hline $\begin{array}{lc}\text { Zero-point correction }= & 0.712010 \text { (Hartree/Particle) } \\
\text { Thermal correction to Energy }= & 0.762072 \\
\text { Thermal correction to Enthalpy }= & 0.763016 \\
\text { Thermal correction to Gibbs Free Energy= } & 0.623382 \\
\text { Sum of electronic and zero-point Energies= } & -2313.357052 \\
\text { Sum of electronic and thermal Energies }= & -2313.306990 \\
\text { Sum of electronic and thermal Enthalpies= } & -2313.306046 \\
\text { Sum of electronic and thermal Free Energies }= & -2313.445681 \\
& \\
\text { Solvent }=-2314.8657051 & \end{array}$ & $\begin{array}{l}\text { Fe } \\
\text { C } \\
\text { C } \\
\text { C } \\
\text { C } \\
\text { H } \\
\text { H } \\
\text { C } \\
\text { C } \\
\text { C } \\
\text { H } \\
\text { H } \\
\text { H } \\
\text { C } \\
\text { C } \\
\text { H } \\
\text { H } \\
\text { C } \\
\text { H } \\
\text { C } \\
\text { C } \\
\text { C } \\
\text { H } \\
\text { C } \\
\text { C } \\
\text { H } \\
\text { C } \\
\text { H } \\
\text { H } \\
\text { H } \\
\text { C } \\
\text { H } \\
\text { C } \\
\text { H } \\
\text { C } \\
\text { H } \\
\text { C } \\
\text { H } \\
\text { C } \\
\text { H } \\
\text { C } \\
\text { H } \\
\text { C } \\
\text { H } \\
\text { O } \\
\text { O } \\
\text { N } \\
\text { N } \\
\text { H } \\
\text { H } \\
\text { C } \\
\text { N } \\
\text { C } \\
\text { H } \\
\text { H } \\
\text { C } \\
\text { C } \\
\text { C } \\
\text { C } \\
\text { C } \\
\text { H } \\
\text { C } \\
\text { H } \\
\text { C } \\
\text { H } \\
\text { H } \\
\text { H } \\
\text { H } \\
\text { H } \\
\text { H } \\
\text { H } \\
\text { C } \\
\text { H } \\
\text { H } \\
\text { N } \\
\text { H } \\
\text { C } \\
\text { H } \\
\text { C } \\
\text { H } \\
\text { H } \\
\text { H } \\
\text { C } \\
\text { H } \\
\text { H } \\
\text { H } \\
\text { B } \\
\text { F } \\
\text { F } \\
\text { F } \\
\text { F } \\
\end{array}$ & 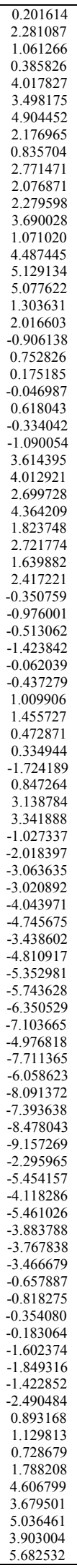 & 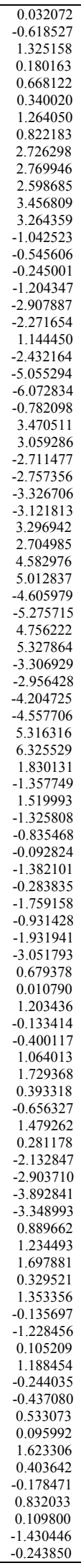 & 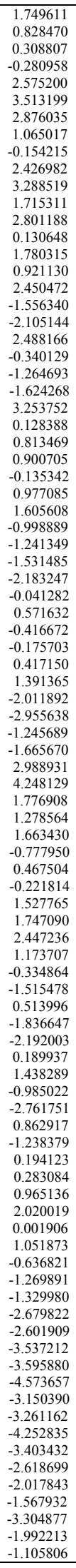 \\
\hline
\end{tabular}


Table S27. 3D view and $x y z$ coordinate data sets and absolute energies in a.u. for DFT optimized complex Fe3-VI $\left(\mathrm{BF}_{4}\right)$.

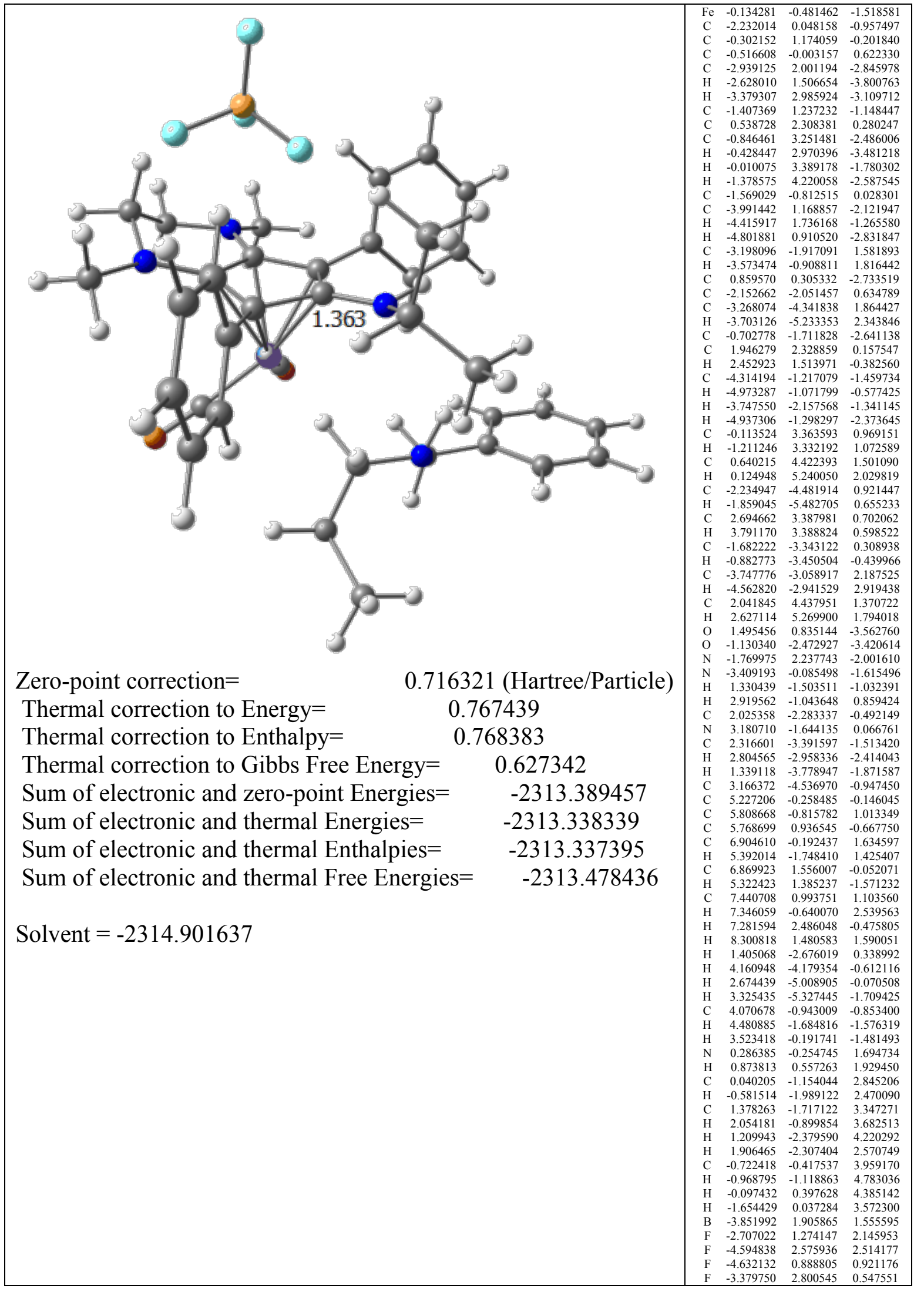


Table S28. 3D view and $x y z$ coordinate data sets and absolute energies in a.u. for DFT optimized complex Fe3-II-III $\left(\mathrm{BF}_{4}\right)^{\prime}$.

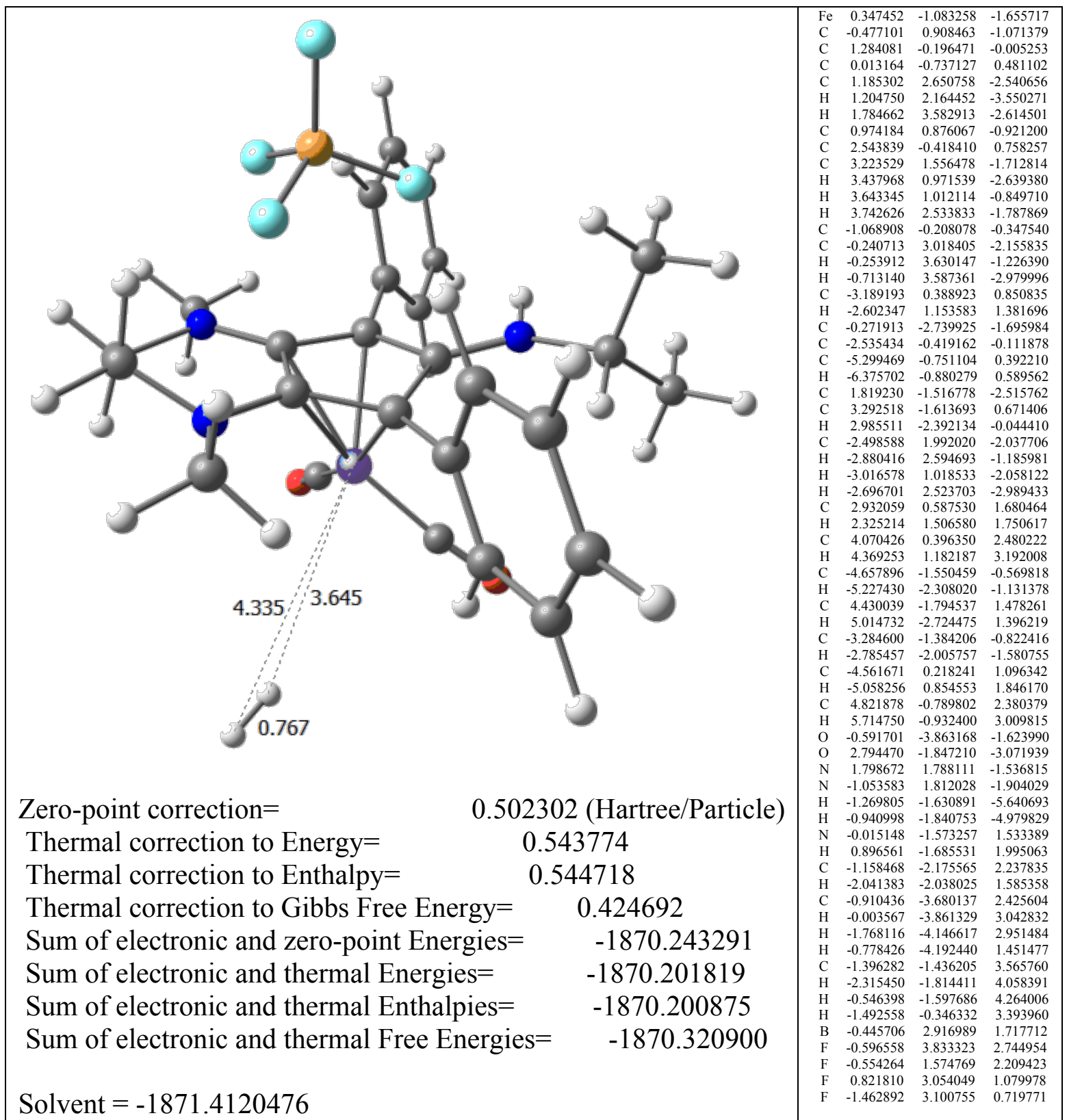


Table S29. 3D view and $x y z$ coordinate data sets and absolute energies in a.u. for DFT optimized complex Fe3-III $\left(\mathrm{BF}_{4}\right)$ '.

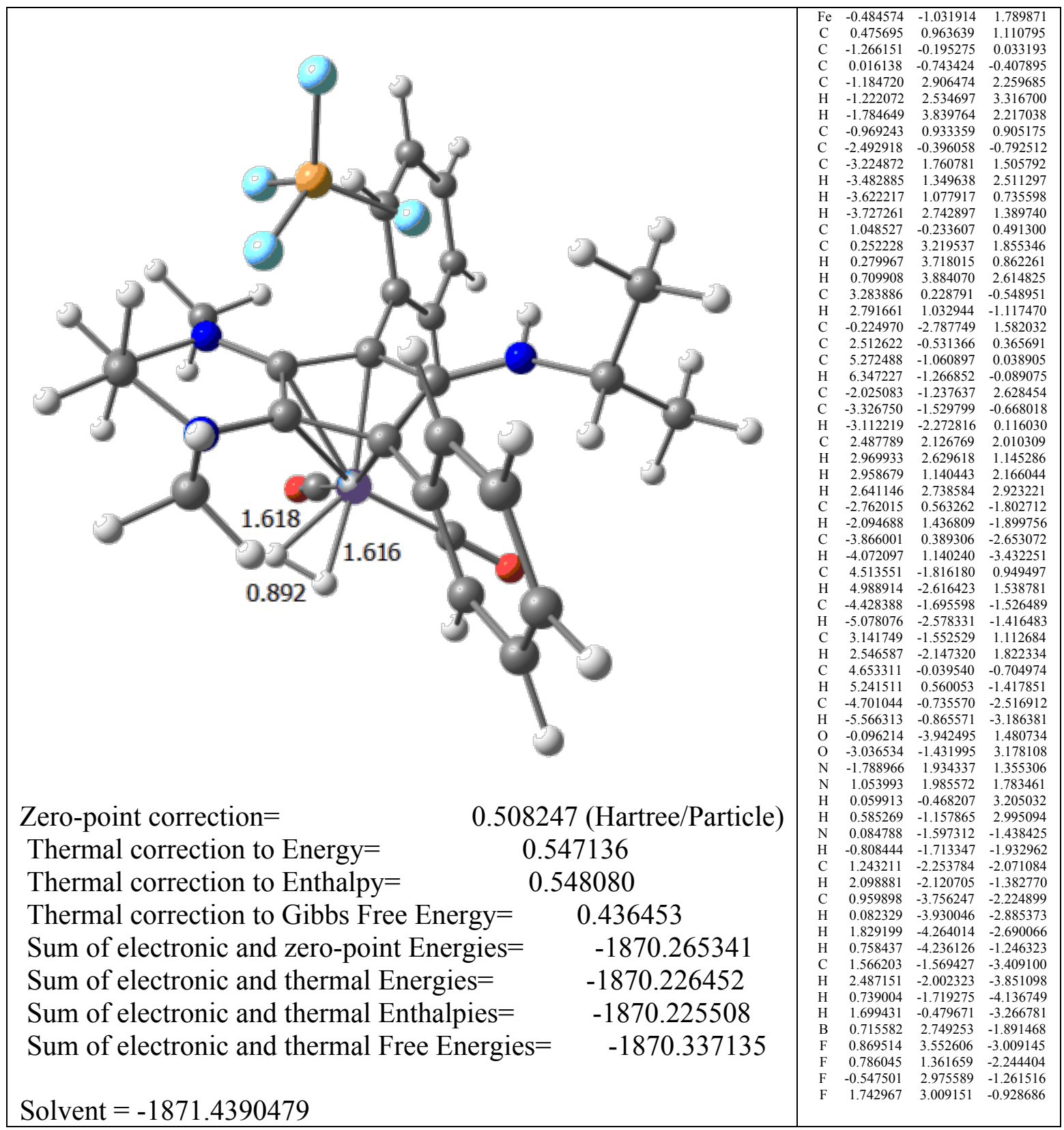


Table S30. 3D view and $x y z$ coordinate data sets and absolute energies in a.u. for DFT optimized complex Fe3-III-IV $\left(\mathrm{BF}_{4}\right)^{\prime}$.

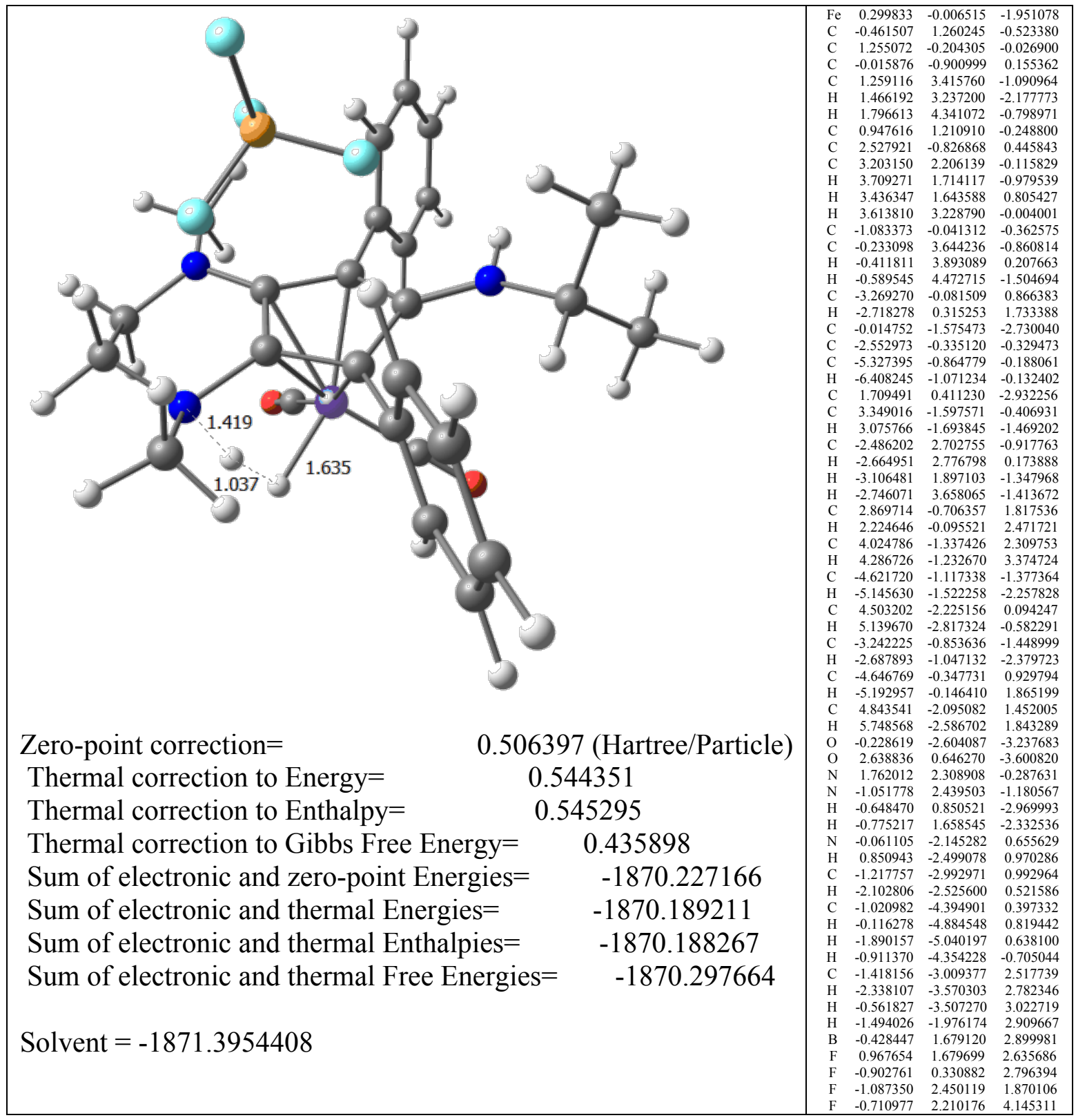


Table S31. 3D view and $x y z$ coordinate data sets and absolute energies in a.u. for DFT optimized complex Fe3-III-IV+1EtOH $\left(\mathrm{BF}_{4}\right)$ '.

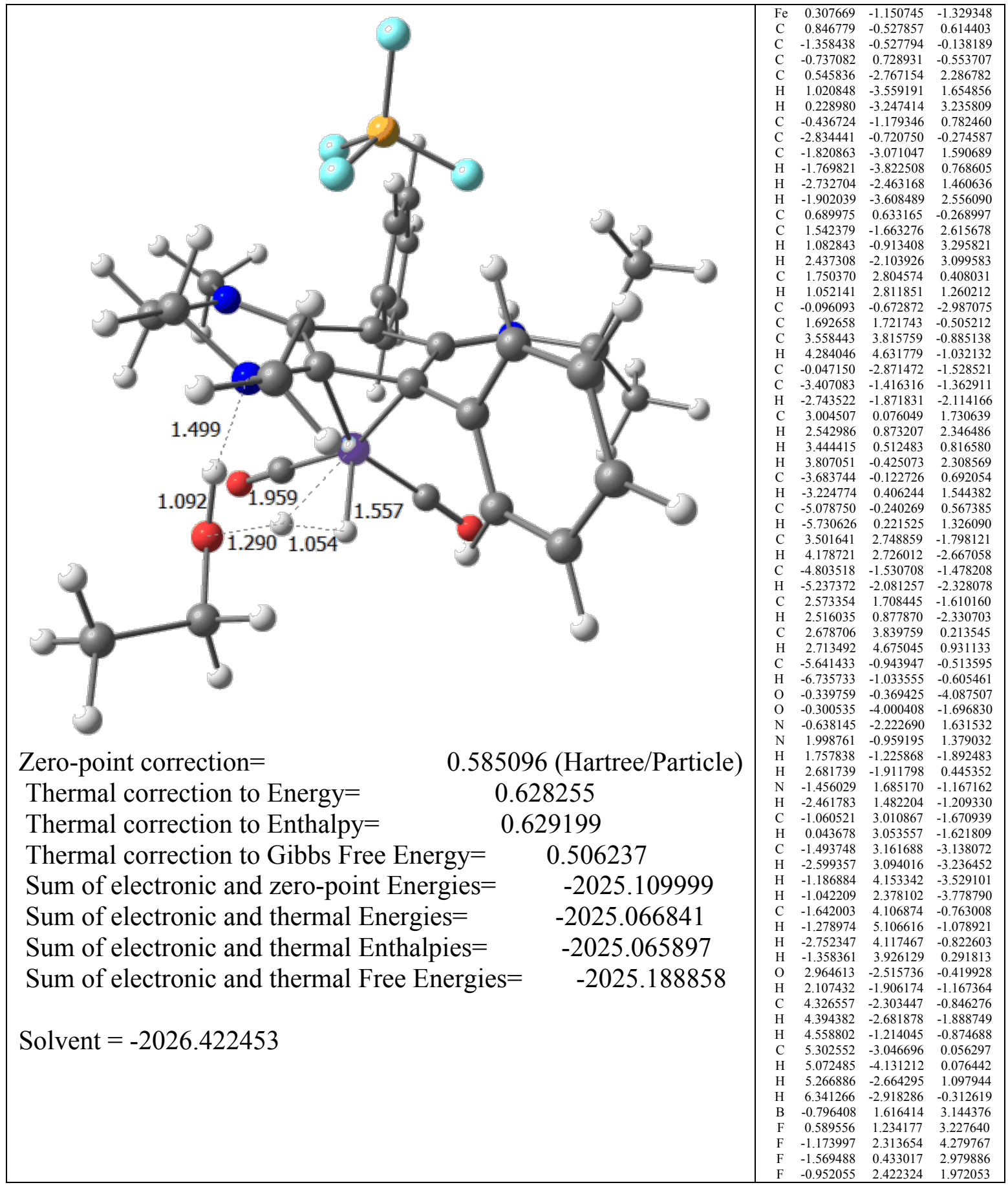


Table S32. $\quad 3 \mathrm{D}$ view and $x y z$ coordinate data sets and absolute energies in a.u. for DFT optimized complex Fe3-IV $\left(\mathrm{BF}_{4}\right)$ '.

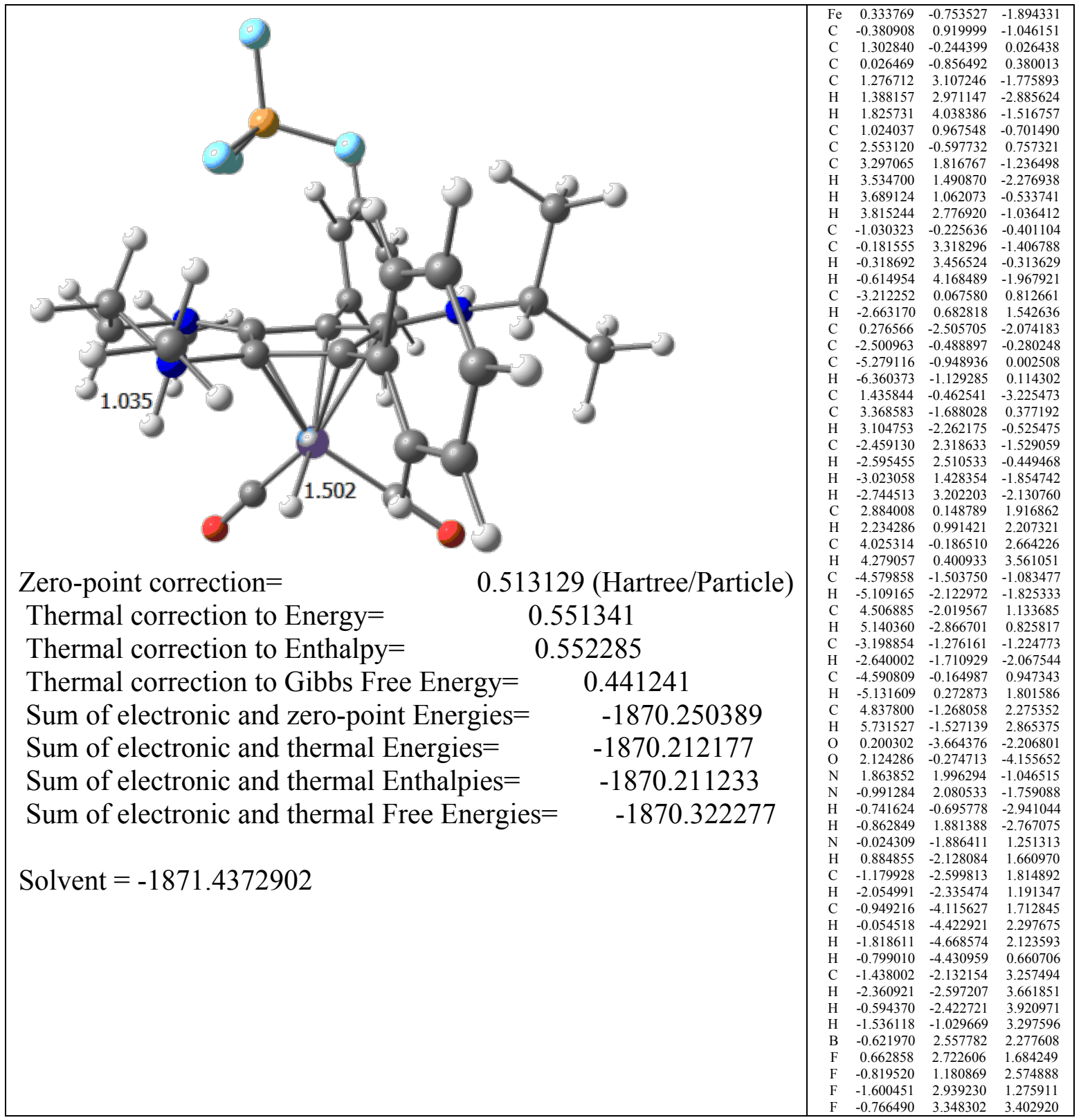


Table S33. 3D view and $x y z$ coordinate data sets and absolute energies in a.u. for DFT optimized complex Fe3-V $\left(\mathrm{BF}_{4}\right)$ '.

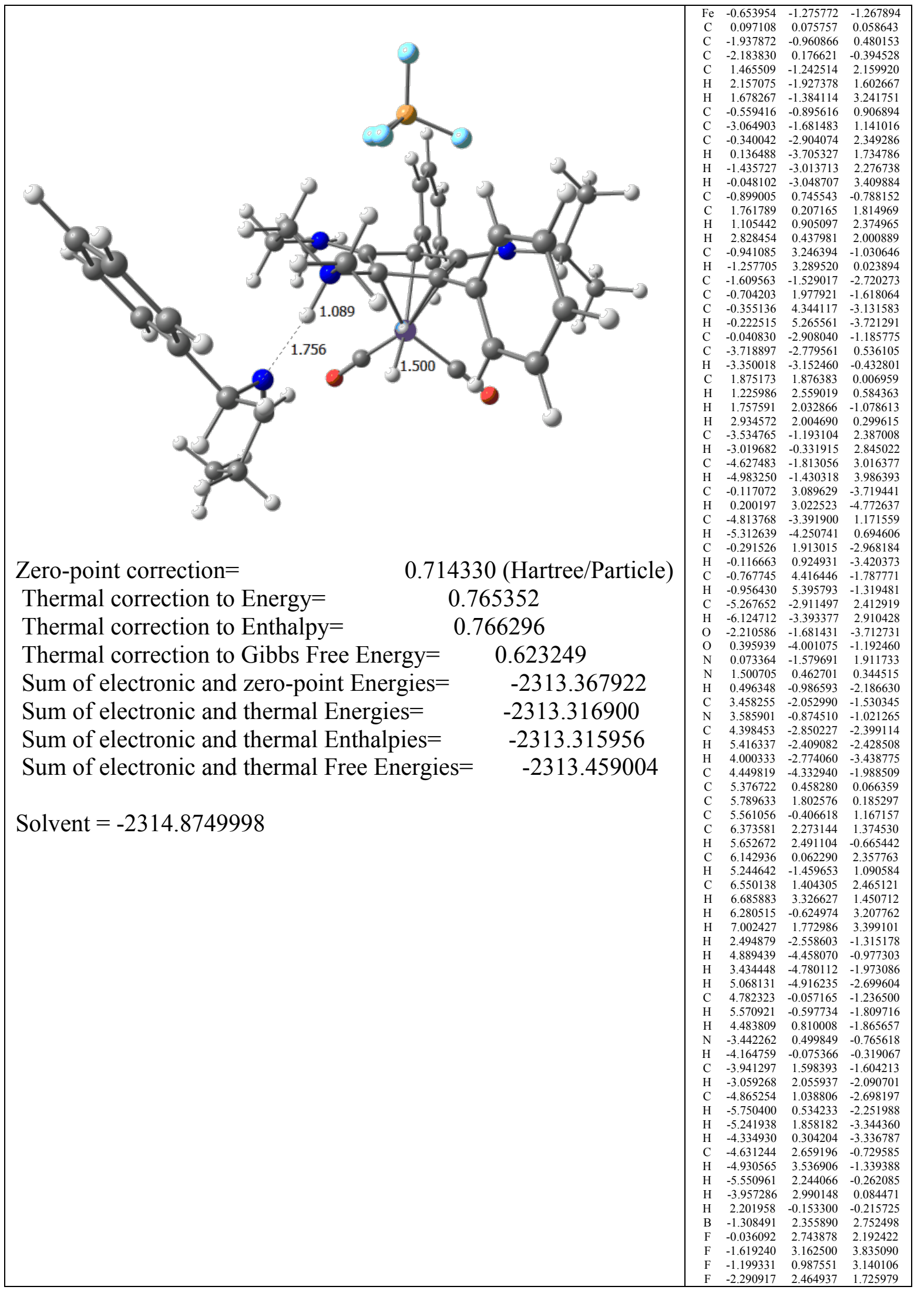


Table S34. 3D view and $x y z$ coordinate data sets and absolute energies in a.u. for DFT optimized complex Fe3-V-VI $\left(\mathrm{BF}_{4}\right)^{\prime}$.

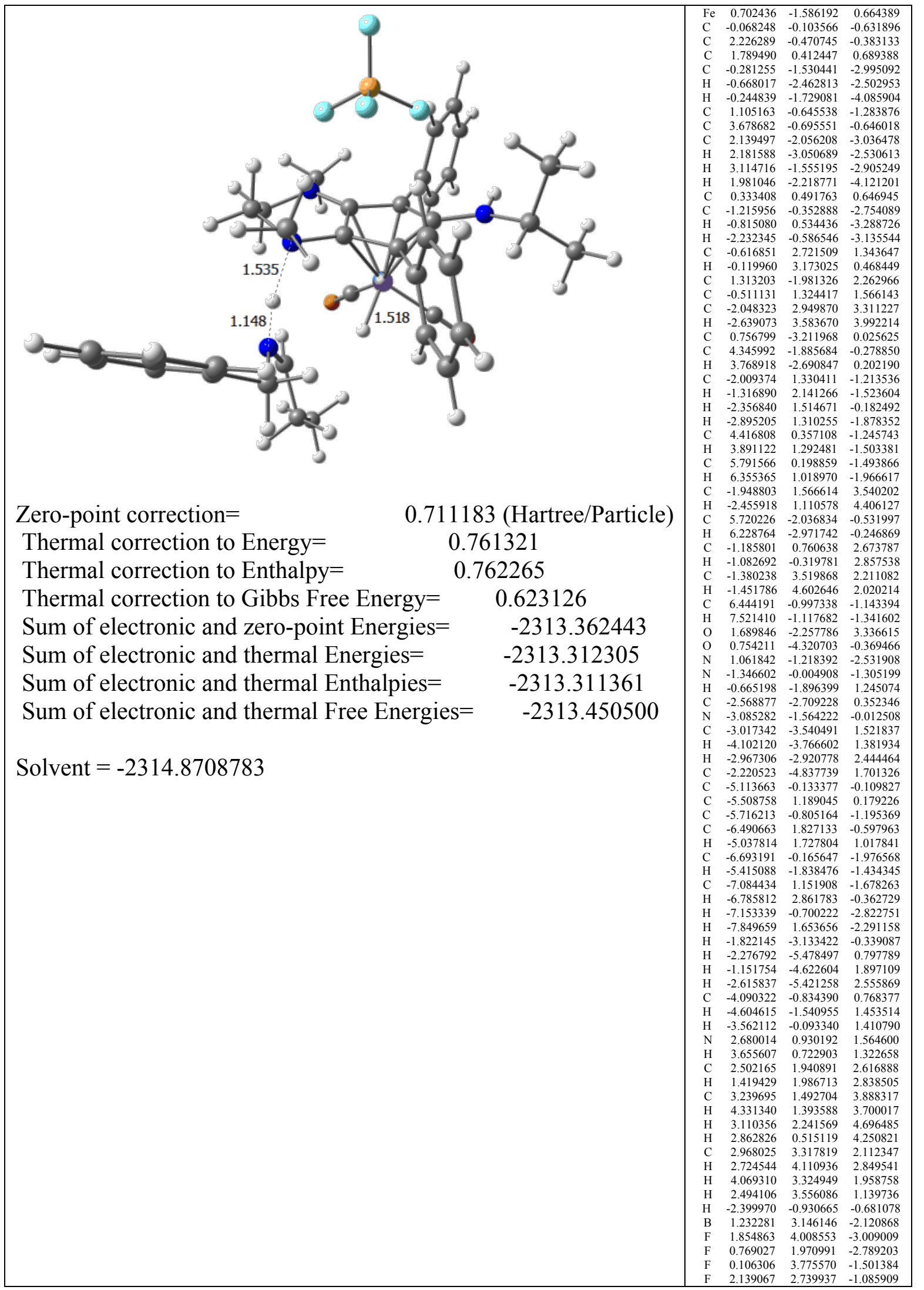


Table S35. 3D view and $x y z$ coordinate data sets and absolute energies in a.u. for DFT optimized complex Fe3-VI $\left(\mathrm{BF}_{4}\right)$ '.

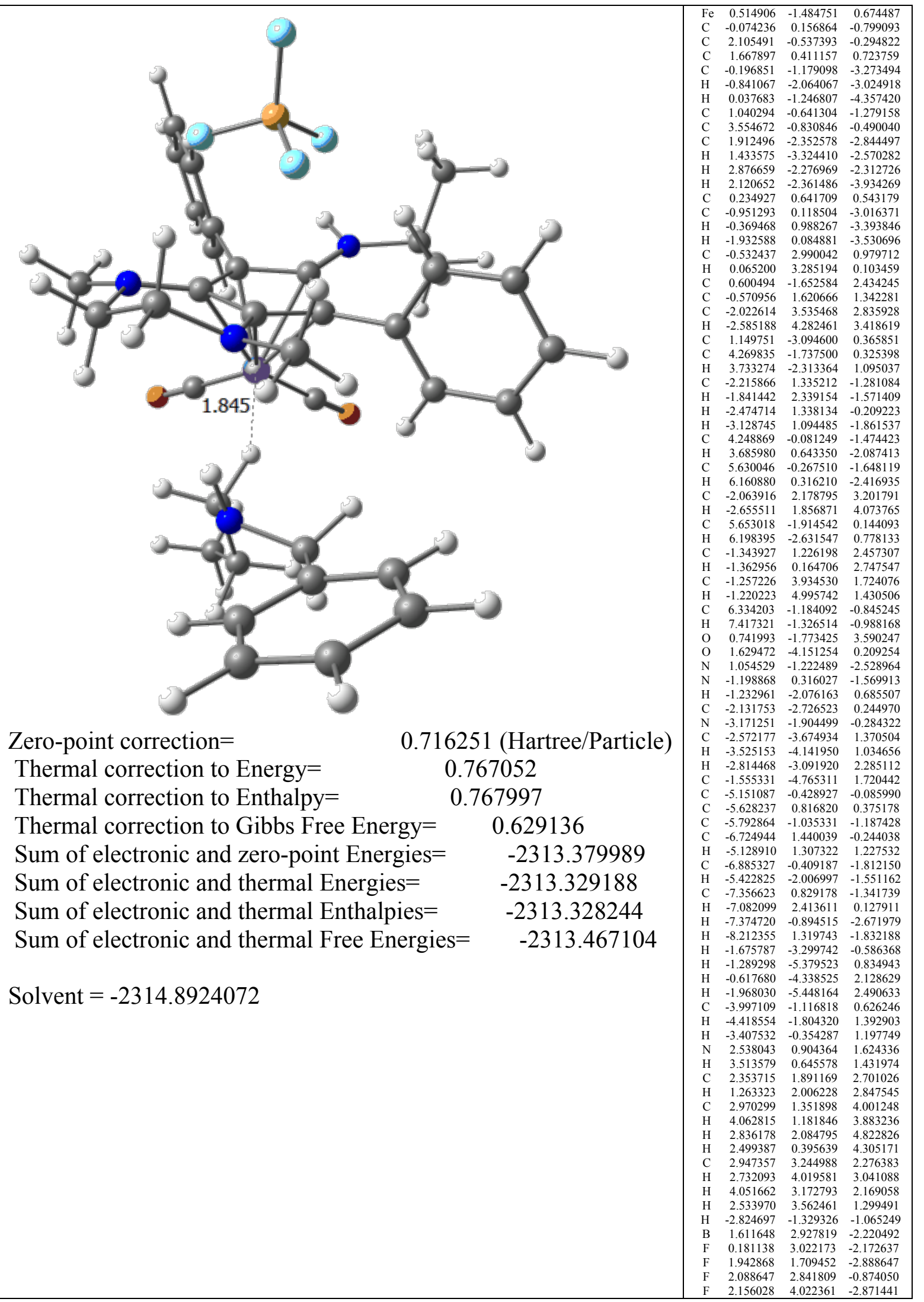


Table S36. 3D view and $x y z$ coordinate data sets and absolute energies in a.u. for DFT optimized complex Fe3-IIIwithoutH $\left(\mathrm{BF}_{4}\right)^{-1}$.

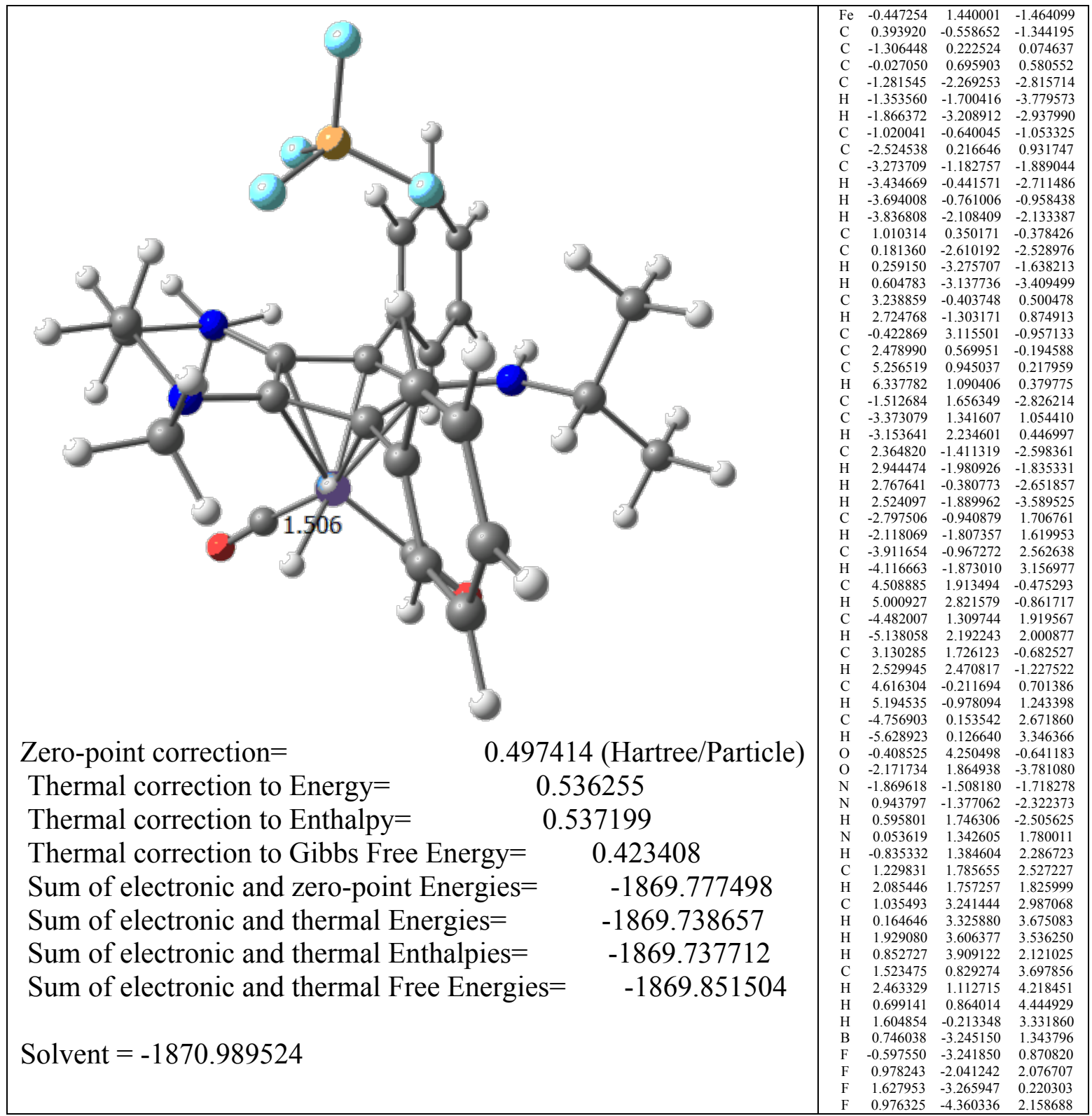


Table S37. 3D view and $x y z$ coordinate data sets and absolute energies in a.u. for DFT optimized complex Fe3-I'

\begin{tabular}{|c|c|c|c|}
\hline $\begin{array}{lc}\text { Zero-point correction }= & 0.485294(\text { Hartree/Particle }) \\
\text { Thermal correction to Energy= } & 0.519695 \\
\text { Thermal correction to Enthalpy= } & 0.520639 \\
\text { Thermal correction to Gibbs Free Energy= } & 0.418621 \\
\text { Sum of electronic and zero-point Energies }= & -1558.067027 \\
\text { Sum of electronic and thermal Energies }= & -1558.032627 \\
\text { Sum of electronic and thermal Enthalpies }= & -1558.031683 \\
\text { Sum of electronic and thermal Free Energies }= & -1558.133701 \\
& \\
\text { Solvent }=-1558.9539074 & \end{array}$ & 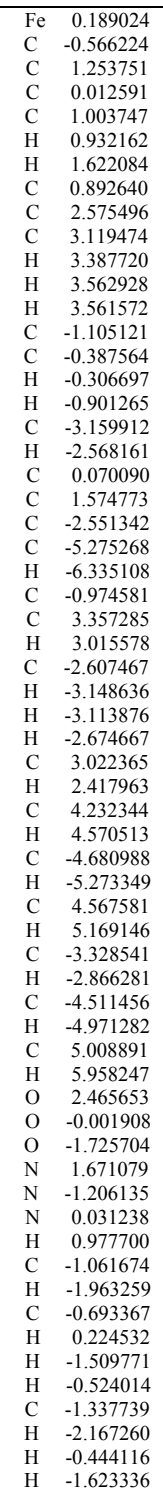 & 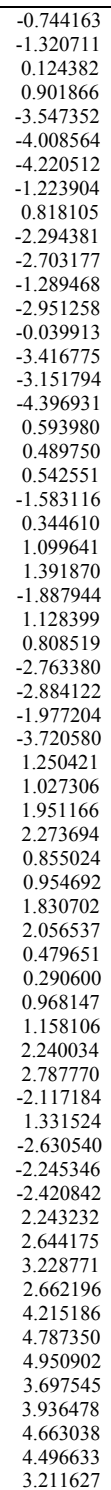 & 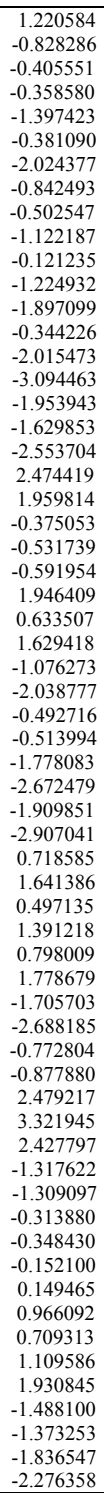 \\
\hline
\end{tabular}


Table S38. $\quad 3 \mathrm{D}$ view and $x y z$ coordinate data sets and absolute energies in a.u. for DFT optimized complex Fe3-I-II'.

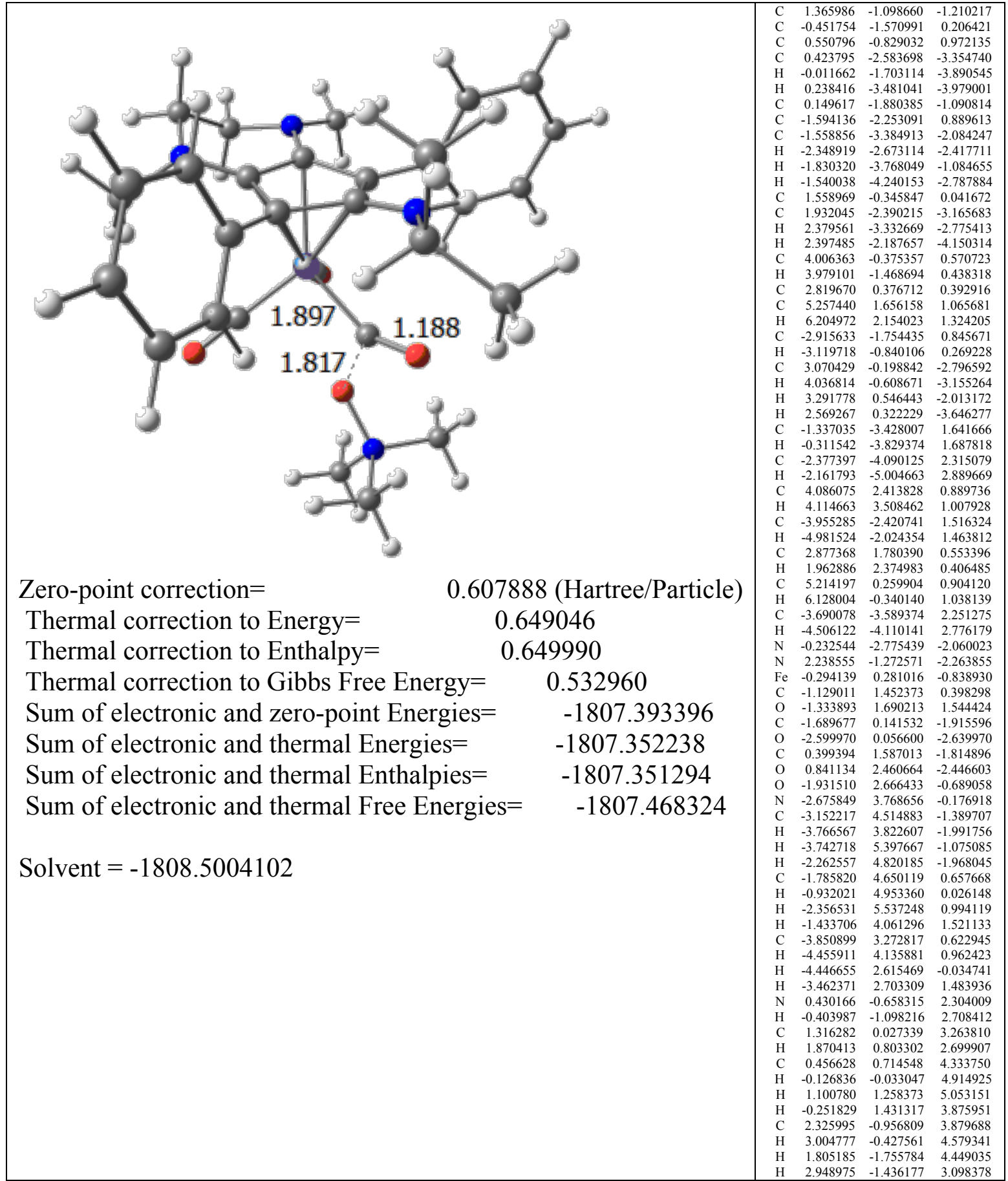


Table S39. 3D view and $x y z$ coordinate data sets and absolute energies in a.u. for DFT optimized complex Fe3-II'

\begin{tabular}{|c|c|c|c|}
\hline $\begin{array}{lc}\text { Zero-point correction }= & 0.476416 \text { (Hartree/Particle) } \\
\text { Thermal correction to Energy }= & 0.508814 \\
\text { Thermal correction to Enthalpy= } & 0.509758 \\
\text { Thermal correction to Gibbs Free Energy= } & 0.410858 \\
\text { Sum of electronic and zero-point Energies }= & -1444.788501 \\
\text { Sum of electronic and thermal Energies }= & -1444.756103 \\
\text { Sum of electronic and thermal Enthalpies }= & -1444.755159 \\
\text { Sum of electronic and thermal Free Energies }= & -1444.854059\end{array}$ & 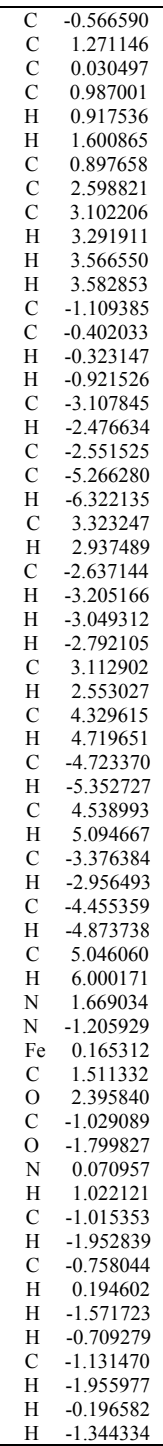 & 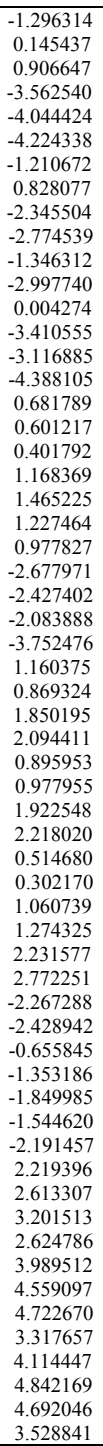 & 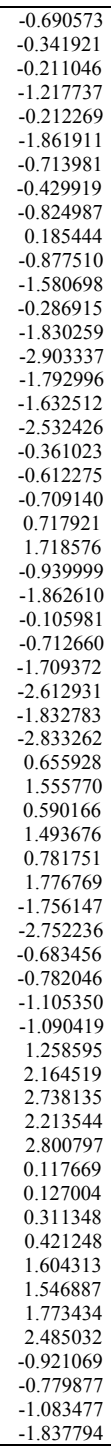 \\
\hline
\end{tabular}


Table S40. 3D view and $x y z$ coordinate data sets and absolute energies in a.u. for DFT optimized complex Fe3-II-III ${ }^{+}$.

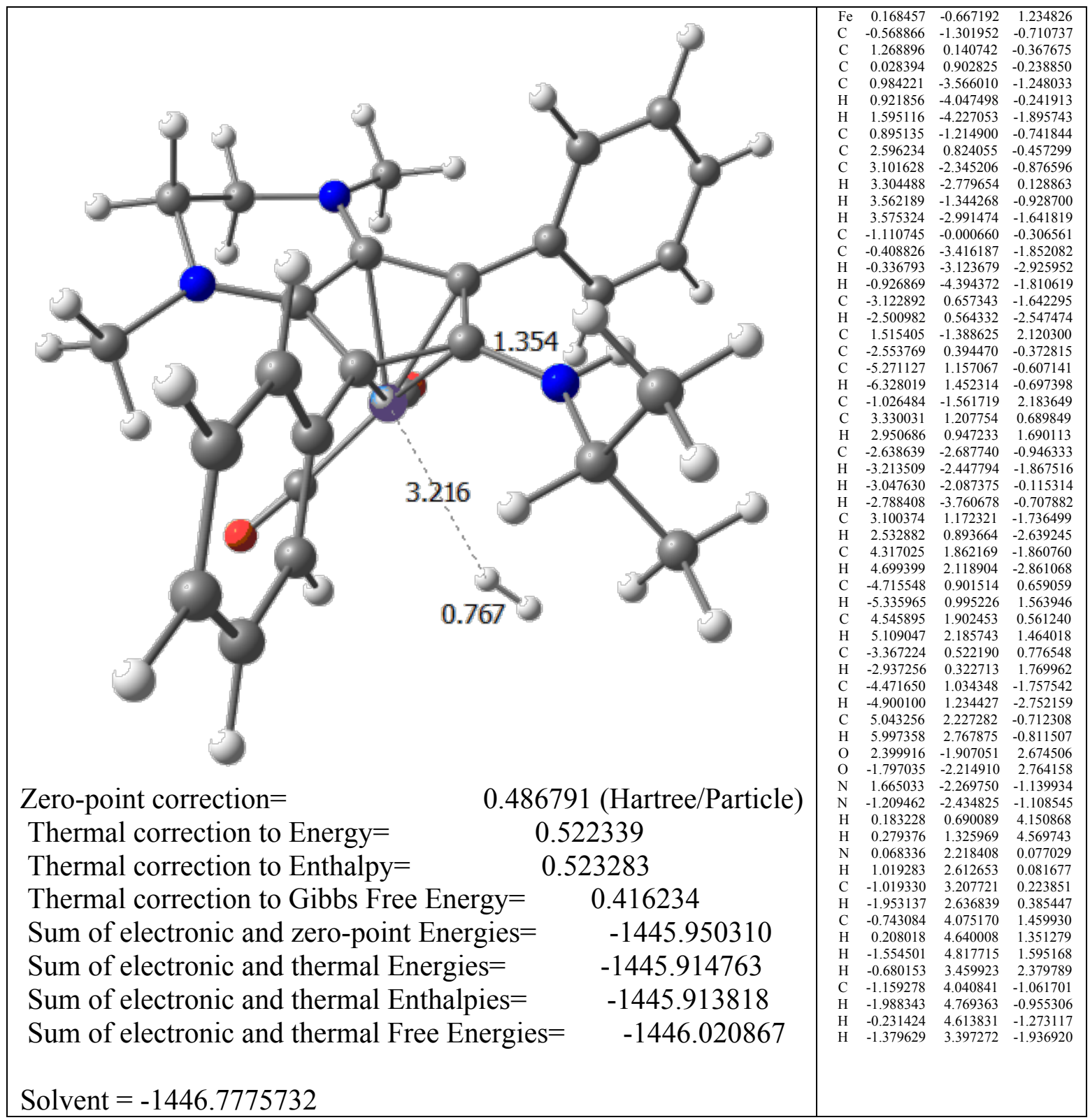


Table S41. 3D view and $x y z$ coordinate data sets and absolute energies in a.u. for DFT optimized complex Fe3-III .

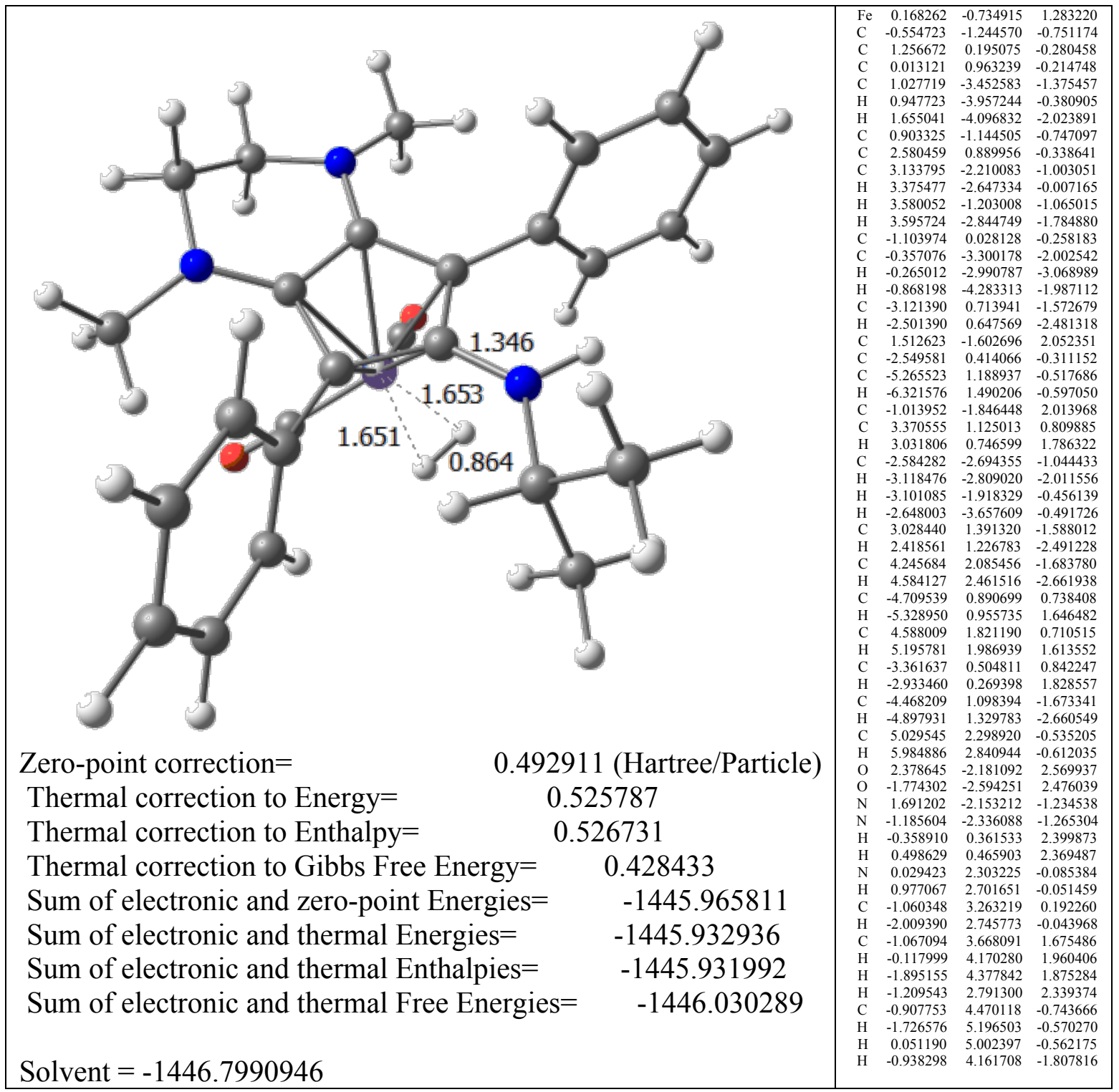


Table S42. 3D view and $x y z$ coordinate data sets and absolute energies in a.u. for DFT optimized complex Fe3-III-IV ${ }^{+}$.

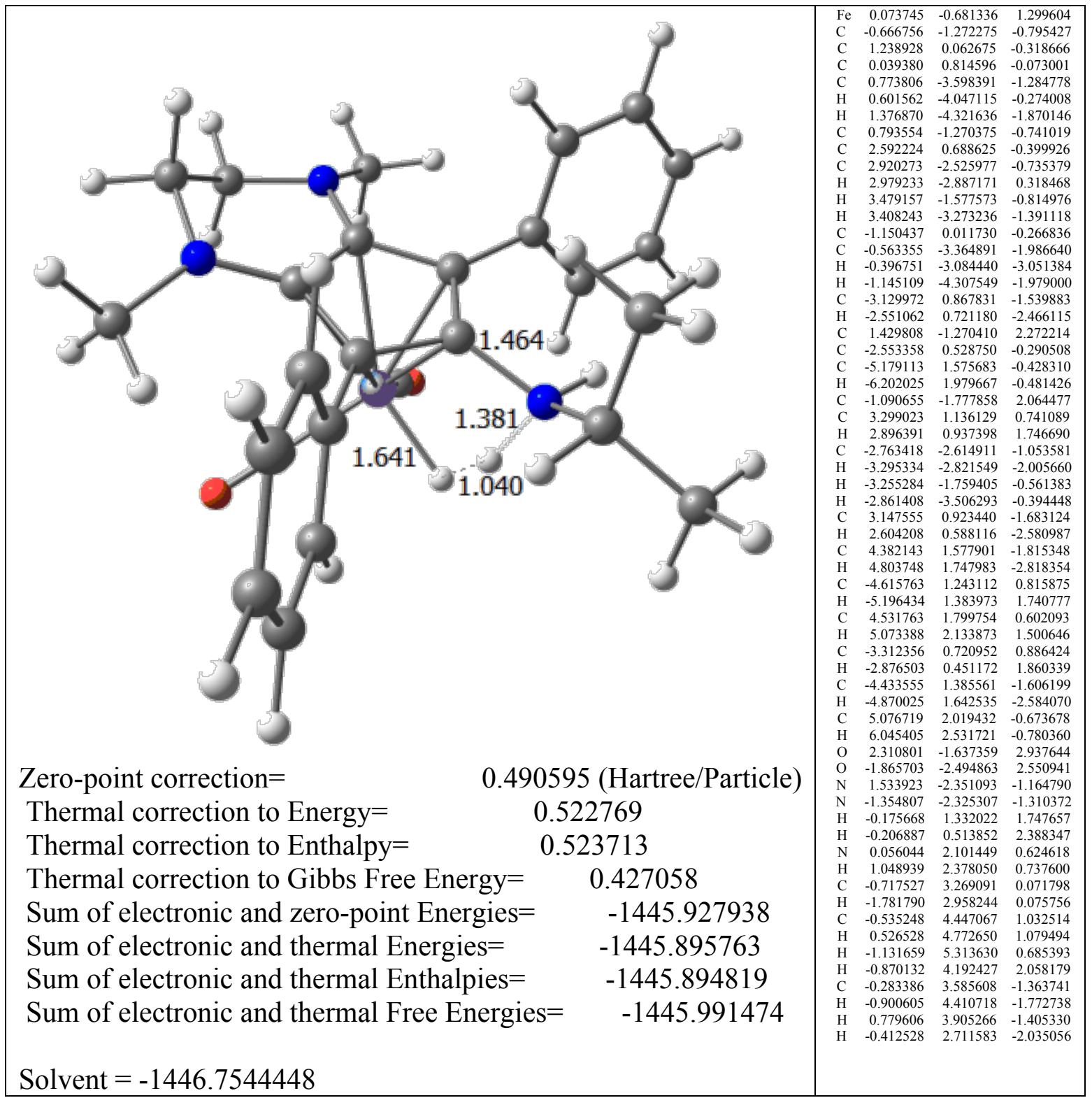


Table S43. 3D view and $x y z$ coordinate data sets and absolute energies in a.u. for DFT optimized complex Fe3-III-IV+EtOH ${ }^{+}$.

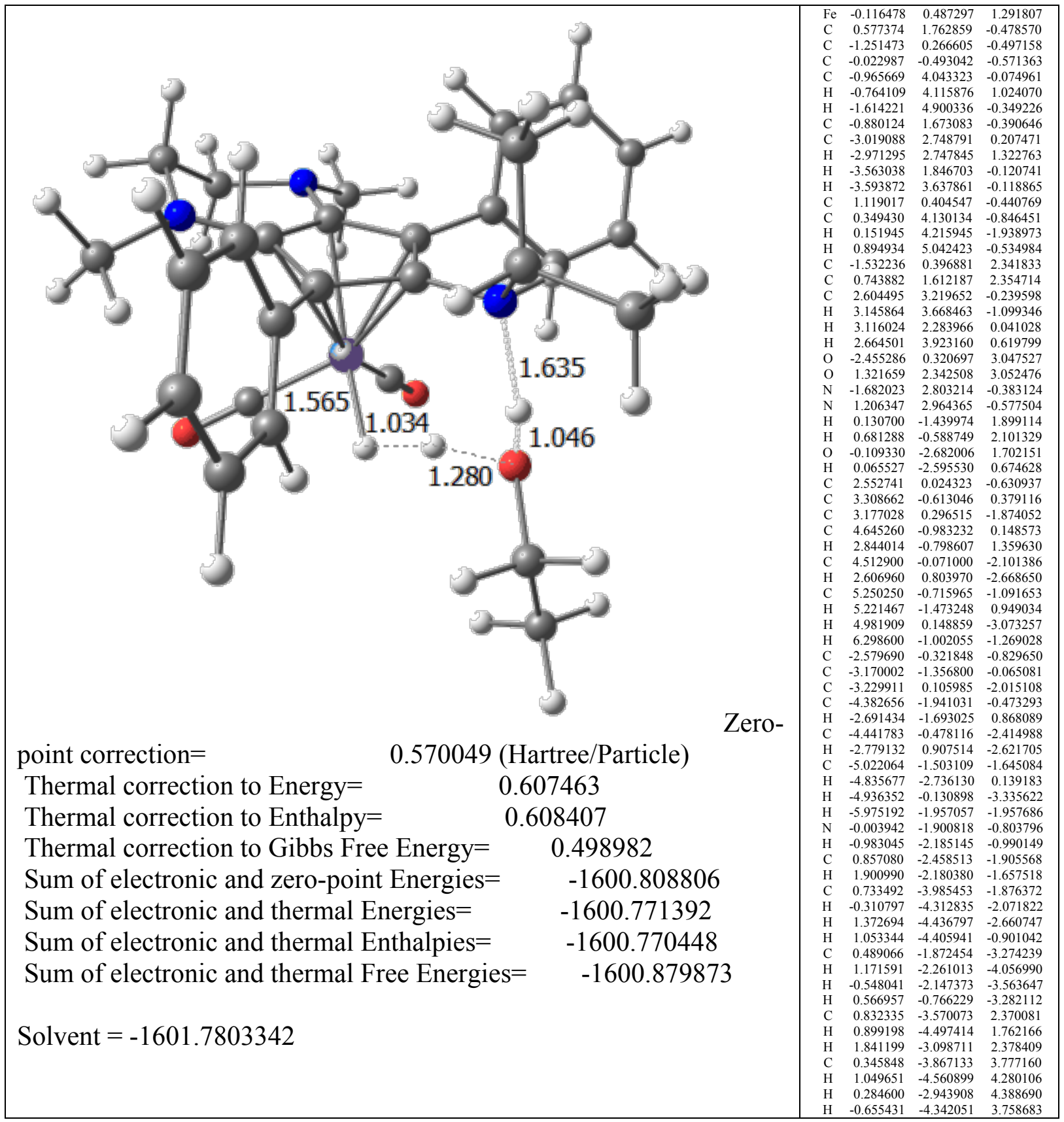


Table S44. 3D view and $x y z$ coordinate data sets and absolute energies in a.u. for DFT optimized complex Fe3-IV ${ }^{+}$.

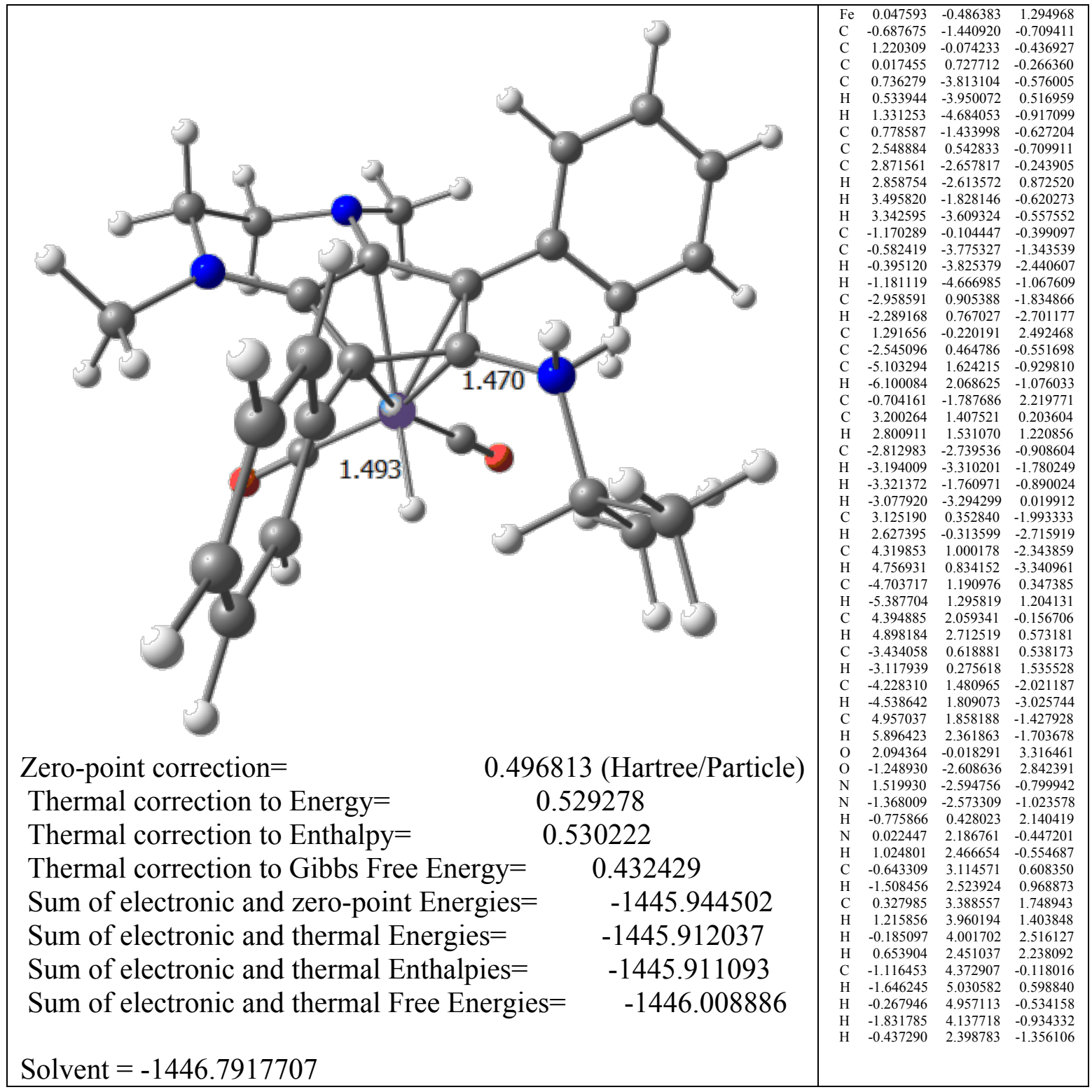


Table S45. 3D view and $x y z$ coordinate data sets and absolute energies in a.u. for DFT optimized complex Fe3-V ${ }^{+}$.

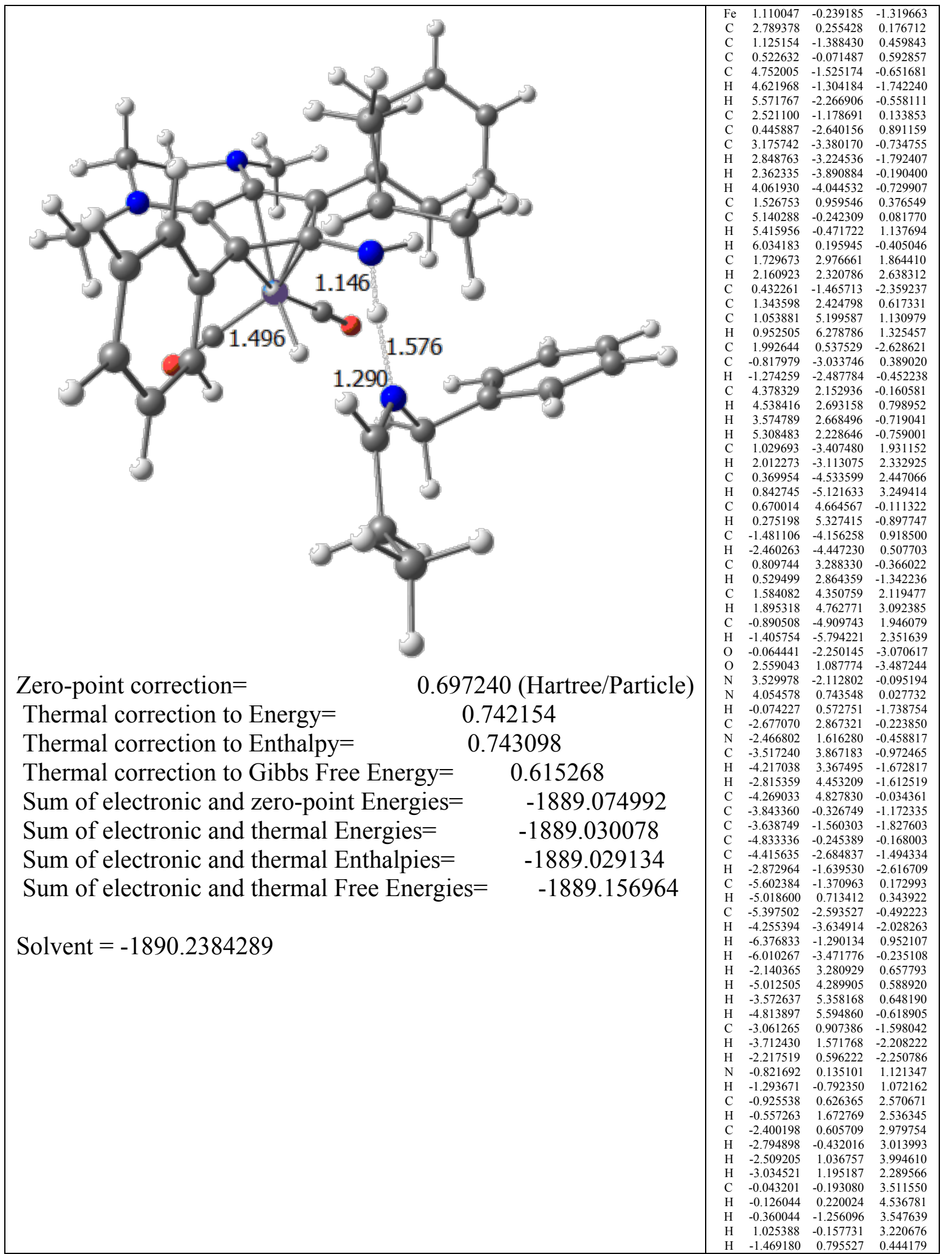


Table S46. 3D view and $x y z$ coordinate data sets and absolute energies in a.u. for DFT optimized complex Fe3-V-VI ${ }^{+}$.

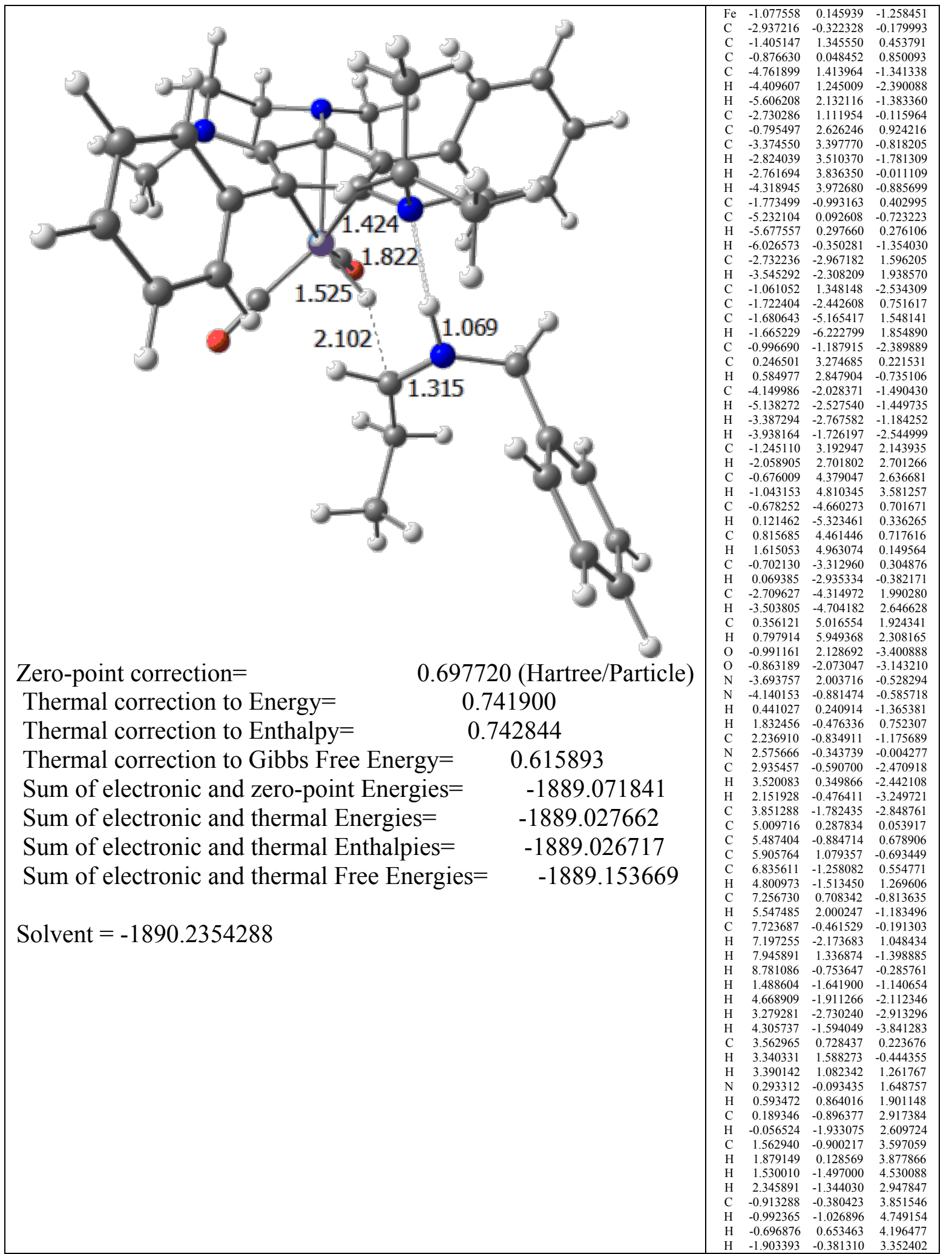


Table S47. 3D view and $x y z$ coordinate data sets and absolute energies in a.u. for DFT optimized complex Fe3-VI ${ }^{+}$

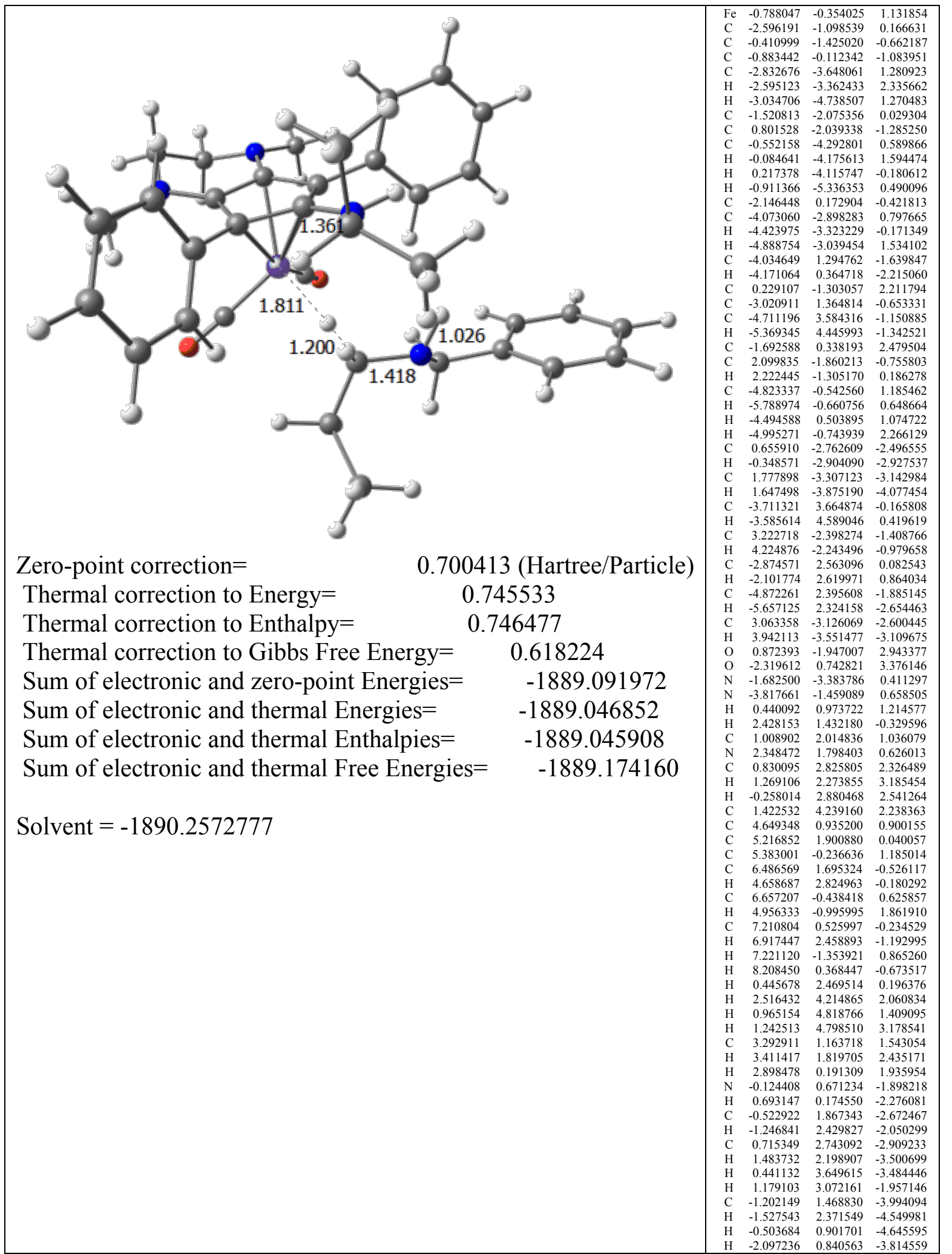


Table S48. 3D view and $x y z$ coordinate data sets and absolute energies in a.u. for DFT optimized complex Fe3-III--H'.

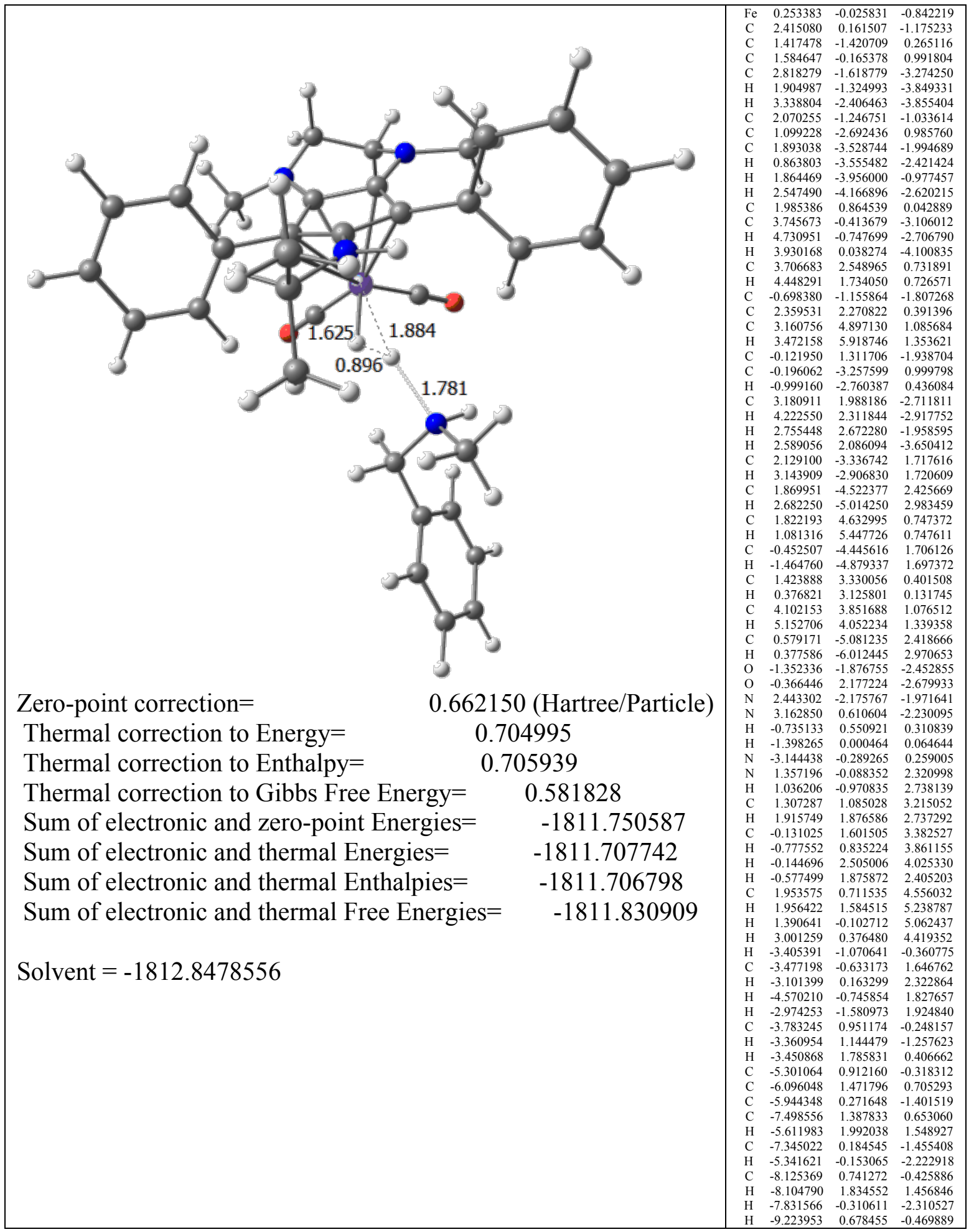


Table S49. 3D view and $x y z$ coordinate data sets and absolute energies in a.u. for DFT optimized complex Fe3-III (without $\mathrm{H}^{+}$).

\begin{tabular}{|c|c|c|c|}
\hline $\begin{array}{lc}\text { Zero-point correction }= & 0.483180 \text { (Hartree/Particle) } \\
\text { Thermal correction to Energy= } & 0.515218 \\
\text { Thermal correction to Enthalpy= } & 0.516162 \\
\text { Thermal correction to Gibbs Free Energy= } & 0.418986 \\
\text { Sum of electronic and zero-point Energies }= & -1445.575475 \\
\text { Sum of electronic and thermal Energies }= & -1445.543437 \\
\text { Sum of electronic and thermal Enthalpies }= & -1445.542493 \\
\text { Sum of electronic and thermal Free Energies }= & -1445.639669\end{array}$ & 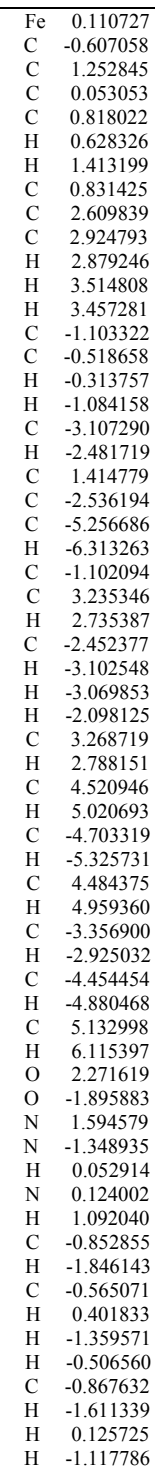 & 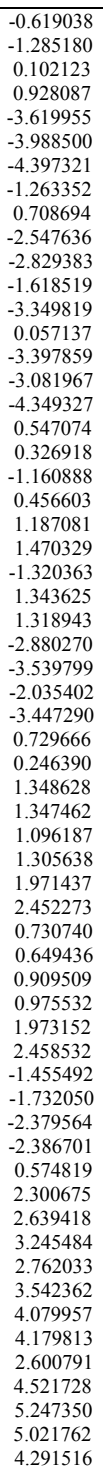 & 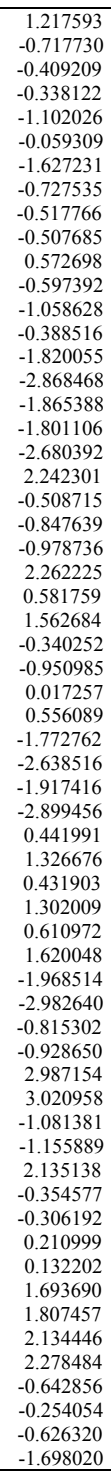 \\
\hline
\end{tabular}


Table S50. 3D view and $x y z$ coordinate data sets and absolute energies in a.u. for DFT optimized complex Fe3-II-III ${ }^{+}$.

\begin{tabular}{|c|c|c|c|}
\hline $\begin{array}{lc}\text { Zero-point correction }= & 0.486896 \text { (Hartree/Particle) } \\
\text { Thermal correction to Energy= } & 0.522278 \\
\text { Thermal correction to Enthalpy= } & 0.523222 \\
\text { Thermal correction to Gibbs Free Energy= } & 0.417470 \\
\text { Sum of electronic and zero-point Energies }= & -1445.940797 \\
\text { Sum of electronic and thermal Energies }= & -1445.905416 \\
\text { Sum of electronic and thermal Enthalpies }= & -1445.904472 \\
\text { Sum of electronic and thermal Free Energies }= & -1446.010224 \\
& \\
\text { Solvent }=-1446.7696468 & \end{array}$ & 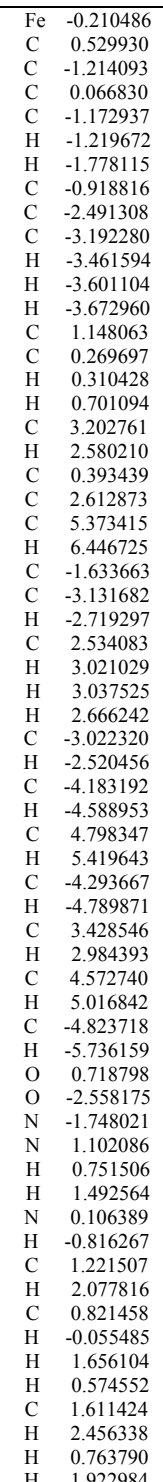 & 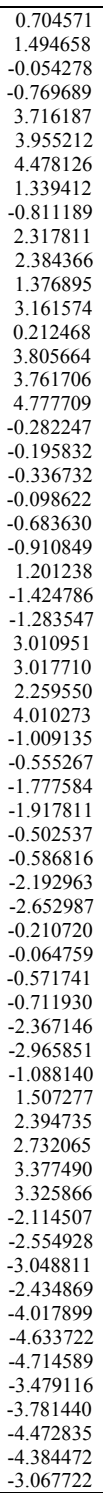 & 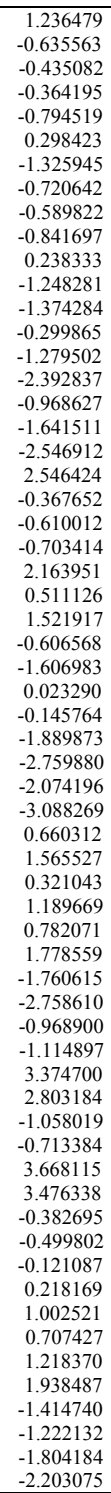 \\
\hline
\end{tabular}


Table S51. 3D view and $x y z$ coordinate data sets and absolute energies in a.u. for DFT optimized complex Fe3-III ${ }^{+}$.

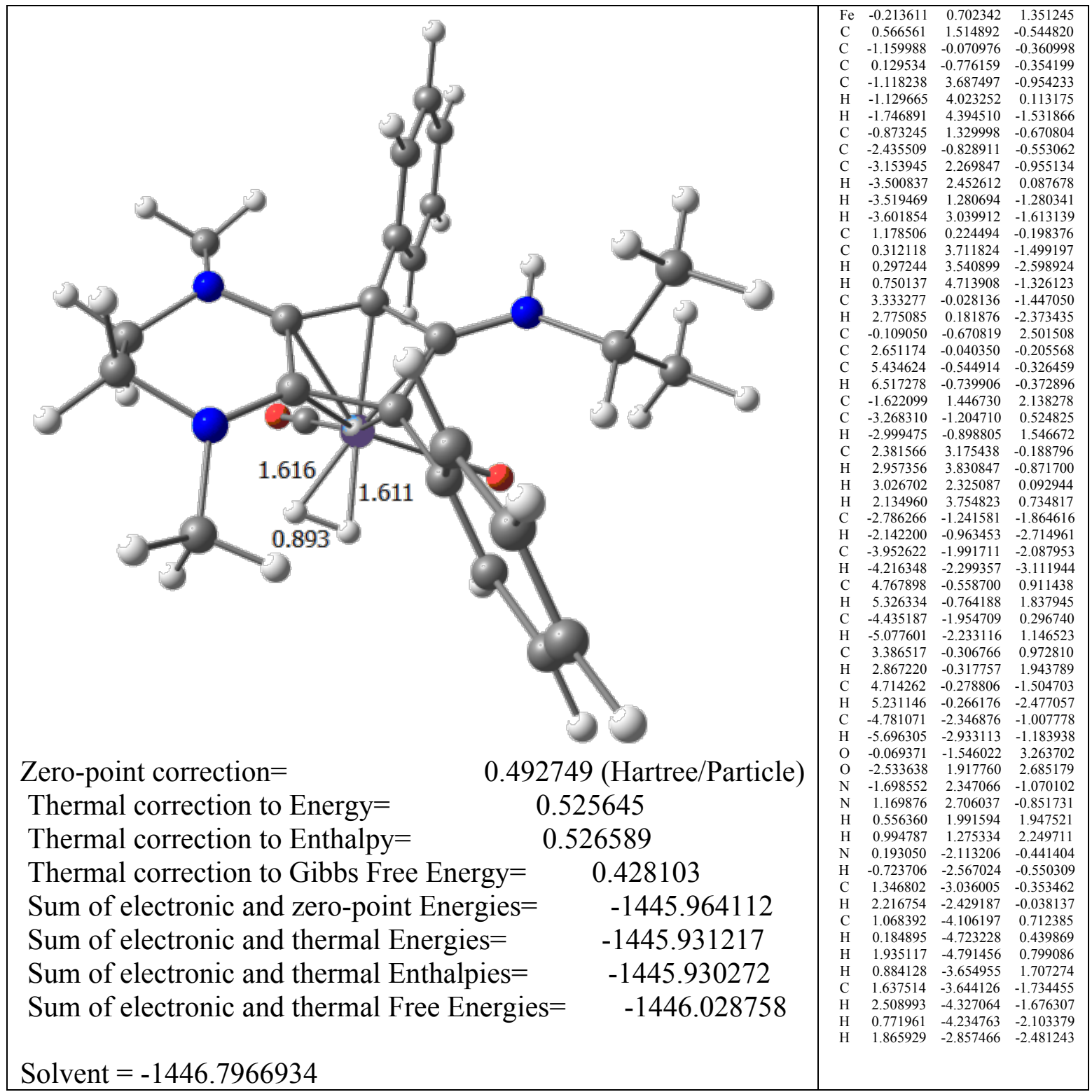


Table S52. 3D view and $x y z$ coordinate data sets and absolute energies in a.u. for DFT optimized complex Fe3-III-IV ${ }^{+}$.

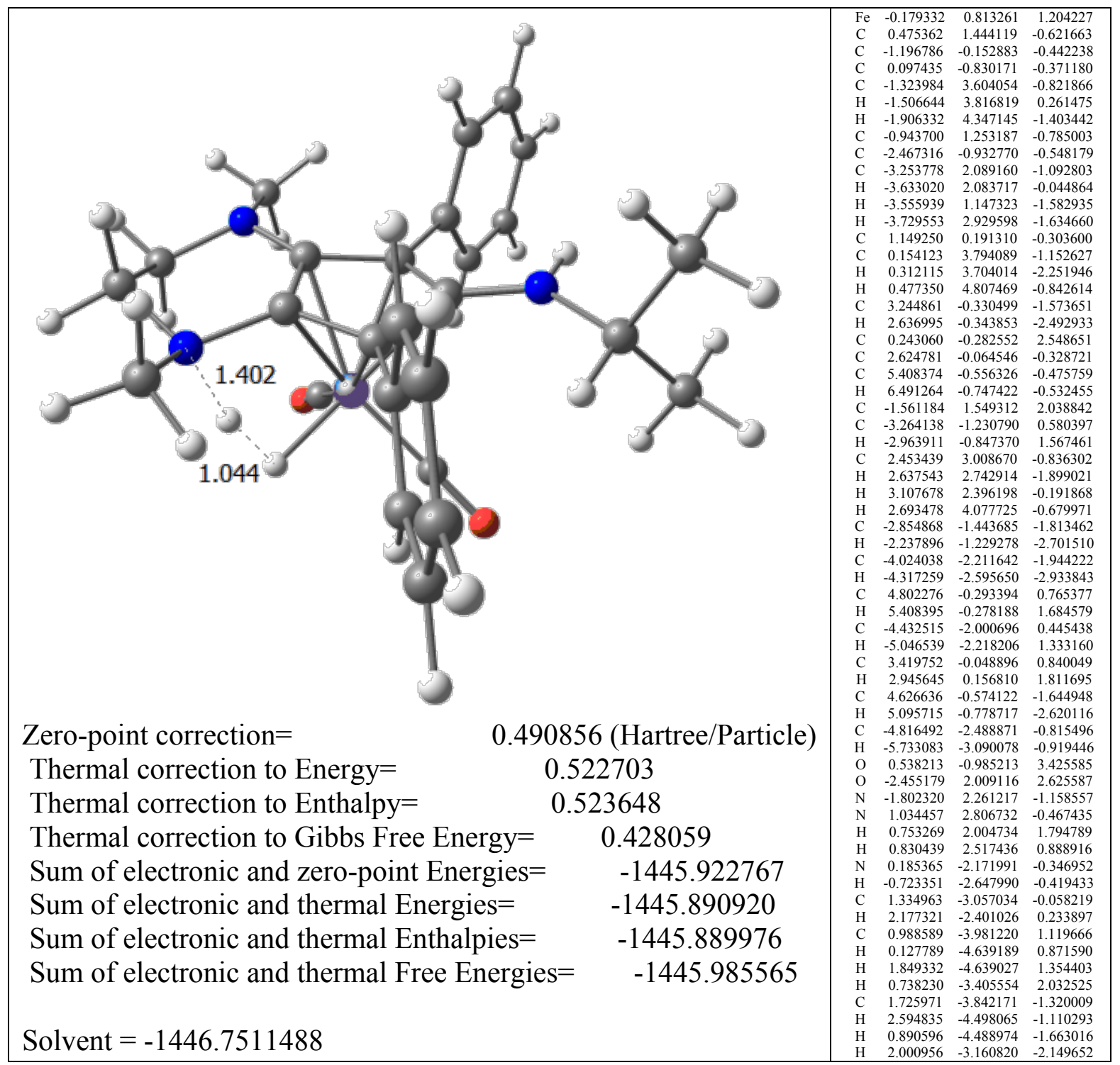


Table S53. 3D view and $x y z$ coordinate data sets and absolute energies in a.u. for DFT optimized complex Fe3-IV ${ }^{+}$.

\begin{tabular}{|c|c|c|c|}
\hline $\begin{array}{lc}\text { Zero-point correction }= & 0.497795 \text { (Hartree/Particle) } \\
\text { Thermal correction to Energy= } & 0.529819 \\
\text { Thermal correction to Enthalpy= } & 0.530763 \\
\text { Thermal correction to Gibbs Free Energy= } & 0.434197 \\
\text { Sum of electronic and zero-point Energies= } & -1445.940496 \\
\text { Sum of electronic and thermal Energies }= & -1445.908473 \\
\text { Sum of electronic and thermal Enthalpies }= & -1445.907529 \\
\text { Sum of electronic and thermal Free Energies }= & -1446.004095 \\
& \\
\text { Solvent }=-1446.7936153 & \end{array}$ & 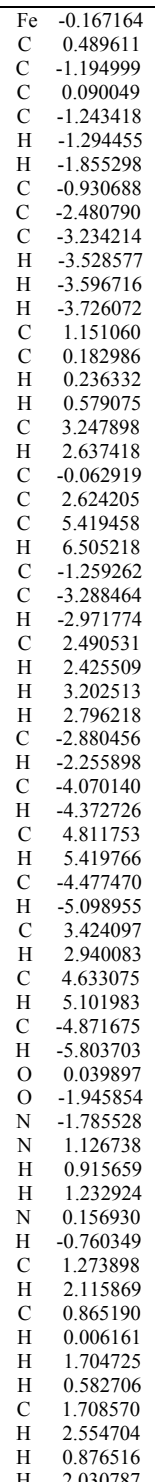 & 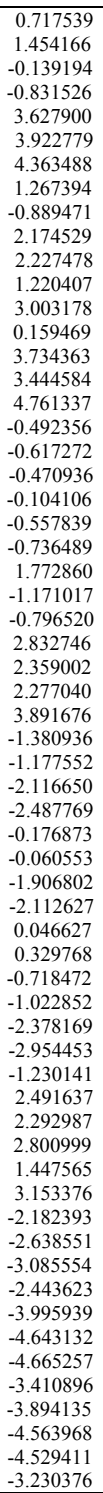 & 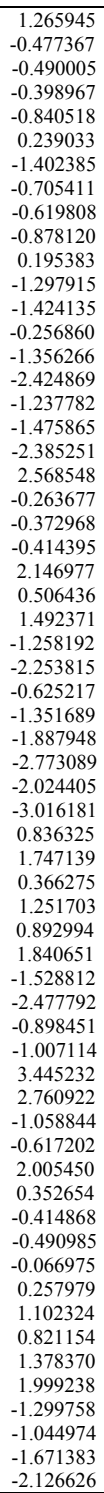 \\
\hline
\end{tabular}


Table S54. 3D view and $x y z$ coordinate data sets and absolute energies in a.u. for DFT optimized complex Fe3-III-IV+1EtOH ${ }^{+}$.

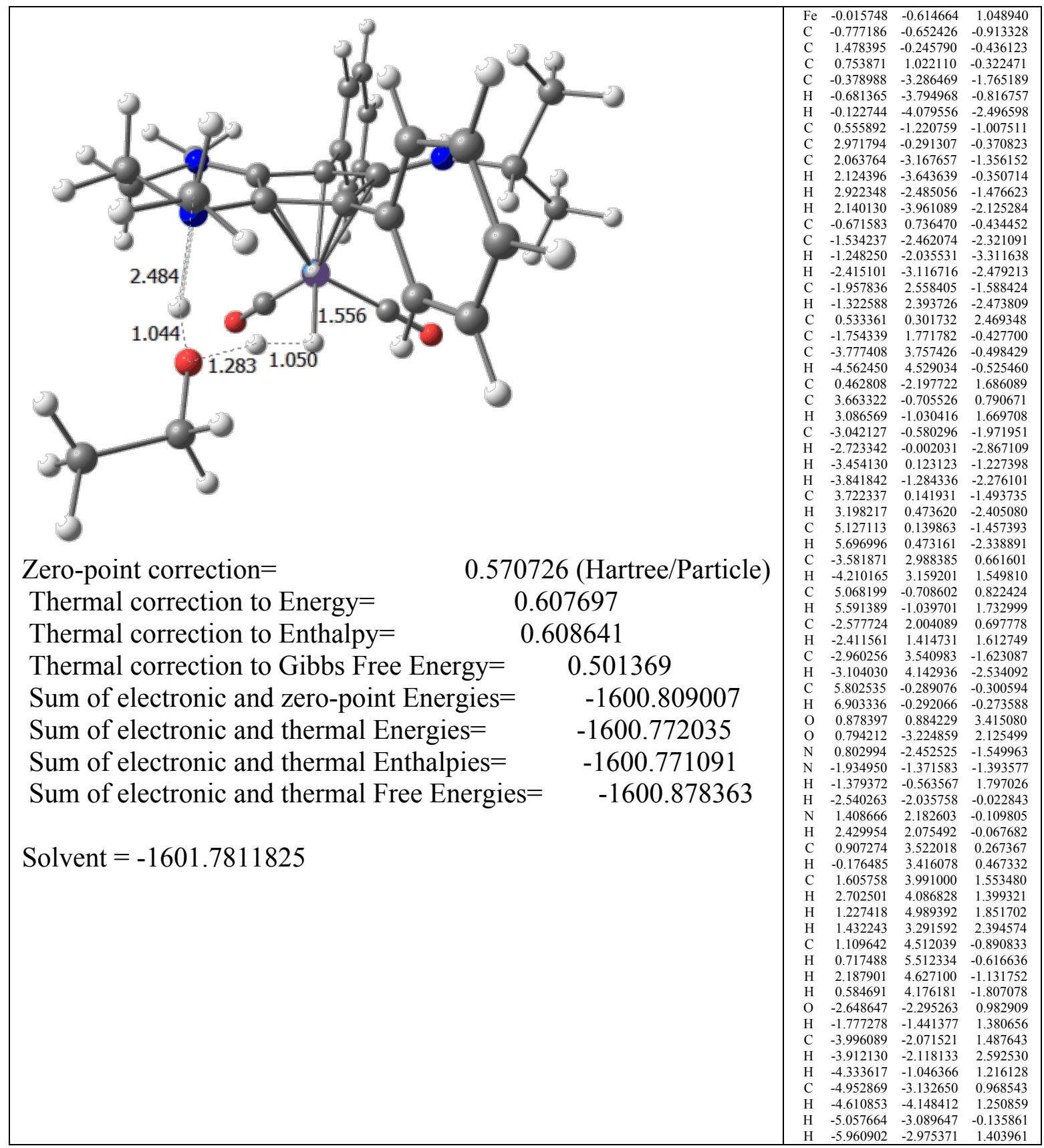


Table S55. 3D view and $x y z$ coordinate data sets and absolute energies in a.u. for DFT optimized complex $\mathbf{F e} 3-\mathbf{V}^{+}$.

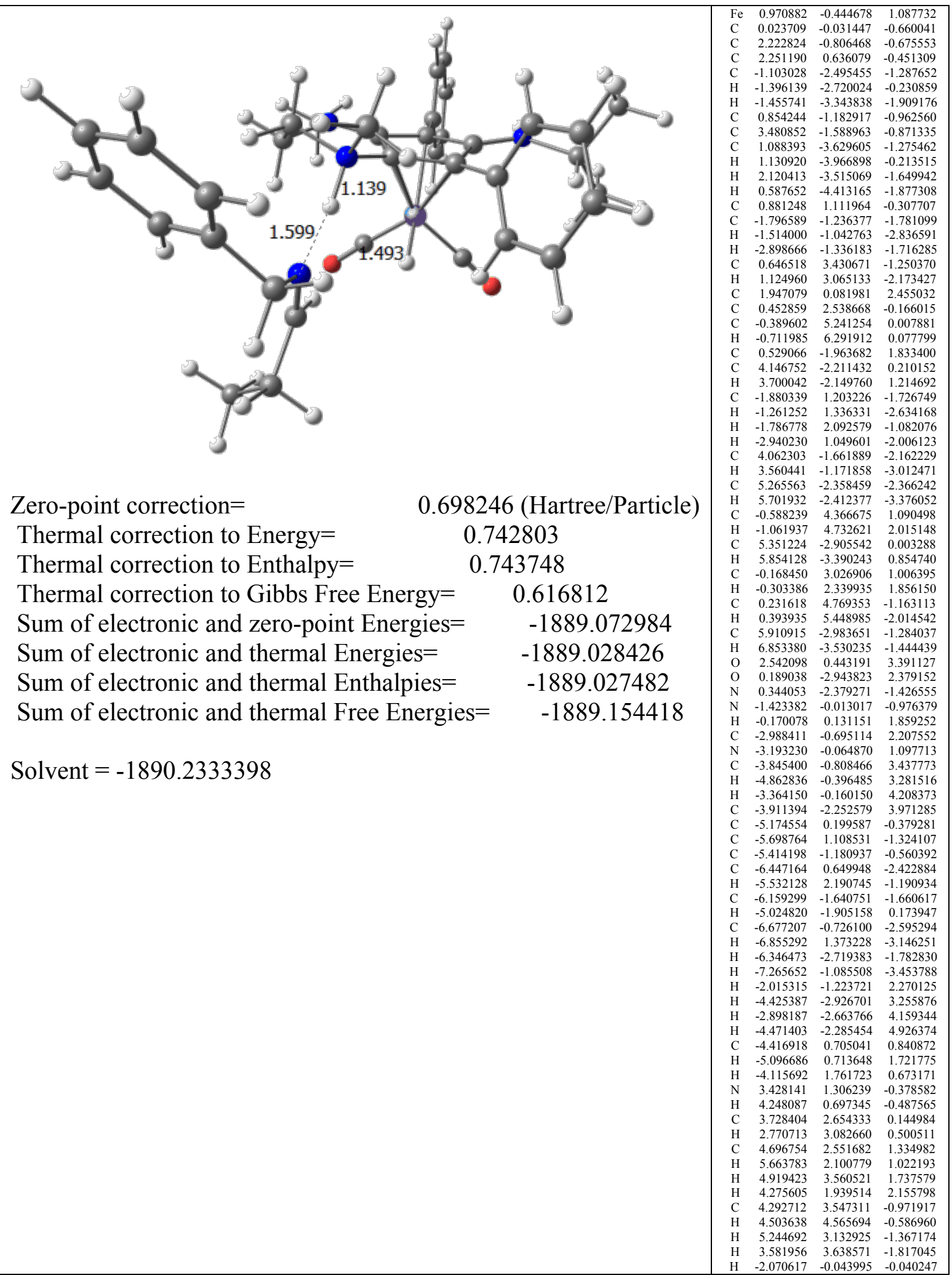


Table S56. 3D view and $x y z$ coordinate data sets and absolute energies in a.u. for DFT optimized complex Fe3-V-VI, ${ }^{+}$.

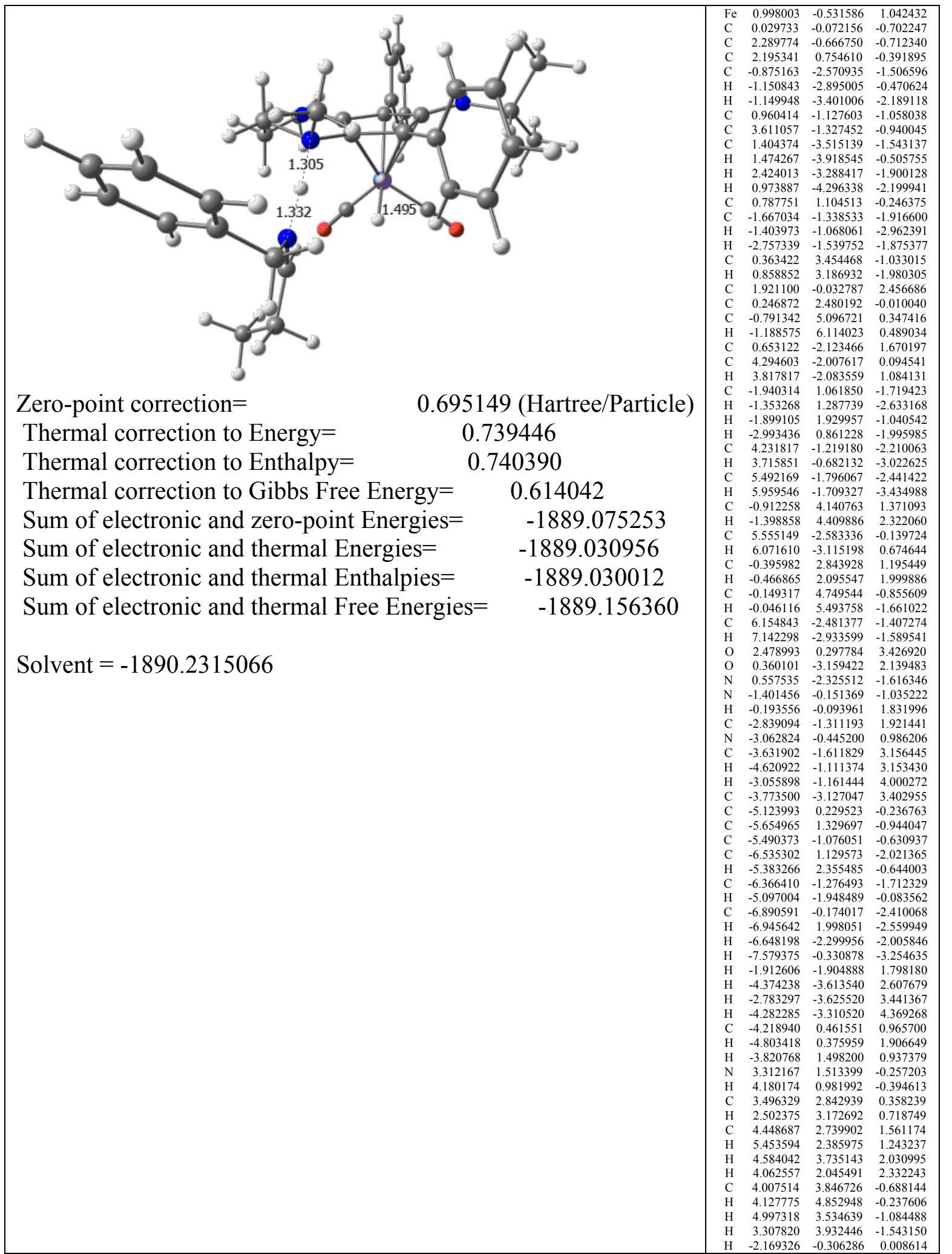


Table S57.3D view and $x y z$ coordinate data sets and absolute energies in a.u. for DFT optimized complex Fe3-VI, ${ }^{+}$.

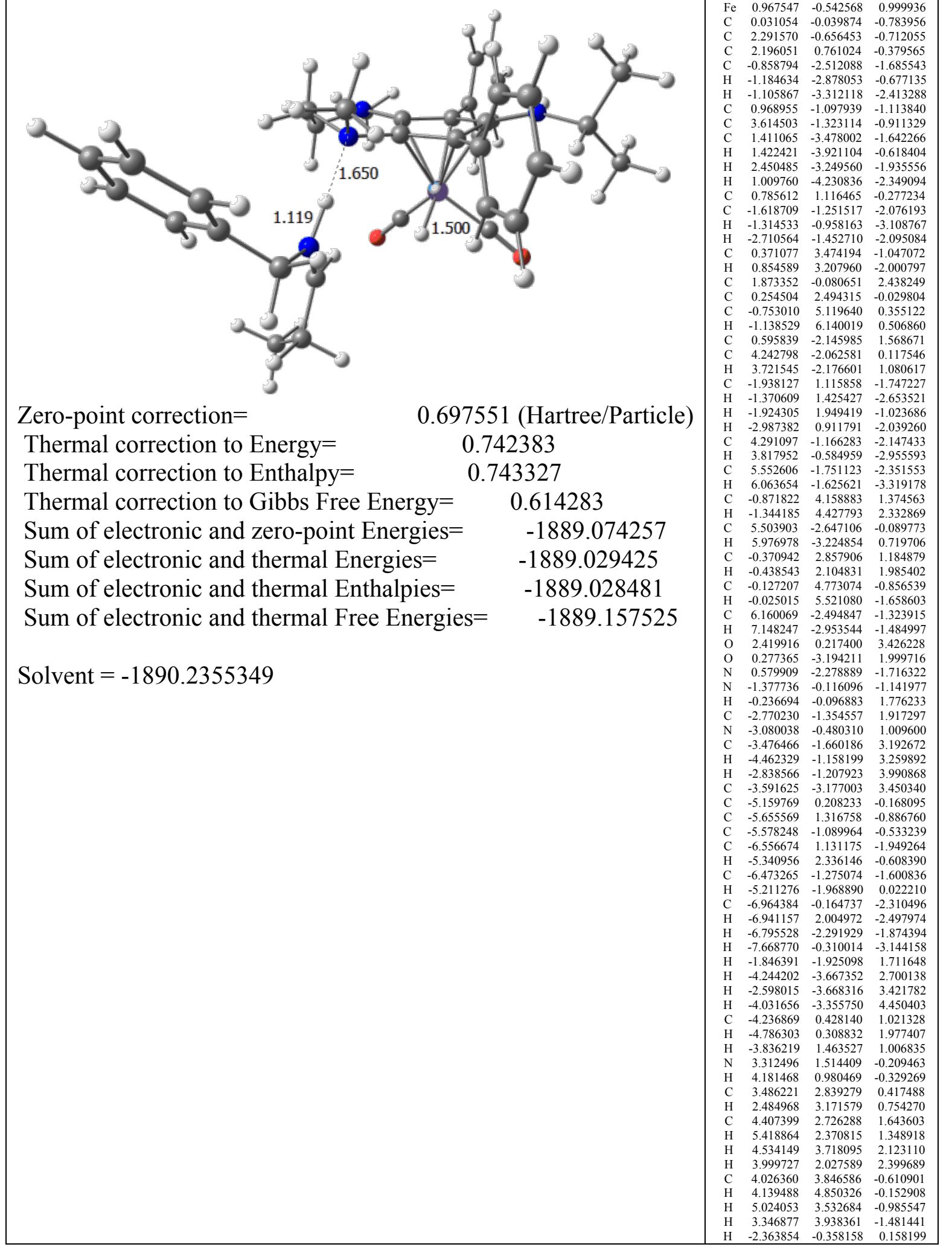


Table S58.3D view and $x y z$ coordinate data sets and absolute energies in a.u. for DFT optimized complex Fe3-VI, ${ }^{+}$.

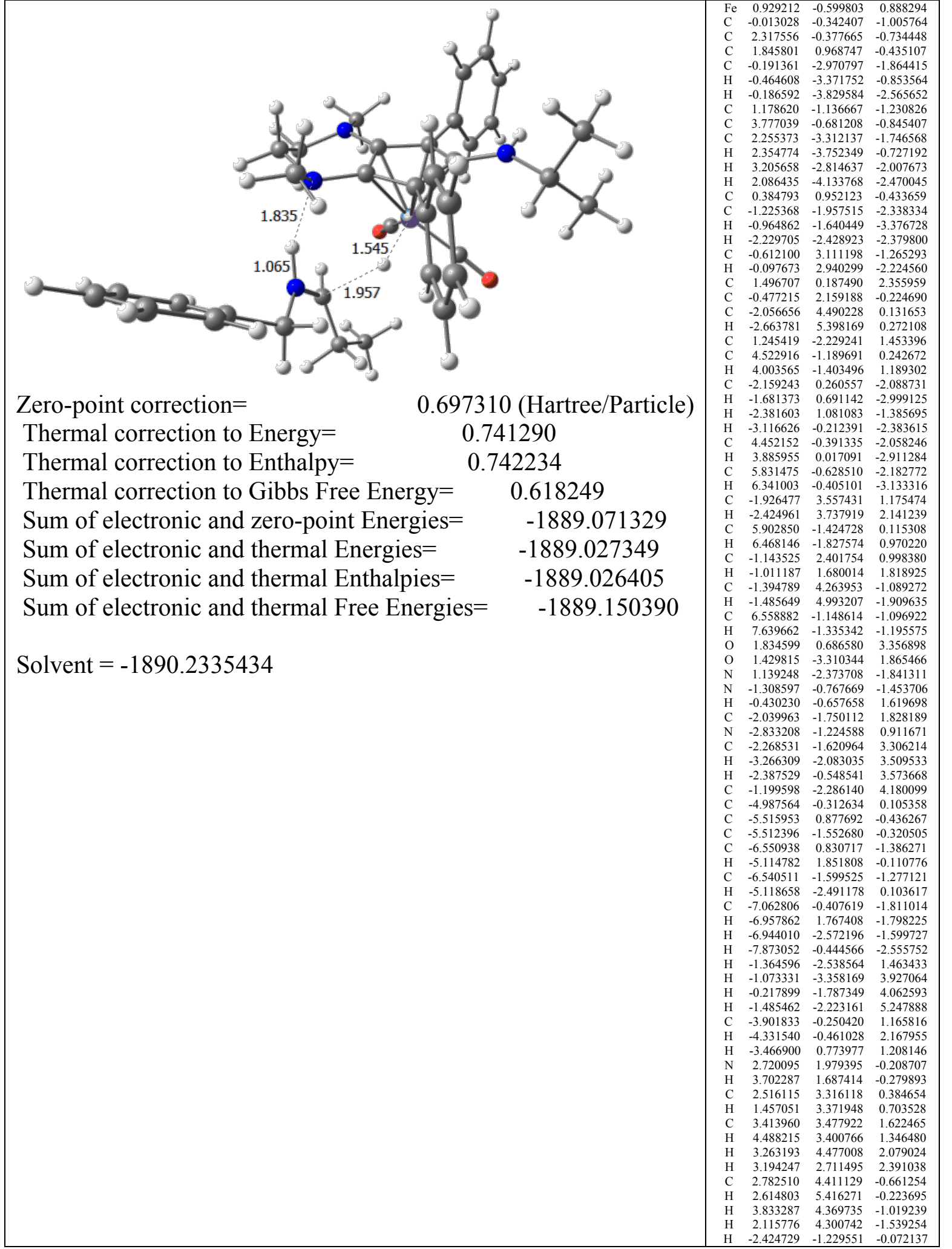


Table S59.3D view and $x y z$ coordinate data sets and absolute energies in a.u. for DFT optimized complex Fe3-VI, ${ }^{+}$.

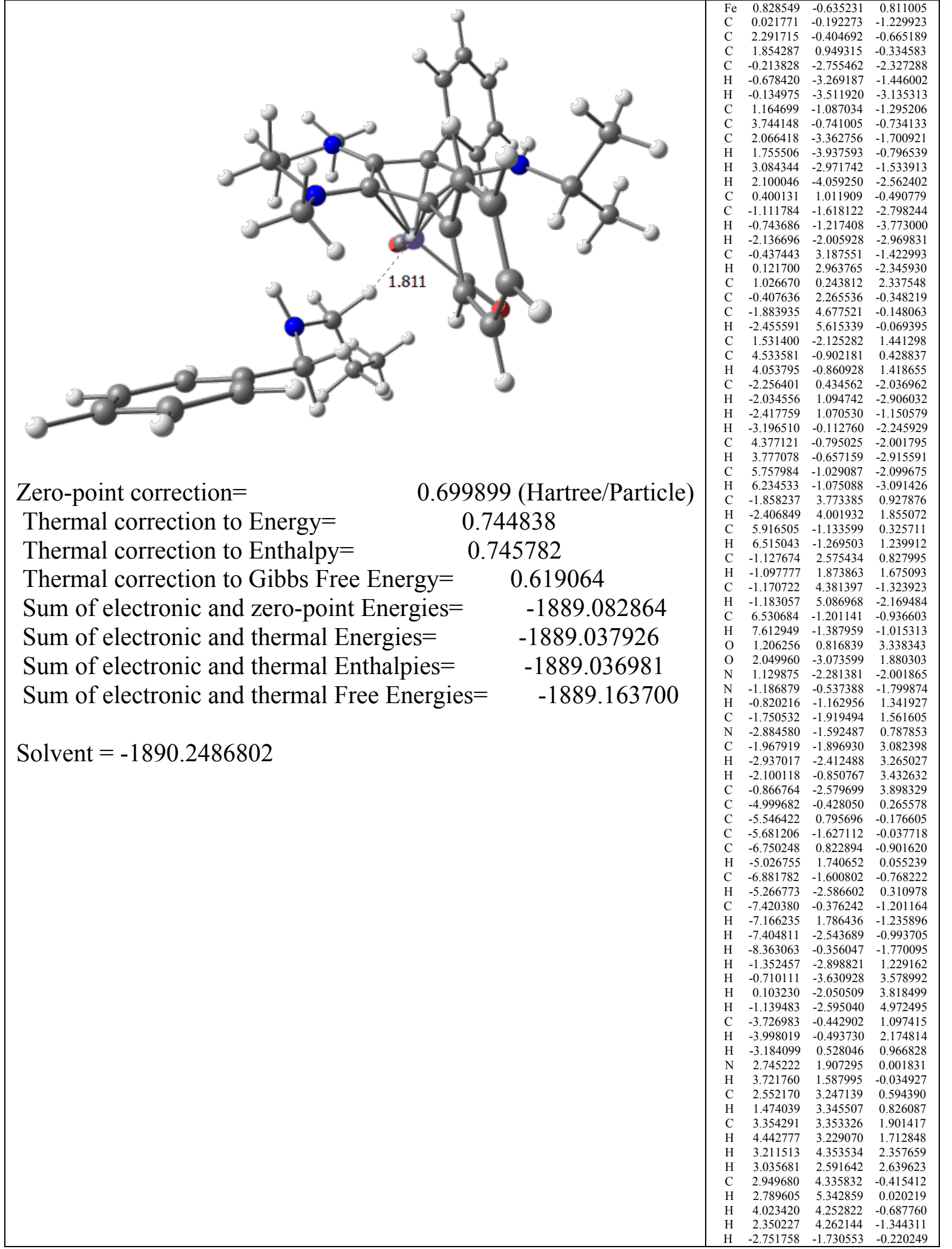


Table S60. $\quad 3 \mathrm{D}$ view and $x y z$ coordinate data sets and absolute energies in a.u. for DFT optimized complex Fe3-IIIwithoutH'.

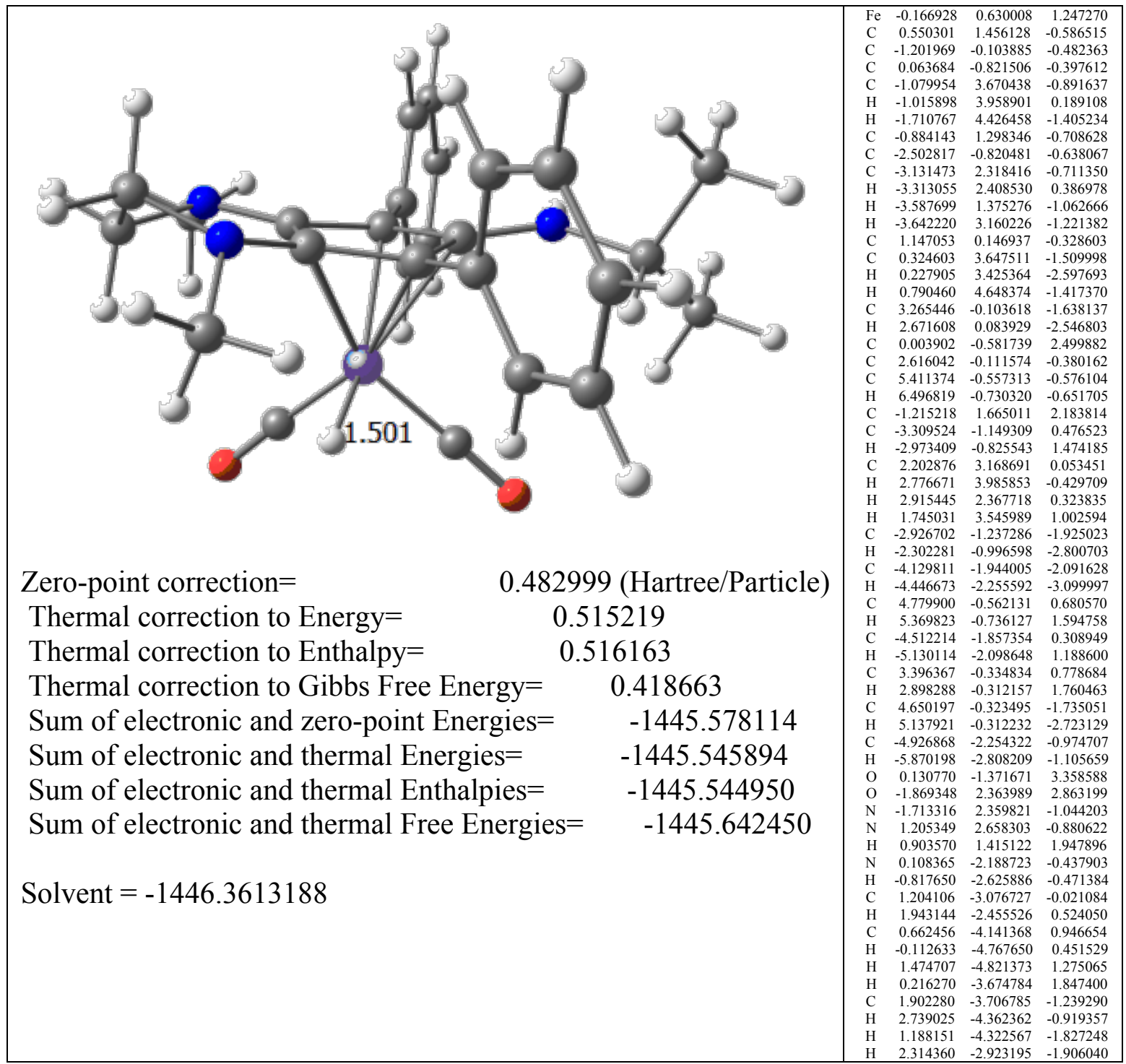


Table S61. 3D view and $x y z$ coordinate data sets and absolute energies in a.u. for DFT optimized $\mathrm{NH}_{2} \mathrm{iPr}$.

\begin{tabular}{|c|c|c|c|}
\hline$P$ & 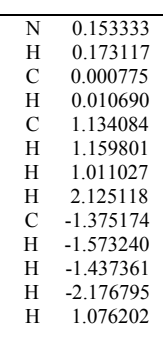 & $\begin{array}{l}1.434087 \\
1.472741 \\
0.030661 \\
0.034405 \\
-0.900984 \\
-0.950922 \\
-1.938482 \\
-0.534097 \\
-0.477727 \\
-1.503948 \\
-0.058432 \\
0.195192 \\
1.783340\end{array}$ & 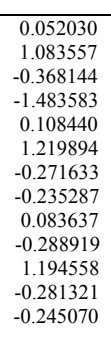 \\
\hline 0.116717 (Hartree/Particle) & & & \\
\hline Thermal correction to Energy= & & & \\
\hline Thermal correction to Enthalpy= $\quad 0.123319$ & & & \\
\hline Thermal correction to Gibbs Free Energy $=\quad 0.089189$ & & & \\
\hline Sum of electronic and zero-point Energies $=$ & & & \\
\hline Sum of electronic and thermal Energies $=$ & & & \\
\hline Sum of electronic and thermal Enthalpies $=$ & & & \\
\hline Sum of electronic and thermal Free Energies $=$ & & & \\
\hline
\end{tabular}


Table S62. 3D view and $x y z$ coordinate data sets and absolute energies in a.u. for DFT optimized $\mathrm{EtOH}$.

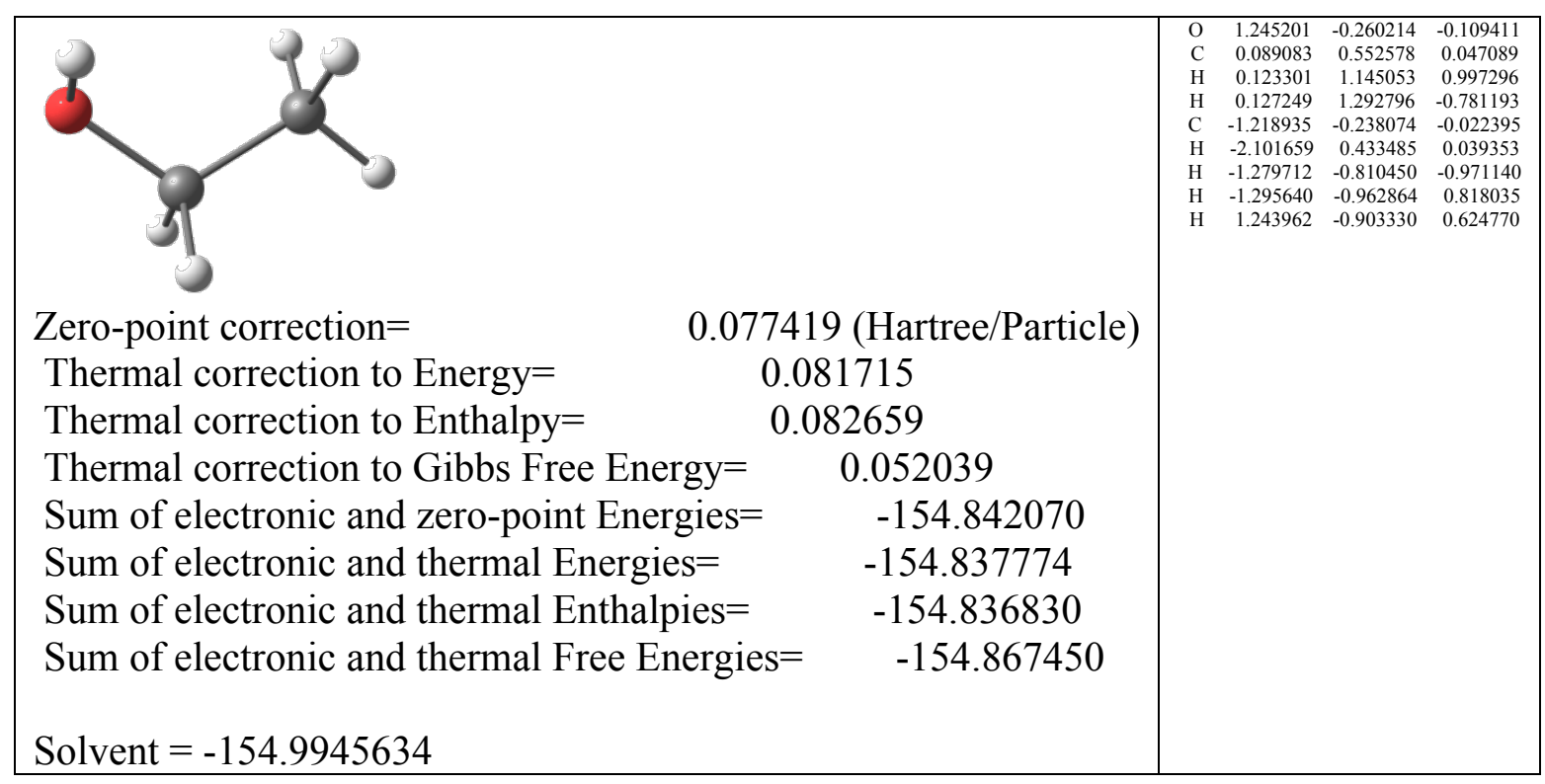


Table S63. 3D view and $x y z$ coordinate data sets and absolute energies in a.u. for DFT optimized complex Ligand-OEt ${ }^{+}$.

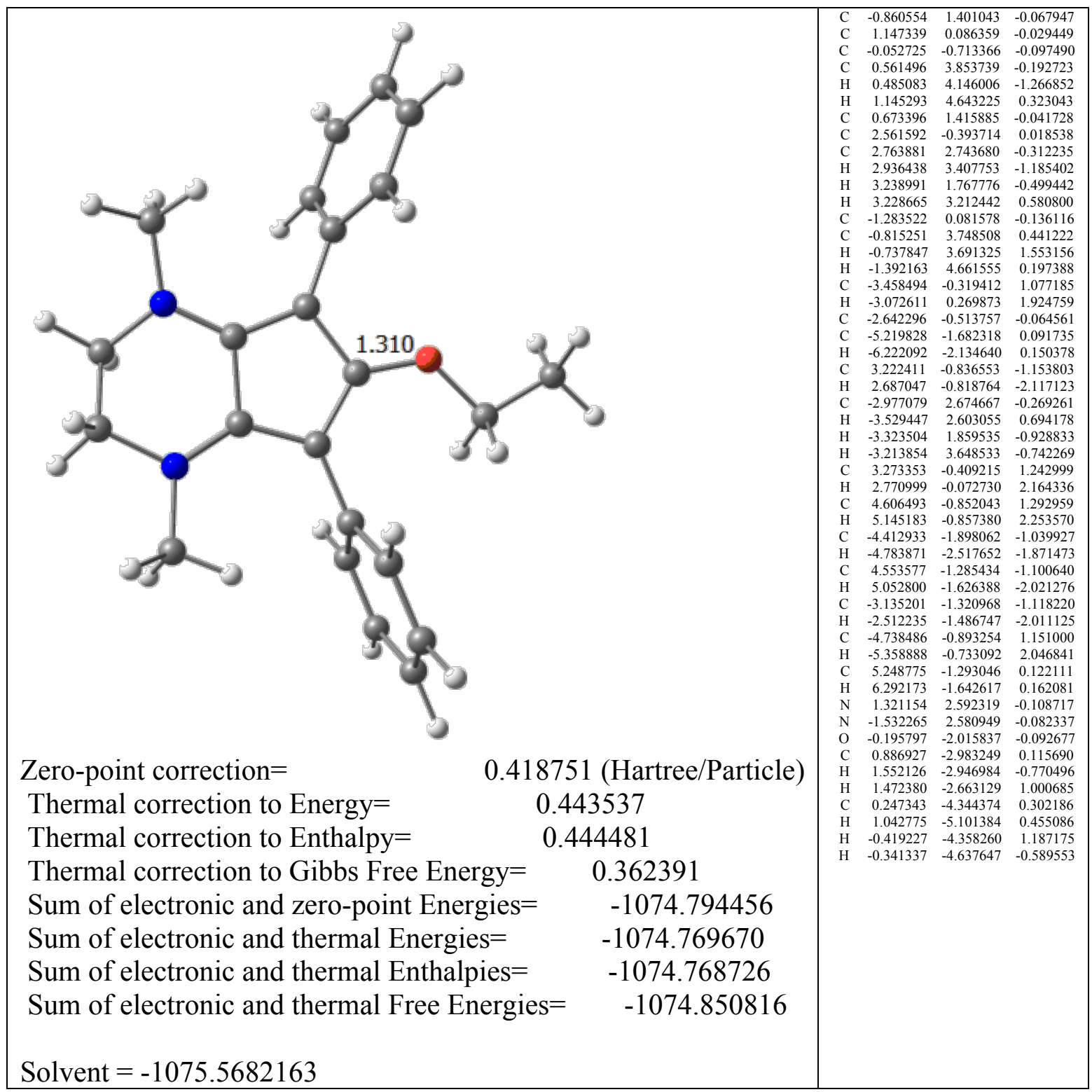


Table S64. 3D view and $x y z$ coordinate data sets and absolute energies in a.u. for DFT optimized complex Ligand-Ketone--NHiPr ${ }^{+}$.

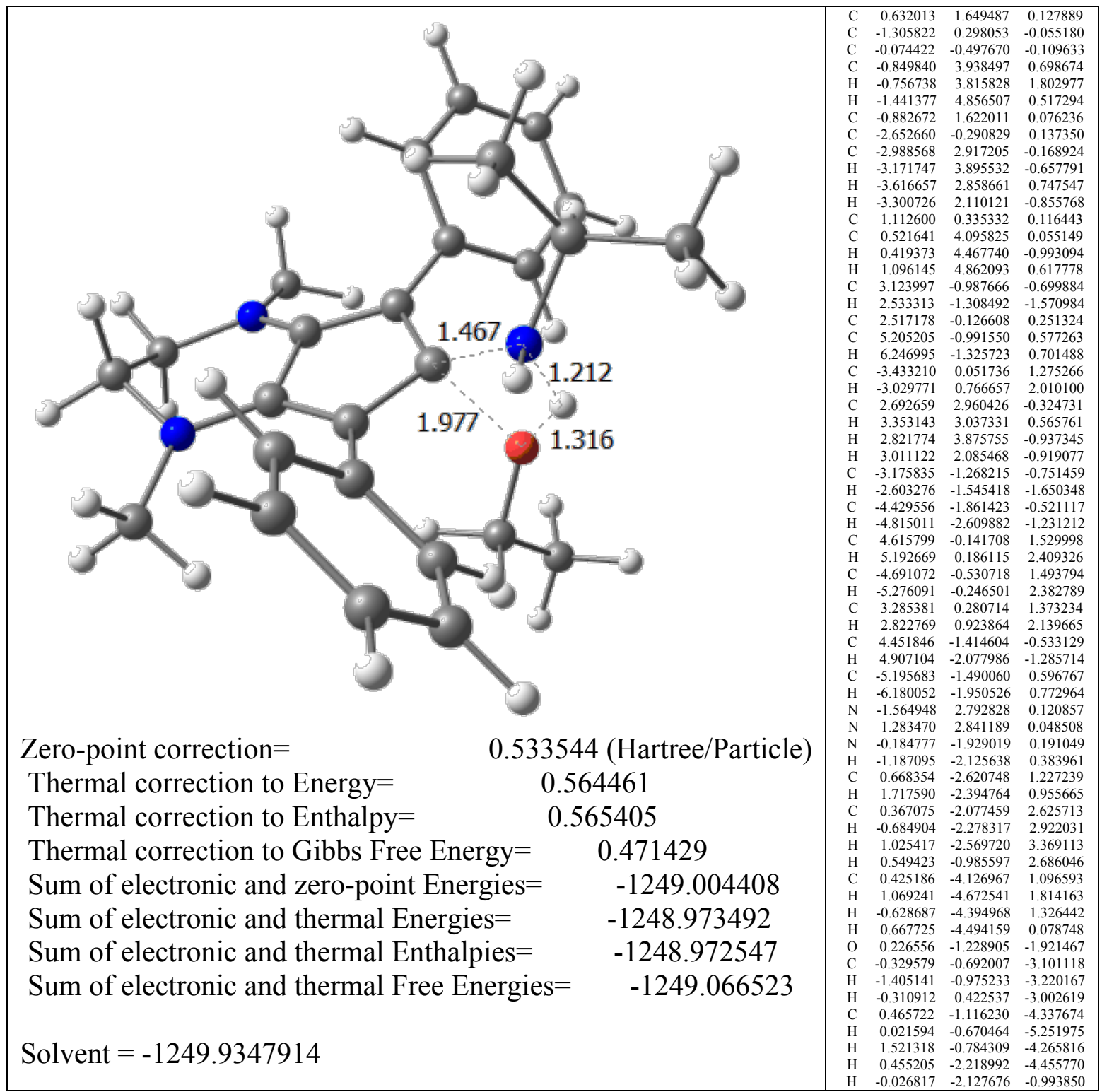


Table S65. 3D view and $x y z$ coordinate data sets and absolute energies in a.u. for DFT optimized complex Ligand-NHiPr ${ }^{+}$.

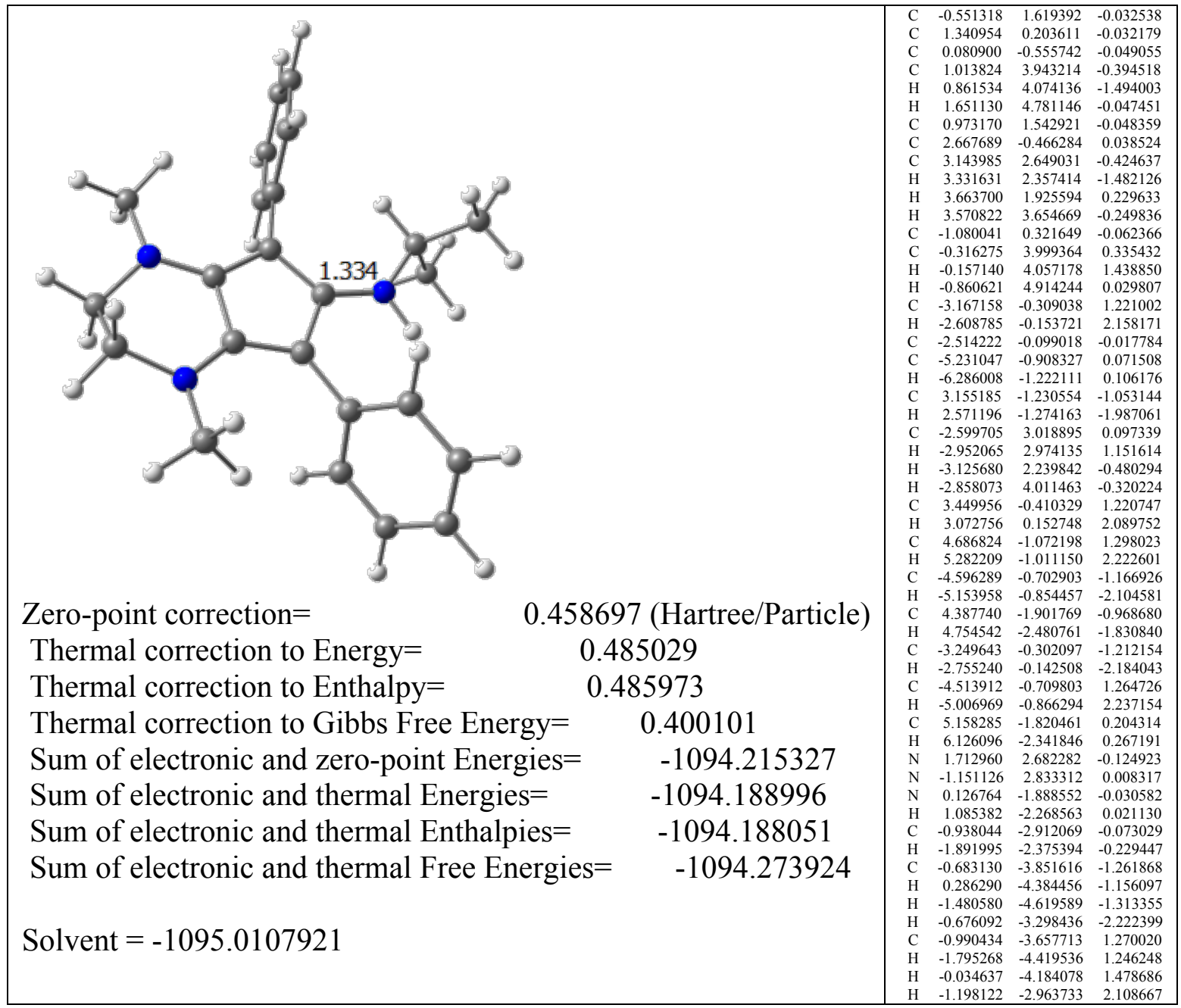


Table S66. 3D view and $x y z$ coordinate data sets and absolute energies in a.u. for DFT optimized complex Ligand-OEt( $\left(\mathbf{B F}_{4}\right)$.

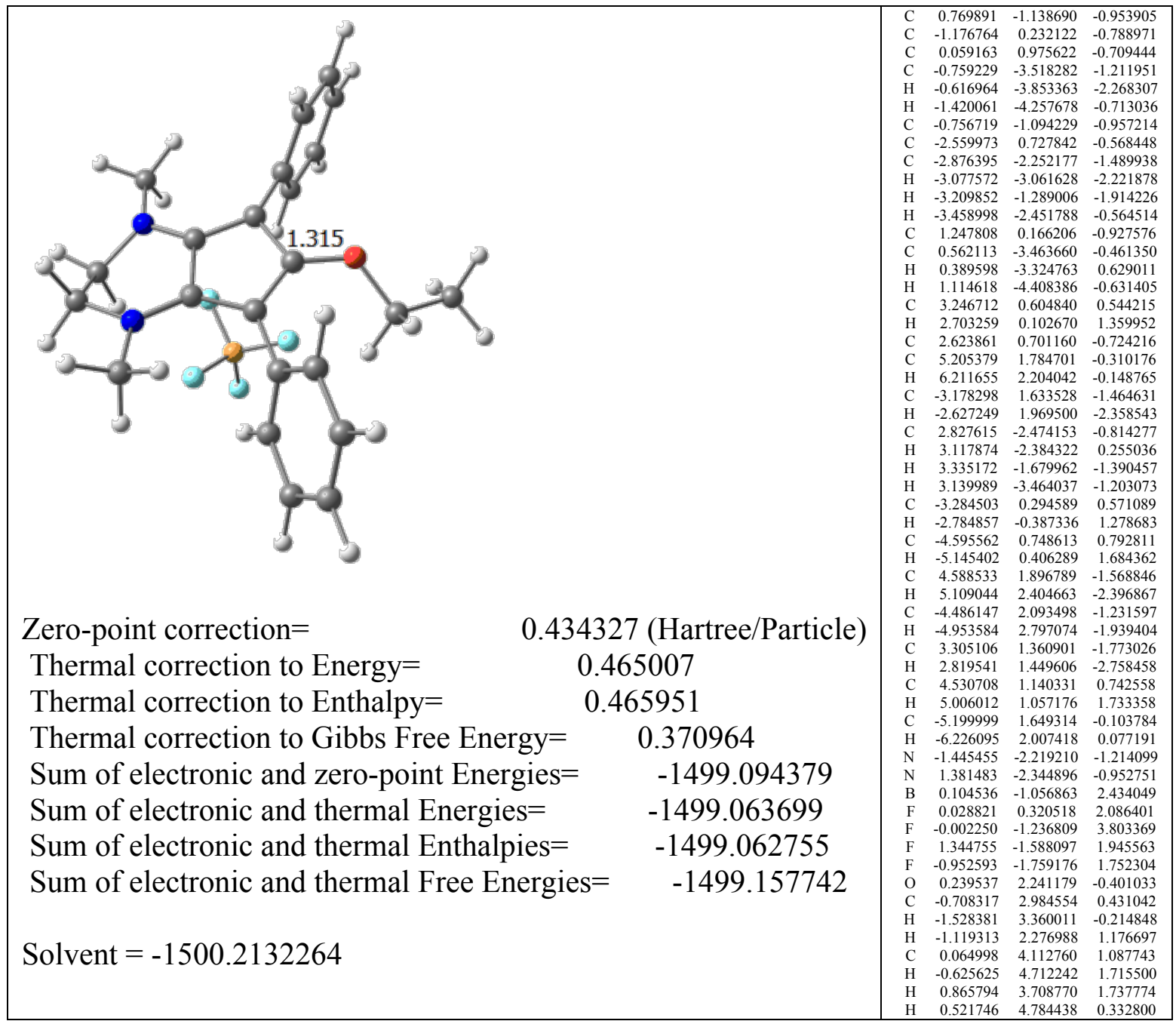


Table S67. 3D view and $x y z$ coordinate data sets and absolute energies in a.u. for DFT optimized complex Ligand-OEt--NHiPr( $\left(\mathbf{B F}_{4}\right)$.

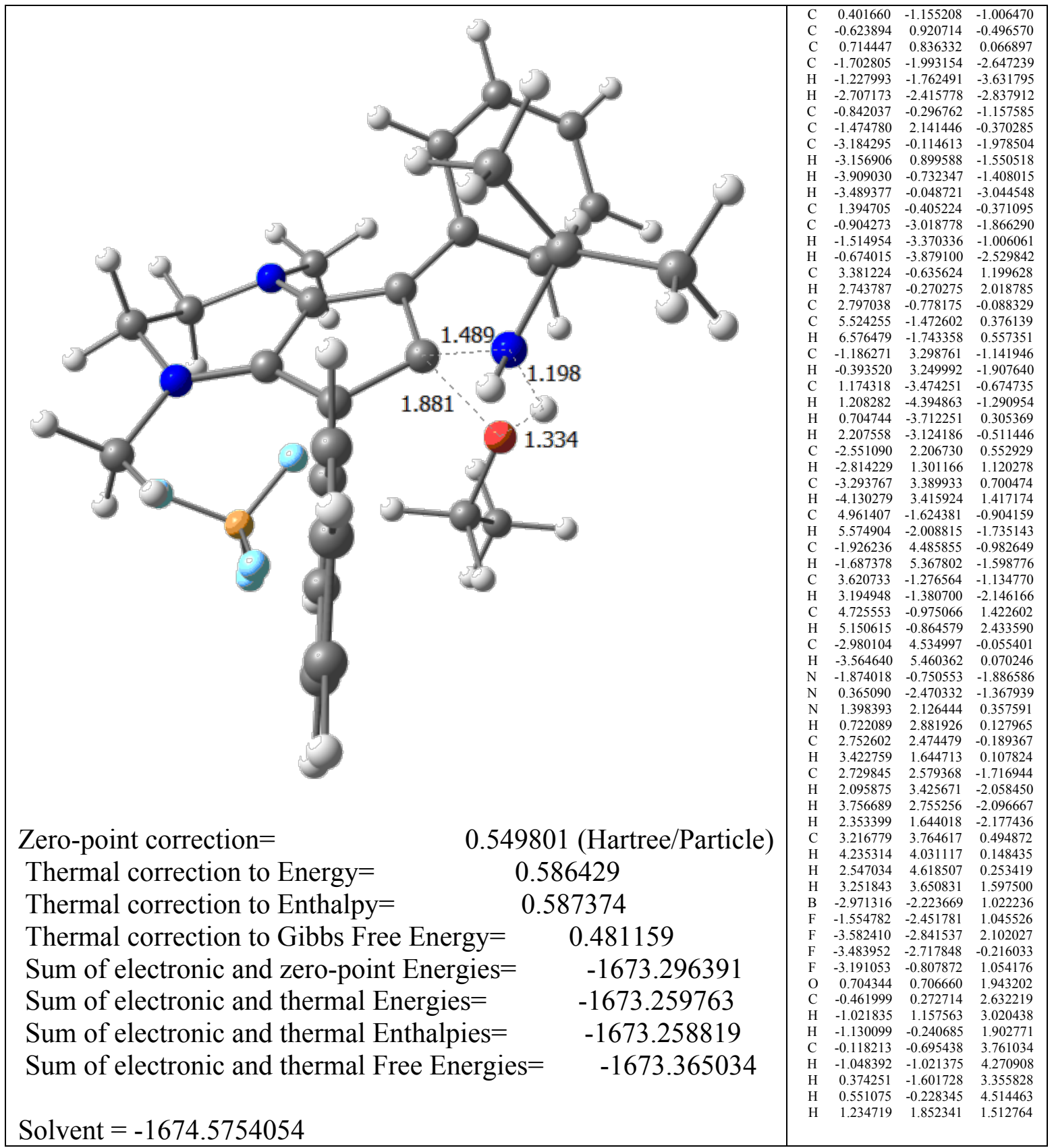


Table S68. 3D view and $x y z$ coordinate data sets and absolute energies in a.u. for DFT optimized complex Ligand-OEt-NHiPr+EtOH(BF 4$)$.

\begin{tabular}{|c|c|c|c|}
\hline $\begin{array}{lc}\text { Zero-point correction }= & \begin{array}{c}0.628470(\text { Hartree/Particle }) \\
0.669690\end{array} \\
\text { Thermal correction to Energy= } & 0.670634 \\
\text { Thermal correction to Enthalpy }= & 0.553811 \\
\text { Thermal correction to Gibbs Free Energy= } & -1828.167965 \\
\text { Sum of electronic and zero-point Energies= } & -1828.126744 \\
\text { Sum of electronic and thermal Energies }= & -1828.125800 \\
\text { Sum of electronic and thermal Enthalpies }= & -1828.242623 \\
\text { Sum of electronic and thermal Free Energies }= & \\
& \\
\text { Solvent }=-1829.6078243 & \end{array}$ & 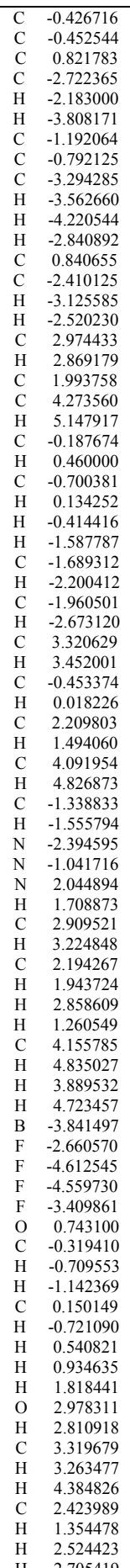 & 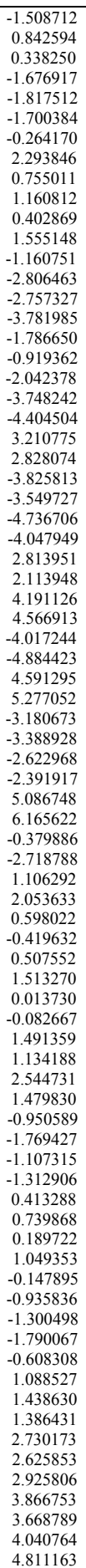 & 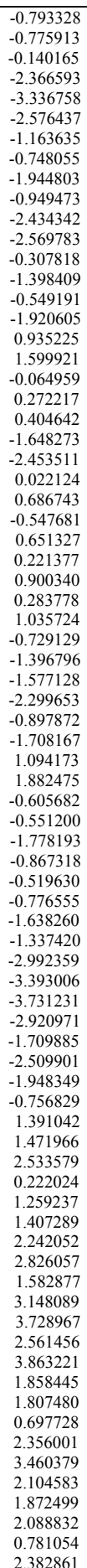 \\
\hline
\end{tabular}


Table S69. 3D view and $x y z$ coordinate data sets and absolute energies in a.u. for DFT optimized complex Ligand-NHiPr( $\left(\mathrm{BF}_{4}\right)$.

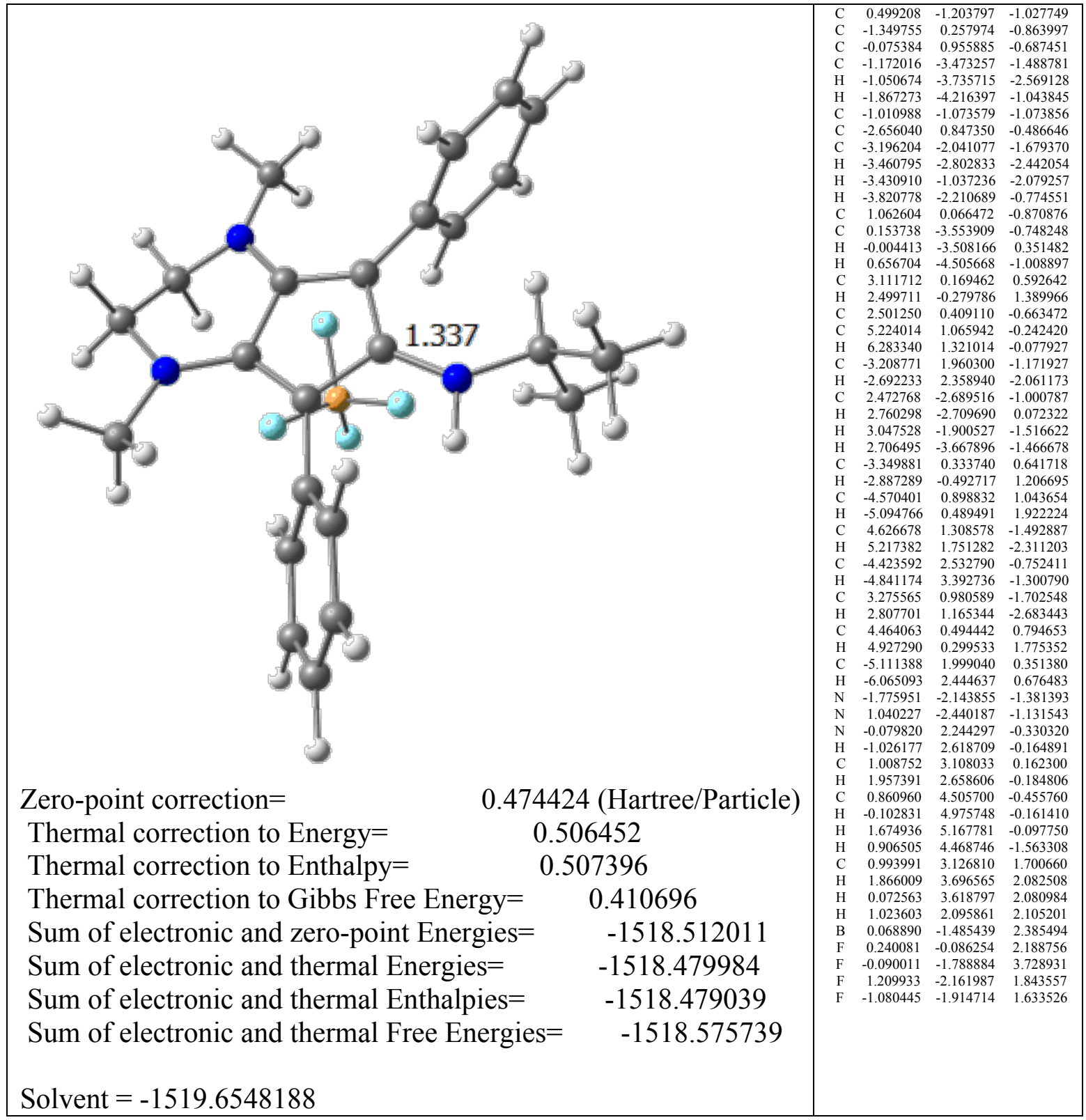


Table S70. 3D view and $x y z$ coordinate data sets and absolute energies in a.u. for DFT optimized complex Fe4-I.

\begin{tabular}{|c|c|c|c|c|}
\hline $\begin{array}{lc}\text { Zero-point correction }= & 0.386882 \text { (Hartree/Particle) } \\
\text { Thermal correction to Energy= } & 0.419121 \\
\text { Thermal correction to Enthalpy= } & 0.420065 \\
\text { Thermal correction to Gibbs Free Energy= } & 0.325235 \\
\text { Sum of electronic and zero-point Energies= } & -1704.419585 \\
\text { Sum of electronic and thermal Energies }= & -1704.387346 \\
\text { Sum of electronic and thermal Enthalpies }= & -1704.386401 \\
\text { Sum of electronic and thermal Free Energies }= & -1704.481232 \\
& \\
\text { Solvent }=-1705.1996232 & \end{array}$ & & 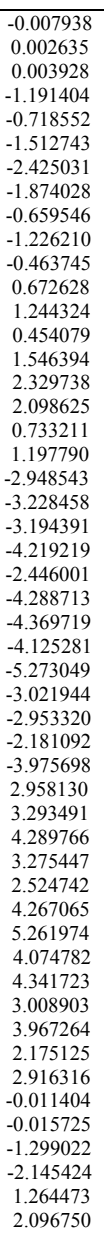 & 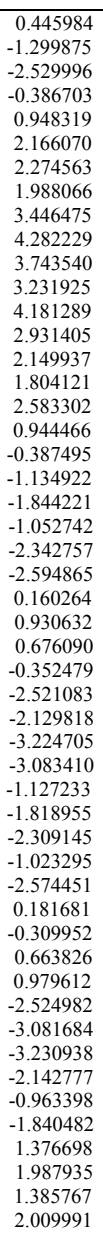 & 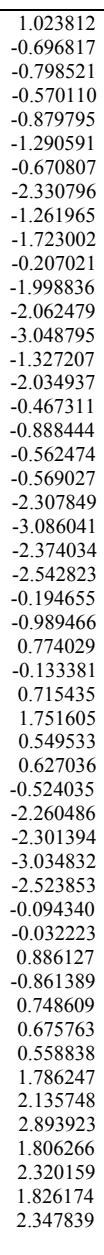 \\
\hline
\end{tabular}


Table S71. 3D view and $x y z$ coordinate data sets and absolute energies in a.u. for DFT optimized complex Fe4-I-II.

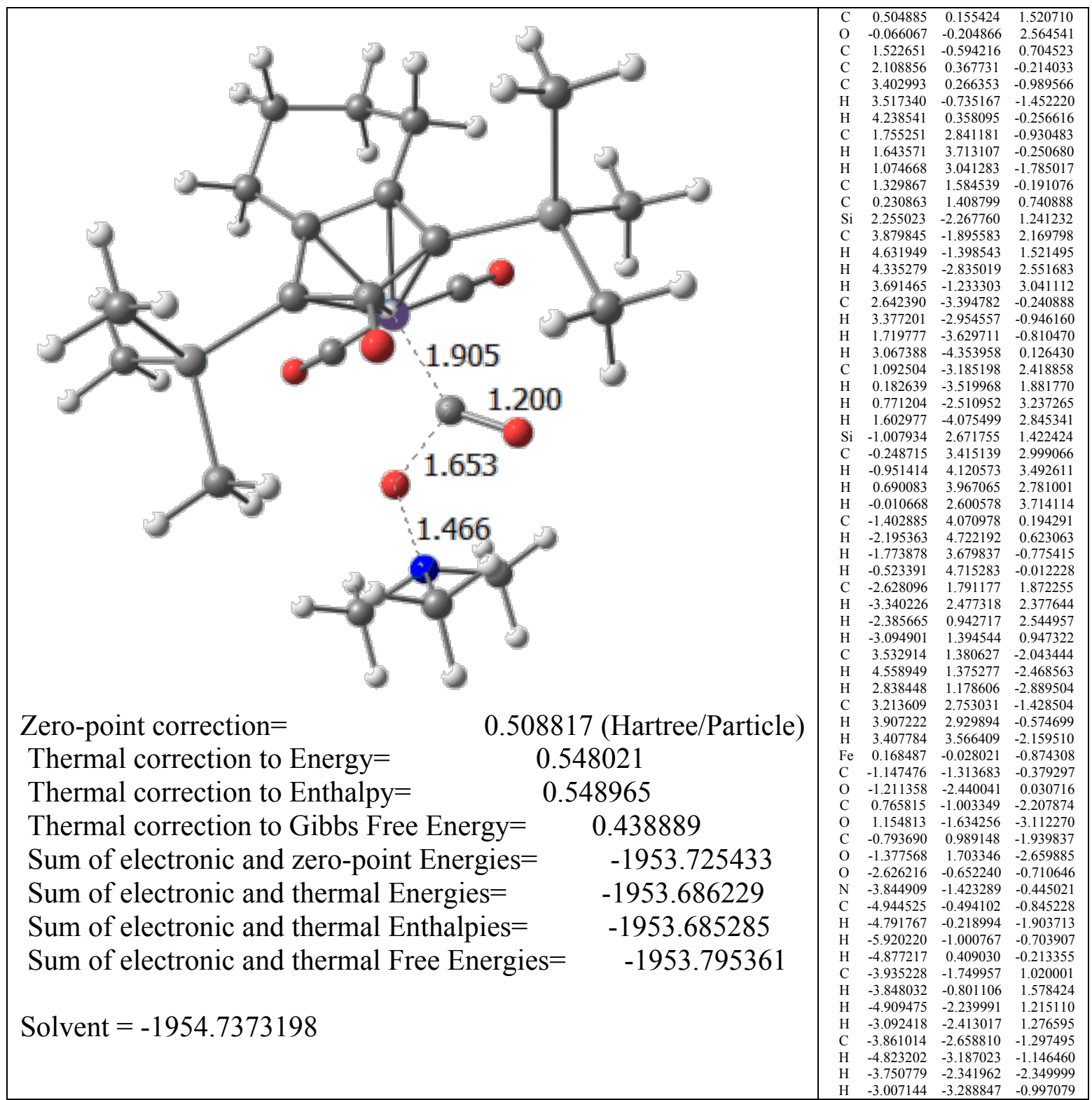


Table S72. 3D view and $x y z$ coordinate data sets and absolute energies in a.u. for DFT optimized complex Fe4-II.

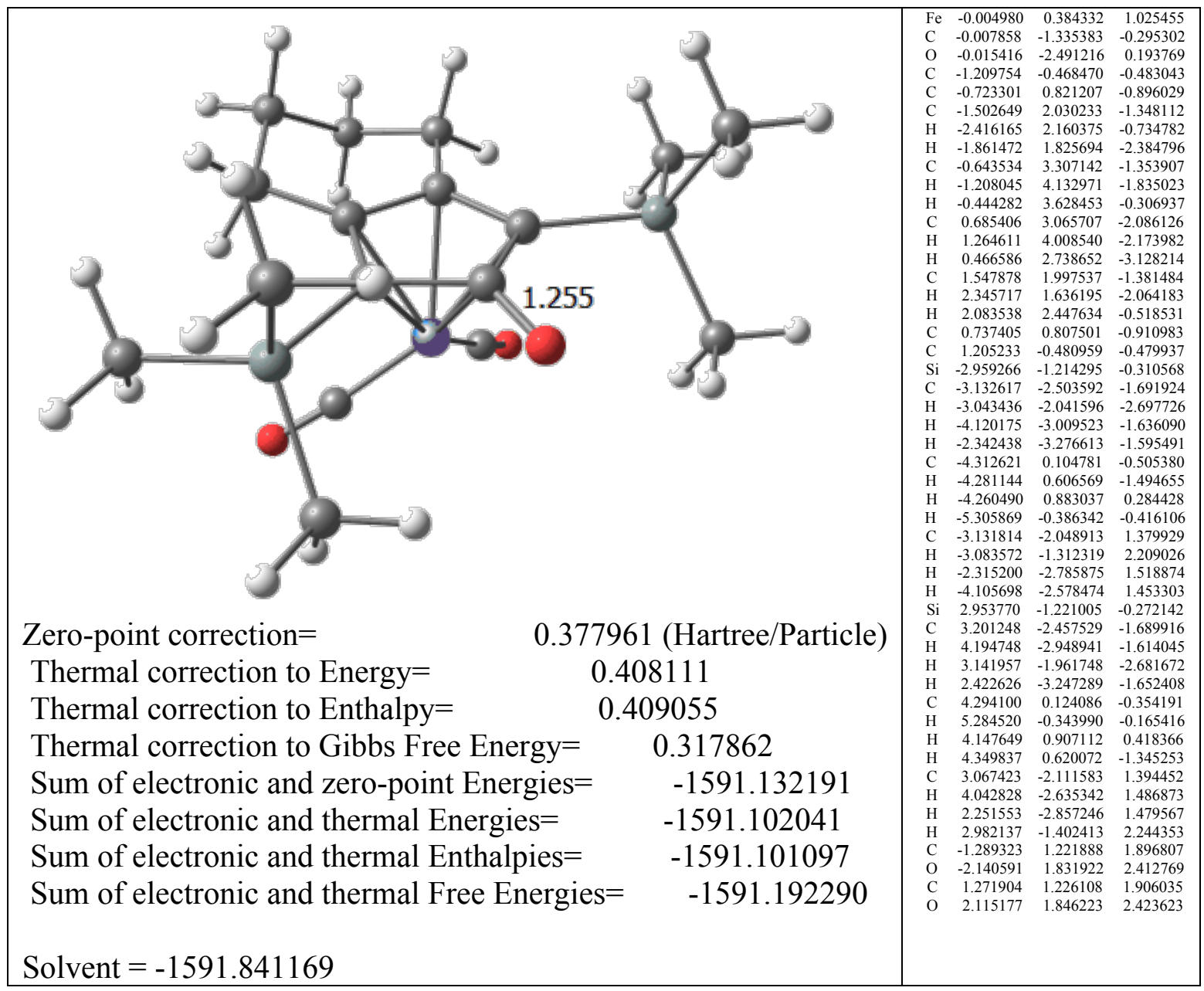


Table S73. 3D view and $x y z$ coordinate data sets and absolute energies in a.u. for DFT optimized complex Fe4-II-III.

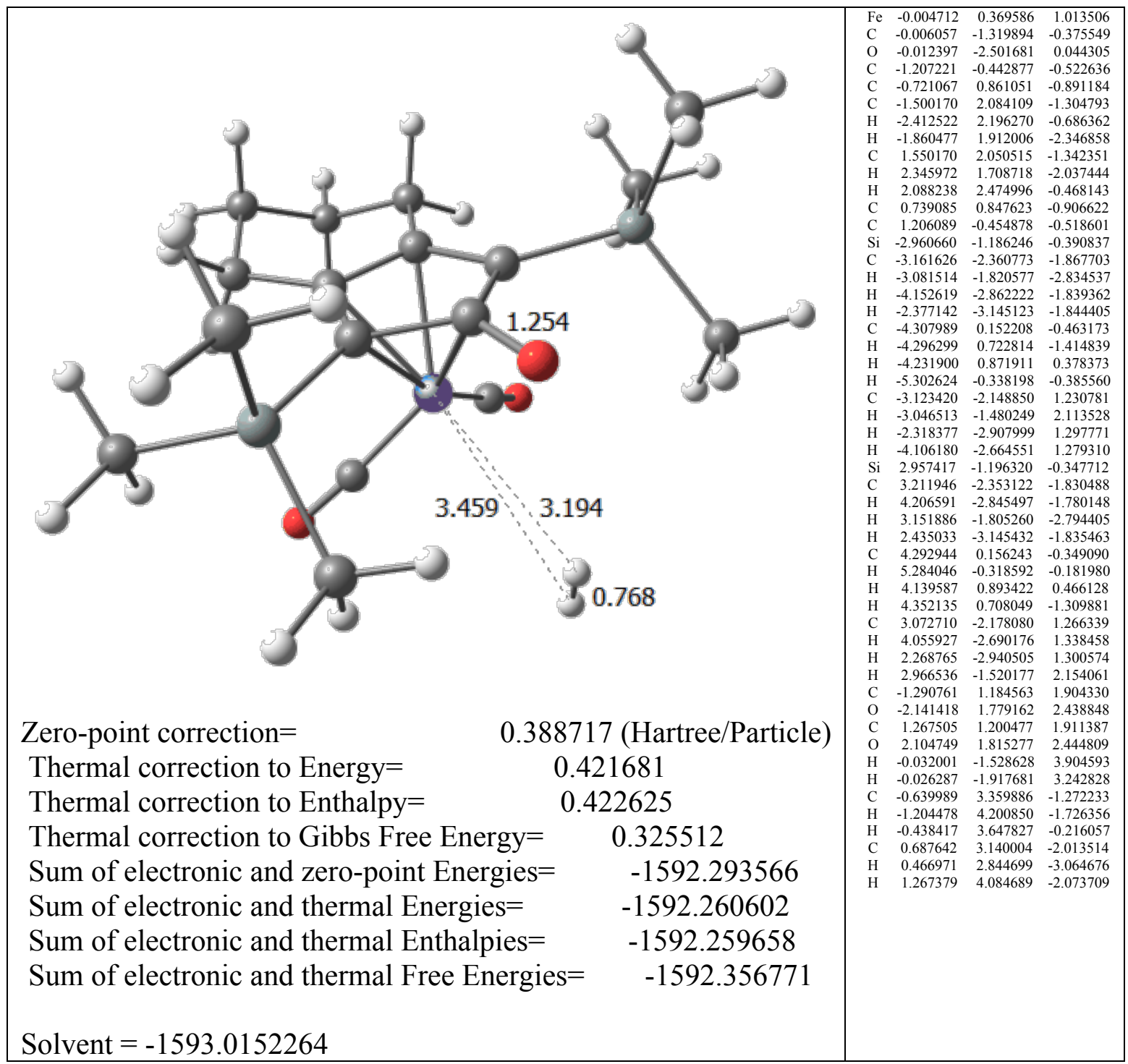


Table S74. 3D view and $x y z$ coordinate data sets and absolute energies in a.u. for DFT optimized complex Fe4-III.

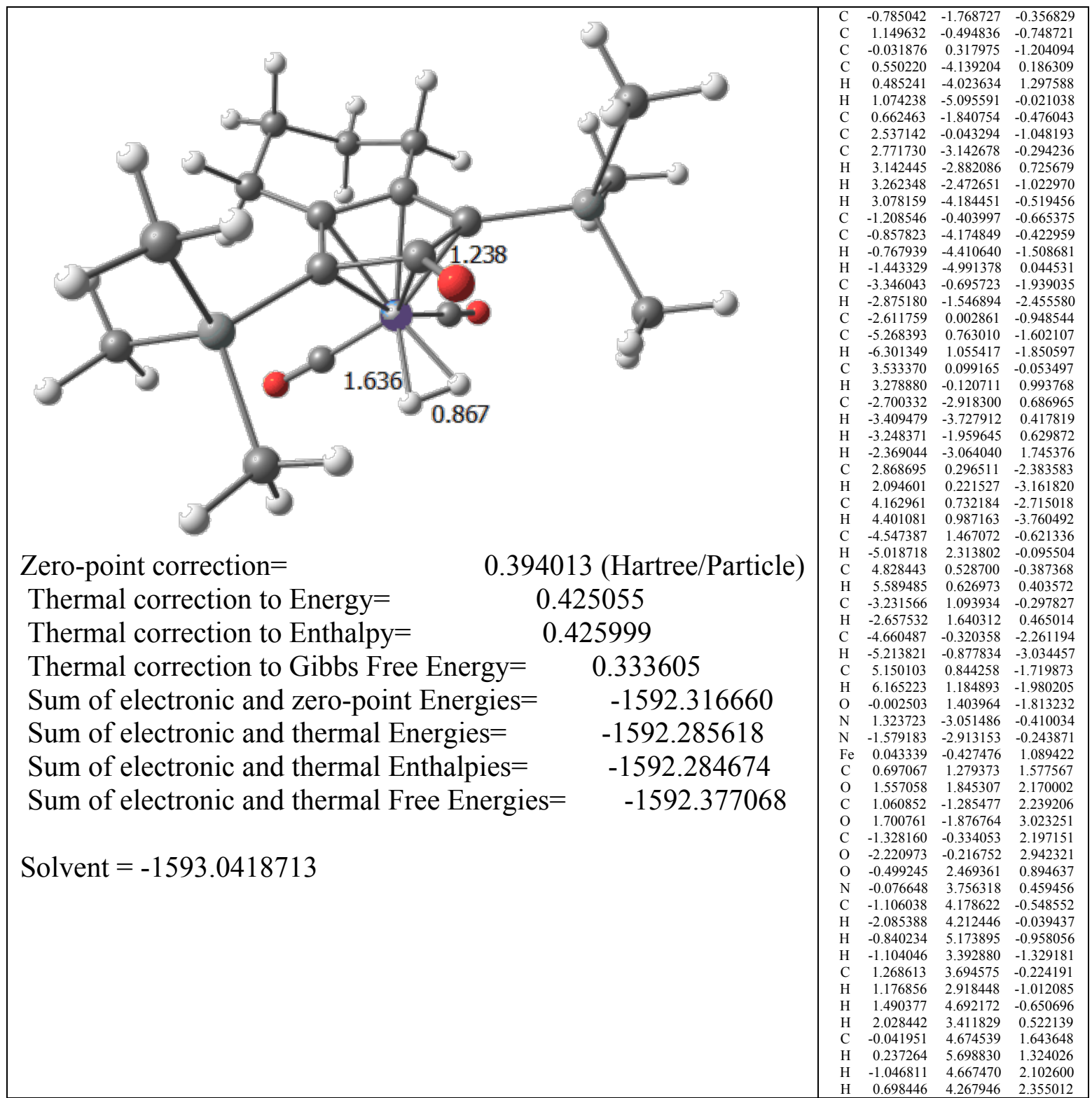


Table S75. 3D view and $x y z$ coordinate data sets and absolute energies in a.u. for DFT optimized complex Fe4-III-IV.

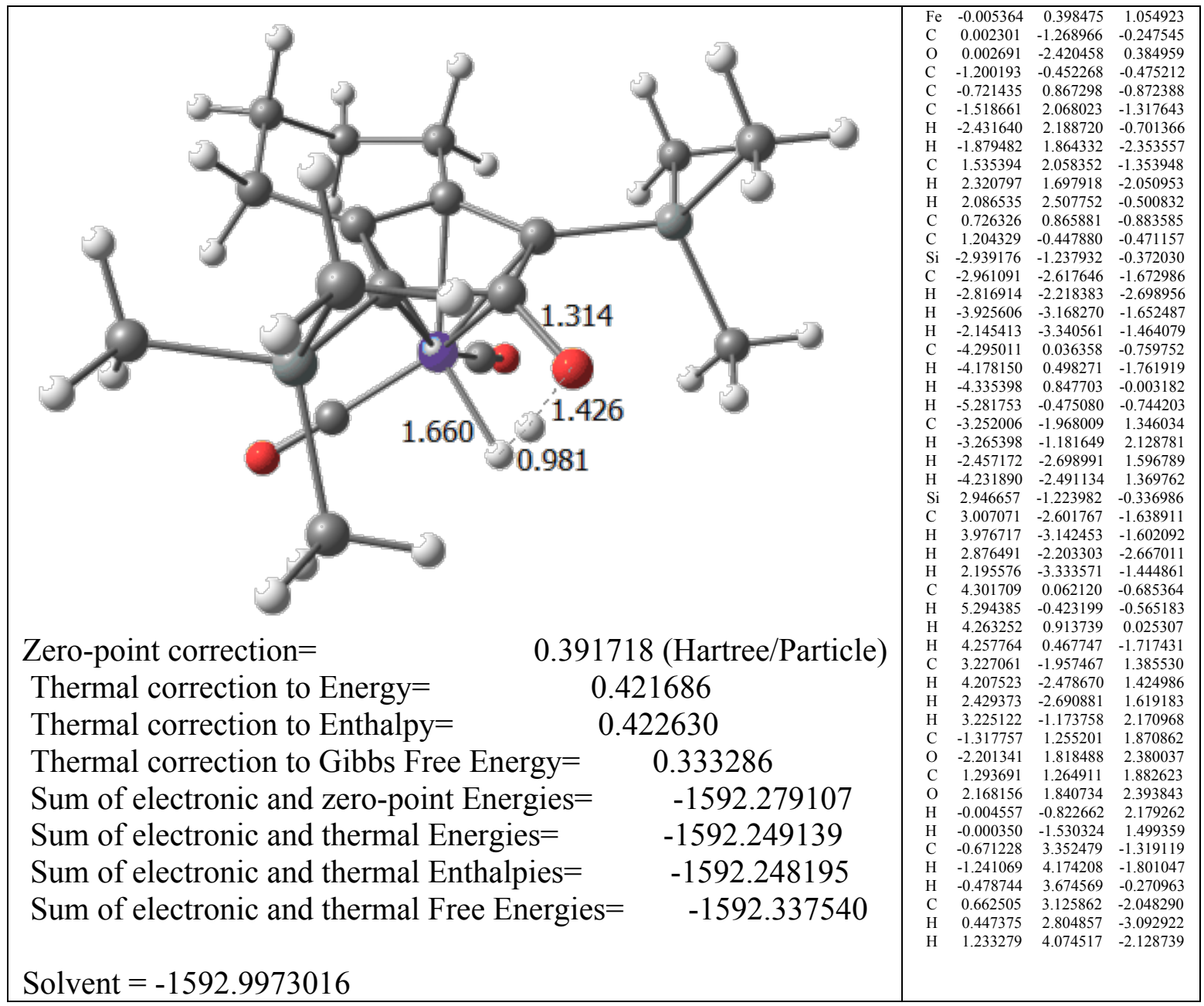


Table S76. 3D view and $x y z$ coordinate data sets and absolute energies in a.u. for DFT optimized complex Fe4-III-IV+1EtOH.

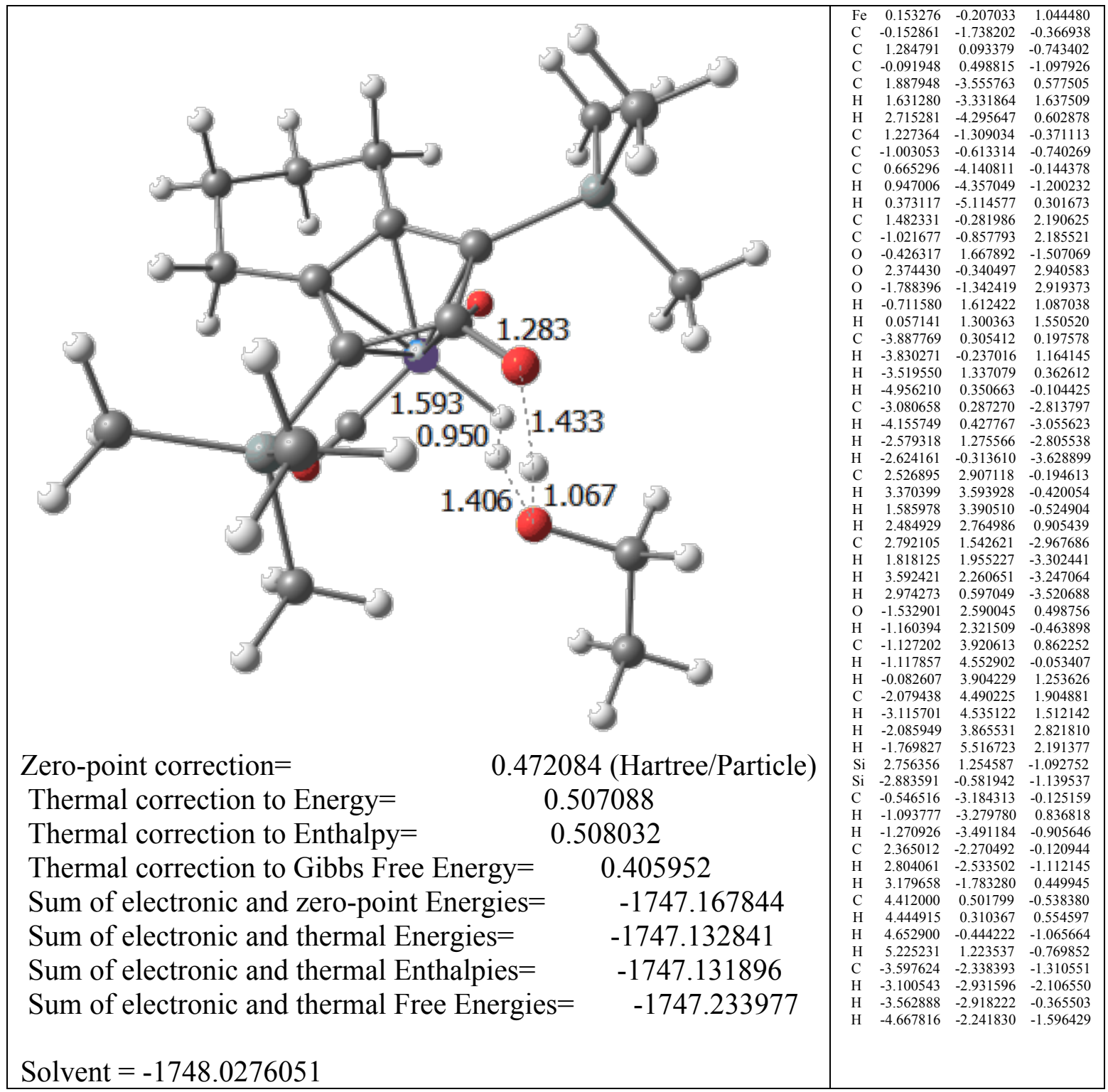


Table S77. 3D view and $x y z$ coordinate data sets and absolute energies in a.u. for DFT optimized complex Fe4-IV.

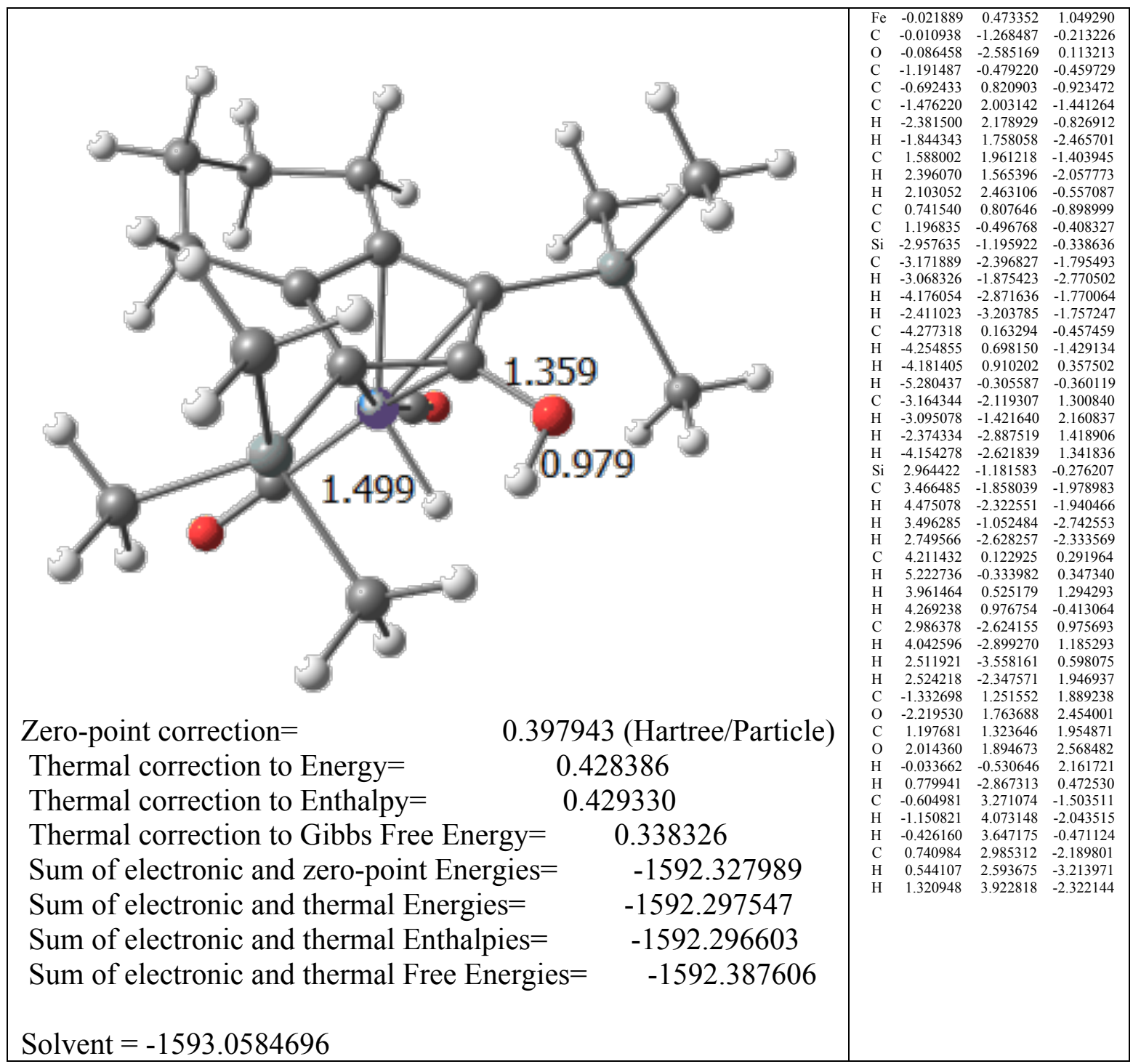


Table S78. $\quad 3 \mathrm{D}$ view and $x y z$ coordinate data sets and absolute energies in a.u. for DFT optimized complex Fe4-V.

\begin{tabular}{|c|c|c|c|c|}
\hline $\begin{array}{lc}\text { Zero-point correction }= & 0.599093 \text { (Hartree/Particle) } \\
\text { Thermal correction to Energy= } & 0.642273 \\
\text { Thermal correction to Enthalpy= } & 0.643217 \\
\text { Thermal correction to Gibbs Free Energy= } & 0.518283 \\
\text { Sum of electronic and zero-point Energies }= & -2035.435267 \\
\text { Sum of electronic and thermal Energies }= & -2035.392086 \\
\text { Sum of electronic and thermal Enthalpies }= & -2035.391142 \\
\text { Sum of electronic and thermal Free Energies }= & -2035.516076 \\
& \\
\text { Solvent }=-2036.4892401 & \end{array}$ & $\begin{array}{l}\mathrm{H} \\
\mathrm{H} \\
\mathrm{H} \\
\mathrm{C} \\
\mathrm{H} \\
\mathrm{H} \\
\mathrm{H} \\
\mathrm{H} \\
\mathrm{C} \\
\mathrm{H} \\
\mathrm{H} \\
\mathrm{H} \\
\mathrm{H} \\
\mathrm{C} \\
\mathrm{H} \\
\mathrm{H} \\
\mathrm{H} \\
\mathrm{C} \\
\mathrm{H} \\
\mathrm{H} \\
\mathrm{H} \\
\mathrm{C} \\
\mathrm{O} \\
\mathrm{C} \\
\mathrm{C} \\
\mathrm{H} \\
\mathrm{H} \\
\mathrm{C} \\
\mathrm{C} \\
\mathrm{C} \\
\mathrm{C} \\
\mathrm{H} \\
\mathrm{H} \\
\mathrm{C} \\
\mathrm{C} \\
\mathrm{C} \\
\mathrm{C} \\
\mathrm{C} \\
\mathrm{H} \\
\mathrm{C} \\
\mathrm{H} \\
\mathrm{C} \\
\mathrm{H} \\
\mathrm{H} \\
\mathrm{H} \\
\mathrm{H} \\
\mathrm{H} \\
\mathrm{C} \\
\mathrm{H} \\
\mathrm{H} \\
\mathrm{C} \\
\mathrm{H} \\
\mathrm{H}\end{array}$ & 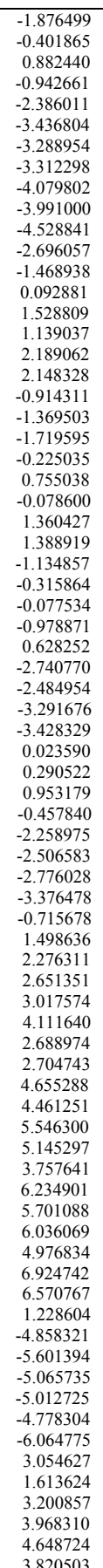 & 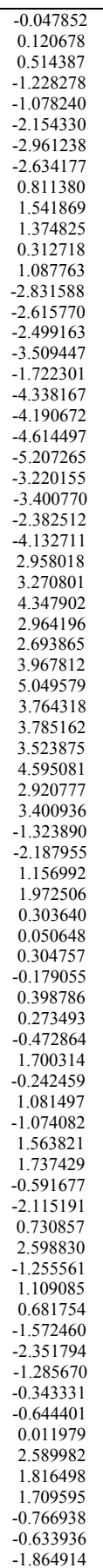 & 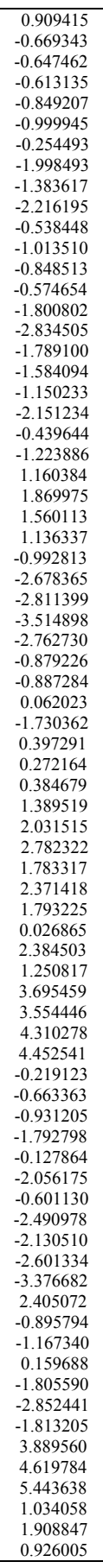 \\
\hline
\end{tabular}


Table S79. $\quad 3 \mathrm{D}$ view and $x y z$ coordinate data sets and absolute energies in a.u. for DFT optimized complex Fe4-V-VI.

\begin{tabular}{|c|c|c|c|c|}
\hline $\begin{array}{lc}\text { Zero-point correction }= & 0.595963 \text { (Hartree/Particle) } \\
\text { Thermal correction to Energy }= & 0.638282 \\
\text { Thermal correction to Enthalpy= } & 0.639227 \\
\text { Thermal correction to Gibbs Free Energy= } & 0.518812 \\
\text { Sum of electronic and zero-point Energies= } & -2035.427762 \\
\text { Sum of electronic and thermal Energies= } & -2035.385443 \\
\text { Sum of electronic and thermal Enthalpies= } & -2035.384499 \\
\text { Sum of electronic and thermal Free Energies }= & -2035.504914\end{array}$ & $\begin{array}{l}\text { Fe } \\
\text { C } \\
\text { O } \\
\text { C } \\
\text { C } \\
\text { C } \\
\text { H } \\
\text { H } \\
\text { C } \\
\text { H } \\
\text { H } \\
\text { C } \\
\text { C } \\
\text { Si } \\
\text { C } \\
\text { H } \\
\text { H } \\
\text { H } \\
\text { C } \\
\text { H } \\
\text { H } \\
\text { H } \\
\text { C } \\
\text { H } \\
\text { H } \\
\text { H } \\
\text { Si } \\
\text { C } \\
\text { H } \\
\text { H } \\
\text { H } \\
\text { C } \\
\text { H } \\
\text { H } \\
\text { H } \\
\text { C } \\
\text { H } \\
\text { H } \\
\text { H } \\
\text { C } \\
\text { O } \\
\text { C } \\
\text { O } \\
\text { H } \\
\text { H } \\
\text { C } \\
\text { N } \\
\text { C } \\
\text { H } \\
\text { H } \\
\text { C } \\
\text { C } \\
\text { C } \\
\text { C } \\
\text { C } \\
\text { H } \\
\text { C } \\
\text { H } \\
\text { C } \\
\text { H } \\
\text { H } \\
\text { H } \\
\text { H } \\
\text { C } \\
\text { H } \\
\text { H } \\
\text { C } \\
\text { H } \\
\text { H } \\
\text { H } \\
\text { H } \\
\text { H } \\
\text { C } \\
\text { H } \\
\text { H } \\
\text { H }\end{array}$ & 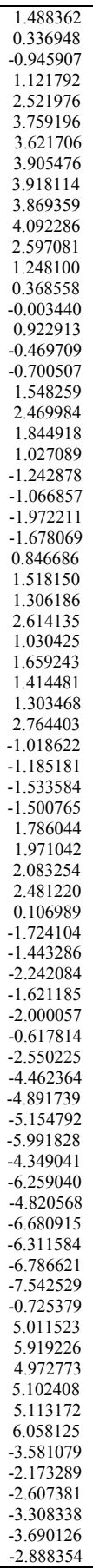 & 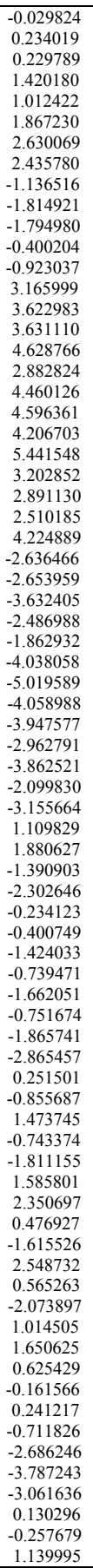 & 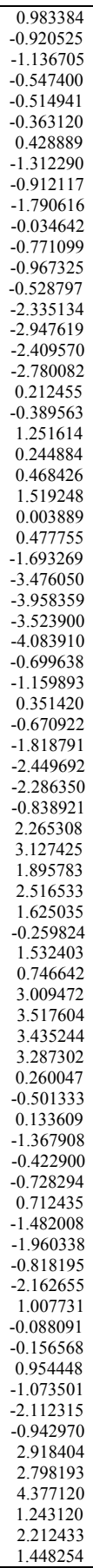 \\
\hline
\end{tabular}


Table S80. 3D view and $x y z$ coordinate data sets and absolute energies in a.u. for DFT optimized complex Fe4-VI.

\begin{tabular}{|c|c|c|c|c|}
\hline $\begin{array}{lc}\text { Zero-point correction }= & 0.602287 \text { (Hartree/Particle) } \\
\text { Thermal correction to Energy }= & 0.644881 \\
\text { Thermal correction to Enthalpy= } & 0.645825 \\
\text { Thermal correction to Gibbs Free Energy= } & 0.526145 \\
\text { Sum of electronic and zero-point Energies }= & -2035.437785 \\
\text { Sum of electronic and thermal Energies }= & -2035.395191 \\
\text { Sum of electronic and thermal Enthalpies }= & -2035.394246 \\
\text { Sum of electronic and thermal Free Energies }= & -2035.513927 \\
& \\
\text { Solvent }=-2036.4934538 & \end{array}$ & 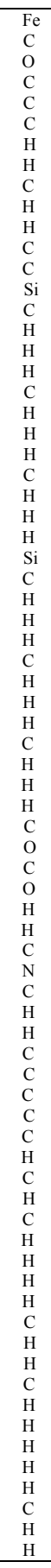 & 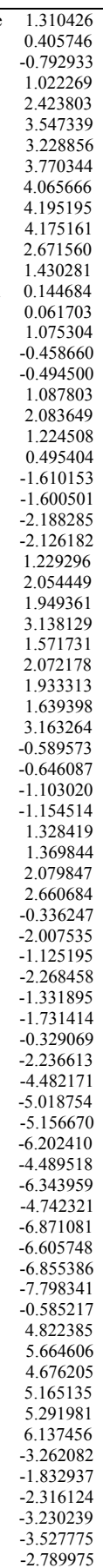 & 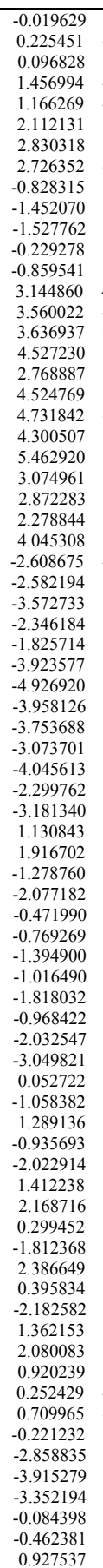 & 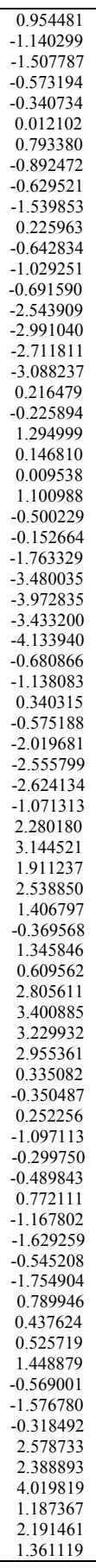 \\
\hline
\end{tabular}


Table S81. 3D view and $x y z$ coordinate data sets and absolute energies in a.u. for DFT optimized complex Fe4-III--H.

\begin{tabular}{|c|c|c|c|c|}
\hline $\begin{array}{lc}\text { Zero-point correction }= & 0.564215 \text { (Hartree/Particle) } \\
\text { Thermal correction to Energy= } & 0.604570 \\
\text { Thermal correction to Enthalpy= } & 0.605514 \\
\text { Thermal correction to Gibbs Free Energy= } & 0.490432 \\
\text { Sum of electronic and zero-point Energies }= & -1958.092529 \\
\text { Sum of electronic and thermal Energies }= & -1958.052174 \\
\text { Sum of electronic and thermal Enthalpies }= & -1958.051230 \\
\text { Sum of electronic and thermal Free Energies }= & -1958.166312\end{array}$ & $\begin{array}{l}\mathrm{H} \\
\mathrm{H} \\
\mathrm{C} \\
\mathrm{O} \\
\mathrm{C} \\
\mathrm{O} \\
\mathrm{H} \\
\mathrm{C} \\
\mathrm{H} \\
\mathrm{H} \\
\mathrm{C} \\
\mathrm{H} \\
\mathrm{H} \\
\mathrm{H} \\
\mathrm{C} \\
\mathrm{N} \\
\mathrm{C} \\
\mathrm{C} \\
\mathrm{C} \\
\mathrm{C} \\
\mathrm{H} \\
\mathrm{C} \\
\mathrm{H} \\
\mathrm{C} \\
\mathrm{H} \\
\mathrm{H} \\
\mathrm{H} \\
\mathrm{H} \\
\mathrm{C} \\
\mathrm{H} \\
\mathrm{H} \\
\mathrm{H}\end{array}$ & 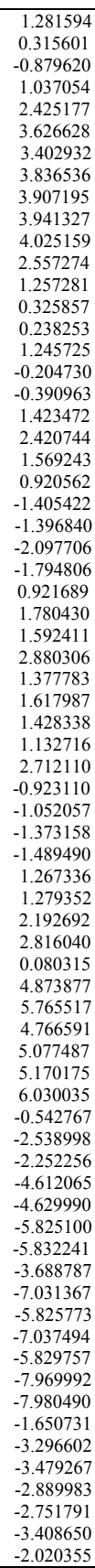 & 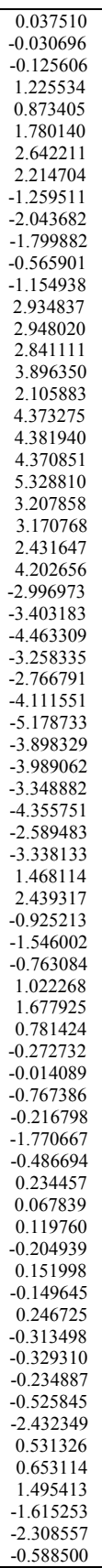 & 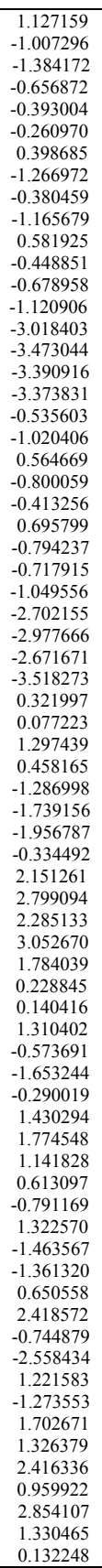 \\
\hline
\end{tabular}


Table S82. 3D view and $x y z$ coordinate data sets and absolute energies in a.u. for DFT optimized complex Fe4-III (without $\mathrm{H}^{+}$).

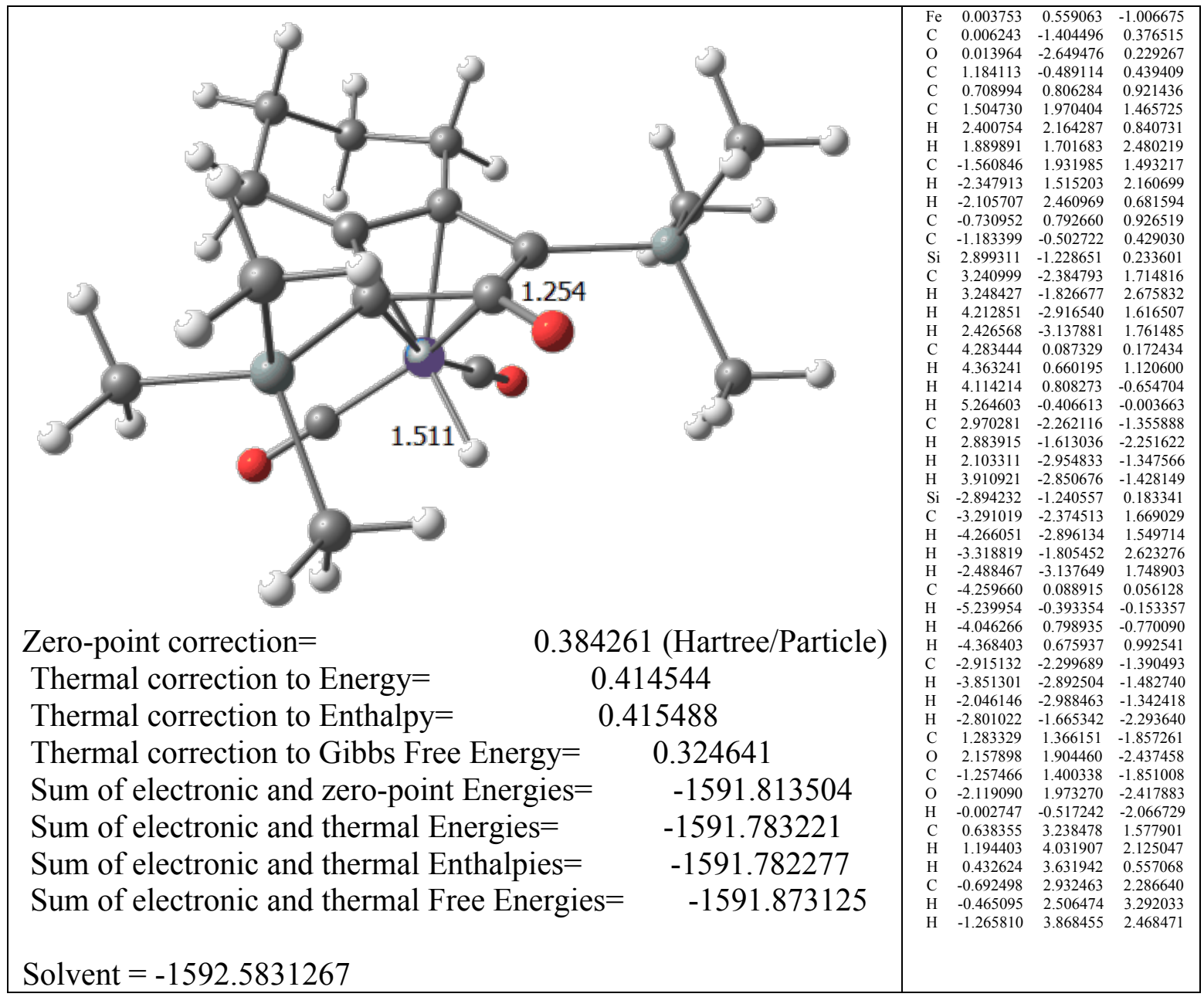


Table S83. 3D view and $x y z$ coordinate data sets and absolute energies in a.u. for DFT optimized complex Fe4-III-IV+2 EtOH $\left(\mathrm{BF}_{4}\right)$.

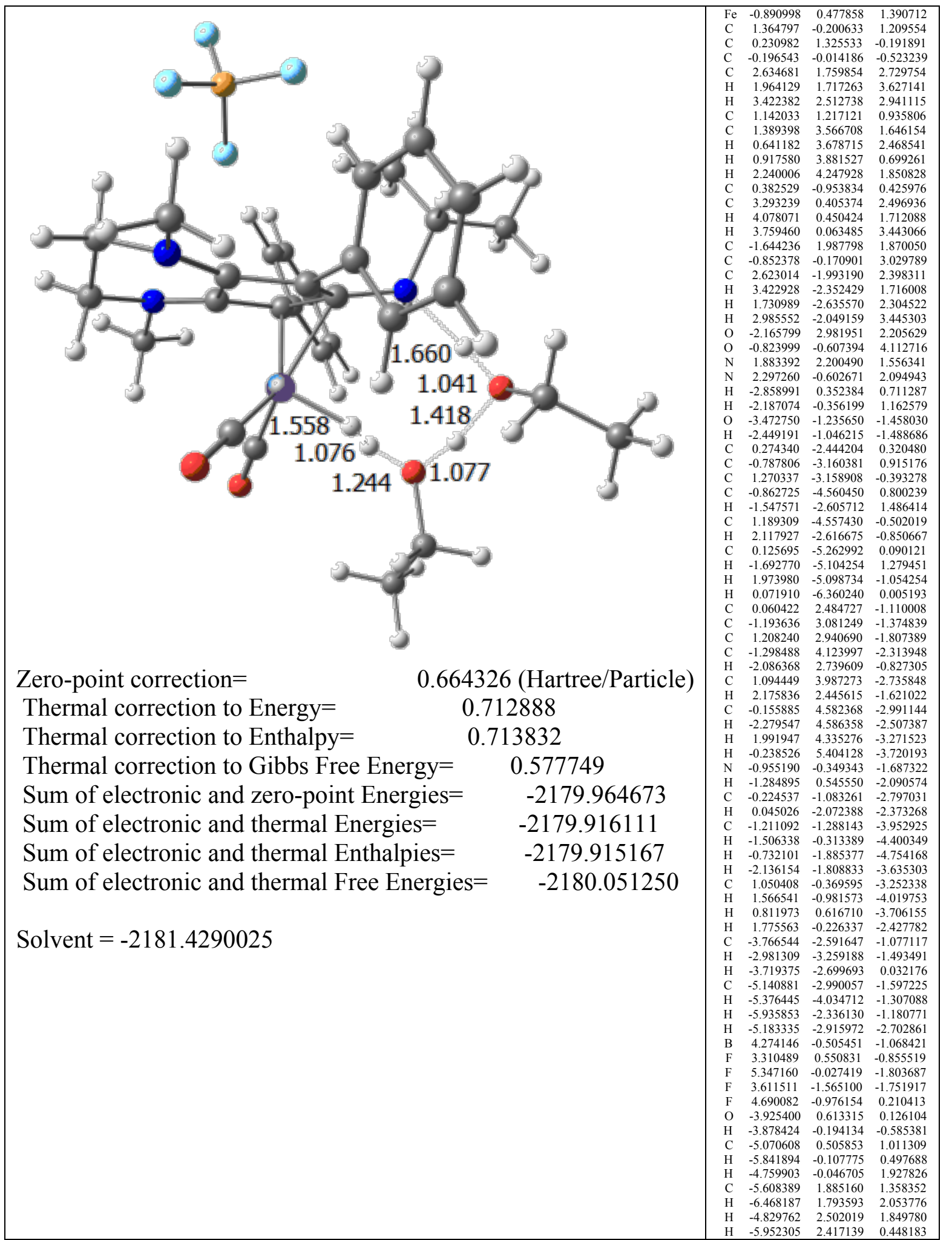


Table S84. 3D view and $x y z$ coordinate data sets and absolute energies in a.u. for DFT optimized complex Fe4-III-IV+2EtOH.

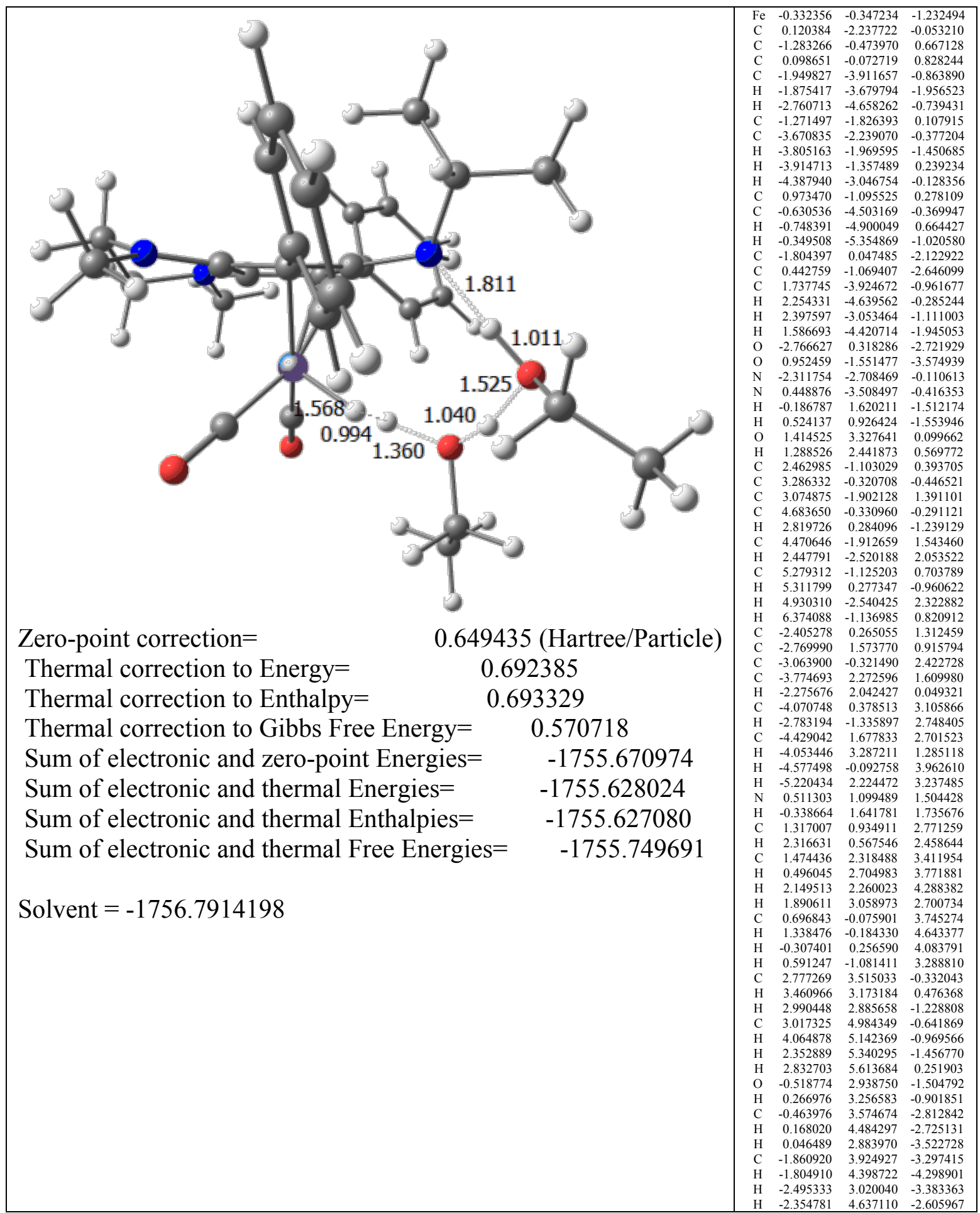

